Universidade de São Paulo

Instituto de Astronomia, Geofísica e Ciências Atmosféricas

Departamento de Geofísica

Alane Neves Barbosa

\title{
Estudo Magnetotelúrico na Região da Faixa \\ Paraguai Norte
}

São Paulo 
Alane Neves Barbosa

\title{
Estudo Magnetotelúrico na Região da Faixa Paraguai Norte
}

\author{
Versão Corrigida
}

(O original encontra-se disponível na Unidade)

Dissertação apresentada ao Departamento de Geofísica do Instituto de Astronomia, Geofísica e Ciências Atmosféricas da Universidade de São Paulo como requisito parcial para obtenção do título de Mestre em Ciências.

Área de Concentração: Geofísica

Orientador: Prof. Dr. Mauricio de Souza Bologna

São Paulo 
À minha mãe (Eliane Stela) e às minhas tias (Niza, Gó, Lêla, Nick, Maza e Gêca), por serem inspirações como mulheres inteligentes, amorosas, empáticas e corajosas. 


\section{AGRADECIMENTOS}

Inicialmente, agradeço à Deus, por estar guiando meus passos e iluminando meus pensamentos. E à Nossa Senhora Aparecida pela proteção constante.

Agradeço também o apoio do Conselho Nacional de Desenvolvimento Científico e Tecnológico (CNPq) e o Programa de Pós-Graduação em Geofísica do IAG/USP pela concessão de uma bolsa de estudos número do processo: 169807/2018-5 durante meu mestrado.

Ao GEOMA/INPE pela aquisição e processamento dos dados apresentados nesse trabalho.

À Universidade de São Paulo (USP), em especial ao Departamento de Geofísica do Instituto de Astronomia, Geofísica e Ciências Atmosféricas (IAG) por disponibilizar estrutura física, oportunidades e conhecimentos. Aos representantes desta instituição: corpo docente, técnicos e servidores, pela formação e suporte durante esses anos.

Ao meu orientador, Dr. Mauricio de Souza Bologna, pela paciência, orientações e voto de confiança durante a realização desse trabalho.

À minha mãe, Eliane Stela, por vibrar junto comigo durante minhas conquistas e pelos consolos nos momentos tristes. Às minhas irmãs, Aline e Júnia, por acreditarem no meu potencial. À minha grande família, Pessoa Neves, pela torcida constante. Ao meu padrinho, Ivo, pelo incentivo aos estudos e a caminhada da vida.

Ao Flávio, pelo companheirismo, amor, incentivo e disponibilidade em me ouvir durante todos esses anos. E aos meus sogros, Evelin e Paulo por todo carinho e acolhimento.

Por fim, aos colegas, em especial Gabriel Dragone e Alanna Dutra, pela disponibilidade em explanar dúvidas e fazer sugestões construtivas durante esse processo. Aos amigos que a "Pós" me deu, obrigada pela caminhada, paciência, dúvidas compartilhadas, pelos trabalhos realizados juntos e momentos de lazer na "salinha do café", churrascos e saídas. Às amigas, Gabi e Fabi, pelo companheirismo, acolhimento e conselhos. Por estarem ao meu lado nos momentos difíceis e nas conquistas compartilhadas, levo vocês sempre comigo. E aos amigos que não foram citados, mas que torcem sempre por mim, meu muito obrigado! 


\section{RESUMO}

BARBOSA, A. N. Estudo Magnetotelúrico na Região da Faixa Paraguai Norte. 2021. 122p. Dissertação (Mestrado em Geofísica) - Instituto de Astronomia, Geofísica e Ciências Atmosféricas, Universidade de São Paulo, São Paulo, 2021.

Este trabalho analisa dados magnetotelúricos de 11 estações banda larga adquiridos ao longo de um perfil de aproximadamente $200 \mathrm{~km}$ de comprimento entre o Cráton Amazônico e a Bacia do Paraná, posicionado ortogonalmente à Anomalia de Condutividade da Faixa ParaguaiAraguaia (PACA; BOLOGNA et al., 2014). O objetivo principal do trabalho foi obter mais detalhes da posição e estrutura da PACA. Após análise dimensional e determinação do azimute geoelétrico regional (N70E) por meio de uma técnica de decomposição do tensor de impedâncias, os dados foram rotacionados para o sistema de coordenadas da estrutura regional e modelados usando o código de inversão bidimensional REBOCC. Para testar a consistência dos resultados, foram efetuadas mais de 100 inversões, variando-se diferentes parâmetros, incluindo o modelo inicial. Os modelos geoelétricos resultantes indicam uma zona relativamente condutiva $(10-100 \Omega \mathrm{m})$ na base da Bacia do Paraná, que pode significar a presença de um gráben soterrado ou uma zona crustal rasa mais fraturada. Na crosta profunda, ocorrem dois corpos fortemente condutivos $(0,1-1 \Omega \mathrm{m})$ com topo entre 10 e $15 \mathrm{~km}$ e extensão lateral total de $100 \mathrm{~km}$. Embora uma dessas feições possa estar associada a um evento tectonomagmático do Cretáceo Inferior, é mais provável que ambas anomalias crustais profundas representem a PACA. O fato dessa estrutura elétrica coincidir espacialmente com a zona mais deformada da Faixa Paraguai sugere uma relação genética entre a PACA e o evento tectônico que formou a faixa no final do Neoproterozóico.

Palavras-chave: Faixa Paraguai. Condutividade elétrica. Magnetotelúrica. 


\begin{abstract}
BARBOSA, A. N. Magnetotelluric Study in the Northern Paraguay Belt. 2021. 122 p. Dissertation (Master of Science, Geophysics) - Instituto de Astronomia, Geofísica e Ciências Atmosféricas, Universidade de São Paulo, São Paulo, 2021.

This work analyzes magnetotelluric data from 11 broadband stations, acquired in an approximately $200 \mathrm{~km}$-long profile between the Amazonian Craton and the Paraná Basin, positioned orthogonally to the Paraguay-Araguaia Belt Conductivity Anomaly (PACA; BOLOGNA et al., 2014). The main objective of the work is to obtain more detail on the position and the structure of the PACA. After a dimensional analysis and the determination of the regional geoelectric strike (N70E) through an impedance tensor decomposing technique, the data were rotated to the coordinate system of the regional structure and modeled using the bidimensional inverse code REBOCC. To test the consistency of the results, more than 100 inversions were run, varying differing parameters, including the initial model. The resulting geoelectric models display a relatively conductive zone $(10-100 \Omega \mathrm{m})$ at the base of the Paraná Basin, which may indicate either a buried graben or a more fractured uppermost crustal zone. At the deep crust, there are two strongly conductive bodies $(0.1-1 \Omega \mathrm{m})$ with a top between 10 and $15 \mathrm{~km}$ and a total lateral extension of about $100 \mathrm{~km}$. Although one of these features may be associated with a magmatic-tectonic event from the Lower Cretaceous, it is more probable that both deep crustal anomalies represent the PACA. The fact that this electrical structure coincides spatially with the most deformed zone of the Paraguay Belt suggests a genetic relationship between the PACA and the tectonic event that formed the belt at the end of the Neoproterozoic.
\end{abstract}

Keywords: Paraguay Belt. Electric conductivity. Magnetotelluric. 
1 INTRODUÇÃ

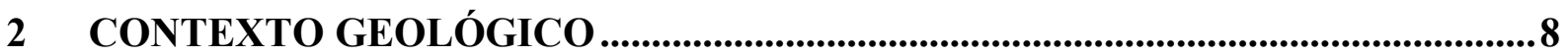

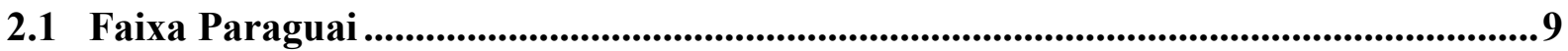

2.2 Bacia do Paraná ........................................................................................................................10

3 FUNDAMENTOS TEÓRICOS DO MÉTODO MT .................................................. 12

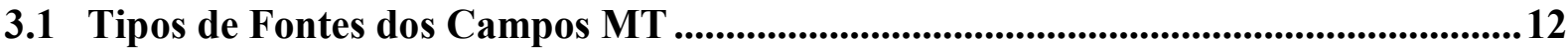

3.2 Princípios Físicos .................................................................................................................15

3.3 Dimensionalidade das Estruturas da Terra ......................................................18

3.4 Princípios Básicos de Processamento de Dados MT.....................................................20

3.5 Distorções Galvânicas .............................................................................................23

3.6 Resistividade Elétrica das Rochas......................................................................23

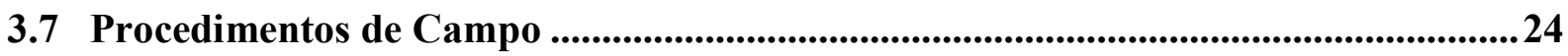

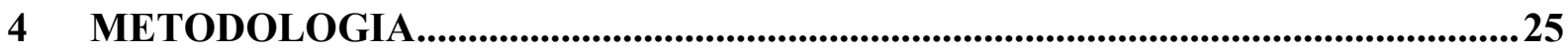

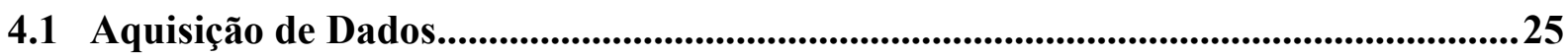

4.2 Processamento e Análise de Dados........................................................................25

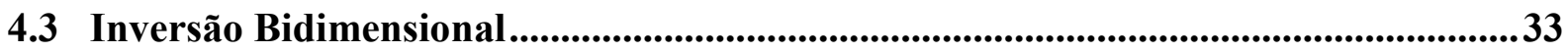

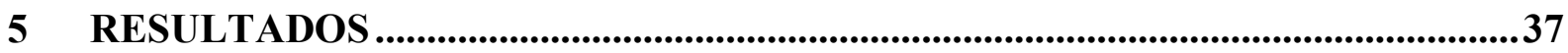

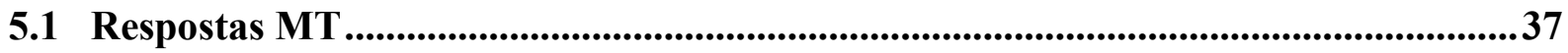

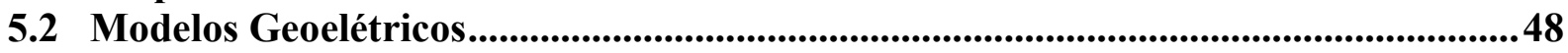

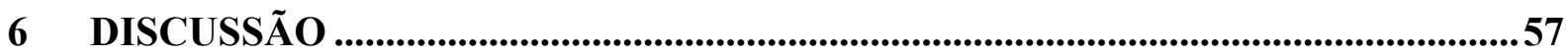

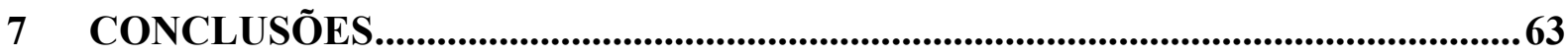

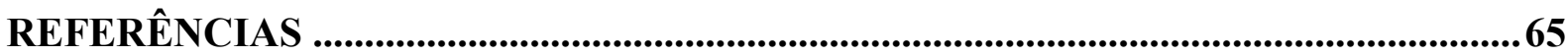

APÊNDICE A - CURVAS DE RESISTIVIDADE APARENTE E FASE.........................73

APÊNDICE B - TESTE DOS PARÂMETROS: INVERSÃO TE+TM..............................77 



\section{INTRODUÇÃO}

A Anomalia de Condutividade da Faixa Paraguai-Araguaia (PACA; BOLOGNA et al., 2014) bordeja as margens sul e sudeste do Cráton Amazônico. Trata-se de uma feição litosférica bastante extensa, com aproximadamente $1200 \mathrm{~km}$ de comprimento e relativamente condutiva, com valores de resistividade elétrica chegando à $0,1 \Omega \mathrm{m}$ (ou condutividade elétrica de $10 \mathrm{~S} / \mathrm{m}$ ). Sua semelhança com a feição geoelétrica NACP (JONES et al., 1993) do orógeno Paleoproterozóico Trans-Hudson na América do Norte levou Bologna et al. (2014) a favoreceram a hipótese de colisão entre o Cráton Amazônico e um bloco litosférico sob a Bacia do Paraná em consequência do fechamento de um oceano na região da Faixa Paraguai. Essa interpretação contraria modelos geológicos tradicionais (TROMPETTE, 1994) que invocam uma evolução ensiálica para esse cinturão.

A localização da PACA foi originalmente baseada em dados de sondagens geomagnéticas profundas (Geomagnetic deep sounds - GDS), cujo espaçamento entre as estações usadas na análise da anomalia foi de aproximadamente $100 \mathrm{~km}$. Como consequência dessa distribuição relativamente esparsa, a posição da PACA não é bem definida. Também, dados GDS são capazes de recuperar a posição horizontal e contrastes laterais de estruturas anômalas, mas não sua profundidade e os valores absolutos de sua resistividade elétrica (SIRIPUNVARAPORN; EGBERT, 2009).

Bologna et al. (2014) obtiveram mais informações sobre a posição da PACA usando dados magnetotelúricos (MT) coletados ao longo de um perfil próximo à região de Cuiabá, no Estado de Mato Grosso. Modelagem dos dados daquele perfil mostra a PACA como um corpo condutor de aproximadamente $100 \mathrm{~km}$ de largura, exibindo uma resistividade de aproximadamente $1 \Omega \mathrm{m}$; seu topo está localizado a uma profundidade de aproximadamente 2$5 \mathrm{~km}$; a base do corpo anômalo não é bem definida devido ao forte amortecimento dos sinais de MT. Porém, os dados MT na região de Cuiabá foram severamente afetados por efeitos 3D, o que inviabilizou uma inversão $2 \mathrm{D}$ completa.

Diferentes estudos geofísicos sobre a litosfera continental da placa sul-americana, utilizando técnicas como gravimetria, sismicidade, função do receptor e tomografia (ASSUMPÇÃO; SACEK, 2013; ASSUMPÇÃO et al., 2013; VAN DER MEIJDE et al., 2013) tem sido feitos nos últimos anos para determinar a estrutura litosférica da placa sul-americana. Entretanto a resolução relativamente baixa desses dados tem impedido a localização dos limites ocultos de placas litosféricas antigas. 
Aqui, propõe-se um estudo MT entre o Cráton Amazônico e o extremo norte da Bacia do Paraná utilizando um perfil cruzando ortogonalmente à posição estimada da PACA por dados GDS (Figura 1). O perfil MT está orientado na direção norte-sul e possui aproximadamente $200 \mathrm{~km}$ de extensão. Ele é composto por 11 estações MT de banda larga equiespaçadas por aproximadamente $19 \mathrm{~km}$. Este trabalho tem como objetivo principal detalhar, através de dados MT inéditos, as características internas da PACA no norte da Faixa Paraguai.

\section{CONTEXTO GEOLÓGICO}

A Província Tocantins é definida por Almeida et al. (1981) como um cinturão orogênico Neoproterozoico que corresponde à principal feição tectônica presente na porção central do Brasil. Situa-se entre o oeste e sul do Cráton Amazônico e a leste do Cráton do São Francisco. Nesta província ocorrem cinturões de dobras e cavalgamentos com direções preferenciais N-S em sua porção norte e E-W na porção central, onde as estruturas têm direções SSE e E-W (STRIEDER; NILSON, 1993).

Ela é composta de diferentes terrenos: Maciço Mediano de Goiás que abriga as rochas mais antigas; Cinturão Uruaçuano composto pela unidade metassedimentar Araxá com corpos máficos e ultramáficos; Faixa Brasília localizada a leste; e os cinturões dobrados a oeste, que correspondem à Faixa Paraguai e à Faixa Araguaia (ALMEIDA et al.; 1977). Estes cinturões foram desenvolvidos durante a amalgamação do Gondwana ocidental (BRITO NEVES; CORDANI, 1991; TROMPETTE, 1994; BRITO NEVES et al., 1999).

O perfil MT deste estudo está situado entre a porção norte da Faixa Paraguai (norte do perfil), com a extremidade norte do perfil (estação P10) próxima ao contato da zona externa da faixa com a cobertura de plataforma do Cráton Amazônico, e a porção NW da Bacia do Paraná (parte sul do perfil), como é possível observar na Figura 1. Essas regiões são melhor abordadas a seguir. 
Figura 1: Mapa Geológico da região de estudo com as estações MT deste estudo e a posição da PACA inferida através de dados GDS por Bologna et al. (2014).

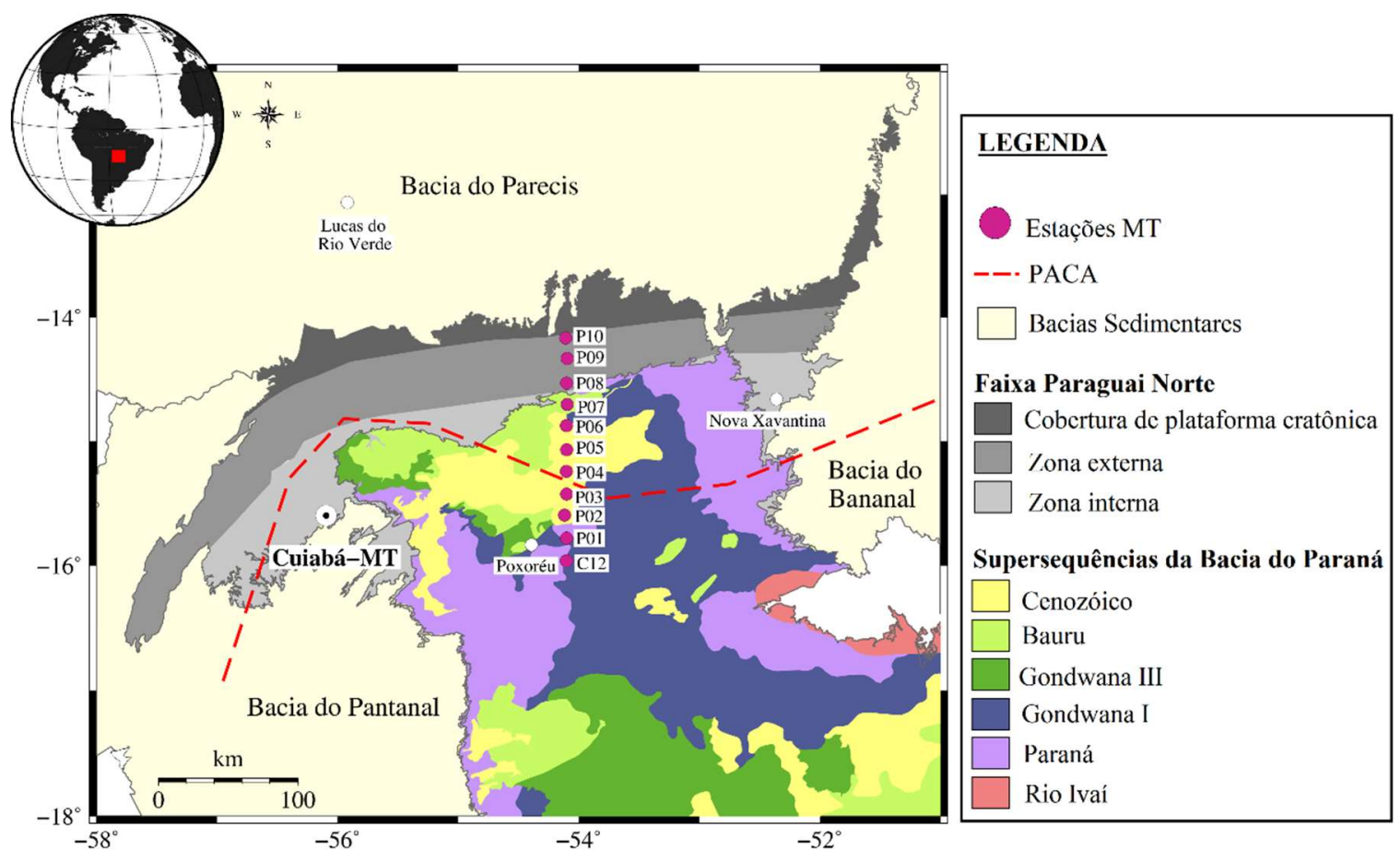

Fonte: Modificado de Litherland et al. (1986); Milani (1997); Schobbenhaus Filho et al. (2003); Milani et al. (2007); Bologna et al. (2014); Cordani et al. (2016).

\subsection{Faixa Paraguai}

A Faixa Paraguai, uma importante unidade geotectônica do evento Brasiliano-PanAfricano na América do Sul (ALMEIDA, 1965), estende-se por cerca de $1000 \mathrm{~km}$ entre sua porção Norte (Sul do Cráton Amazônico e a NW da Bacia do Paraná - Estado de Mato Grosso), e sua porção Sul (Leste do bloco cratônica Rio Apa - Estado de Mato Grosso do Sul). Caracteriza-se pela intensa deformação linear, presença de falhas inversas e/ou empurrão, escassez de vulcanismo e ocorrência de plútons graníticos nas zonas mais internas (ALMEIDA, 1984 apud CAMPANHA et al., 2011). As dobras e deformações são provenientes do Ciclo Brasiliano sendo a faixa composta por rochas metassedimentares, que apresentam uma cobertura sedimentar parcialmente contemporânea, não metamorfizada, levemente dobrada e fraturada em direção ao Cráton Amazônico (ALVARENGA; TROMPETTE, 1993).

A cobertura de plataforma das Faixas Paraguai (e Araguaia) é estratigraficamente representado por formações de ferro bandada e rochas carbonáticas com fósseis de idade Vendiana (ALVARENGA et al., 2000; OSBORNE, 2001). Ambos foram depositados ao longo das margens do Cráton Amazônico, sugerindo que as faixas móveis podem fazer parte de uma única faixa dobrada no Brasiliano (ALMEIDA, 1974), apesar de serem divididas em duas faixas separadas, Paraguai ao sul e Araguaia ao norte (ALMEIDA, 1985). 
A Faixa Paraguai é composta por uma sequência espessa de sedimentos glaciomarinho, turbiditos, rochas carbonáticas e siliciclásticas (ALVARENGA, 1990; ALVARENGA; TROMPETTE, 1992; 1993; ALVARENGA et al., 2000). Ela pode ser dividida, através de unidades estruturais e estratigráficas, em duas: a zona interna e a zona externa.

A Zona Interna é formada por rochas do Grupo Cuiabá, intensamente deformada e moderadamente metamorfoseada. Enquanto a Zona Externa é composta por rochas mais jovens das formações Diamantino, Raizama, Araras, Puga e Bauxi e pela cobertura cratônica (OLIVA et al., 1979; SCHOBBENHAUS FILHO; OLIVA, 1979; SCHOBBENHAUS FILHO et al., 1981; 1984; BARROS et al.; 1982; ALMEIDA, 1984; STROPPER, 2014).

Segundo Alvarenga (1984), a principal controvérsia está na localização da transição entre essas duas zonas; interna (região mais metamorfoseada com intrusões graníticas) e a externa (região mais dobrada, e não metamorfizadas).

A Faixa Paraguai Norte é recoberta por duas bacias paleo-mesozoicas: a do Paraná e do Parecis. Os contatos entre as bacias e a Faixa Paraguai Norte são visíveis e controlados por falhas pré-existentes do embasamento, reativadas, incluindo o Lineamento Transbrasiliano (BRITO NEVES et al., 1984; CORDANI et al., 2009).

As estações P08 à P10 encontram-se sobre litologias da Faixa Paraguai, das quais predominam os metassedimentos do Grupo Cuiabá, dolomitos e calcários da Formação Araras (Superior e Inferior, respectivamente) e os arenitos conglomeráticos com intercalações de argilitos da Formação Raizama.

\subsection{Bacia do Paraná}

A Bacia do Paraná é a principal área sedimentar paleozoica brasileira, abrange mais de 1,1 milhão de $\mathrm{km}^{2}$ no Brasil (QUINTAS et al., 1999), além do leste do Paraguai, Argentina e Uruguai, cobrindo mais de 1,7 milhão de $\mathrm{km}^{2}$. A bacia tem forma elíptica, com direção NNESSW, espessura sedimentar que ultrapassa $7 \mathrm{~km}$ em seu depocentro principal (MILANI; RAMOS, 1998; MILANI et al., 2007).

A estratigrafia da Bacia do Paraná contém rochas com idades entre o Ordoviciano e o Neocretáceo, compreendendo seis supersequências (MILANI, 1997): Rio Ivaí (OrdovicianoSiluriano), Paraná (Devoniano), Gondwana I (Carbonífero-Eotriássico), Gondwana II (Meso a Neotriássico), Gondwana III (Neojurássico-Eocretáceo) e Bauru (Neocretáceo). As três primeiras correspondem a grandes ciclos transgressivos paleozóicos, enquanto as demais são representadas por pacotes sedimentares continentais e rochas ígneas associadas. 
O mapa geológico (Figura 1), mostra que as estações C12 a P07 estão sobre litologias sedimentares da Bacia do Paraná com predominância de arenitos e folhelhos. Destacam-se os arenitos da Formação Cachoeirinha, formada por arenitos argilosos inconsolidados, Aquidauana, com arenitos de ambiente fluvial e lacustre e do Grupo Bauru, cuja granulação é fina. Os folhelhos são representados pelas Formações Ponta Grossa e Diamantino. Interpolação de dados de poço indica que a profundidade do embasamento da região não ultrapassa os 1000 metros.

A Província Ígnea Poxoréu (PIP) encontra-se sob o norte da Bacia do Paraná (Figura 2), localizada na área de estudo. Esta é uma das diversas províncias alcalinas máficas do Cretáceo que foram posicionadas em torno das margens da bacia.

A atividade vulcânica do PIP foi focada ao longo de uma zona extensional de tendência NE-SW (o rift do Rio das Mortes), que se desenvolveu entre a parte mais ao norte da Bacia do Paraná e a margem sul do cráton Amazônico, dentro do Proterozóico superior. A extensão e a formação da bacia associadas ao rift do Rio das Mortes parecem ter sido iniciadas no início do Cretáceo Superior e continuada até o final deste período. Atualmente, grande parte do afloramento superficial dos setores sudoeste e nordeste do rift é mascarado por uma sequência de cobertura Terciário-Quaternário de aproximadamente $30 \mathrm{~m}$ de espessura, o que torna difícil estimar o comprimento de todo o rift. No entanto, a estrutura e estratigrafia de duas bacias relacionadas ao rift estão bem expostas ao redor da Chapada dos Guimarães e Poxoréu (Figura 2). Essas bacias desenvolveram-se ao longo do eixo do rift, e foram separadas por um granito pós-orogênico ordoviciano (o horst de São Vicente; ALMEIDA 1986).

Figura 2: Cenário tectônico da PÍP. Em vermelho, a localização do perfil MT deste trabalho.

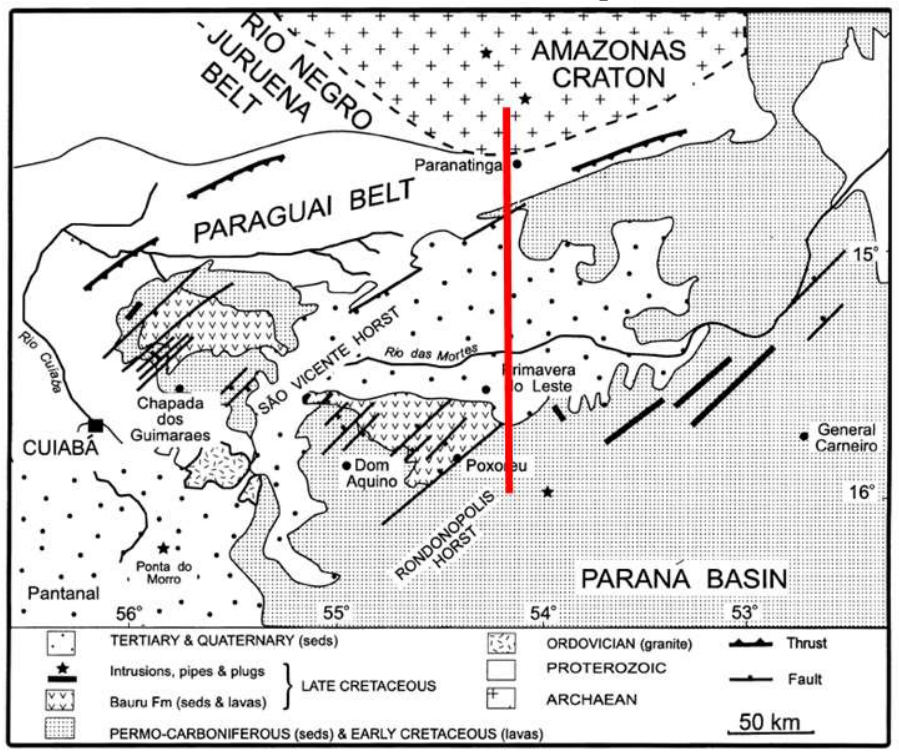

Fonte: Adaptado de Gibson et al. (1997). 


\section{FUNDAMENTOS TEÓRICOS DO MÉTODO MT}

O método MT, proposto por Tikhonov (1950) e por Cagniard (1953), baseia-se na medida simultânea dos campos elétricos e magnéticos naturais na superfície terrestre para determinar a distribuição de resistividade elétrica da subsuperfície. Os sinais MT são gerados por duas fontes: uma de baixa frequência (períodos $>1$ s), a partir da interação do vento solar com a magnetosfera, e outra de alta frequência (períodos $<1$ s), a partir de fenômenos meteorológicos na baixa atmosfera. Em campo, o que se adquire são séries temporais de componentes dos campos elétricos e magnéticos, que são convertidas para o domínio da frequência para então serem estimados o tensor de impedâncias e as funções de transferência do campo magnético vertical (Tipper). As impedâncias são sensíveis a variações de temperatura, presença de minerais condutivos ou fluidos salinos, etc., enquanto o tipper depende apenas do contraste lateral de resistividade das estruturas geológicas.

Para a aplicação do método MT, são assumidas algumas premissas conforme sintetizadas por Simpson e Bahr (2005):

I. Os campos eletromagnéticos obedecem às equações de Maxwell;

II. A Terra não gera energia eletromagnética, ela apenas a dissipa ou a absorve;

III. Todos os campos (elétrico e magnético) devem ser tratado como conservativo longe de suas fontes;

IV. Os campos gerados na ionosfera, relativamente distantes da superfície da Terra, devem ser tratados como ondas uniformes e plano-polarizadas penetrando quase verticalmente no interior terrestre. (Essa premissa é frequentemente violada em regiões polares e equatoriais);

V. A Terra se comporta como um condutor ôhmico e sua carga é conservada;

VI. As correntes de deslocamento são quase estáticas para períodos de sondagens MT, podendo ser negligenciadas em relação às correntes de condução;

VII. As variações na permissividade elétrica e na permeabilidade magnética nas rochas não são relevantes, quando comparadas com as variações da condutividade elétrica nas rochas.

\subsection{Tipos de Fontes dos Campos MT}

Os sinais eletromagnéticos (EM) naturais são gerados por diferentes fontes que vão do núcleo da Terra até às galáxias distantes e tem origem através de diversos processos (VOZOFF, 1991). Para a teoria do método MT considera-se que os campos elétrico e magnético naturais incidam na superfície como ondas planas que se propagam verticalmente no interior da Terra. 
As origens dessas variações temporais, explicadas nas próximas seções, classificam as ondas eletromagnéticas em dois grupos: as ondas eletromagnéticas de baixas frequências (menor que $1 \mathrm{~Hz}$ ) e as ondas eletromagnéticas de altas frequências (maior que $1 \mathrm{~Hz}$ ). Quando as ondas EM incidem na superfície, elas sofrem reflexão e refração. A maior parte da energia EM envolvida nesse processo é refletida, enquanto a outra parte menor penetra no interior da Terra. Essa pequena parcela transmitida induz correntes telúricas em subsuperfície.

\subsubsection{Fonte de Baixa Frequência $(<1 \mathrm{~Hz})$}

A fonte primária de sinais MT com frequências menores que $1 \mathrm{~Hz}$ é a interação entre a magnetosfera terrestre e o vento solar (Figura 3).

Figura 3: Interação do vento solar com a magnetosfera.

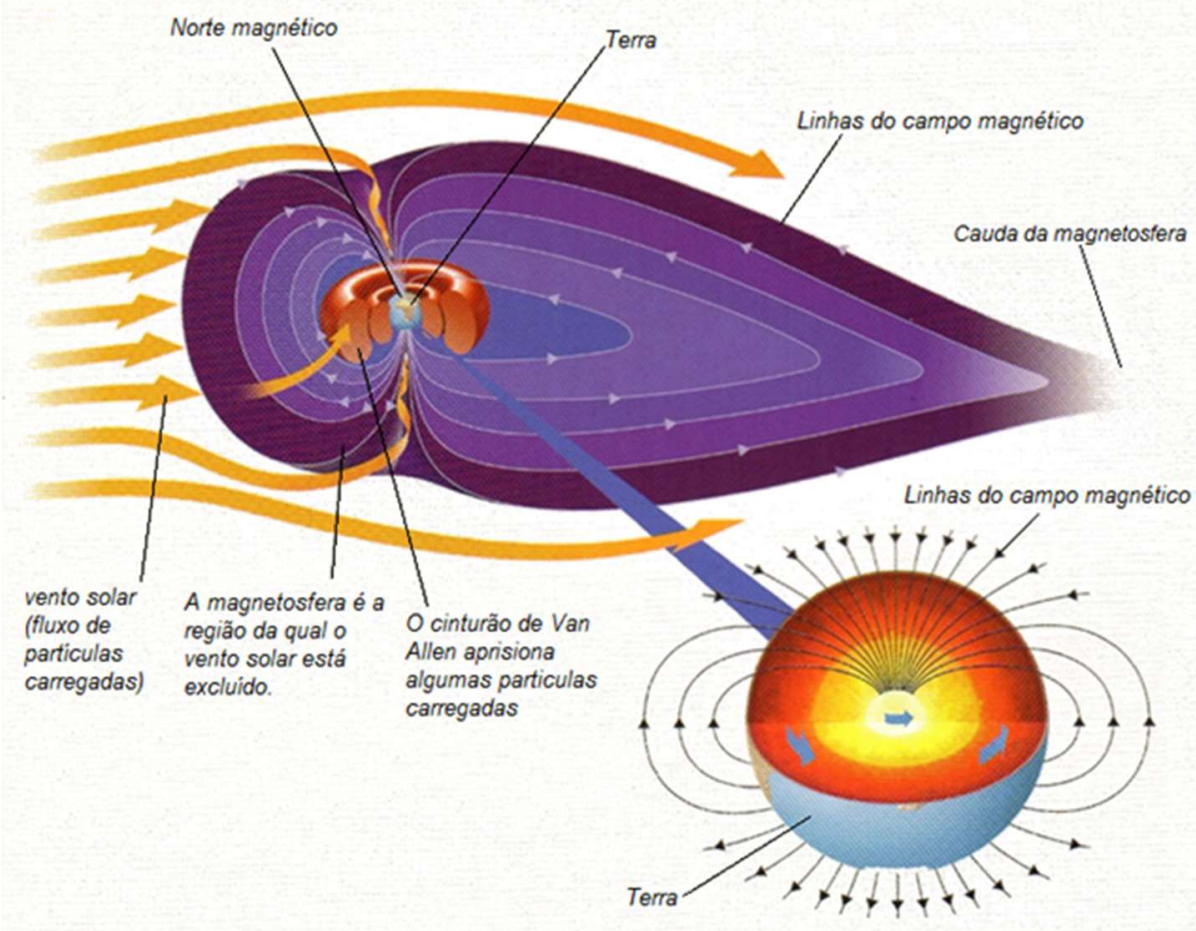

Fonte: James (2013).

Segundo Kaufman e Keller (1981), o vento solar consiste praticamente de hidrogênio ionizado, sendo um plasma constituído de prótons e elétrons. A interação das partículas ionizadas do vento solar com principal campo magnético terrestre não é constante e causam significativas variações no campo magnético externo. Essas interações dão origem a sistemas de correntes na ionosfera e magnetosfera, as quais podem ser vistas com uma forma de variações geomagnéticas na superfície terrestre conhecidas como pulsações geomagnéticas. 


\subsection{Princípios Físicos}

\subsubsection{As Equações de Maxwell}

As equações de Maxwell descrevem a relação entre os campos magnéticos e elétricos, no domínio da frequência, independentemente de qual seja o meio em que esses campos estejam submersos. Assim, as equações de Maxwell apresentam-se no formato diferencial em situação de referência inercial de repouso ou movimento usando o sistema internacional (SI):

Lei de Gauss para o campo elétrico,

$$
\vec{\nabla} \cdot \vec{D}=\rho
$$

Lei de Gauss para o campo magnético,

$$
\vec{\nabla} \cdot \vec{B}=0
$$

Lei de Faraday,

$$
\vec{\nabla} \times \overrightarrow{\mathrm{E}}=-\partial_{t} \overrightarrow{\mathrm{B}}
$$

Lei de Ampère com os termos de Maxwell,

$$
\vec{\nabla} \times \overrightarrow{\mathrm{H}}=\overrightarrow{\mathrm{J}}+\partial_{t} \overrightarrow{\mathrm{D}}
$$

onde, $\overrightarrow{\mathrm{B}}$ é o vetor de indução magnética $\left(W / m^{2}\right.$ ou $\left.T\right), \overrightarrow{\mathrm{H}}$ é o vetor campo magnético $(A / m)$, $\overrightarrow{\mathrm{D}}$ é o vetor da indução elétrica $\left(C / m^{2}\right.$ ou $\left.N / V m\right), \overrightarrow{\mathrm{E}}$ é o vetor do campo elétrico $(V / m$ ou $N / C), \vec{J}$ é o vetor da densidade da corrente elétrica $\left(A / m^{2}\right)$ e $\rho$ é a densidade da carga elétrica $\left(\mathrm{C} / \mathrm{m}^{3}\right)$.

A Lei de Faraday, expressa na equação (3), resume que o campo magnético, variando temporalmente, induz "flutuações" em campo elétrico circulando em loop fechado com eixo orientado na direção do campo indutor. Já a Lei de Ampère corrigida por Maxwell, equação (4), infere que uma corrente elétrica em loop fechado é associada a um campo magnético proporcional ao fluxo de corrente total. Assim, em razão das baixas intensidades dos campos eletromagnéticos naturais podem ser usadas as seguintes relações:

$$
\begin{gathered}
\overrightarrow{\mathrm{B}}=\mu \overrightarrow{\mathrm{H}} \\
\overrightarrow{\mathrm{D}}=\varepsilon \overrightarrow{\mathrm{E}} \\
\overrightarrow{\mathrm{J}}=\sigma \overrightarrow{\mathrm{E}}
\end{gathered}
$$

onde, $\varepsilon$ é a permissividade elétrica $(F / m), \mu$ é a permeabilidade magnética $\left(H / m\right.$ ou $\left.N / A^{2}\right)$ e $\sigma$ é a condutividade elétrica $(S / m)$, esses são parâmetros característicos do meio em que as ondas se propagam.

Assim, para a crosta terrestre utiliza-se os seguintes valores $\mu=\mu_{0}=4 \pi \times 10^{-7} \mathrm{H} / \mathrm{m}$ e $\varepsilon=\varepsilon_{0}=8,85 \times 10^{-12} \mathrm{~F} / \mathrm{m}$. Esses valores estão relacionados com um dos pressupostos do 
método MT, o qual diz que as variações em $\varepsilon$ e $\mu$ são irrelevantes comparadas com as variações da condutividade da rocha. Isso é aplicado em estudos de prospecção, ao supor que os meios são isotrópicos e estáticos deixando de lado qualquer dependência temporal dos parâmetros. Essa suposição é feita porque, em geral, os parâmetros $(\varepsilon, \mu$ e $\sigma)$ são expressos como tensores em meios anisotrópicos e podem variar no tempo.

Supondo campos harmônicos com dependência temporal $e^{i \omega t}$, onde $\omega$ é a frequência angular, as derivadas temporais podem ser expressas no domínio da frequência como:

$$
\frac{\partial}{\partial t}=i \omega \text {. }
$$

Rearranjando as equações (3) e (4) a partir das relações indicadas em (5, 6 e 7) e admitindo a suposição acima, obtemos as seguintes equações:

$$
\begin{gathered}
\vec{\nabla} \times \overrightarrow{\mathrm{E}}=-i \omega \mu \overrightarrow{\mathrm{H}} \\
\vec{\nabla} \times \overrightarrow{\mathrm{H}}=\sigma \overrightarrow{\mathrm{E}}+i \omega \varepsilon \overrightarrow{\mathrm{E}}
\end{gathered}
$$

Para melhor compreensão das próximas etapas, optou-se por aplicar o operador rotacional em ambos os lados da equação (9):

$$
\vec{\nabla} \times(\vec{\nabla} \times \overrightarrow{\mathrm{E}})=\vec{\nabla} \times(-i \omega \mu \overrightarrow{\mathrm{H}})
$$

Aplicando uma identidade vetorial no primeiro termo da equação (11), temos:

$$
-\vec{\nabla}^{2} \vec{E}=-i \omega \mu(\vec{\nabla} \times \overrightarrow{\mathrm{H}})
$$

Substituindo (10) em (12):

$$
-\vec{\nabla}^{2} \overrightarrow{\mathrm{E}}=-i \omega \mu(\sigma \overrightarrow{\mathrm{E}}+i \omega \varepsilon \overrightarrow{\mathrm{E}})
$$

Multiplicando a equação (13) por -1 :

$$
\vec{\nabla}^{2} \overrightarrow{\mathrm{E}}=i \omega \mu \sigma \overrightarrow{\mathrm{E}}+(i \omega)^{2} \mu \varepsilon \overrightarrow{\mathrm{E}}
$$

Para o campo magnético, chega-se ao mesmo resultados:

$$
\vec{\nabla}^{2} \overrightarrow{\mathrm{H}}=i \omega \mu \sigma \overrightarrow{\mathrm{H}}+(i \omega)^{2} \mu \varepsilon \overrightarrow{\mathrm{H}}
$$

A equação (14) pode ser reescrita da seguinte forma:

$$
\vec{\nabla}^{2} \overrightarrow{\mathrm{E}}=i \omega \mu \sigma \overrightarrow{\mathrm{E}}-\omega^{2} \mu \varepsilon \overrightarrow{\mathrm{E}}
$$

onde o primeiro termo do lado direito, equação (16), representa as correntes de condução e o segundo termo, deste mesmo lado, representa as correntes de deslocamento. A razão entre os dois tipos de corrente é dada por:

$$
\frac{\text { correntes de condução }}{\text { correntes de deslocamento }}=\frac{\omega \mu \sigma^{\rightarrow}}{\omega^{2} \mu \varepsilon}=\frac{\sigma}{\varepsilon \omega}
$$

Uma vez que o intervalo de frequências das sondagens MT está entre os valores de 1000 a $0,0001 \mathrm{~Hz}$ e as resistividades elétricas encontradas nos meios estudados estão na faixa de 0,1 
a 10000 ohm.m, é possível desconsiderar as correntes de deslocamento (regime quasiestacionário), pois,

$$
\frac{\sigma}{\varepsilon \omega} \gg 1
$$

Deste modo a equação (14) pode ser reduzida a:

$$
\vec{\nabla}^{2} \overrightarrow{\mathrm{E}} \cong-i \omega \mu \sigma \overrightarrow{\mathrm{E}}
$$

esta equação é uma das Equações de Helmholtz e expressam uma equação de difusão no domínio da frequência. Ela infere que as ondas de alta frequência têm baixo alcance em relação a profundidade do meio e as ondas de baixa frequência têm alto alcance em relação a profundidade do meio de investigação. Por tanto, a propagação das ondas EM no interior da Terra depende unicamente da condutividade do meio e de seus períodos.

\subsubsection{Skin Depth - Profundidades de Investigação}

A profundidade de penetração dos campos MT no interior da Terra em um semi-espaço uniforme é inversamente proporcional à raiz quadrada da frequência dos sinais. Cada faixa de frequência apresenta uma profundidade máxima de investigação, a qual é conhecida como profundidade pelicular - skin depth $(\boldsymbol{\delta})$. Devido à extensa faixa de frequência utilizada, o método MT possui um amplo intervalo de investigação.

O skin depth é definido como a profundidade na qual o campo tenha decaído de $1 / e$ de sua amplitude inicial, na superfície. Além do período de oscilação do sinal, ele dependente também da condutividade elétrica do meio. A equação do skin depth $(\delta)$ é apresentada a seguir:

$$
\delta=\left(\frac{2}{\omega \mu \sigma}\right)^{1 / 2}=0,503 \sqrt{\frac{\rho_{a}}{f}}(m)
$$

onde $\sigma$ é a condutividade elétrica do meio $(S / \mathrm{m}), \omega$ é a frequência angular $(\mathrm{rad} / \mathrm{s}), f$ é a frequência linear $\left(H_{z}\right), \mu$ é a permeabilidade magnética $(H / m)$ e $\rho_{a}$ é a resistividade aparente do meio $(\Omega m)$.

Assim, as ondas EM penetram a grandes profundidades, para rochas mais resistivas e para frequências mais baixas. Entretanto, na prática, sabendo que o interior da Terra não é homogêneo, utiliza-se o skin depth apenas como referência para o cálculo do amortecimento que os sinais MT sofrem ao se propagarem em um meio resistivo.

A profundidade de penetração do sinal MT é limitada pela absorção exponencial da energia do campo incidente. Em geral, as frequências utilizadas no MT estão no intervalo de $10^{-4}$ a $10^{4} \mathrm{~Hz}$, que correspondem aos períodos de $10000 \mathrm{~s}$ (segundos) e 0,0001 s, respectivamente. 


\subsection{Dimensionalidade das Estruturas da Terra}

As respostas MT são intimamente dependentes da distribuição espacial da resistividade elétrica no meio estudado, em especial entre as relações das componentes do tensor impedância que são reduzidas a expressões específicas. As distribuições espaciais, ou estruturas geoelétricas, podem ser divididas em unidimensional (1D), bidimensional (2D) e tridimensional (3D).

\subsubsection{Terra Unidimensional (1D)}

A variação das resistividades elétricas em profundidade (direção $\mathbf{z}$ ) refere-se às medidas unidimensionais (1D) da Terra. Se a resistividade elétrica não varia em qualquer direção horizontal, os campos EM são ortogonais entre si. Como condição de contorno para a diminuição do campo com o aumento da profundidade é utilizado os cálculos das equações de impedância. Na Figura 4, temos uma exemplificação do modelo de Terra 1D.

Para o modelo de terra 1D, a resistividade do meio é dada por:

$$
\rho_{x y}=\frac{1}{\omega \mu_{0}}\left[\frac{E_{x}}{H_{y}}\right]^{2}
$$

e a relação dos campos elétricos e magnéticos seguem a seguinte equação (22). Neste caso as componentes direcionais do tensor impedância são $Z_{y x}=-Z_{x y}$ e $Z_{x x}=Z_{y y}=0$.

$$
\left[\begin{array}{c}
E_{x} \\
E_{y}
\end{array}\right]=\left[\begin{array}{cc}
0 & Z_{x y} \\
-Z_{x y} & 0
\end{array}\right]\left[\begin{array}{l}
H_{x} \\
H_{y}
\end{array}\right]
$$

Figura 4: Exemplificação da estrutura interna da Terra-1D, com variação da resistividade em todas as direções.

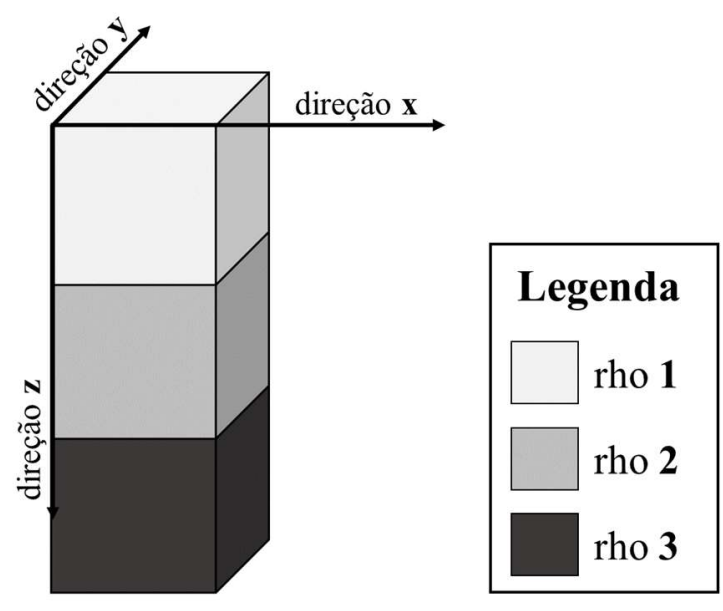

\subsubsection{Terra Bidimensional (2D)}

Consideremos agora a indução EM para um modelo da Terra com variação da resistividade elétrica em duas dimensões, (Figura 5). O strike geoelétrico é paralelo ao eixo x, 
a resistividade varia apenas nas direções $\mathbf{y}$ e $\mathbf{z}$, na direção $\mathbf{x}$ a resistividade não varia e todas as estruturas se estendem ao infinito. Em contraste com o modelo da Terra-1D, as componentes $E_{z}$ e $H_{z}$ do campo podem não ser iguais a zero.

Figura 5: Exemplificação da estrutura interna da Terra-2D, com variação da resistividade em todas as direções.

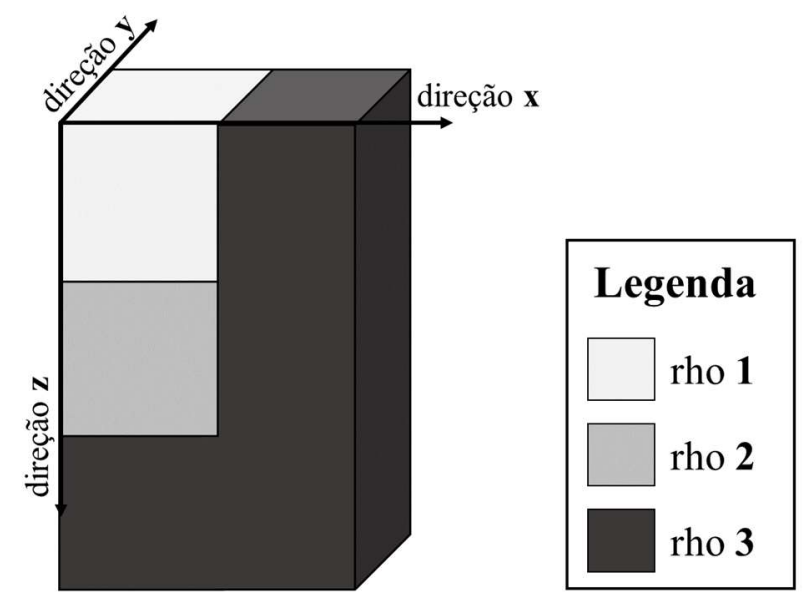

Assim, a partir das equações (9) e (10), levando em consideração que $\partial E / \partial x=0$ e $\partial H / \partial x=0$, podemos decompor o tensor impedância em modo Transverso Elétrico (TE) com o conjunto $E_{x}, H_{\mathrm{y}}$ e $H_{z}$ e o modo Transverso Magnético (TM) com o conjunto $H_{x}, E_{y}$ e $E_{z}$.

- TE: No modo TE, o campo elétrico está polarizado paralelamente a direção do strike (eixo $\mathbf{x}$ ), portanto o modo descreve correntes fluindo paralelamente a direção $\mathbf{x}$.

- TM: No modo TM, o campo magnético está polarizado paralelamente a direção do strike, e nesse contexto, as correntes elétricas estão fluindo perpendicular ao strike, ou seja, na direção do eixo $\mathbf{y}$.

Neste caso, o tensor impedância é representado pela seguinte equação (23) e as componentes $Z_{x y} \neq Z_{y x}$.

$$
\left[\begin{array}{c}
E_{x} \\
E_{y}
\end{array}\right]=\left[\begin{array}{cc}
0 & Z_{x y} \\
Z_{y x} & 0
\end{array}\right]\left[\begin{array}{l}
H_{x} \\
H_{y}
\end{array}\right]
$$

\subsubsection{Terra Tridimensional (3D)}

Em um modelo tridimensional (3D) as resistividades elétricas podem variar nas três componentes direcionais do tensor impedância $(Z), \mathbf{x}, \mathbf{y}$ e $\mathbf{z}$, sendo essas diferentes entre si e não nulas. Assim, não será possível encontrar uma direção para qual os elementos em diagonais se anulem em todos os períodos. Para esse caso o tensor de impedância torna se completo:

$$
\left[\begin{array}{l}
E_{x} \\
E_{y}
\end{array}\right]=\left[\begin{array}{ll}
Z_{x x} & Z_{x y} \\
Z_{y x} & Z_{y y}
\end{array}\right]\left[\begin{array}{l}
H_{x} \\
H_{y}
\end{array}\right]
$$


A Figura 6 é uma exemplificação da estrutura interna de uma Terra 3D, com as variações da resistividade em todas as direções.

Figura 6: Exemplificação da estrutura interna da Terra-3D, com variação da resistividade em todas as direções.

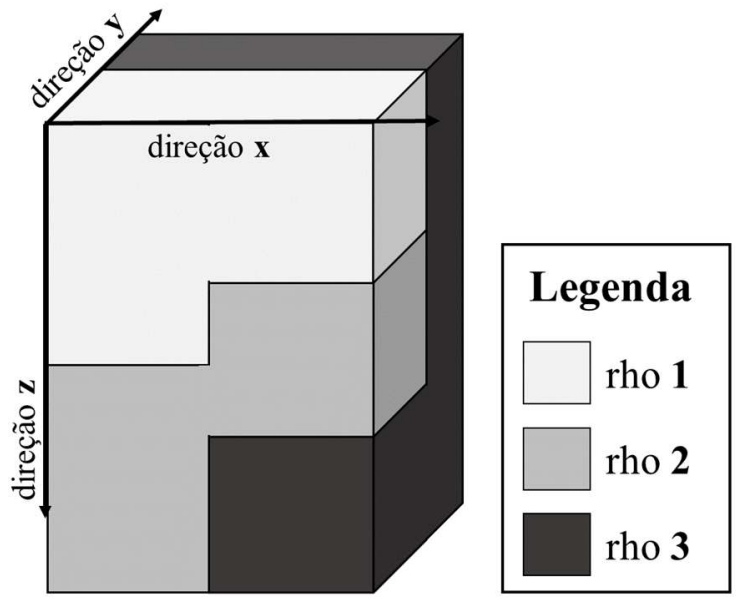

\subsection{Princípios Básicos de Processamento de Dados MT}

Uma análise e interpretação de alta confiabilidade dos dados MT é dependente da qualidade da estimativa dos elementos da matriz de impedância. Por isso, a necessidade de obtêla com maior precisão possível.

Em geral, o objetivo do processamento de dados MT é extrair a partir dos sinais eletromagnéticos, que geralmente são ruídosos, um conjunto de repetiveis e suaves funções que representam a resposta da Terra. Estas respostas podem ser usadas para interpretar estruturas condutivas em subsuperficie (VOZOFF, 1991). Essas funções correspondem aos tensores impedância e a funções de transferência do campo magnético (conhecido também como tipper).

\subsubsection{Tensor Impedância}

Uma das premissas na qual a teoria MT é baseada, diz que os campos eletromagnéticos se propagam como ondas planas. Segundo Berdichevsky e Zhdanov (1984 apud MENEZES, 2013), diversos estudos demostram que essa premissa implica em uma existência de um conjunto de relações lineares entre os campos EM na superfície terrestre.

Assim, quando não há ruído, esta relação linear pode ser descrita no domínio da frequência como é visto na equação (24).

Uma solução da equação (24) para um levantamento de estação única é:

$$
\boldsymbol{Z}=\frac{\left[E H^{c}\right]}{\left[H H^{c}\right]},
$$

onde o índice c denota a matriz transposta conjugada. Os colchetes indicam uma matriz de potência espectral. 
A relação (25) quando aplicada aos dados reais, obriga a estimar as funções respostas e seus erros associados a partir de realizações finitas do processo de indução na presença de ruído, tornando o problema estatístico.

Geralmente, a maioria dos métodos de estimação são baseados na análise espectral clássica e na regressão de mínimos quadrados. Esse último fornece a melhor estimativa não tendenciosa quando, os erros não estão correlacionados, possuem uma variação comum e os resíduos apresentam uma distribuição Gaussiana.

Na realidade, os dados MT exibem desvios dessa situação ideal. Geralmente esses dados contém resíduos espúrios que não são ajustados ao modelo Gaussiano. Dois grupos deste tipo de desvios, chamados de outliers, são mais comuns: os efeitos pontuais e a não estacionaridade.

Defeitos pontuais são outliers isolados que existem independentemente do processo estudado, como por exemplo o ruído localizado, ou spikes, causados por fenômenos, como relâmpagos próximos. A não-estacionaridade são desvios do estado estacionário do campo, como as tempestades magnéticas.

Com o intuito de se obter estimativas mais confiáveis das respostas MT foram criados uma série de métodos robustos, no sentido de serem relativamente insensíveis a presença de quantidade moderada de outliers.

Os métodos mais conhecidos para estimar o tensor impedância são os mínimos quadrados, referência remota e métodos robustos. Atualmente, os mais utilizados são os métodos robustos, teoria descrita abaixo.

Egbert e Booker (1986) apresentaram uma introdução sobre os métodos robustos, que consiste em um processo interativo de mínimos quadrados ponderados para minimização das funções erro. Estes métodos seguem os procedimentos estatísticos que fazem com que, na presença de dados espúrios ou inadequações ao modelo estatístico, reajam mais gradualmente a essas perturbações.

$\mathrm{Na}$ primeira iteração, os parâmetros são estimados por mínimos quadrados, depois calculam-se os resíduos, os quais são usados para o cálculo dos pesos. Dados com resíduos abaixo de um certo patamar são tratados de forma convencional (mínimos quadrados), enquanto que para resíduos maiores, os dados são reduzidos por um fator de escala.

\subsubsection{Funções de Transferência Magnética e Vetores de Indução}

Campos magnéticos verticais $\left(\mathbf{H}_{\mathrm{z}}\right)$ podem ser gerados no interior da Terra devido a presença de estruturas que produzem um contraste lateral de condutividade (Figuras $7 \mathrm{a}$ e $7 \mathrm{~b}$ ). Por sua vez, os vetores de indução são representações gráficas da relação complexa (contendo 
partes real e imaginaria) entre a componente do campo magnético vertical e as horizontais (SIMPSON; BAHR, 2005), conforme a relação:

$$
\mathbf{H}_{\mathrm{z}}=\left[\begin{array}{ll}
\mathrm{T}_{\mathrm{x}} & \mathrm{T}_{\mathrm{y}}
\end{array}\right]\left[\begin{array}{l}
\mathrm{H}_{\mathrm{x}} \\
\mathrm{H}_{\mathrm{y}}
\end{array}\right]
$$

onde $\mathrm{T}_{\mathrm{x}} \mathrm{e} \mathrm{T}_{\mathrm{y}}$ são as funções de transferência do campo magnético (Tipper).

$\mathrm{O}$ vetor de indução $\mathbf{T}$ é extraído da parte real e/ou da parte imaginaria das funções de transferência magnética. No exemplo da Figura 7 (item b), para um meio idealmente 2D o vetor extraído da parte imaginaria será nulo. Por outro lado, o vetor de indução obtido da parte real e não nulo e pode ser escrito como a soma vetorial das partes reais das funções de transferência magnética. Usando a convenção de Parkinson (Parkinson, 1959), temos:

$$
\mathbf{T}=\mathrm{T}_{\mathrm{x}} \hat{\mathbf{x}}+\mathrm{T}_{\mathrm{y}} \hat{\mathbf{y}}
$$

Os vetores apontam na direção de concentrações anômalas de corrente e suas magnitudes são tão maiores quanto mais próximos da descontinuidade geoelétrica lateral (Figura 7c). Sendo assim, podem ser usados para diagnosticar a presença ou ausência dessas estruturas sob o meio subjacente.

Figura 7: Em a) Modelo 2D de um condutor imerso em um meio mais resistivo. Em b) Forma do campo magnético vertical que atravessa a anomalia de condutividade 2D mostrada em (a). E em c) Vetores de indução obtidos para diferentes posições ao longo do perfil.

(a)

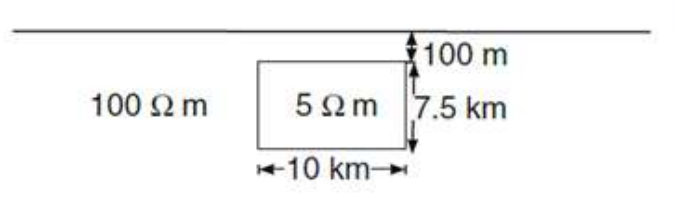

(b)

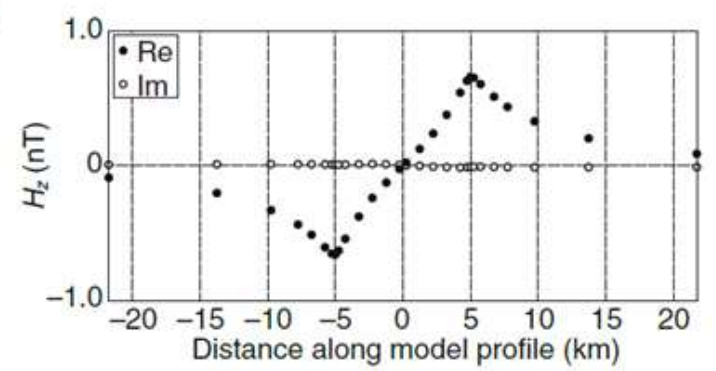

(c)

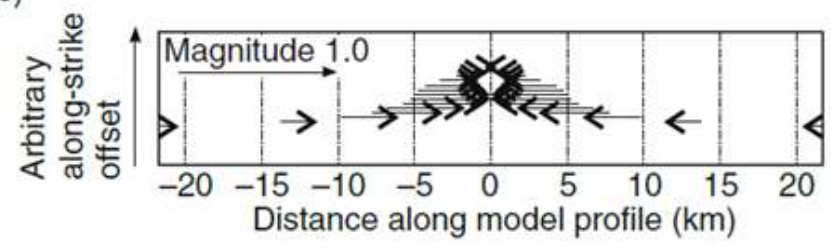

Fonte: Simpson e Bahr (2005). 


\subsection{Distorções Galvânicas}

As distorções galvânicas são causadas pelo acúmulo de cargas superficiais nas interfaces dos contrastes de resistividade. Se existir uma componente do campo elétrico na direção da variação da condutividade elétrica, um campo secundário surgirá e será somado vetorialmente ao campo primário, provocando a distorção do campo elétrico (JIRACEK et al., 2006). A distorção galvânica é percebida diretamente nas curvas de resistividade aparente, que se apresentam deslocadas para valores maiores ou menores por um fator real e constante desconhecido independente da frequência, sendo um exemplo típico do efeito de deslocamento estático (static shift) (SIMPSON; BAHR, 2005). As curvas de sondagem MT são deslocadas para cima quando medidas diretamente sobre corpos resistivos e são reduzidas sobre corpos condutivos.

\subsection{Resistividade Elétrica das Rochas}

Para uma boa interpretação dos resultados do processamento de dados MT, é imprescindível o conhecimento das propriedades elétricas do ambiente estudado.

Podemos definir resistividade elétrica como uma medida da oposição de um material ao fluxo de corrente eléctrica. Assim, quanto mais baixa for a resistividade, mais facilmente o material permite a passagem de uma carga eléctrica. Ainda, destaca-se que dentro de todos os parâmetros geofísicos, a resistividade elétrica é um dos parâmetros mais variáveis (até oito ordens de magnitude), sendo principalmente sensível à presença de fluídos (distribuição e quantidade), salinidade, porosidade, temperatura, sulfetos, óxidos de ferro e grafita (JONES, 1992). A Figura 8 mostra os valores de resistividade elétrica de rochas e minerais mais comuns.

A condução eletrônica é definida como a corrente elétrica que se desloca por meio do movimento ordenado de seus elétrons em um fio condutor. Em uma rocha, a corrente elétrica desloca-se através da solução eletrolítica que preenche os poros interconectados, e/ou fraturas, na dependência da maior ou menor quantidade de íons presentes (condução iônica).

$\mathrm{Na}$ condução eletrolítica, a resistividade da rocha depende das propriedades do fluído intersticial, da porosidade e interconexão dos poros (e não da propriedade da matriz). A condução eletrolítica ocorre na crosta terrestre em pequena profundidade, quando comparada com as profundidades de outros tipos de condução.

No manto predomina a semi-condução e a condutividade elétrica depende sobretudo da temperatura. Daí a condutividade elétrica tende a aumentar gradualmente com a profundidade. 
Figura 8: Tabela de valores de resistividade elétrica

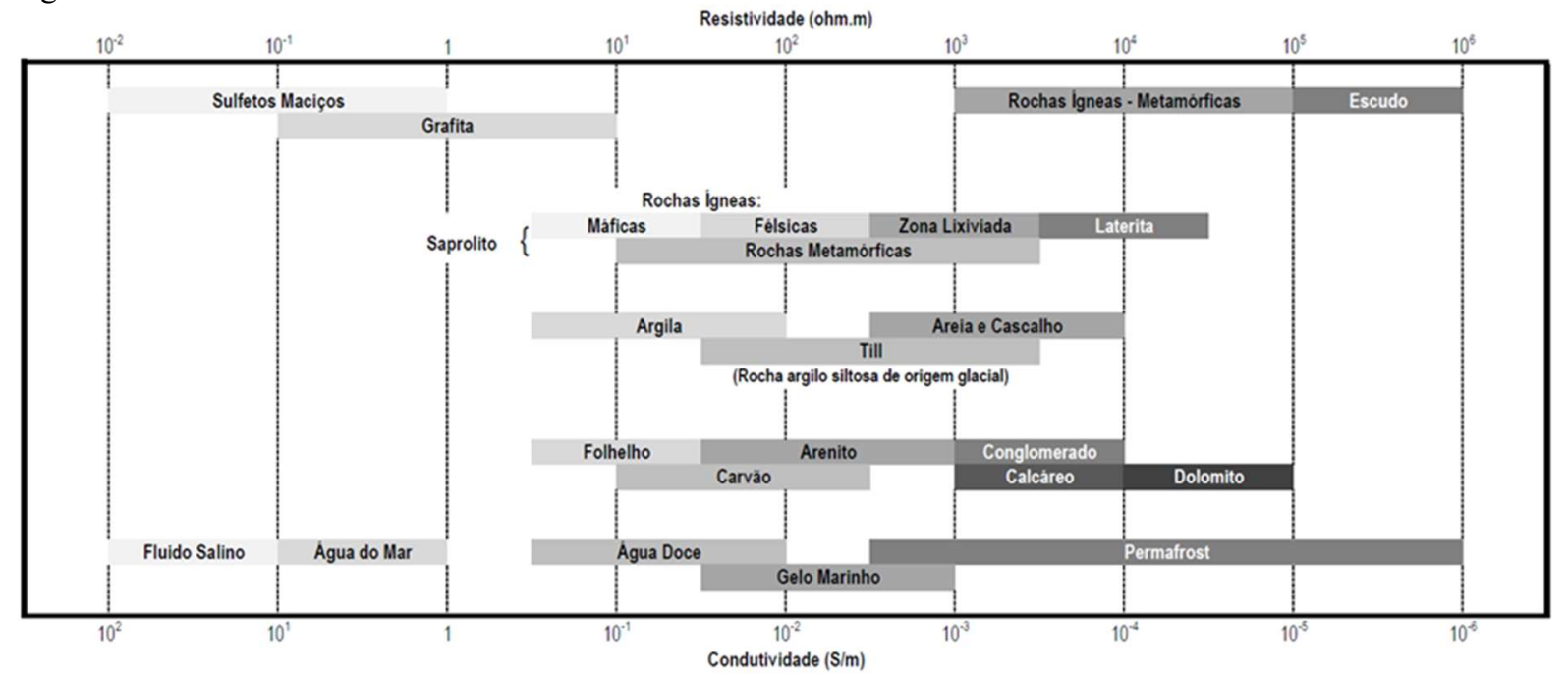

Fonte: Palacky (1988).

\subsection{Procedimentos de Campo}

A Figura 9 mostra o arranjo de um campo para a aquisição das cinco componentes ortogonais $\left(\mathrm{H}_{\mathrm{x}}, \mathrm{H}_{\mathrm{y}}, \mathrm{H}_{\mathrm{z}}, \mathrm{E}_{\mathrm{x}}\right.$ e $\left.\mathrm{E}_{\mathrm{y}}\right)$ do campo EM. Para o sistema usado no exemplo da Figura 9, ADU-07, os pares de eletrodos (não polarizáveis e a base de cloreto de chumbo) são dispostos em cruz, cada dipolo elétrico com comprimento podendo variar entre 50 e 200 metros. Duas das bobinas de indução são posicionadas horizontalmente, paralelas aos dipolos elétricos, enquanto uma terceira (opcional) é disposta verticalmente para medida do $\mathrm{Hz}$, o que possibilita calcular o tipper. As bobinas devem ser completamente enterradas no solo, como forma de garantir a estabilidade térmica do sistema. Caso haja variações de temperatura, poderá ocorrer a dilatação, ou contração, das bobinas de indução gerando ruídos no campo magnético.

Os dados MT de sistemas como o ADU07 são coletados em janelas de amostragem. O tamanho em tempo de cada janela depende do comprimento da série temporal e da frequência de amostragem. O tempo ideal para a medição dos dados, dependerá do alvo e, portanto, da faixa de frequência das medidas em questão. Quanto mais profundo estiver o alvo da pesquisa, maior será o tempo de aquisição desta estação. No geral, a duração típica de cada sondagem foi de 24 horas. 
Figura 9: Esquema ilustrativo de montagem do equipamento em campo

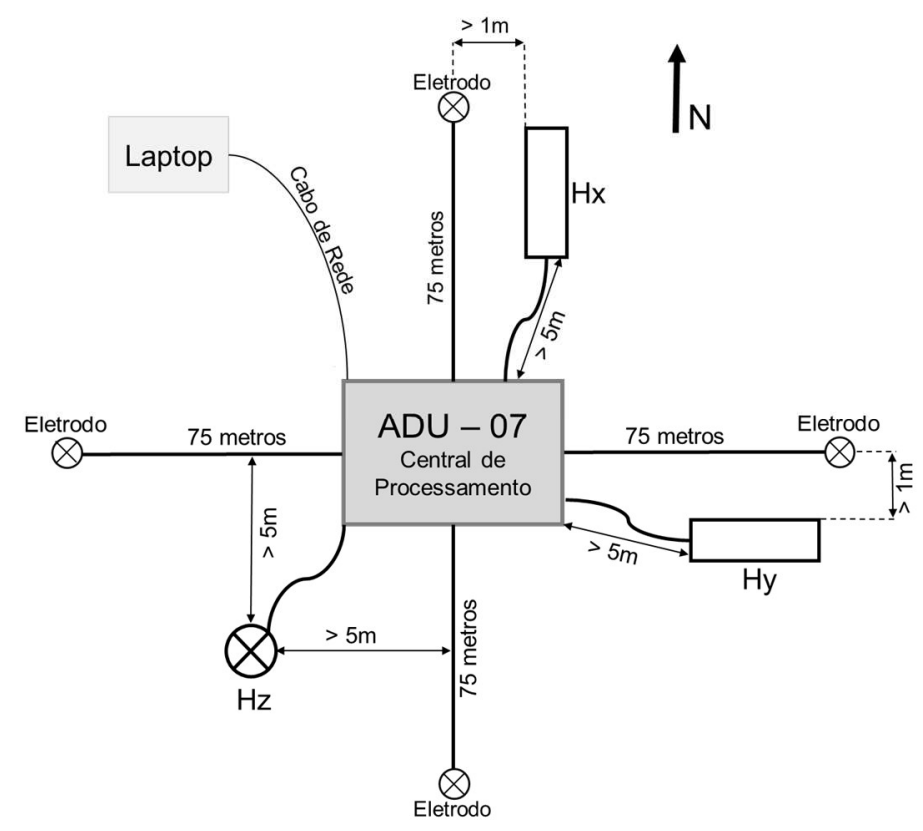

\section{METODOLOGIA}

\subsection{Aquisição de Dados}

Os dados MT usados neste trabalho foram previamente coletados com o sistema ADU07 (Metronix Gmbh), pelo Grupo de Geomagnetismo do Instituto Nacional de Pesquisas Espaciais, o qual pertence o equipamento. A autora não participou da aquisição.

No total, foram realizadas 10 sondagens MT (P01 a P10) com espaçamento regular entre estações de aproximadamente $19 \mathrm{~km}$. A estação C12 foi coletada em um levantamento prévio, descrito em Bologna et al. (2014).

O ADU-07 é um sistema de aquisição MT de banda larga (correspondente aos intervalos de períodos de $0,0001 \mathrm{~s}$ a $1000 \mathrm{~s}$ ) de cinco componentes. Esse sistema é composto por uma unidade central de condicionamento do sinal analógico/digital, eletrodos não polarizáveis à base de cloreto de chumbo que medem as componentes $\mathrm{x}$ e y do campo elétrico e sensores magnéticos do tipo de bobina de indução para as medidas das componentes $\mathrm{x}, \mathrm{y}$ e $\mathrm{z}$ do campo magnético, sistema de referência global (GPS), laptop e um conjunto de baterias que fornece energia ao sistema. Em cada estação, o comprimento dos dipolos elétricos ficou em torno de $100 \mathrm{~m}$.

\subsection{Processamento e Análise de Dados}

O processamento dos dados MT foi feito usando o código robusto desenvolvido por Egbert (1997). 
As etapas do processamento iniciam-se com a conversão dos dados binários, obtidos em campo, para o formato de texto. Estes dados são adquiridos em forma de séries temporais que para serem trabalhados, eles são convertidos para o domínio da frequência através da transformada discreta de Fourier. Com os dados convertidos, realiza-se a estatística robusta, com intuito de remover os outliers e estimar o tensor impedância e tipper. A consistência destas respostas foi feita usando o programa RhoPlus (PARKER; BOOKER, 1996), que compara as curvas de resistividade aparente medidas e as calculadas a partir das fases usando a transformada de Hilbert.

As etapas descritas, sobre o processamento dos dados, foram realizadas pelo Grupo de Geomagnetismo do Instituto Nacional de Pesquisas Espaciais.

\subsubsection{Transformada Niblett-Bostick}

Uma forma simples de se obter uma primeira aproximação da variação de resistividade com a profundidade bem da profundidade de investigação de sondagens MT é por meio da transformada de Niblett-Bostick (NIBLETT; SAYAN-WITTGENSTEIN, 1960; BOSTICK, 1977). Esta técnica reproduz uma distribuição da resistividade em função da profundidade $\left(\rho_{N B}(h)\right)$, onde $h$ equivale a uma profundidade de penetração do sinal eletromagnético (EM) em um semi-espaço homogêneo de resistividade aparente $\left(\rho_{a}(T)\right)$ para uma frequência particular, que é multiplicada pelo gradiente da mesma $(m(T))$, isto em uma escala logarítmica (JONES, 1983). Esta profundidade é definida como:

$$
\rho_{N B}(h)=\left|\rho_{a}\right| \frac{1+m(T)}{1-m(T)}
$$

onde $m(T)$ é dado por:

$$
\begin{gathered}
m(T)=\frac{d \log \left|\rho_{a}\right|}{d \log (T)} \\
m(T)=\frac{T}{\rho_{a}(T)} \frac{d \rho_{a}(T)}{d T}
\end{gathered}
$$

e $h$ por:

$$
h=\sqrt{\frac{\rho_{a}(T) T}{2 \pi \mu_{0}}}
$$

onde $\mu_{0}$ é a permeabilidade magnética do vácuo.

Na prática, a transformada Niblett-Bostick foi aplicada em todas as sondagens MT do perfil para toda todo intervalo de frequência. Os dados estavam no sistema de coordenadas de campo (XY e YX). 


\subsubsection{Análise Dimensional}

A análise de dimensionalidade é uma etapa muito importante, pois auxilia na caracterização das estruturas geológicas regionais. Esta análise permite ajudar na decisão sobre qual a melhor abordagem para as etapas de modelagem e inversão, além de contribuir na interpretação dos resultados obtidos.

\subsubsection{Skew}

A técnica tradicional para verificar a dimensionalidade (1D, 2D ou 3D) de dados MT é a do skew (SWIFT, 1967), posteriormente modificada por Bahr (1988).

O skew $(k)$, é frequentemente utilizado como um parâmetro para verificar se os dados se adequam a um modelo 2D. Se o modelo for adequado, o modulo da soma da diagonal principal da matriz será uma pequena fração do modulo da subtração da diagonal secundária, ou seja:

$$
k=\frac{\left|z_{x x}+Z_{y y}\right|}{\left|z_{x y}-Z_{y x}\right|}
$$

onde $k$ é o parâmetro de inclinação, e $\boldsymbol{Z}$ são as componentes do tensor impedância.

A técnica proposta por Bahr (1988) utiliza de uma série de invariantes de rotação para propor uma dimensionalidade regional. Segundo Kaufman e Keller (1981), em dados MT sem ruído o parâmetro $k$ é igual a zero para estruturas $1 \mathrm{D}$ e 2D. Para estruturas 3D $k$ é diferente de zero. Em dados reais, no entanto, os valores de $k$ são geralmente diferentes de zero: até 0,1 para estruturas 1D ou 2D (Swift, 1967). De acordo com Bahr (1988), valores maiores do que 0,1 são aceitos para modelos 2D ou 3D em áreas com distorção galvânica baixa. Um ponto de quebra para estruturas multidimensionais é $k=0,3$, onde os valores mais baixos estão relacionados a comportamento 2D (Swift, 1967) e acima de $k=0,3$ estruturas puramente 3D.

\subsubsection{WALDIM}

Com objetivo de acrescentar mais informações sobre a dimensionalidade das estruturas regionais foi aplicado o código WALDIM (MARTÍ et al., 2009) que se utiliza de uma série de invariantes de rotação para propor uma dimensionalidade regional, conforme apresentado por Weaver et al. (2000). Esse código, apresentado em Fortran, utiliza algoritmos e testes estatísticos para classificar a estrutura geoelétrica como 1D, 2D, 3D e quatro modelos de superposições (3D/2D com uma torção do tensor de impedâncias, estruturas 3D/1D-2D, estruturas 3D/1D-2D resultando em um tensor $\mathrm{Z}$ diagonal e um 3D/2D geral). 
Oito invariantes rotacionais são calculados $(I 1$ a $I 7+Q)$, de forma que $Q$ é uma combinação de $I 1, I 2, I 3 \mathrm{e} I 4$ (linearmente dependente). A relação entre esses invariantes e o grau da classificação em relação a dimensionalidade das estruturas geoelétricas é mostrada na Figura 10.

Figura 10: Dimensionalidade, segundo o código WALDIM

\begin{tabular}{|c|c|c|}
\hline Case & $I_{3}$ to $I_{7}$ and $Q$ values & Geoelectric dimensionality \\
\hline 1 & $I_{3}=I_{4}=I_{5}=I_{6}=0$ & $\begin{array}{l}\text { 1D } \\
\rho_{1 \mathrm{D}}=\mu_{0}\left(\left(I_{1}^{2}+I_{2}^{2}\right) / \omega\right), \varphi_{1 \mathrm{D}}=\arctan \left(I_{2} / I_{1}\right)\end{array}$ \\
\hline 2 & $I_{3} \neq 0$ or $I_{4} \neq 0 ; I_{5}=I_{6}=0 ; I_{7}=0$ or $Q=0\left(\xi_{4} \neq 0\right.$ and $\left.\eta_{4} \neq 0\right)$ & 2D \\
\hline 3a & $I_{3} \neq 0$ or $I_{4} \neq 0 ; I_{5} \neq 0 ; I_{6}=0 ; I_{7}=0$ & $\begin{array}{l}\text { 3D/2D twist } \\
\text { 2D affected by galvanic distortion (only twist) }\end{array}$ \\
\hline 3b & $I_{3} \neq 0$ or $I_{4} \neq 0 ; I_{5} \neq 0 ; I_{6}=0 ; Q=0$ & $\begin{array}{l}\text { 3D/1D 2D } \\
\text { Galvanic distortion over a 1D or 2D structure (non-recoverable strike direction) }\end{array}$ \\
\hline $3 c$ & $I_{3} \neq 0$ or $I_{4} \neq 0 ; I_{5}=I_{6}=0 ; I_{7}=0$ or $Q=0\left(\xi_{4}=0\right.$ and $\left.\eta_{4}=0\right)$ & $\begin{array}{l}\text { 3D/1D 2D diag } \\
\text { Galvanic distortion over a 1D or 2D structure resulting in a diagonal MT tensor }\end{array}$ \\
\hline 4 & $I_{3} \neq 0$ or $I_{4} \neq 0 ; I_{5} \neq 0 ; I_{6} \neq 0 ; I_{7}=0$ & $\begin{array}{l}\text { 3D/2D } \\
\text { General case of galvanic distortion over a 2D structure }\end{array}$ \\
\hline 5 & $I_{7} \neq 0$ & $\begin{array}{l}\text { 3D } \\
\text { (affected or not by galvanic distortion) }\end{array}$ \\
\hline
\end{tabular}

Fonte: Martí et al, (2009).

\subsubsection{Tensor de Fase}

O tensor de fase é uma quantidade derivada do tensor de impedância que representa a relação de fase regional entre os campos elétrico e magnético (CALDWELL et al., 2004). Indica o grau de defasagem entre as componentes ortogonais $x y$ e $y x$ do tensor de impedância. A fase de um número complexo é definida a partir da razão entre suas partes real e imaginária. Dessa forma o tensor de fase é um tensor complexo, 2 x 2, dependente do período definido da seguinte forma:

$$
\Phi=X^{-1} Y
$$

Em que $\mathrm{X}$ é a parte real do tensor de impedância e $\mathrm{Y}$ é a parte imaginária. Em um sistema de coordenadas Cartesianas, o tensor de fase $\Phi$ pode ser reescrito como a matriz:

$$
\left[\begin{array}{ll}
\Phi_{11} & \Phi_{12} \\
\Phi_{21} & \Phi_{22}
\end{array}\right]=\frac{1}{\operatorname{det} \mathbf{X}}\left[\begin{array}{ll}
X_{22} Y_{11}-X_{12} Y_{21} & X_{22} Y_{12}-X_{12} Y_{22} \\
X_{11} Y_{21}-X_{21} Y_{11} & X_{11} Y_{22}-X_{21} Y_{12}
\end{array}\right]
$$

em que det $\mathbf{X}=X_{11} X_{22}-X_{21} X_{12}$ é o determinante de $X$. Em geral $\Phi$ não é simétrico e pode ser caracterizado por uma direção e três invariantes em relação às coordenadas: o eixo maior $\Phi_{\max }$, o eixo menor $\Phi_{\text {min }}$, e o ângulo de enviesamento $\beta$ ou skew, expressos da seguinte maneira:

$$
\begin{aligned}
& \Phi_{\text {max }}=\frac{1}{2}\left[\left(\Phi_{11}+\Phi_{22}\right)^{2}+\left(\Phi_{12}-\Phi_{21}\right)^{2}\right]^{\frac{1}{2}}+\frac{1}{2}\left[\left(\Phi_{11}-\Phi_{22}\right)^{2}+\left(\Phi_{12}+\Phi_{21}\right)^{2}\right]^{\frac{1}{2}} \\
& \Phi_{\text {min }}=\frac{1}{2}\left[\left(\Phi_{11}+\Phi_{22}\right)^{2}+\left(\Phi_{12}-\Phi_{21}\right)^{2}\right]^{\frac{1}{2}}-\frac{1}{2}\left[\left(\Phi_{11}-\Phi_{22}\right)^{2}+\left(\Phi_{12}+\Phi_{21}\right)^{2}\right]^{\frac{1}{2}}
\end{aligned}
$$

e

$$
\beta=\frac{1}{2} \tan ^{-1}\left(\frac{\Phi_{12}-\Phi_{21}}{\Phi_{11}+\Phi_{22}}\right)
$$


em que $\beta$ (ou skew) é uma medida da assimetria causada por estruturas 3D existentes na estrutura subjacente, isto é, mede em graus o quanto um tensor de fase se afasta de uma resposta 2D ou 1D. Para definir, por completo, o tensor de fase, há ainda um ângulo complementar, $\alpha$, que exprime a dependência do tensor no sistema de coordenadas cartesiano:

$$
\alpha=\frac{1}{2} \tan ^{-1}\left(\frac{\Phi_{12}+\Phi_{21}}{\Phi_{11}-\Phi_{22}}\right)
$$

O tensor de fase pode ser representado graficamente por uma elipse (Figura 11) cujos eixos são regulados a partir dos valores principais do tensor, $\Phi_{\max } \mathrm{e} \Phi_{\min }$; o ângulo que o eixo de referência da elipse faz com o eixo maior é $\beta$ e o ângulo que o eixo de referência faz com o sistema de coordenadas é $\alpha$. Com isto, a orientação do eixo maior é então definida a partir da diferença $\alpha-\beta$ (direção azimutal).

Figura 11: Representação gráfica do tensor fase.

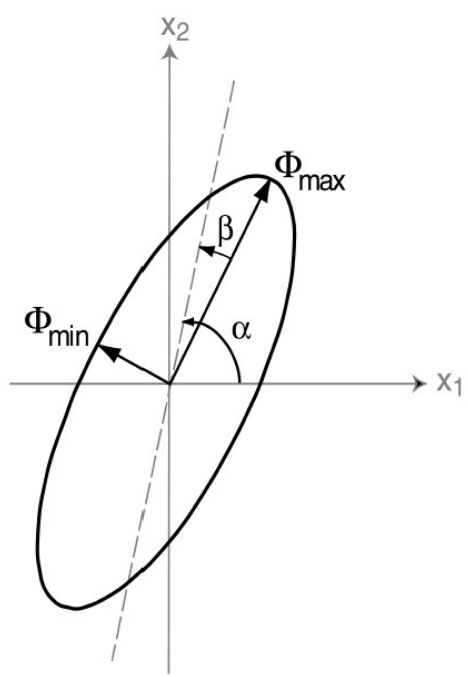

Fonte: Caldwell et al. (2004).

A análise da dimensionalidade do meio é feita considerando o aspecto dessa elipse. A representação gráfica mais simples é quando a estrutura geológica é dada por um meio 1D. Nesse caso, a representação das elipses será circular. Para o caso de um meio 2D, tem-se uma elipse com o eixo maior alinhado com o eixo de referência $(\beta=0)$, que por sua vez deve estar perpendicular à direção da camada caso a elipse esteja sobre um meio condutivo ou paralelo caso a elipse esteja em um meio resistivo. Quando o eixo maior está desalinhado com o eixo de referência é sinal de que a estrutura regional tem heterogeneidades tridimensionais $(\beta \neq 0)$. Se estas heterogeneidades forem resistivas, o eixo maior vai rotacionar de maneira que a elipse fique paralela a elas. No caso de serem condutivas, o eixo maior vai rotacionar de forma que a elipse se posicione perpendicularmente a elas. 


\subsubsection{Decomposição Groom-Bailey}

Diferentes métodos têm sido propostos consistindo de parametrizações 3D onde assume-se que a resposta da estrutura regional seja sobreposta àquela da estrutura local causadora da distorção. Deste modo, a resposta regional e o strike regional podem ser recuperadas a partir da decomposição do tensor impedância. O método proposto por Groom e Bailey (1989), e adotado neste trabalho, é um dos métodos mais usados atualmente.

\subsection{Princípio da decomposição}

O modelo de distorção galvânica de Groom e Bailey (1989) propõe uma forma de decompor o tensor de impedâncias medido $(\mathbf{Z})$ em:

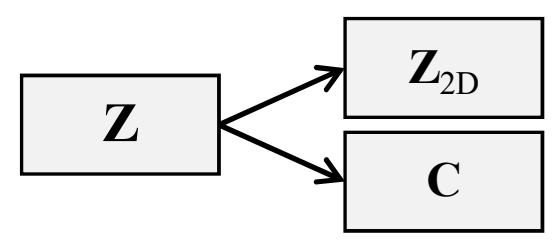

onde $\mathbf{Z}_{2 \mathrm{D}}$ é a representação do tensor impedância da estrutura $2 \mathrm{D}$ regional e $\mathbf{C}$ é o tensor de distorção. C é composto por:

$$
\mathbf{C}=g \mathrm{~T} \mathrm{SA}
$$

sendo $g$ um fator de ganho, $\mathrm{T}$ o tensor de distorção twist, $\mathrm{S}$ o tensor de distorção shear e A o tensor de anisotropia.

O twist e o shear são parâmetros que descrevem os efeitos da distorção local e a anisotropia gera um estiramento ao longo das direções principais do campo regional por diferentes fatores. Como os fatores $g$ e A não podem ser determinados sem informações adicionais, estes são vinculados ao tensor regional a ser calculado $\left(\mathbf{Z}_{2 \mathrm{D}}\right)$, como mostra a relação a seguir, restando os fatores $\mathrm{T}$ e $\mathrm{S}$ a serem mensurados.

$$
\begin{gathered}
\boldsymbol{Z}=g T S A \\
\boldsymbol{Z}_{2 D}=T S \boldsymbol{Z}^{\prime}{ }_{2 D}
\end{gathered}
$$

Como geralmente as medidas não são adquiridas no sistema de coordenadas alinhado à estrutura regional, é preciso rotacionar o tensor de impedâncias medido $\mathrm{Z}$ por um ângulo $\theta$, para a direção da estrutura 2D regional. Para isso utiliza-se a seguinte relação:

$$
\boldsymbol{Z}(\omega)=R(\theta) \quad T \quad S \quad \boldsymbol{Z}_{2 D}^{\prime}(\omega) \quad R^{T}(\theta)
$$

onde $\mathrm{R}$ é a matriz de rotação e $\mathrm{R}^{\mathrm{T}}$ é a matriz de rotação transposta.

O resultado da direção do strike nesse método possui uma ambiguidade de $90^{\circ}$, sendo a solução $\theta$ ou $\theta+90^{\circ}$. Informações complementares, como a análise dos vetores de indução, dados geológicos e/ou geofísicos auxiliam a definir a direção verdadeira do strike. 


\subsection{Procedimentos adotados}

A estação C12 (Figura 12a) foi escolhida para mostrar como foi o procedimento geral adotado para estimar o strike geoelétrico do conjunto de dados, utilizando o programa STRIKE (MCNEICE; JONES, 2001). Este programa efetua a decomposição Groom-Bailey em cada estação magnetotelúrica individualmente, como também pode efetuar a decomposição simultânea para obter um strike que represente o conjunto de dados.

A decomposição foi feita inicialmente frequência por frequência, para observar o comportamento geral dos parâmetros, procurando identificar qual dos parâmetros (azimute, shear e twist) era mais estável, ou seja, não varia com a frequência; bem como identificar quais faixas de períodos em que estes parâmetros eram estáveis. Em seguida, com a mesma finalidade, a decomposição foi feita também década por década (Figura 12b). No caso da estação em questão, observou-se de uma maneira geral que os parâmetros twist e shear são relativamente pequenos $\left(<20^{\circ}\right)$, um indicativo de que os dados são pouco distorcidos. Como esperado, o parâmetro menos estável foi o strike. O twist e o shear são relativamente mais estáveis, sobretudo nos períodos de 0,001 a 60 segundos. Depois, fixou-se o parâmetro mais regular, esperando com isto um resultado mais estável uma vez que se diminui o grau de liberdade. Assim, para a estação C12, fixou-se o primeiramente o parâmetro shear em $-10^{\circ}$ (Figura 13c) mantendo-se os demais parâmetros livres durante a decomposição. Com isto, o strike ficou mais estável, principalmente em períodos mais longos que $1 \mathrm{~s}$. Para períodos mais curtos, entretanto, as curvas de fase XY e YX permanecem quase juntas (pouca anisotropia), indicando que os dados são aproximadamente $1 \mathrm{D}$, o que justifica a não adequação desse faixa a parametrização Groom-Bailey. Mesmo assim, nota-se uma tendência de os strikes permanecerem entre $+20^{\circ}$ e $+60^{\circ}$ (ou $-70^{\circ}$ e $-30^{\circ}$ ). Para períodos mais longos, a decomposição é mais robusta, mostrando que o strike deva estar entre $+40^{\circ} \mathrm{e}+50^{\circ}$. Resultados similares foram atingidos quando se fixou twist em $-2^{\circ}$ (Figura 13d) deixando o strike e o shear livres, confirmando que o strike varia com o período (e então, com a profundidade). Como o principal o objetivo do trabalho é estudar estruturas geoelétricas profundas, adicionalmente ao fato que a anisotropia das fases é bem maior, deu-se mais importância para o strike de longo período.

Considerando os resultados previamente descritos, aplicou-se novamente a decomposição com o strike fixo em $+40^{\circ}$, deixando livres os demais parâmetros (Figura 14e). Um strike bem recuperado pela decomposição implica que quando fixado, os demais parâmetros deveriam estabilizar em torno de seus valores quando da decomposição sem restrição (ou seja, todos parâmetros livres), o que de fato ocorreu. Em alguns casos, dois dos três parâmetros também eram fixados simultaneamente para checar a estabilidade do azimute 
do terceiro parâmetro mantido livre. Por último, ainda se refez um refinamento do modelo variando de alguns graus o azimute do strike e escolhendo o de menor erro até, por fim, obterse o modelo final (Figura 14f). A linha horizontal no gráfico de erro de todas as Figuras $(12,13$ e 14) é um limite aceitável para a parametrização (GROOM et al., 1993).

Ainda que a decomposição possa ser feita automaticamente, as etapas realizadas passo a passo evita a determinação de strikes inconsistentes (GROOM et al., 1993).

Figura 12: Decomposição Groom-Bailey a) frequência por frequência e b) por décadas
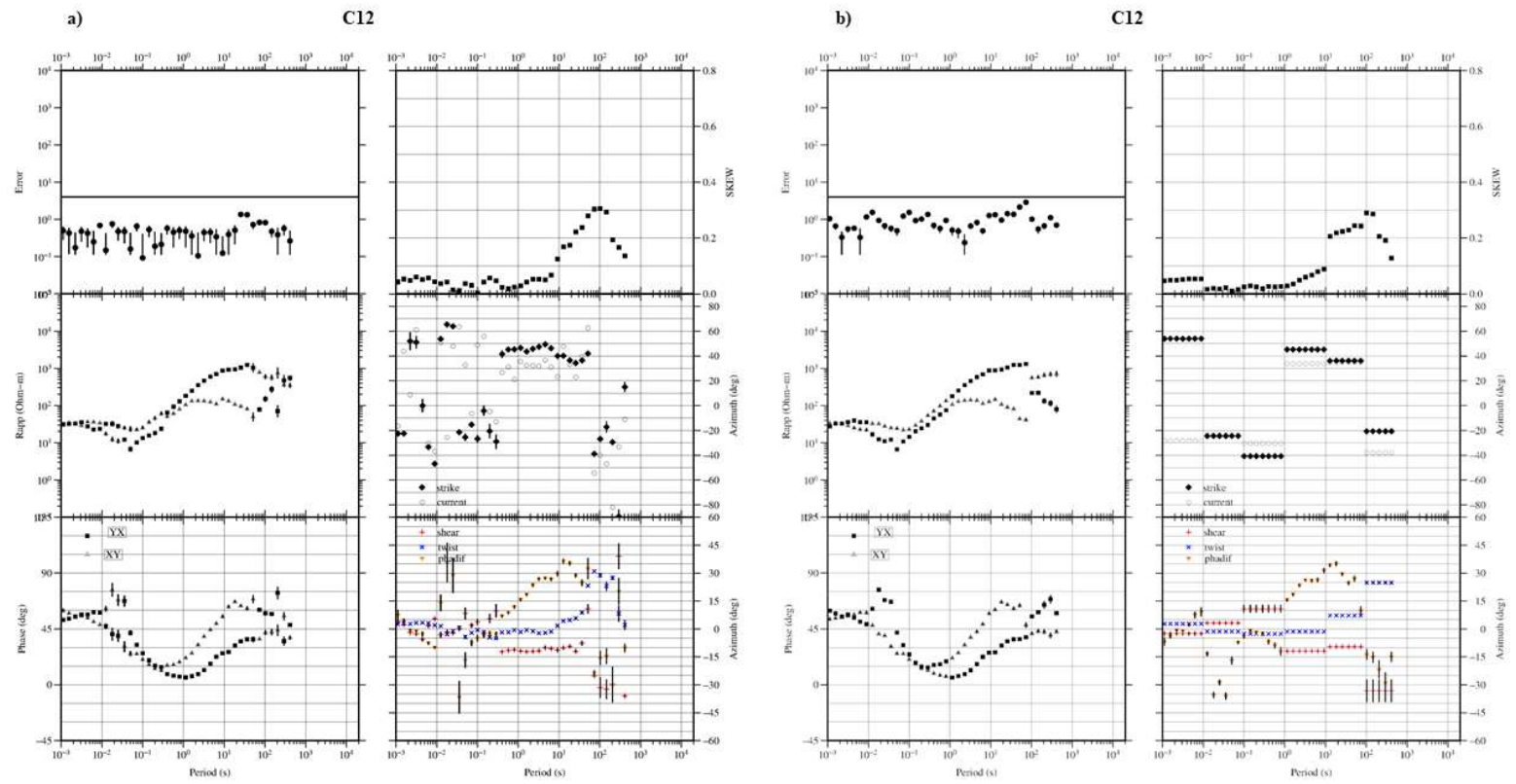

Figura 13: Decomposição Groom-Bailey c) frequência por frequência com shear fixo e d) frequência por frequência com twist fixo.
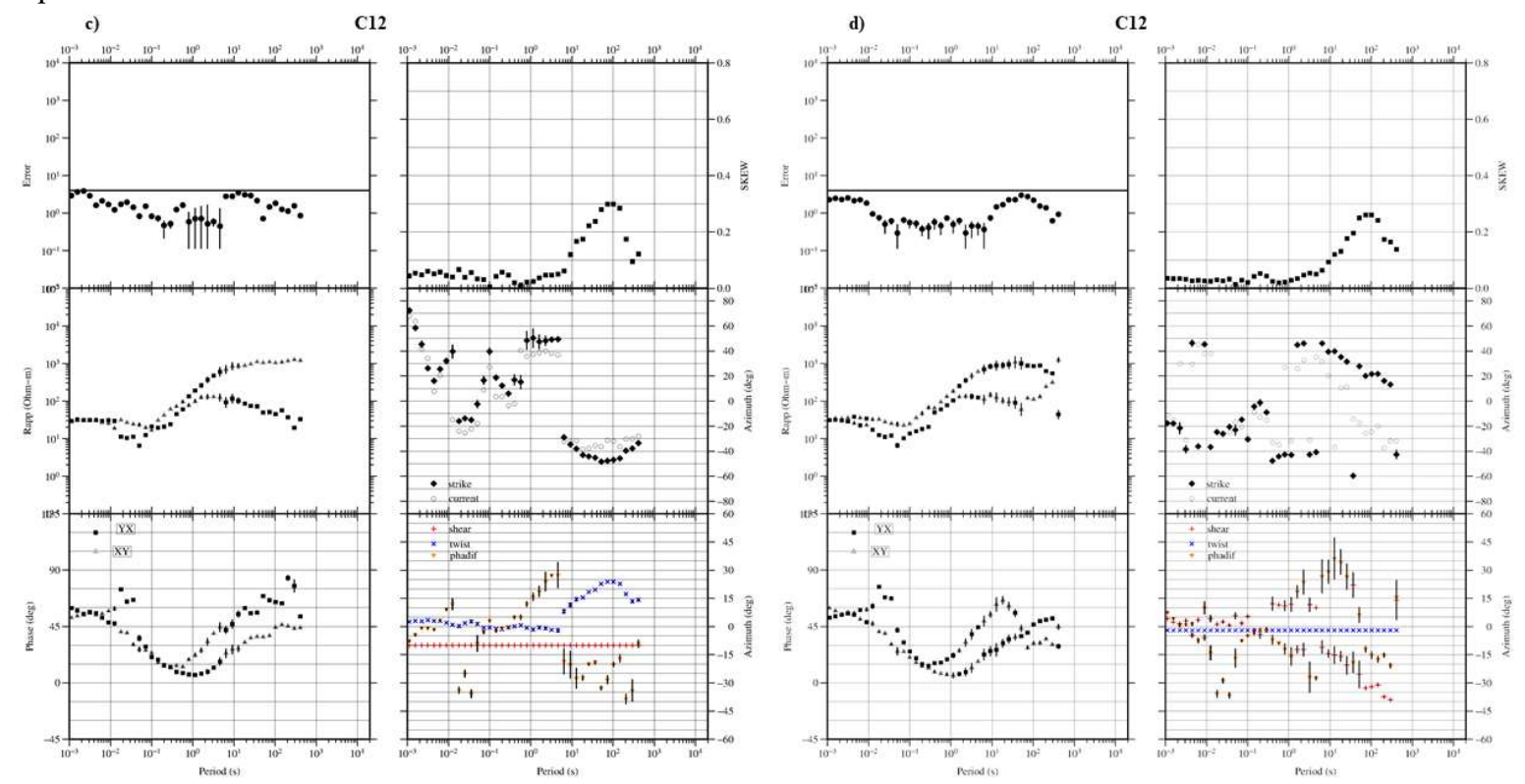
Figura 14: Decomposição Groom-Bailey e) frequência por frequência com strike fixado e f) de todo o espectro de frequências

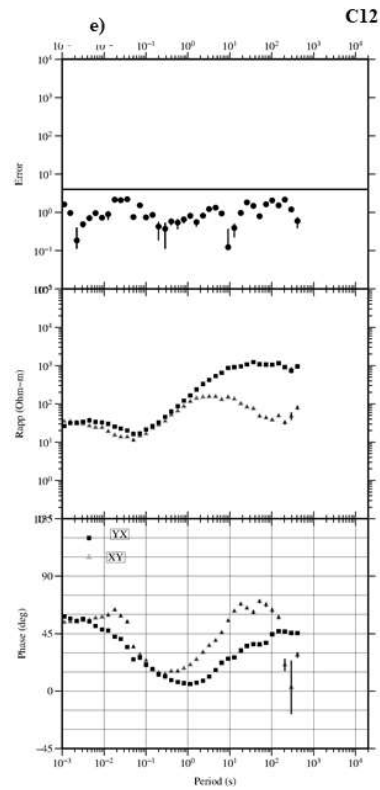

C12
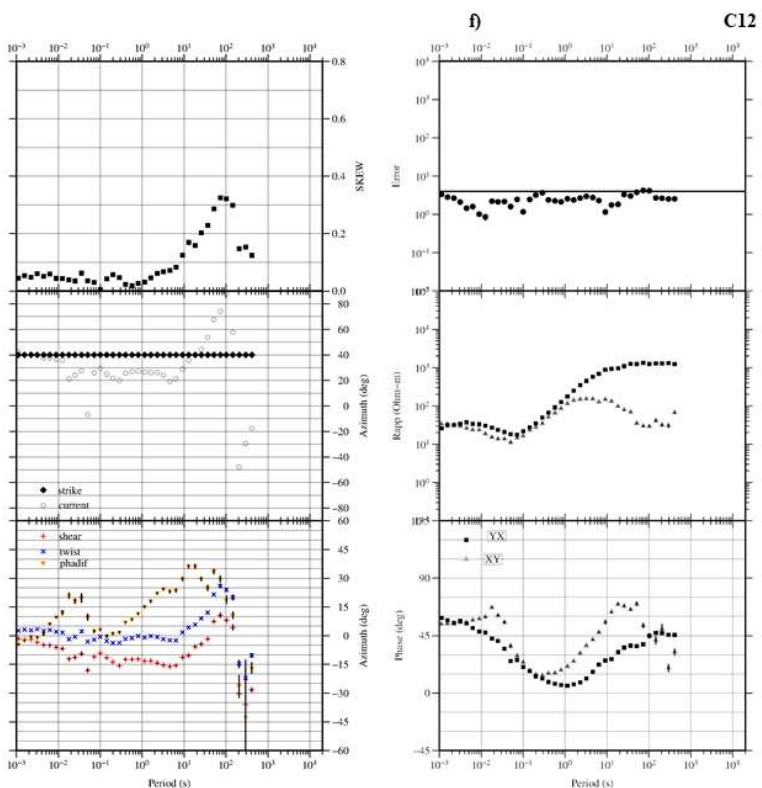

C12

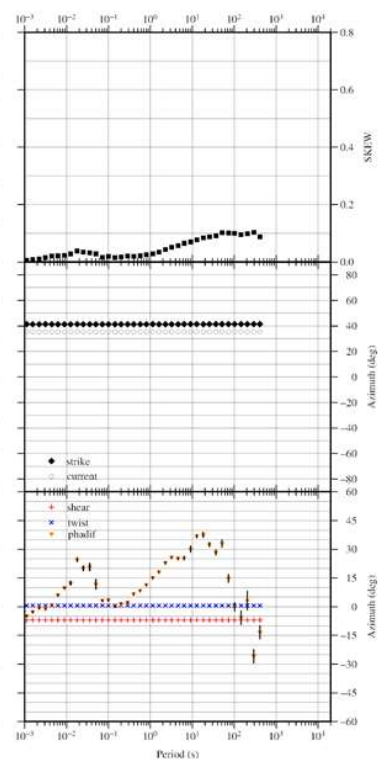

\subsection{Inversão Bidimensional}

A inversão bidimensional de dados, quando comparada à inversão tridimensional, é uma maneira rápida de se obter um modelo a partir dos dados observados. A realização de etapas intermediarias, como as análises dimensionais (descrita nos capítulos anteriores), ajudaram na construção de modelos de resistividades diferentes e coerentes com as informações geológicas e geofísicas obtidas até aqui. Segundo Simpson e Bahr (2005), esta exploração de modelos tem a finalidade de evitar armadilhas decorrentes da não unicidade associada com a modelagem.

A inversão dos dados MT consiste em obter um modelo de distribuição de condutividades sob o perfil de medidas, que ajuste, dentro de certos limites pré-estabelecidos (erros), os diferentes parâmetros obtidos em aquisição de campo. A inversão foi feita com os dados rotacionados para a direção do strike regional (N70E) determinado pela decomposição Groom-Bailey. Assim, as direções N20W e N70E correspondem aos modos TM e TE, respectivamente. O código REBOCC (Reduced Basis Occam's Inversion) de inversão 2D para dados MT (SIRIPUNVARAPORN; EGBERT, 2000) foi usado para obter um modelo suavizado de distribuição de condutividade em subsuperfície.

\subsubsection{O Código Empregado}

O REBOCC é um algoritmo muito utilizado pela comunidade MT devido a sua rapidez, estabilidade numérica e fácil manejo. 
O programa é baseado no método de Occam (CONSTABLE et al., 1987), que busca por soluções suavizadas na tentativa de se reduzir o número de soluções possíveis do problema inverso. O código admite que as curvas de resistividade e fase variam lentamente com o período, de modo que pontos adjacentes possam ser considerados redundantes. Assim, pontos de uma certa curva podem ser tomados a cada $\mathrm{N}$ períodos, reduzindo significativamente a base de dados sobre a qual o modelo inverso deverá convergir.

A modelagem direta é usada no código tanto para a obtenção da matriz de sensibilidade quanto para a obtenção da resposta do modelo e cálculo do desajuste. Para isso, as equações diferenciais de segunda ordem são resolvidas pela técnica das diferenças finitas.

O modelo é parametrizado como uma seção bidimensional descrita por células de altura e largura variáveis às quais são atribuídos valores de resistividade. A grade é construída seguindo alguns critérios. Horizontalmente, adota-se um número de células entre cada estação, a fim de manter o modelo o mais homogêneo possível. Para evitar problemas de borda, o modelo é estendido lateralmente para além do limite das estações. Fora da região dos dados, a dimensão de cada célula é aumentada na horizontal por um fator de 1,5 até que atinja a distância de três vezes o valor máximo do skin depth dos dados. Verticalmente, a resolução do modelo deve decrescer com a profundidade, o que mimetiza o conceito de skin depth. A espessura da primeira e segunda camada é determinada como um quinto do menor skin depth dos dados MT. A partir da terceira linha, a espessura das células é incrementada por um fator entre 1,05 e 1,2 até que se atinja uma distância equivalente a três vezes o valor do máximo skin depth.

A inversão da resistividade aparente e a fase por meio do REBOCC pode ser feita usando somente um dos modos (TE ou TM) ou, simultaneamente, inversão de ambos os modos. Para qualquer dos casos citados pode-se atribuir pesos distintos as fases e resistividades em cada estação e em cada período através de uma matriz de inclusão de dados, que pode assumir $n$ valores inteiros positivos. Para $n \geq 1$, os desvios fixos (error floor) percentuais são multiplicados por um fator $2_{n-1}$ ao passo que para $n=0$ o dado é excluído da inversão. Eventualmente, um ou mais dados pode ser completamente excluído da inversão.

Na inversão do Tipper é possível realizar a inversão usando a parte real e/ou a parte imaginária do tensor. Assim como descrito para a inversão da resistividade aparente e fase, é possível atribuir pesos distintos para cada parte real e imaginária em cada estação e em cada período através de uma matriz de inclusão de dados.

O REBOCC requer no mínimo três arquivos de entrada para efetuar a inversão: o primeiro deles é o "startup file", que define todos os parâmetros de entrada para a inversão. O segundo é o arquivo contendo os dados de entrada com todas as informações de resistividade 
aparente e fase dos modos TE e/ou TM, ou contendo as informações do Tipper e seus respectivos erros. Por último, um arquivo de modelo de entrada contendo informações sobre a malha utilizada bem como os valores iniciais de resistividade para cada uma das células.

Para testar a consistência do modelo obtido a partir desta inversão é importante que diferentes modelos de entrada sejam testados. A convergência para modelos similares, independente do modelo de entrada, pode reforçar a consistência da inversão.

\subsubsection{Discretização do Meio}

As grades usadas neste trabalho, foram construídas usando os critérios descritos abaixo e representados na Figura 15.

O comprimento $(\Delta \mathrm{x})$ dos blocos do perfil foi de um quarto do espaçamento médio entre as estações, que é de $19 \mathrm{~km}$, para três das seis grades. E para as outras três grades, o comprimento dos blocos do perfil foi de um oitavo do espaçamento médio entre as estações. Para os espaçamentos diferentes de $19 \mathrm{~km}$ adaptou-se o comprimento dos blocos, tomando o cuidado para: a) não ultrapassar o fator de 1,5 de entre os blocos adjacentes; b) que a posição das estações estivesse em cima dos nós da malha; e c) que os blocos adjacentes às estações tivessem o mesmo comprimento. Para os blocos anteriores à primeira estação do perfil e os blocos posteriores à última, o comprimento foi gradativamente ampliado pelo fator de 1,5 até que o comprimento total da malha fosse atingido. A fim de minimizar efeitos de borda, foi estabelecido como comprimento total da malha o valor de três skin depth máximo (definido pela maior resistividade observada no período máximo) para cada lado a partir do centro.

A espessura $(\Delta y)$ dos blocos das duas primeiras linhas da malha foi de um quinto do skin depth mínimo (definido pela menor resistividade observada na frequência máxima). A espessura dos blocos a partir da terceira linha da malha teve o seu valor multiplicado por um fator (FM) espessados gradativamente por um fator de 1,1 ou 1,2 ou 1,05 (nos primeiros $20 \mathrm{~km}$ ) depois assumindo o fator de 1,2, até que a espessura total da malha (profundidade total) fosse atingida. Igualmente ao que foi feito com relação ao comprimento a fim de minimizar efeitos de borda, a espessura total da malha foi definida por três skin depth máximos.

Ao todo, dezoito modelos iniciais foram construídos, todos constituídos de um semiespaço homogêneo. Os valores da resistividade usados nos testes foram de 10,100 e $1000 \Omega$ m. A Tabela 1 sintetiza as características de cada modelo construído. 
Figura 15: Exemplo de grade criada para atribuição de valores de resistividade elétrica para modelos 2D do REBOCC.

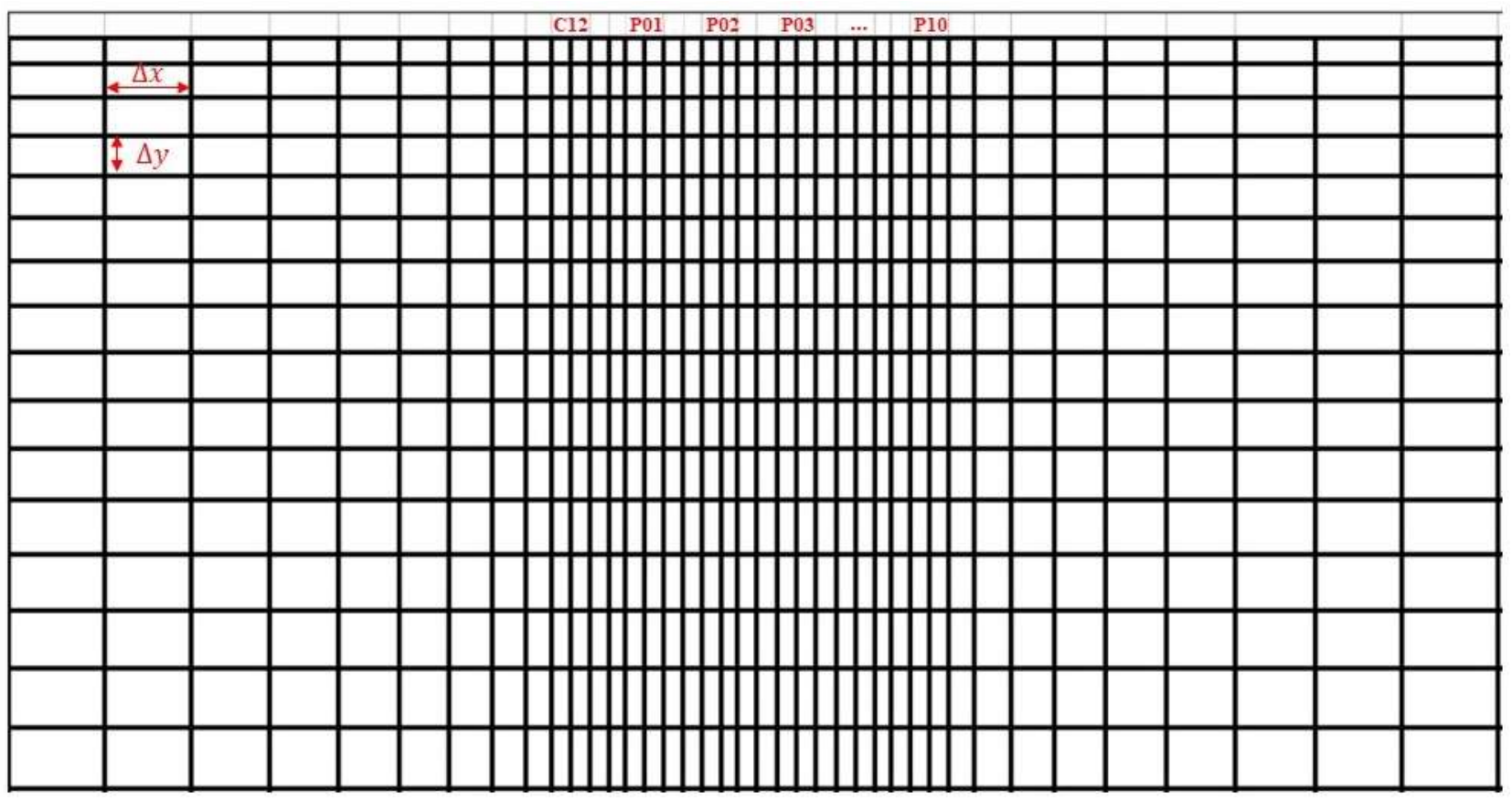

Tabela 1: Distribuição dos parâmetros da grade por modelo.

\begin{tabular}{|c|c|c|c|}
\hline Modelo & $\Delta \mathbf{x}$ & FM & Semi-espaço $(\Omega m)$ \\
\hline 1 & \multirow{9}{*}{$\frac{1}{4}$} & \multirow{3}{*}{1,1} & 10 \\
\hline 2 & & & 100 \\
\hline 3 & & & 1000 \\
\hline 4 & & \multirow{3}{*}{1,2} & 10 \\
\hline 5 & & & 100 \\
\hline 6 & & & 1000 \\
\hline 7 & & \multirow{3}{*}{$\begin{array}{c}1,05 \text { (os primeiros } 20 \mathrm{~km} \text { ) } \\
1,2\end{array}$} & 10 \\
\hline 8 & & & 100 \\
\hline 9 & & & 1000 \\
\hline 10 & \multirow{9}{*}{$\frac{1}{8}$} & \multirow{3}{*}{1,1} & 10 \\
\hline 11 & & & 100 \\
\hline 12 & & & 1000 \\
\hline 13 & & \multirow{3}{*}{1,2} & 10 \\
\hline 14 & & & 100 \\
\hline 15 & & & 1000 \\
\hline 16 & & \multirow{3}{*}{$\begin{array}{c}1,05 \text { (os primeiros } 20 \mathrm{~km} \text { ) } \\
1,2\end{array}$} & 10 \\
\hline 17 & & & 100 \\
\hline 18 & & & 1000 \\
\hline
\end{tabular}




\subsubsection{Parametrização}

A parametrização dos modelos prediletos foi elaborada com 56 células horizontais, sendo 40 da região dos dados e 16 nas laterais, e 62 células verticais. As inversões foram realizadas para os dois modos, TM e TE, individualmente e simultaneamente e para o tipper. As inversões individuais foram realizadas para averiguar o comportamento da inversão e o ajuste dos dados.

Para verificar a robustez das respostas encontradas, além de diferentes grades e modelos iniciais, realizaram-se testes variando os error floor (desvio fixo). Também, foram comparadas inversões com e sem algum tipo de correção do efeito estático apresentado no Apêndice B.

Em relação ao error floor, foram testados, para os dois modos da inversão tanto individualmente como simultaneamente, dois pares de valores. O primeiro par apresentou o valor de $12 \%$ para a resistividade aparente e $4 \%$ para a fase, e o segundo par de $25 \%$ para a resistividade aparente e 5\% para a fase. O maior valor do error floor para a resistividade aparente permite variações no modelo que levam em conta os efeitos galvânicos que eventualmente não tenham sido corrigidos. Assim, escolhemos o modelo predileto cujo o error floor é de $25 \%$ para a resistividade aparente e $5 \%$ para a fase.

Durante a realização da inversão simultânea, notou-se que a resistividade aparente de uma determinada estação estava sub ou superestimada e que a fase correspondente não se ajustava bem. Assim, uma correção é aplicada no nível da curva de resistividade aparente. Apesar dessa correção poder ser realizada automaticamente pelo REBOCC, a analise manual das curvas e dos efeitos dessas correções nas estações adjacentes, permite um maior controle e compreensão dos aspectos envolvidos na correção do static shift. Depois de alguns testes, a correção foi estabelecida segundo os valores de $(+0,7)$ para a estação P01 do modo TM e de (0,30) para a estação P08 também no modo TM.

\section{RESULTADOS}

\section{$5.1 \quad$ Respostas MT}

Os dados processados serão apresentados, neste trabalho, através de pseudo-seções das respostas MT (resistividade aparente e fase) e mapas de vetores de indução (tipper). A transformada Niblett-Bostick (JONES, 1983) das respostas MT também é apresentada como pseudo-seções; ela foi aplicada por ser uma forma simples de se obter uma primeira aproximação da variação de resistividade com a profundidade. Para obter a dimensionalidade e estimar o strike geoelétrico, usamos o código de McNeice e Jones (2001) baseado no método 
Groom-Bailey (GROOM; BAILEY, 1989), além das técnicas Skew (SWIFT, 1967; BAHR, 1988), WALDIM (MARTÍ et al., 2009) e tensor de fase (CALDWELL et al., 2004).

\subsubsection{Pseudo-seções das Respostas MT}

Segundo Jones (1988), as pseudo-seções de fase são mais uniformes quando comparadas com as de resistividade aparente, pois as fases não são afetadas pelo deslocamento estático (static shift), permitindo uma visão qualitativa inicial das principais estruturas geoelétricas da área estudada. Entretanto estruturas muito rasas são melhores visualizadas nos dados de resistividade aparente.

A Figura 16 mostra as pseudo-seções de resistividade aparente nas direções XY e YX. Em geral, elas indicam um meio geoeletricamente heterogêneo. Estruturas moderadamente resistivas $(100 \Omega \mathrm{m})$ entre as estações $\mathrm{P} 10$ e P08, para o intervalo de período entre 0,0001 á $1 \mathrm{~s}$ e podem estar relacionadas com o embasamento da Faixa Paraguai. O meio é condutivo na região da Bacia Sedimentar do Paraná (estações 12 e 01, entre os períodos 0,0001 a 1 segundo) e para períodos maiores que 1 segundo, principalmente entre as estações 03 e 06 . A maior condutividade observada na região da bacia do Paraná pode estar relacionada ao pacote sedimentar que compõem as mesmas. Na zona condutiva mais profunda, a alta condutividade deve estar relacionada com a PACA. Essas resistividades mais baixas estão na ordem de 10 $\Omega \mathrm{m}$.

Nas pseudosseções de fase (Figura 17), regiões com fases menores que $45^{\circ}$ são regiões mais resistivas, enquanto regiões maiores que $45^{\circ}$ são mais condutivas. Assim, a partir das pseudosseções observamos duas zonas condutoras. A primeira zona está localizada entre as estações 12 e 04 e entre os períodos 0,0001 - 0,1 segundo (s). Esta região condutora está relacionada à bacia sedimentar do Paraná. A segunda zona está localizada entre as estações 03 - 09 e entre os períodos $0,1-100 \mathrm{~s}$, e provavelmente está associada à PACA. Então as pseudoseções de fase, de uma forma geral apresentam concordância com as pseudo-seções de resistividade.

Destaca-se que as pseudosseções de resistividade aparente mostram variações abruptas nos valores de resistividade aparente, onde não há correspondência nas pseudosseções de fase. Isso ocorre devido ao efeito de deslocamento estático, indicando que as áreas de alta resistividade mostradas principalmente entre as estações 02 e 07 para a direção XY e YX são de certa forma irregulares. As estações citadas apresentam uma resistividade maior do que o esperado, quando comparadas às estações vizinhas. Este efeito descrito, tem origem desconhecida. 
Figura 16: Pseudosseção de resistividade aparente tensor de impedância para a direção XY e YX.

\section{Faixa Paraguai}

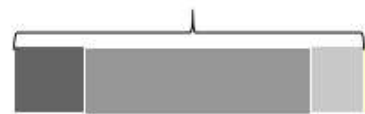

\section{Bacia do Paraná}
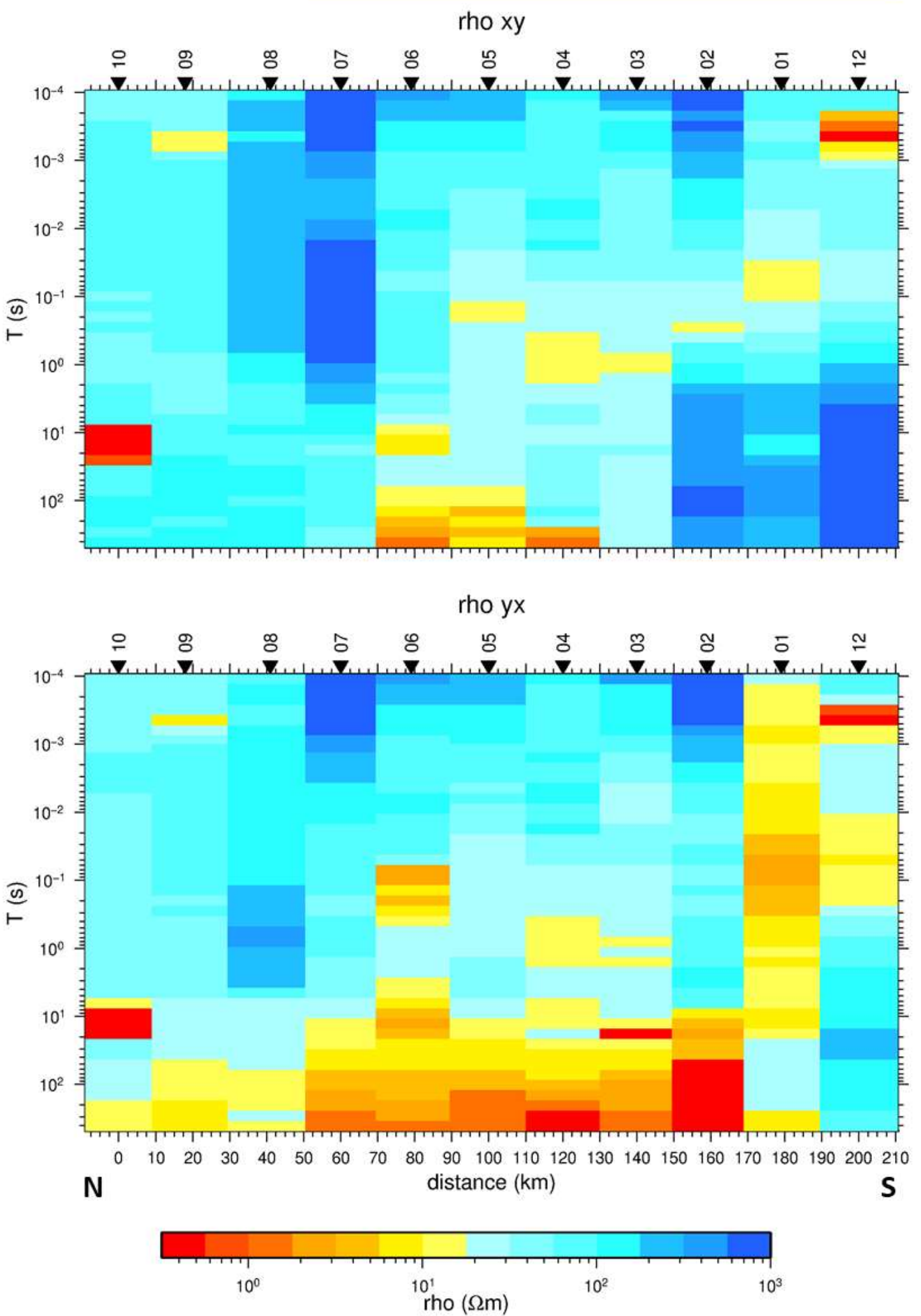
Figura 17: Pseudosseção da fase do tensor de impedância para a direção XY e YX.

\section{Faixa Paraguai}

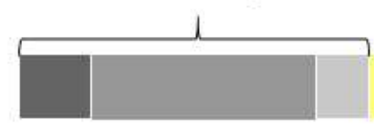

\section{Bacia do Paraná}
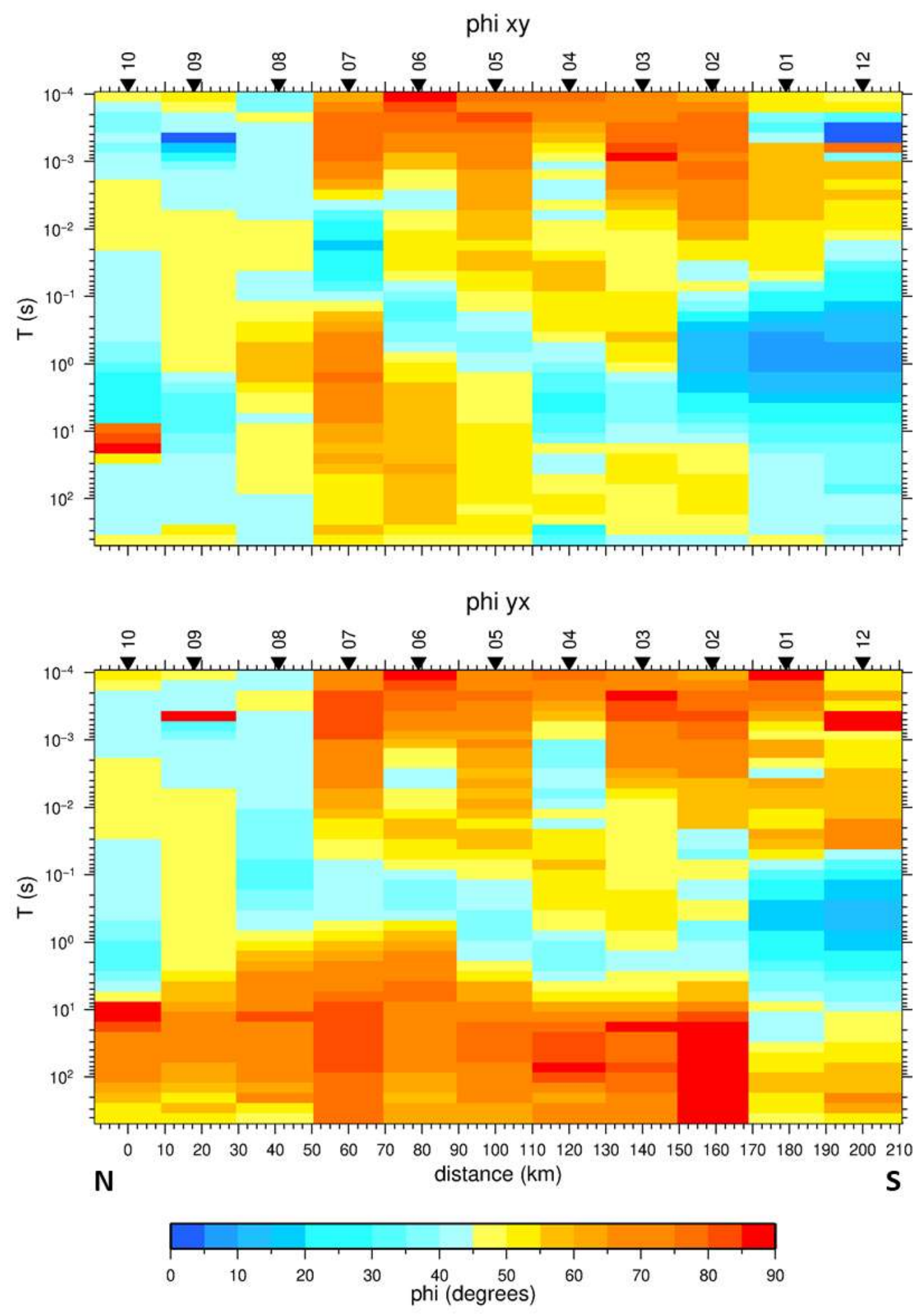


\subsubsection{Vetores de Indução}

Os vetores de indução são uma representação gráfica do tipper e, ao serem revertidos, apontam na direção de estruturas condutivas, auxiliando na identificação de variações laterais abruptas de resistividade (SIMPSON; BAHR, 2005). Esses vetores podem ser usados para inferir a presença ou ausência de efeitos laterais na condutividade, devido aos gradientes de condutividade lateral gerados pelos campos magnéticos verticais.

Os vetores de indução podem indicar uma dimensionalidade para aquele meio, embora não seja a técnica ideal para uma análise dimensional em situações geológicas complexas. A Figura 20 mostra os vetores de indução, componente real em azul e componente imaginário em vermelho, para 3 períodos diferentes (2,2857 s; 25,6 s e 292,5714 s). Ambos os períodos apresentam um comportamento regional parecido. Os vetores apontam quase paralelamente ao perfil, com uma reversão ao redor da estação P06 (indicado pela seta azul). Tal comportamento é próximo ao esperado para uma estrutura 2D orientada aproximadamente na direção lesteoeste atravessando a parte central do perfil MT deste trabalho.

Além disso, optou-se por plotar o componente imaginário dos vetores, em vermelho na imagem a seguir, para análise conjunta com a componente real dos vetores. Quando estas componentes estão dispostas paralelamente ou em antiparalelo, estes dados apresentam uma natureza bidimensional. Isto é visto principalmente nas estações P03, P04 e P05, para os três períodos apresentados. 
Figura 18: Vetores de indução para os períodos 2,2857; 25,6 e 292,5714 segundos.
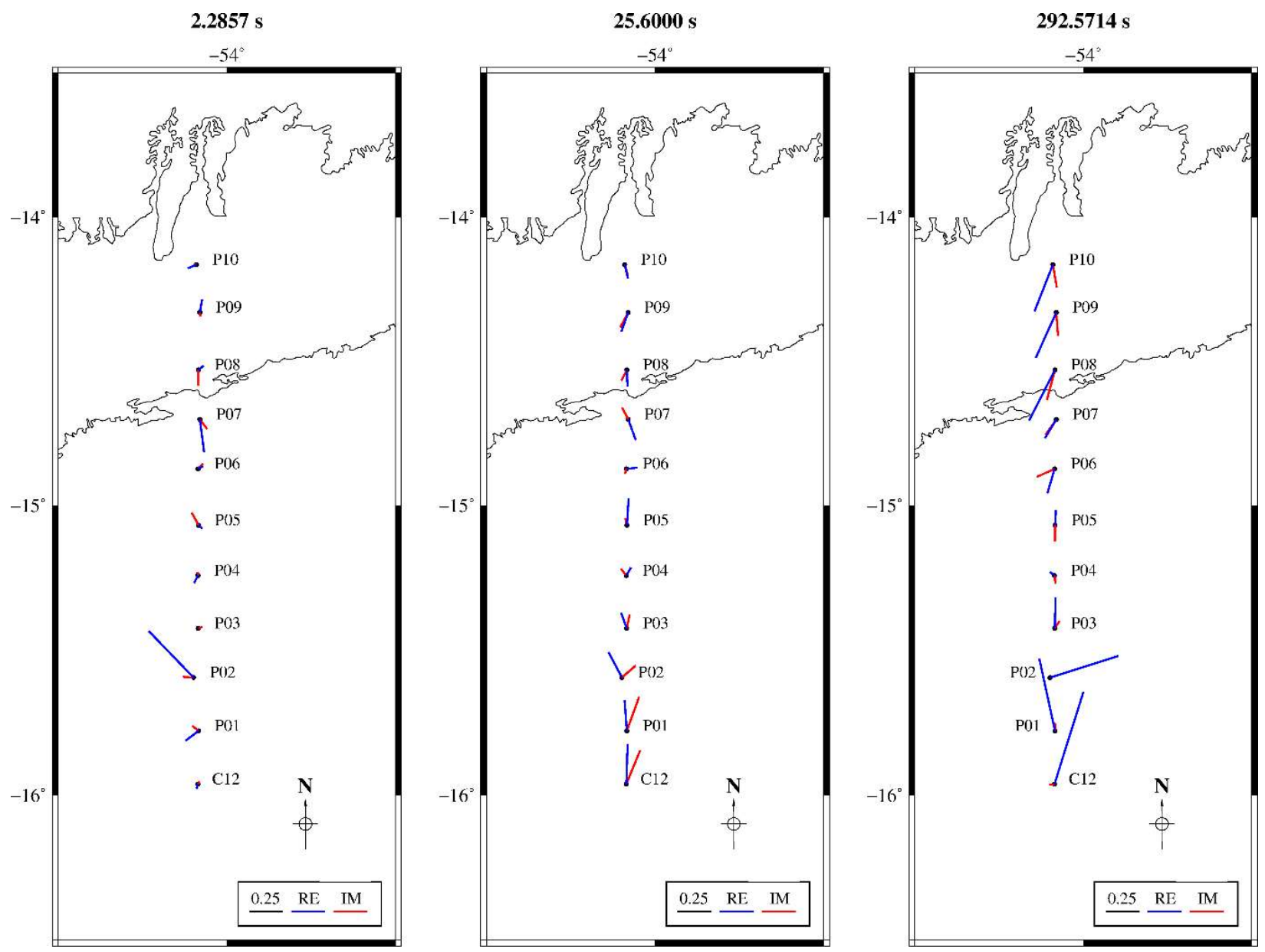

\subsubsection{Transformada Niblett-Bostick}

Os resultados da transformada dos dados de direções de medidas XY e YX são ilustrados nas Figuras 19 e 20, respectivamente.

Figura 19: Seção de resistividade elétrica obtida pela transformada de Niblett-Bostick para a direção XY.

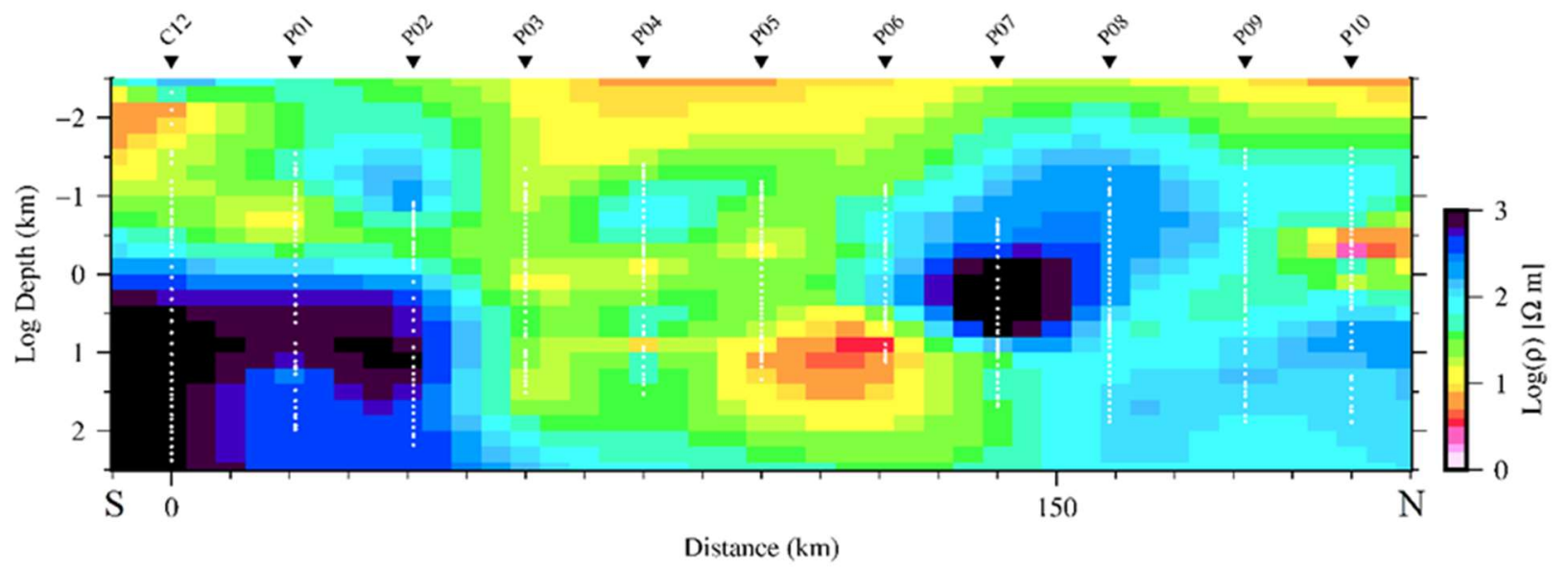


Figura 20: Seção de resistividade elétrica obtida pela transformada de Niblett-Bostick para a direção YX.

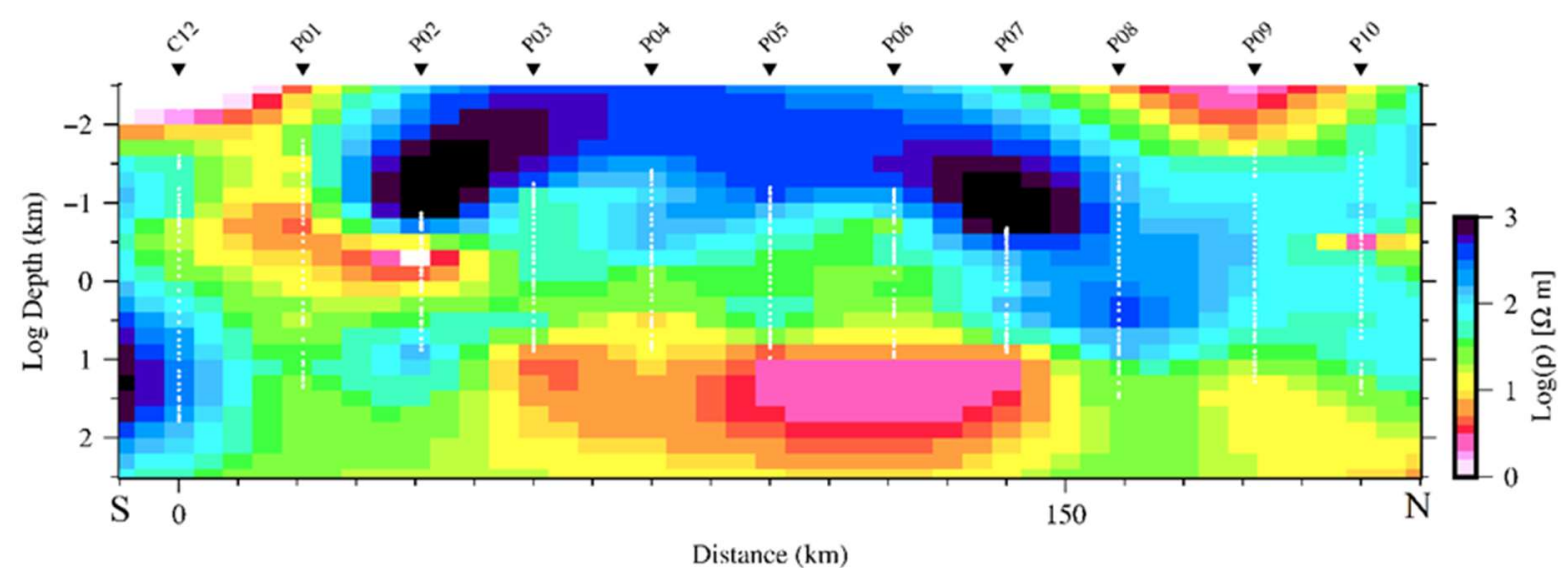

A Figura 21 mostra a transformada da média aritmética das impedâncias XY e YX, uma resposta que é invariante à rotação.

Figura 21: Seção de resistividade elétrica obtida pela transformada de Niblett-Bostick da resposta invariante em cada estação do perfil.

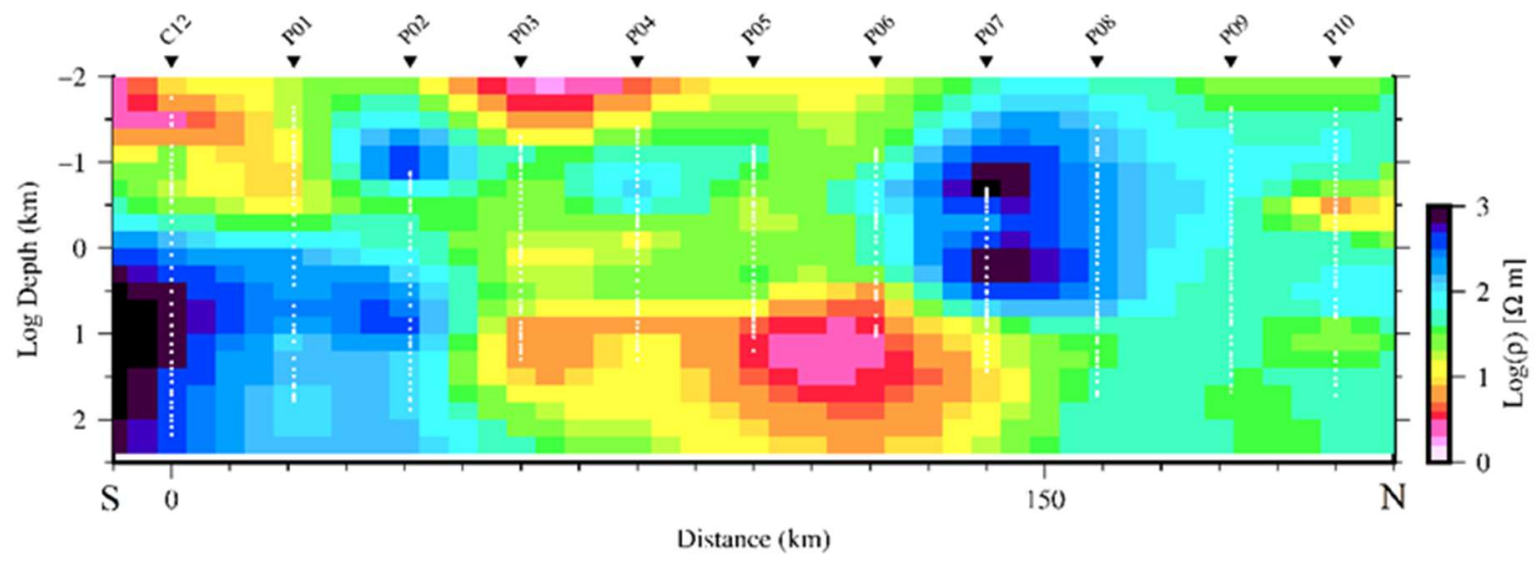

Em geral, a máxima penetração do sinal varia de 20 a $100 \mathrm{~km}$. havendo uma clara tendência de maior penetração para os dados das pontas do perfil, onde se observam profundidades em torno de $100 \mathrm{~km}$. Isto é condizente com os valores mais elevados de resistividade observados, principalmente na porção sul do perfil, uma vez que o skin depth é proporcional a raiz quadrada da resistividade.

Enfim, os resultados obtidos pelo método MT são consistentes com os dados geológicos e geofísicos disponíveis para a área. Entre as estações C12 e P02 é possível observar uma região mais condutiva até o limite de aproximadamente 500 metros, provavelmente relacionada com o pacote sedimentar da bacia do Paraná, e a partir de $1 \mathrm{~km}$ uma raiz mais resistiva (entre 300 e $800 \Omega \mathrm{m})$. A porção central do perfil, entre as estações P03 e P07, uma raiz mais condutiva (aproximadamente $5 \Omega \mathrm{m}$ ) de topo localizado a uma profundidade aproximada a $7 \mathrm{~km}$, que é possivelmente relacionada à PACA. Para a parte norte do perfil MT, entre as estações P07 e 
P10, uma segunda unidade resistiva é observada. De menor magnitude, menos homogênea e mais próxima à superfície (profundidade da base da anomalia $5 \mathrm{~km}$ ) que a primeira, provavelmente relacionada a Faixa Paraguai Norte.

\subsubsection{Análise dimensional}

\subsubsection{Skew}

As Figuras 22 e 23 apresentam as distribuições dos valores de $k$ das 11 estações ao longo do perfil, no intervalo dos períodos estudados $\left(10^{-3}\right.$ à $10^{3}$ segundos $)$, tanto para a técnica proposta por Swift (1967; Figura 22), quanto para a técnica de Bahr (1988; Figura 23).

De acordo com as Figuras 22 e 23, para ambas técnicas, é possível observar que, em geral, entre as estações C12 e P07, os dados obedecem uma condição 3D a partir do período de 1 segundo. As estações P08, P09 e P10 apresentam uma característica mais bidimensional.

Figura 22: Gráfico do valor do Skew (Swift, 1967) em função do período.

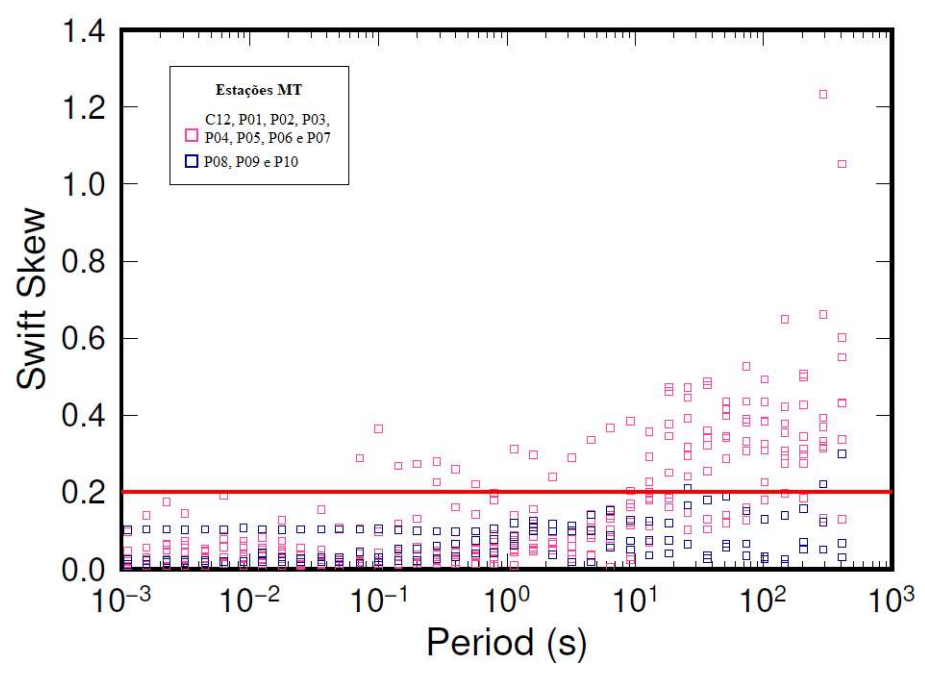

Figura 23: Gráfico do valor do Skew (Bahr, 1988) em função do período.

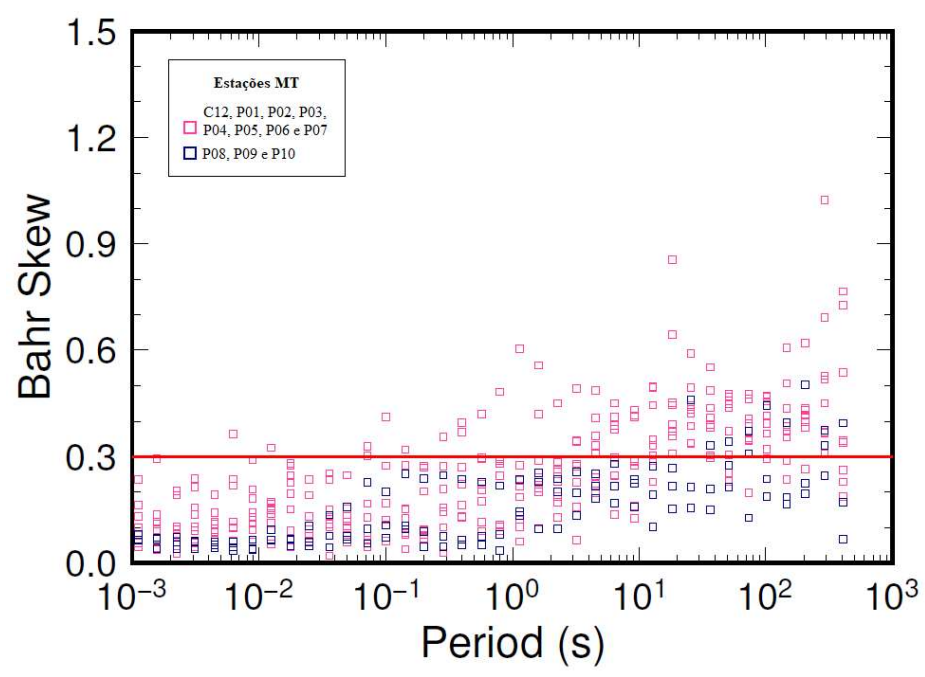




\subsubsection{WALDIM}

De acordo com a Figura 24, a maior parte dos dados obedece a uma condição 3D principalmente para períodos maiores que $0,1 \mathrm{~s}$. As estações localizadas sob a bacia do Paraná apresentam uma dimensionalidade mais pra 1D para períodos mais curtos embora apareçam alguns pontos indicando uma estrutura 3D, 2D e 3D/2D. Para a PACA, a dimensionalidade obtida pelo código WALDIM confirmou a dimensionalidade obtida pelo Skew (no item anterior).

Figura 24: Gráfico de dimensionalidade ao longo do perfil com base no WALDIM em função do período.

10

\subsubsection{Tensor de fase}

O tensor de fase (Figura 25) foi disposto em pseudosseção para melhor análise transversal sobre a anomalia PACA. Em períodos curtos fora da região da Bacia sedimentar, as elipses são quase circulares, indicando um ambiente unidimensional, enquanto para os períodos mais curtos dentro da Bacia sedimentar as elipses apresentam uma característica 2D/3D com algumas estruturas 3D mais rasa. Em períodos intermediários (aproximadamente 0,01 e $1 \mathrm{~s}$ ), as elipses são menos arredondadas com valores intermediários para $\Phi_{\min }$ e $\beta$ próximas de zero, o que sugere um ambiente 3D. Maiores valores de $\beta$ são observados em períodos mais longos, particularmente na região associada ao PACA. 
Figura 25: Pseudosseção dos tensores de fase, em função do skew $(\beta)$.

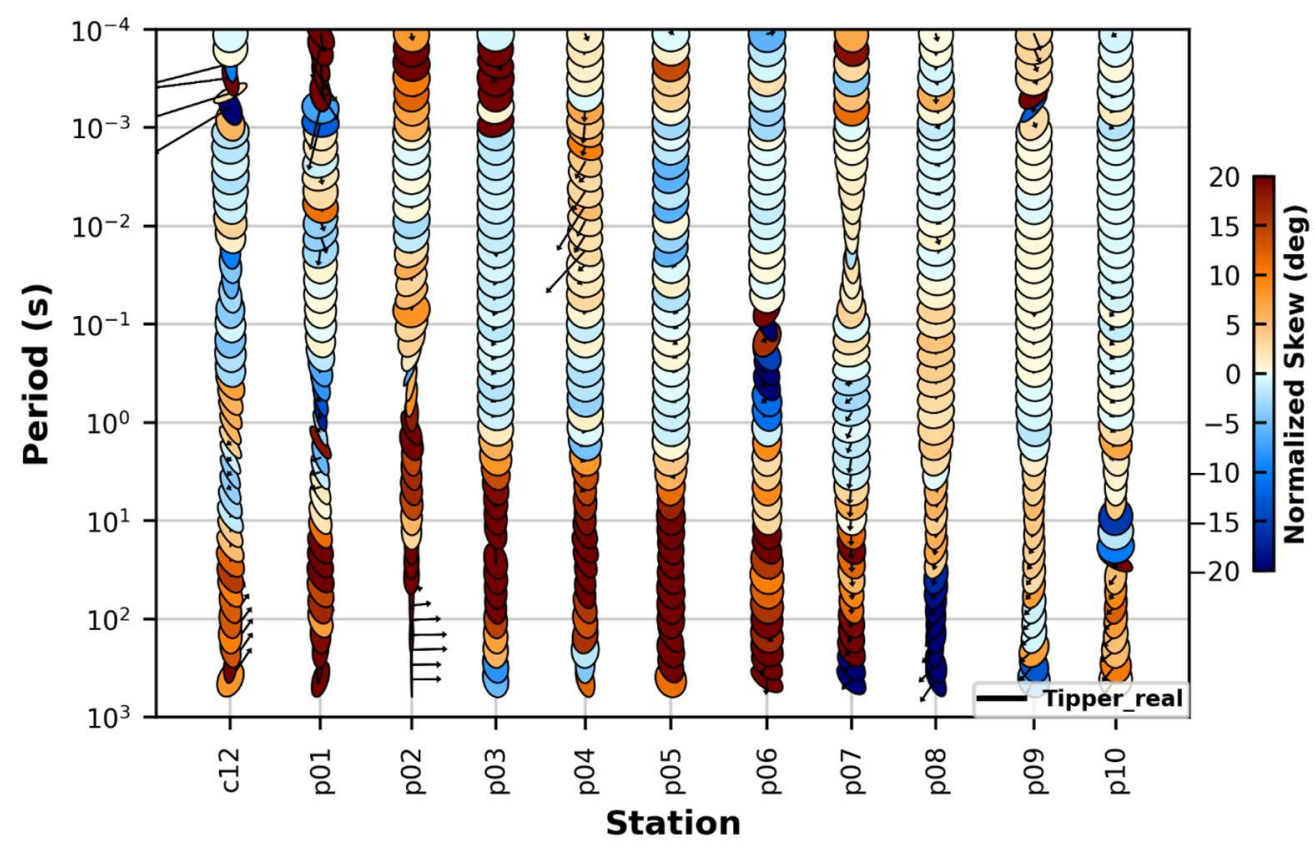

\subsubsection{Decomposição Groom-Bailey e o Strike regional}

A Figura 26 mostra as direções dos strikes obtidas em cada estação sobrepostas a um mapa de estruturas geológicas da Faixa Paraguai Norte. Para as estações P08, P09 e P10 a direção do strike geoelétrico se manteve $\left(\sim 80^{\circ}\right)$. Além do mais, há uma variação na direção do strike geoelétrico para diferentes intervalos de períodos, entre as estações C12 e P07. Esta análise inicial concorda com as outras técnicas de analise dimensional já relatadas.

Entretanto, nas estações $\mathrm{C} 12$ a P07, a direção do strike geoelétrico é relativamente constante, variando pouco, em direção ortogonal ao perfil, alterando-se apenas em algumas regiões localizadas. Isto sugere que a parametrização 3D/2D assumida é válida e que existe um meio $2 \mathrm{D}$ regional com strike geoelétrico, estimado em torno de $70^{\circ}$.

Para remoção da ambiguidade de $90^{\circ}$ do strike foram utilizadas informações geofísicas e geologia regionais. Na Figura 27 as direções dos strikes estão sobrepostas ao campo magnético total do modelo EMAG 2 (MEYER; SALTUS; CHULLIAT, 2017), observa-se que a estrutura magnética regional de direção NE coincidindo com a direção dos principais lineamentos geológicos. A análise dessas informações permitiu concluir que a direção geoelétrica regional mais adequada é N70E, a qual são paralelas as principais estruturas geológicas e a anomalia PACA.

Então, observando a geologia da área simultaneamente com os vetores de indução e o valor do strike estimado pela técnica Groom-Bailey, optou-se por rotacionar os dados para a direção N70E antes da inversão. 
Figura 26: Direção dos strikes geoelétricos, plotados em barras azuis, sobre o mapa geológico . Alinha tracejada vermelha é a posição central da PACA estimada por Bologna et al. (2014).
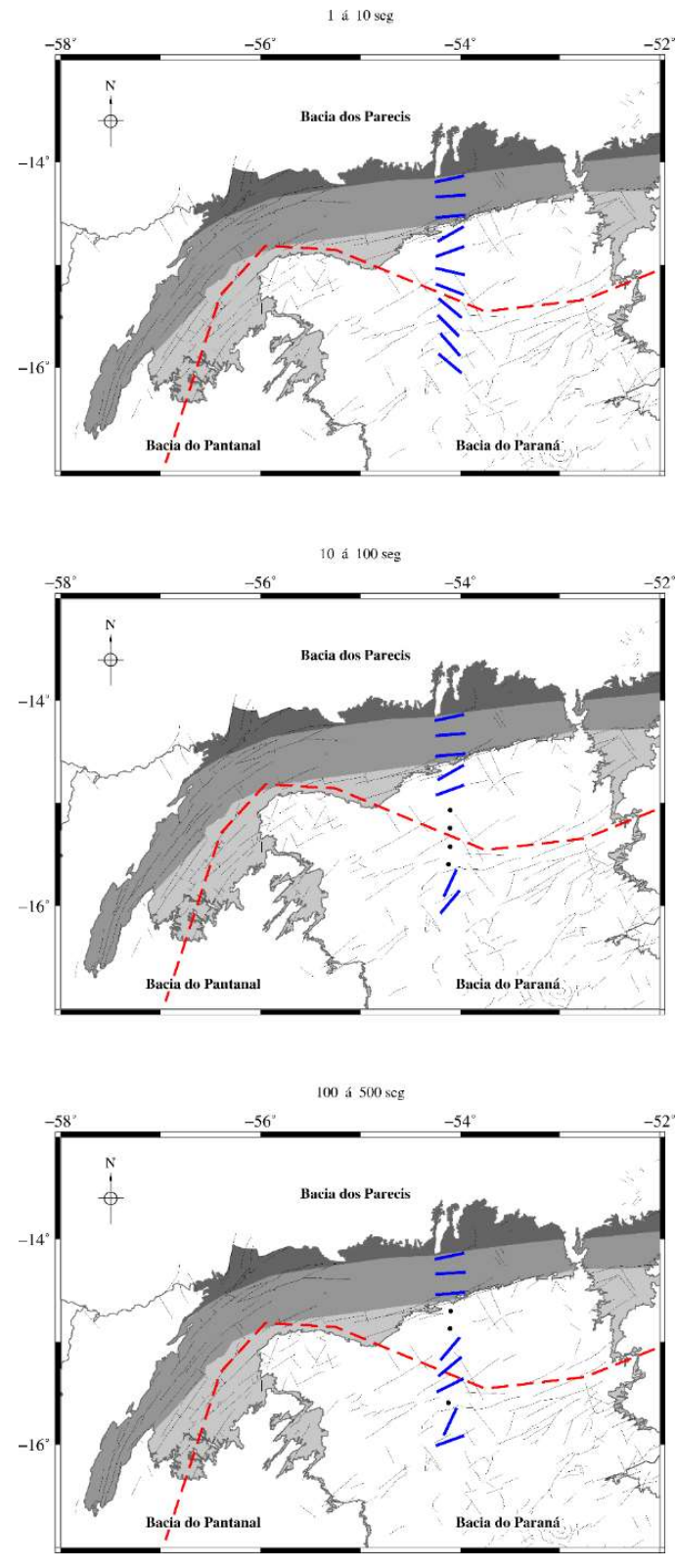
Figura 27: Azimutes dos strikes geoelétricos sobrepostos ao mapa de campo magnético total, a partir do modelo mundial EMAG 2 (MEYER; SALTUS; CHULLIAT, 2017)
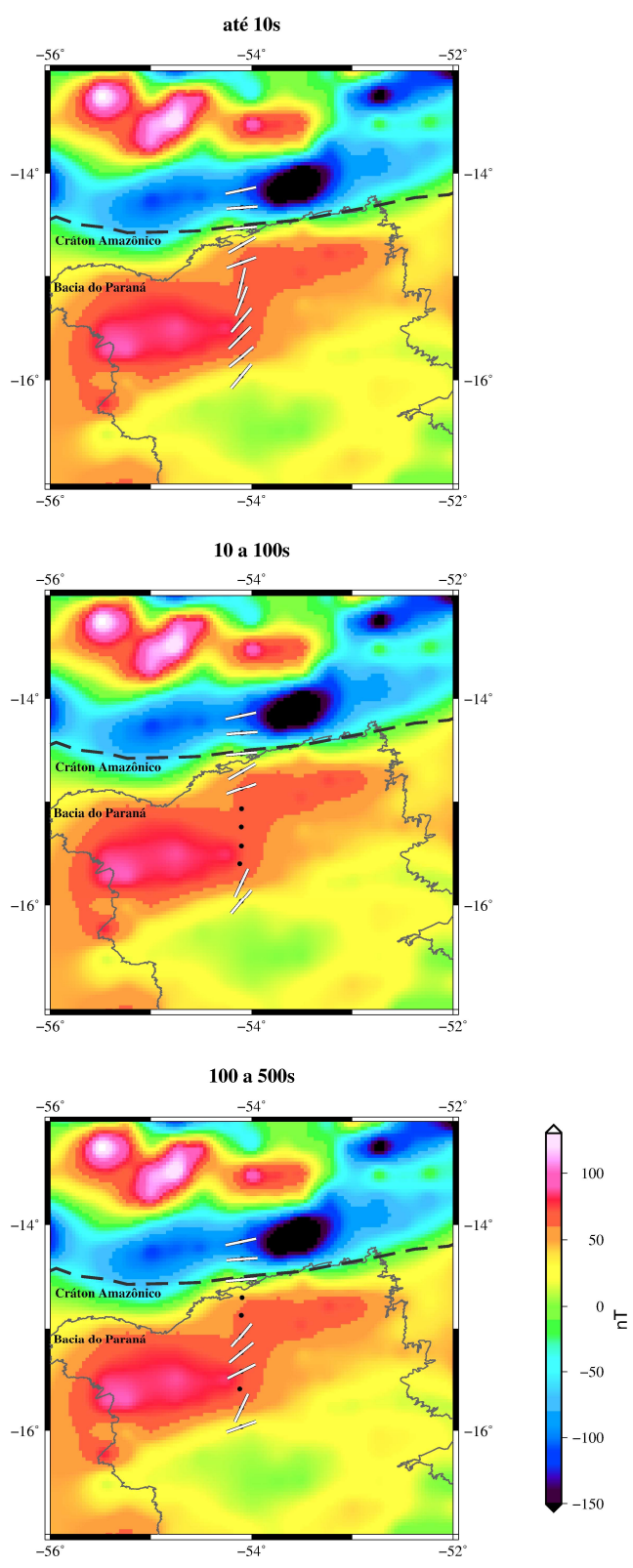

\subsection{Modelos Geoelétricos}

A inversão foi feita com os dados rotacionados para a direção do strike regional (N70E), determinado pela decomposição Groom-Bailey. Assim, as direções N20W e N70E correspondem aos modos TM e TE, respectivamente. O código REBOCC foi usado para obter um modelo suavizado de distribuição de resistividade em subsuperfície.

Ao analisar que os primeiros resultados obtidos através das inversões dos modos TM, TE e da inversão simultânea (TM + TE), notou-se que os resultados eram similares, indicando uma independência do modelo inicial. Daí, optou-se pela grade mais simples, a qual o $\Delta \mathrm{x}$ é de um quarto do espaçamento entre as estações MT e o FM é de 1,2, uma vez que uma menor 
quantidade de blocos aumenta o rendimento computacional das inversões. Em relação ao semiespaço homogêneo, o de valor igual a $1000 \Omega \mathrm{m}$ foi o escolhido por apresentar o menor RMS (erro quadrático médio).

\subsubsection{Modo Transverso Magnético (TM)}

O modelo final predileto da inversão do modo TM é o resultado da inversão com o error floor de $5 \%$ para a fase e $25 \%$ para a resistividade aparente em todas as estações, usando um semi-espaço homogêneo de $1000 \mathrm{ohm}$ metro $(\Omega \mathrm{m})$ como modelo inicial e com RMS de 1,39. Este modelo foi o que apresentou menores desajustes nas estações P06 e P07, particularmente.

O ajuste visual das curvas de resistividade aparente e fase, de uma forma geral, é adequado para todo intervalo de período (Figura 29), com exceção das estações P06 e P07, que apresentam pequenos desajustes na fase e na resistividade aparente a partir de 10 segundos (estação P06) e 0,1 segundos (estação P07).

A Figura 28 mostra o modelo TM predileto no intervalo de profundidades entre 0 e 100 $\mathrm{km}$. De um modo geral, observa-se uma crosta cuja a resistividade decresce com a profundidade (variando entre 150 e $50 \Omega \mathrm{m}$ ). Esta crosta possui cinco regiões anômalas, sendo três mais resistivas e duas mais condutivas. A primeira anomalia resistiva se localiza entre as estações P09 e P10, com o topo em $\sim 15 \mathrm{~km}$, devendo corresponder ao embasamento da cobertura de plataforma e da zona externa de Faixa Paraguai; a segunda entre as estações P06 e P08, com espessura máxima de $10 \mathrm{~km}$ sob a estação P07, e a terceira entre as estações C12 e P02, correspondendo ao embasamento da Bacia Sedimentar do Paraná. Já a primeira anomalia condutiva, com $\sim 3 \Omega \mathrm{m}$, encontra-se entre as estações P05 e P07 com topo em $\sim 5 \mathrm{~km}$. Sua posição é centrada na região de reversão dos vetores de indução e, portanto, deve corresponder à PACA. A segunda anomalia condutiva ocorre entre as estações P02 e P05 com o topo em $45 \mathrm{~km}$ e com menor intensidade que a primeira anomalia condutiva. Sua origem não está clara, e será discutida posteriormente. 
Figura 28: Modelo de resistividade elétrica resultante da inversão 2D do modo TM até 100 km de profundidade.

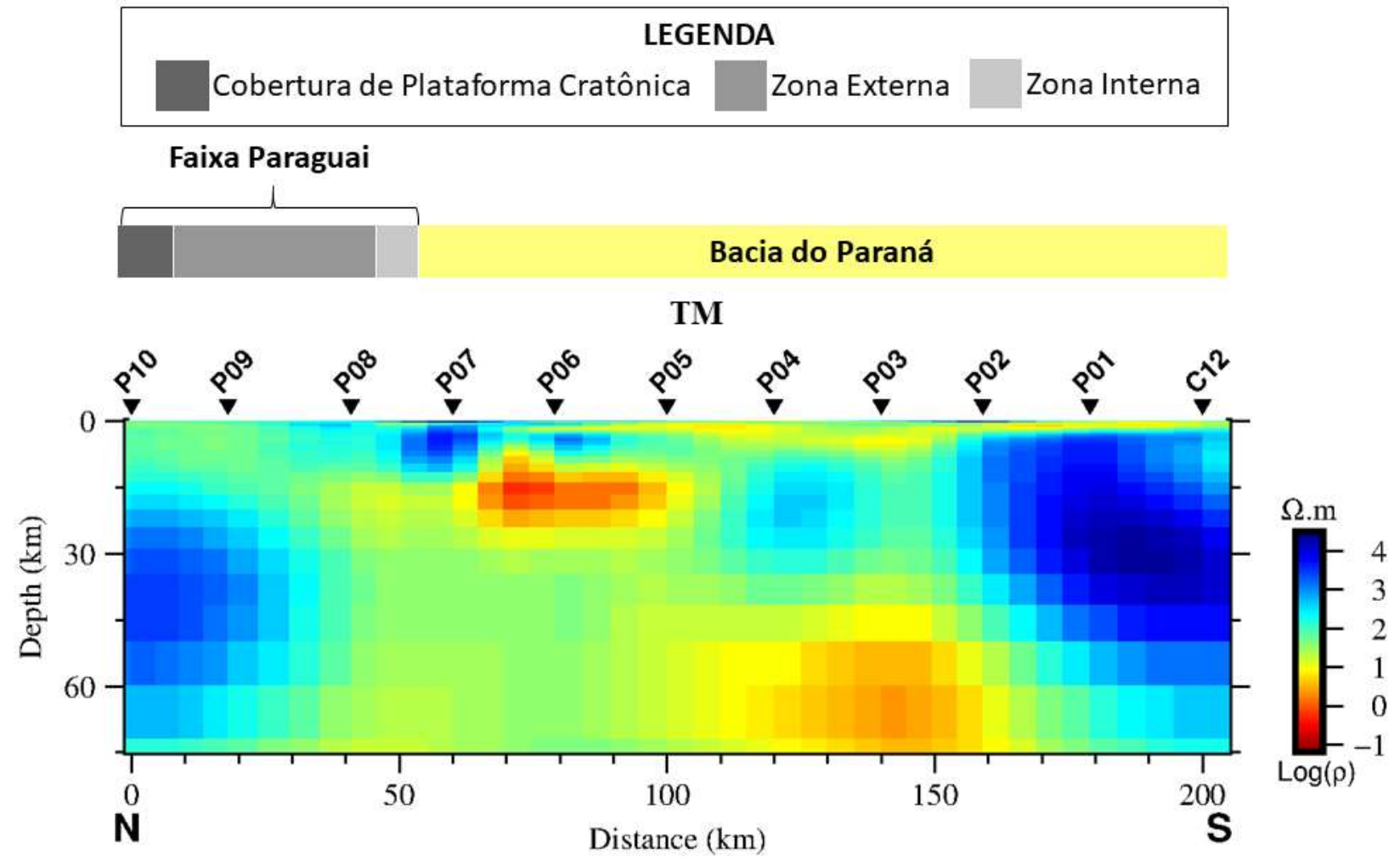


Figura 29: Comparação entre as respostas MT do modo TM observadas (símbolos) e calculadas (linhas contínuas) para o modelo da Figura 28.

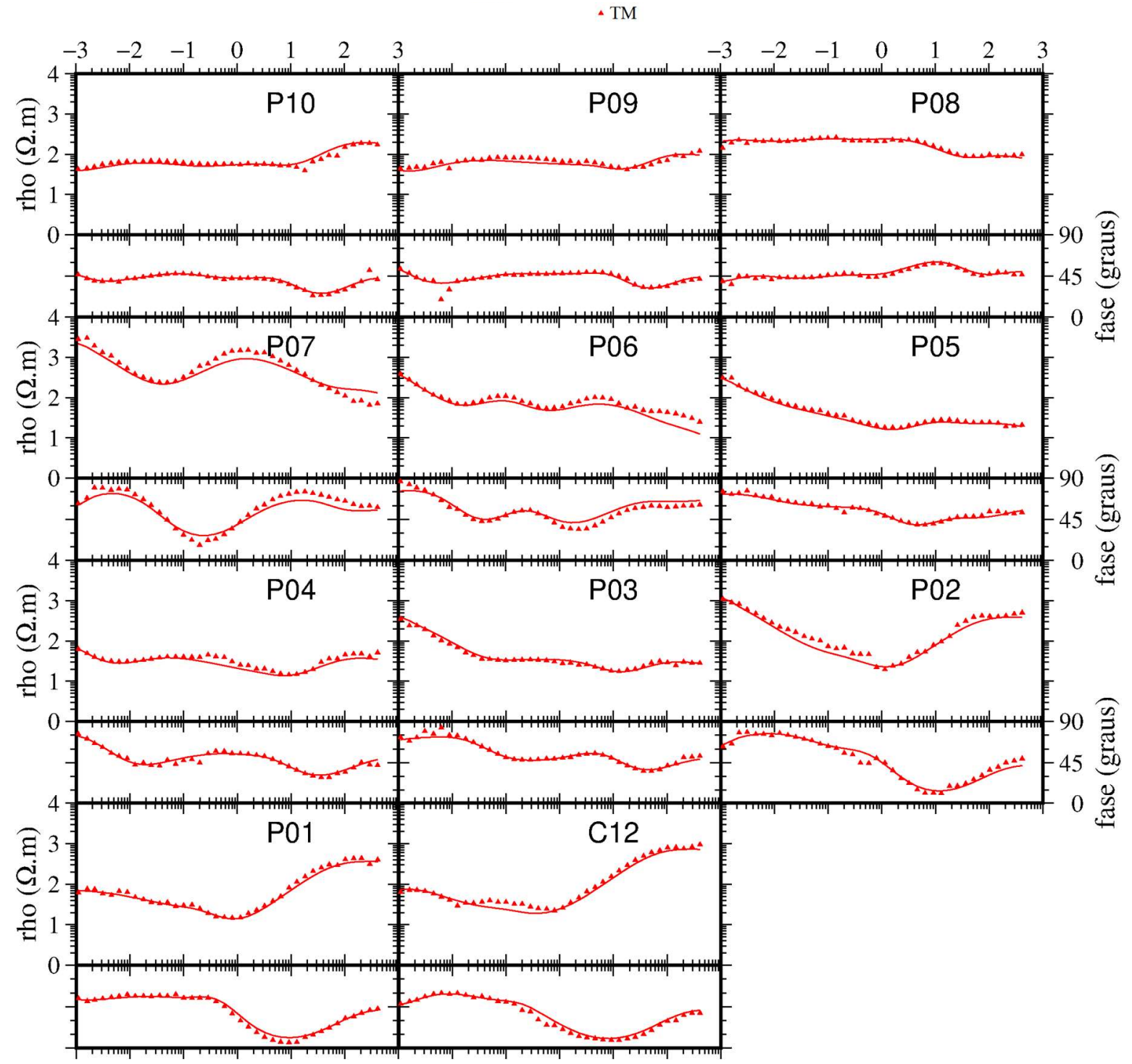

\subsubsection{Modo Transverso Elétrico (TE)}

Os procedimentos para a inversão do modo TE foram adotados de forma análoga ao modo TM. Assim como no modo TM, o modelo final predileto da inversão do modo TE (Figura 30) é feito com o error floor de 5\% para a fase e $25 \%$ para os dados de resistividade aparente em todas as estações, usando um semi-espaço homogêneo de $1000 \Omega \mathrm{m}$ como modelo inicial. Porém, a inversão chegou até a etapa II, onde o modelo é suavizado mantendo-se o valor do RMS $(1,21)$ fixo enquanto durante as interações enquanto diminui-se o valor da norma do modelo.

O ajuste visual das curvas MT é satisfatório, conforme visto na Figura 31. Pequenos desajustes são observados nas estações C12, P01 e P04 a partir de 100 s e nas estações P07 e P08 em todo espectro de período. 
O modelo TE possui características gerais parecidas com o do modo TM, porém algumas informações são acrescentadas. Ao invés de uma anomalia resistiva entre as estações P09 e P10, há uma anomalia condutiva da ordem de $1 \Omega \mathrm{m}$ e com o topo em $\sim 20 \mathrm{~km}$ de profundidade. O resistor localizado entre as estações P06 e P08 é apresentada mais intensamente entre as estações P07 e P08 sendo mais espessa comparada ao modelo anterior. A região resistiva associada ao embasamento da Bacia do Paraná é apresentado neste modelo, com menor magnitude $(\sim 1000 \Omega \mathrm{m})$. Em relação às duas anomalias condutivas mais profundas descritas anteriormente para o modelo de resistividade do modo TM, neste modelo elas são imageadas como uma feição única e bem condutiva $(<1 \Omega \mathrm{m})$, com extensão lateral de $\sim 80 \mathrm{~km}$. Seu topo varia de profundidade, com a parte mais rasa em $\sim 8 \mathrm{~km}$, a norte, e a parte sul mais profunda em $\sim 20 \mathrm{~km}$.

Figura 30: Modelo de resistividade elétrica resultante da inversão 2D do modo TE.
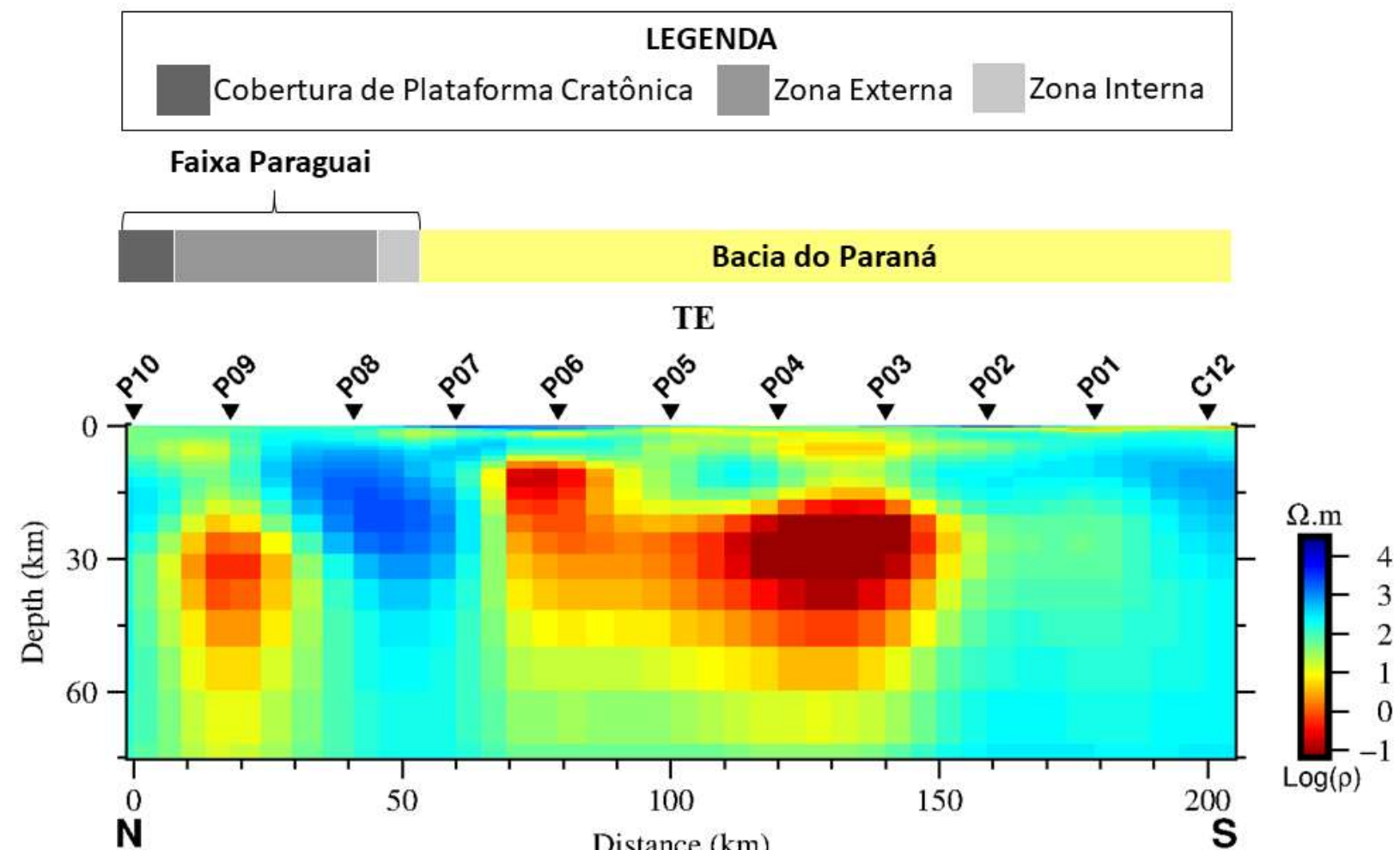
Figura 31: Comparação entre as respostas MT do modo TE observadas (símbolos) e calculadas (linhas contínuas) para o modelo da Figura 30.

- TE

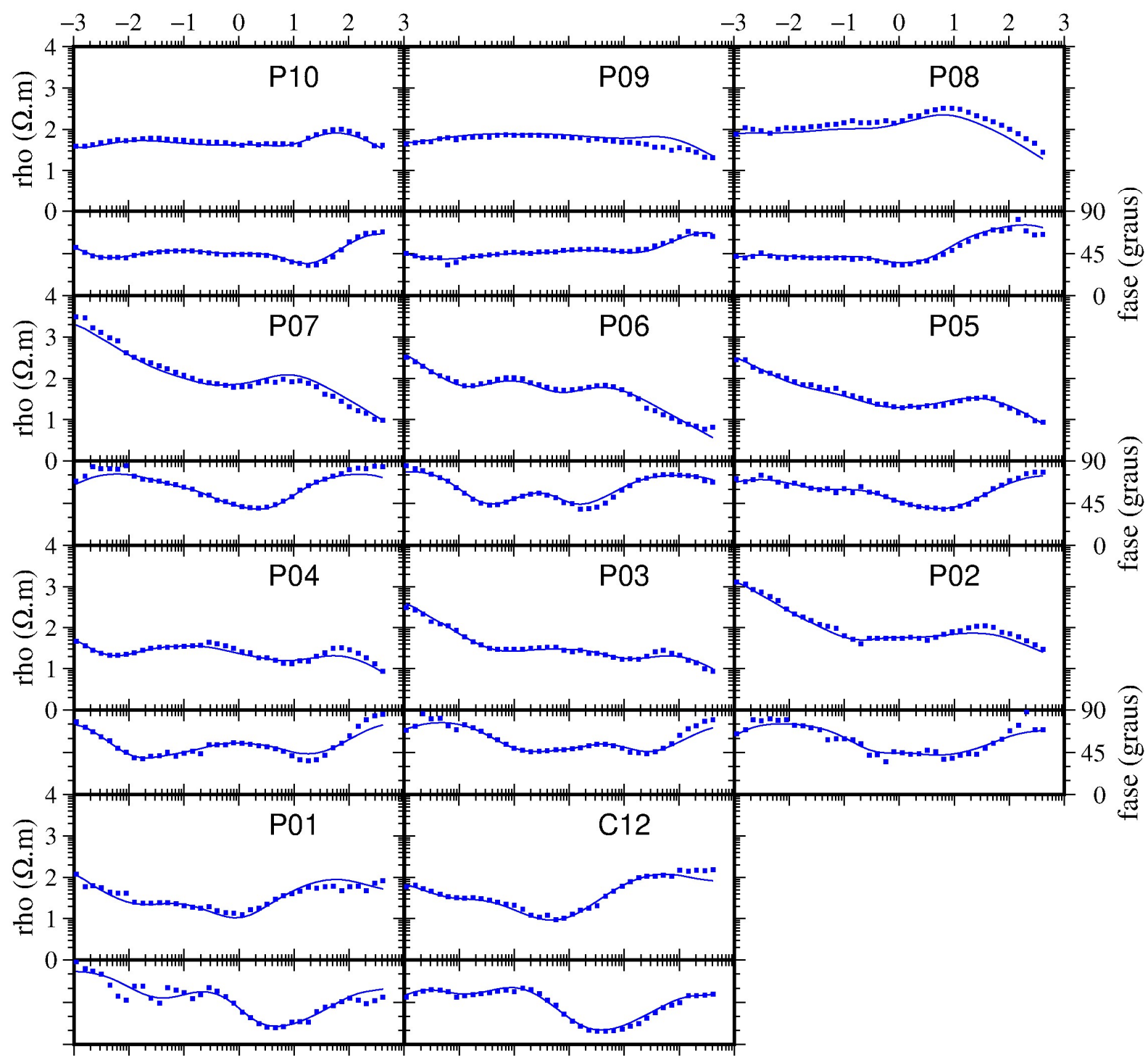

\subsubsection{Tipper}

A inversão somente do tipper é realizada para obter informações adicionais sobre as estruturas condutoras litosféricas. Esta inversão, ajuda na localização da posição horizontal dos condutores mais proeminentes, mas não determina suas profundidades.

O modelo final predileto é o qual o resultado da inversão apresenta o error floor de 0,03 para a componente real e 0,05 para a componente imaginária do tipper em todas as estações para o modelo resultante da inversão do modo TM. Este valor de error floor foi usado para evitar que a inversão fosse dominada por aqueles dados com pequenas variações irrealisticamente. $\mathrm{O}$ valor do RMS é de 2,53. As principais estruturas e contrastes geoelétricos aparecem na seção de resistividade elétrica da inversão. 
O ajuste visual das curvas que representam a parte real e a parte imaginária do Tipper, em geral, é adequado (Figura 33), pois é comum privilegiar a componente real do tipper. Observa-se que em algumas curvas a parte imaginária não consegue ser ajustada, principalmente na porção sul do perfil, então não é aconselhável tentar inversão conjunta do Tipper com as outras impedâncias.

O modelo predileto corresponde a Figura 32. Em geral, este modelo confirma a presença de um condutor na parte central do perfil. O condutor é imerso em uma crosta de resistividade aparente intermediaria com valor médio de $100 \Omega \mathrm{m}$. É possível destacar três estruturas mais condutivas imersa nesta crosta. A primeira estrutura está sob as estações P10 e P05, nota-se que entre as estações P07 e P05 a estrutura fica mais condutiva, com valor de resistividade próximo a $1 \Omega \mathrm{m}$, coincidindo com a localização horizontal das anomalias condutivas associada a PACA também observados nos outros modelos geoelétricos. A segunda zona anômala está entre as estações P05 e P03 e apresenta um valor de resistividade aparente próximo a $10 \Omega \mathrm{m}$. A terceira estrutura localiza-se entre as estações P02 e P01 e apresenta uma resistividade aparente de aproximadamente $1 \Omega \mathrm{m}$. Essa estrutura não é correlacionada com nenhuma anomalia relatada em outros modelos. Ela pode ser um artefato, visto que as componentes imaginárias não conseguiram ser ajustadas nas estações mais a sul do perfil, particularmente.

Figura 32: Modelo de resistividade elétrica resultante da inversão 2D do Tipper
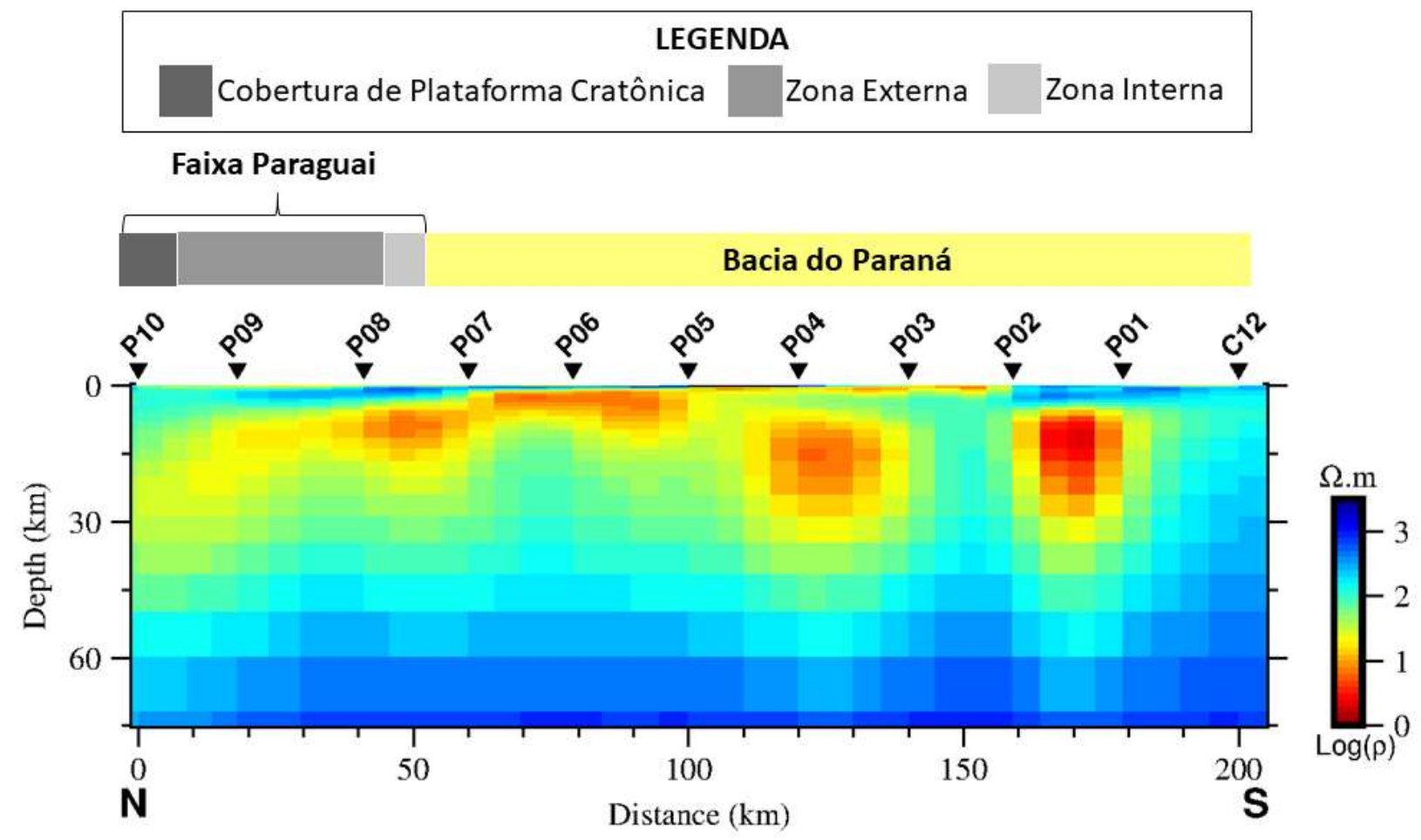
Figura 33: Comparação entre as respostas MT do Tipper observadas (símbolos) e calculadas (linhas contínuas) para o modelo da Figura 32.

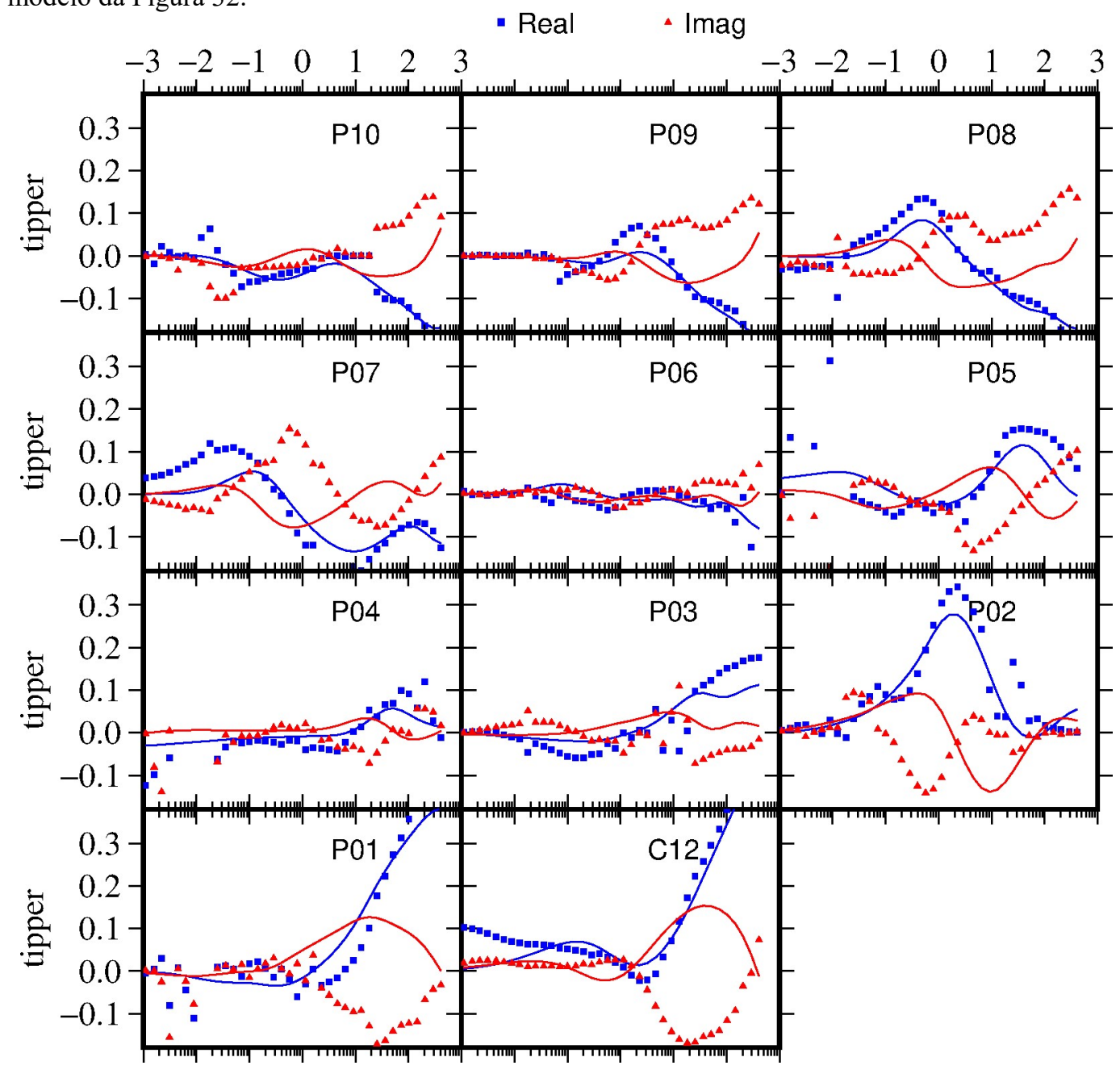

\subsubsection{Modos TE e TM simultâneos}

A inversão simultânea dos modos TE e TM foi realizada seguindo os mesmos procedimentos gerais dos modos individuais, descritas anteriormente. O modelo TE-TM predileto (Figura 34) obteve o RMS final igual à 1,86.

A comparação entre as curvas observadas e calculadas encontra-se na Figura 35, com os dois modos sobrepostos para serem visualizadas ao mesmo tempo. Em geral, o modelo ajusta as curvas observadas de forma satisfatória principalmente no modo TM.

O modelo TE-TM confirma algumas anomalias presentes nos modos TM e TE, validando as análises realizadas anteriormente. Assim como no modo TM, podemos distinguir cinco regiões anômalas no modelo apresentado (Figura 34), três mais resistiva e duas mais condutivas que o meio. Entre as estações P09 e P10 é apresentado um resistor (pertinente com o modelo do modo TM) com o topo em $\sim 15 \mathrm{~km}$ de profundidade corresponder ao embasamento da cobertura de plataforma e da zona externa de Faixa Paraguai que se associa ao embasamento 
da cobertura de plataforma e da zona externa de Faixa Paraguai. Uma segunda anomalia resistiva localizada entre as estações P06 e P08, confirmando uma espessura máxima de $10 \mathrm{~km}$ sob a estação P07. E a terceira região resistiva entre as estações C12 e P02, associada ao embasamento da Bacia do Paraná. Para as duas regiões anômalas condutivas temos, a primeira encontrada entre as estações $\mathrm{P} 05$ e P08, com $\sim 0,5$ ohms metro e a parte mais rasa do topo em $\sim 10 \mathrm{~km}$. Assim como no modelo do modo TM, a posição desta zona condutiva é centrada na região de reversão dos vetores de indução, logo, deve corresponder à PACA A segunda anomalia condutiva está localizada entre as estações P02 e P05, de magnitude maior que 10 $\mathrm{S} / \mathrm{m}$ e com o topo em $\sim 15 \mathrm{~km}$.

Figura 34: Modelo de resistividade elétrica resultante da inversão 2D simultâneo dos modos TE e TM.

\begin{tabular}{|l|l|l|}
\hline \multicolumn{2}{|c|}{ LEGENDA } \\
\hline Cobertura de Plataforma Cratônica & Zona Externa & Zona Interna \\
\hline
\end{tabular}
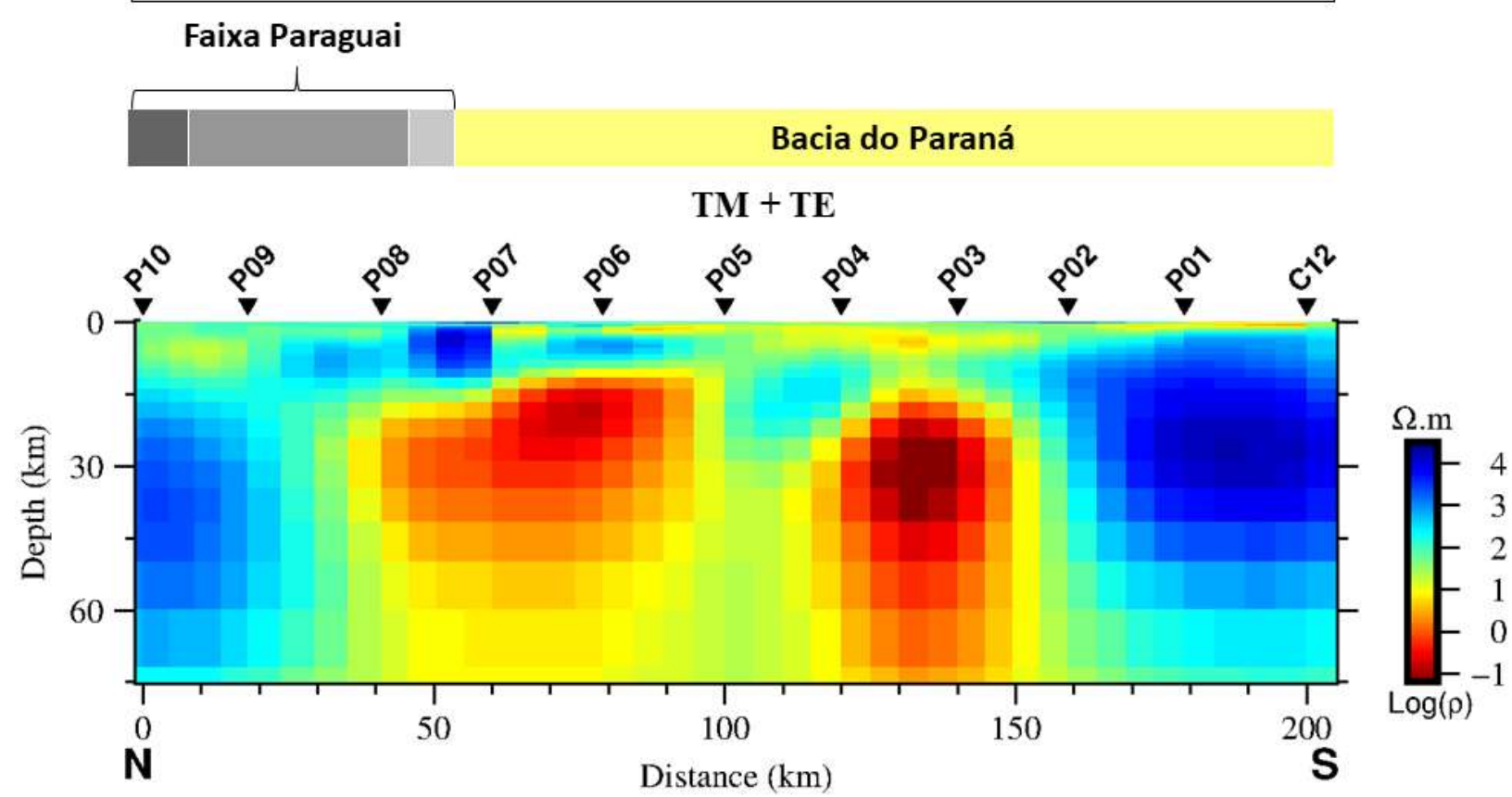
Figura 35: Comparação entre as respostas medidas (símbolos) e calculadas (linhas contínuas) do modelo TE-TM da Figura 34.

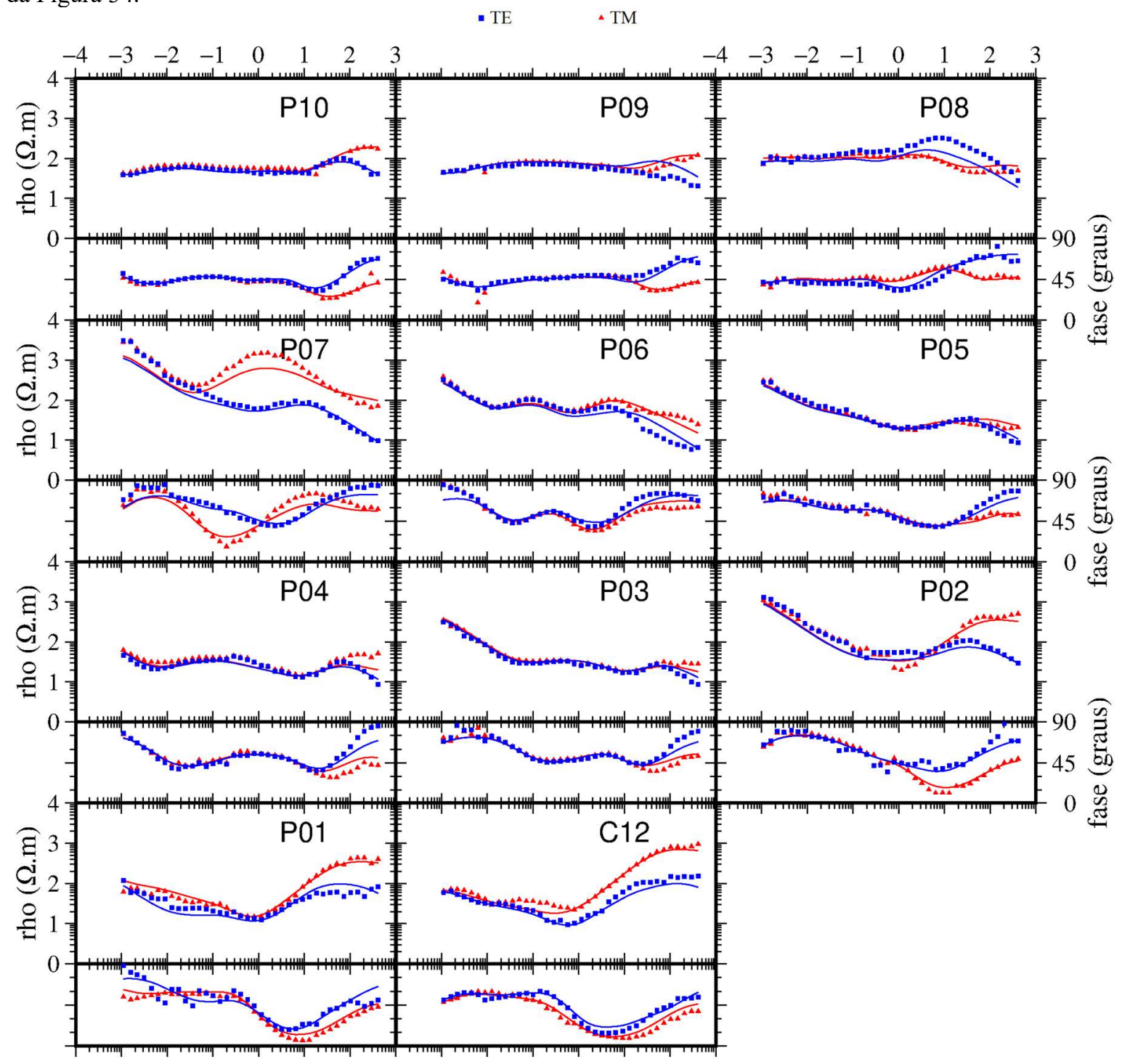

\section{DISCUSSÃO}

Apesar das análises dimensionais WALDIM (MARTÍ et al., 2009) e o Tensor de fase (CADWELL et al., 2004) indicarem que parte dos dados são essencialmente 3D, a análise Groom-Bailey (1989), aplicada com o código de Decomposição de Strike (MCNEICE; JONES, 2001), suporta uma interpretação bidimensional dos dados. Isto ocorre devido ao ajuste das impedâncias serem satisfatórios. De fato, Jones (2012) afirma que a técnica de decomposição Groom-Bailey, na presença de ruído, é superior aos demais métodos pois sua parametrização 3D/2D (distorção local 3D em um ambiente regional 2D) é testado estatisticamente. Também, a técnica do tensor de fase apresenta alguma arbitrariedade em relação aos limites estabelecidos para os valores de $\beta$. Alguns trabalhos, por exemplo o de Evans et al. (2019) nos Apalaches, 
utilizam limites muito acima dos valores proposto por Cadwell e colaboradores que seria de $(+3$ e/ou -3$)$.

O comportamento 2D indicado pelo método Groom-Bailey é suportado pelos vetores de indução. Ou seja, a parte real dos vetores são quase paralelos, apontando para o centro do perfil, e revertendo o sentido próximo à estação P06; a parte imaginaria é disposta paralelamente ou em antiparalelo em relação à parte real, visto nas estações P03, P04 e P05.

O strike médio determinado pela decomposição Groom-Bailey é condizente com a direção das estruturas magnéticas do embasamento e crosta profunda na região em torno de Poxoréu determinadas por Curto et al. (2014) e indicado na Figura 36. Nessa direção também ocorre uma zona sísmica que atravessa a bacia do Paraná cerca de $100 \mathrm{~km}$ ao sul da área de estudo.

Figura 36: Mapa de características geológicas e tectônicas extraída de Curto et al. (2014). A linha em azul é a localização do perfil MT deste estudo.

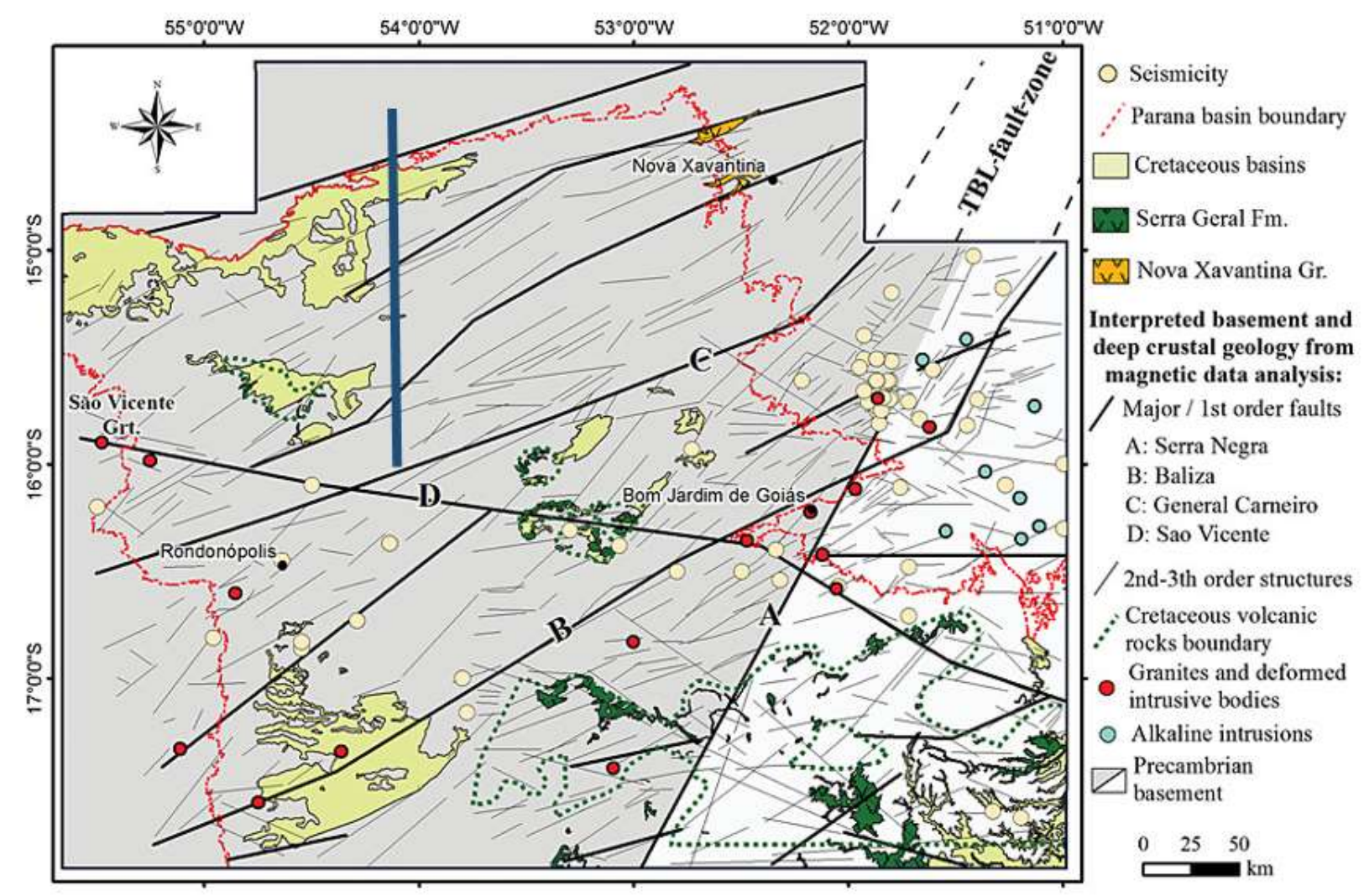

Para melhor observar o embasamento da Bacia do Paraná na região do levantamento MT, optamos por plotar o modelo TE-TM deste estudo até uma profundidade de $8 \mathrm{~km}$ (Figura 37). A Bacia do Paraná é imageada como uma zona condutiva com valores de resistividade elétrica entre 10 e $100 \Omega \mathrm{m}$. Esses valores são consistentes com os obtidos no perfil MT de 
Bologna et al. (2013), cerca de $400 \mathrm{~km}$ ao sul da área deste estudo. A litologia que está sendo imageada são os folhelhos das Formações Ponta Grossa e Diamantino.

Além do mais, o modelo geoelétrico mostra uma variação da profundidade do embasamento na parte Norte da Bacia do Paraná, entre as estações P02 e P05. Onde sua parte mais profunda está entre as estações P03 e P04, em aproximadamente 5 km. Por ser uma região de margem da bacia sedimentar, era esperado um afilamento continuo com a profundidade do embasamento variando entre $500 \mathrm{~m}$ a $1 \mathrm{~km}$ (MILANI, 2004).

A zona condutiva na base da Bacia do Paraná em torno das estações P03 e P04 pode indicar um espessamento abrupto do pacote sedimentar pré-vulcânico, de cerca de $2 \mathrm{~km}$ para 4-5 km. A existência de um gráben soterrado deveria ter uma resposta gravimétrica associadas, como na região de Aporé $200 \mathrm{~km}$ ao sul da região, onde Vidotti et al. (1998) propuseram um gráben Paleozóico com base na modelagem de anomalias Bouguer negativas. De fato, na região de estudo ocorrem anomalias negativas (embora de menor amplitude) e possivelmente uma análise quantitativa poderá posteriormente testar essa hipótese de espessamento localizado do pacote pré-vulcânico.

Uma interpretação alternativa é que a zona condutiva, na base da bacia, esteja associada a presença de fluidos salinos interconectados. Aplicando a Lei de Archie com os parâmetros usados por Unsworth et al. (1997) na falha de San Andreas, a saber condutividade do fluido salino de 0,26 $\Omega \mathrm{m}$ e coeficientes de saturação e cimentação unitários, constata-se que uma porosidade de 2-3 \% apenas pode explicar os valores observados de resistividade. Então, essa zona condutiva poderia indicar que o embasamento (Grupo Cuiabá) da Bacia do Paraná é localmente mais fraturado.

Ainda sobre a Figura 37 é possível observar os valores de resistividade para a Faixa Paraguai. Para a zona externa, o nosso modelo indica um valor de resistividade de aproximadamente $500 \Omega \mathrm{m}$ e para a zona interna, região mais metamorfizadas, valor próximo a $10000 \Omega$ m. Esses valores são próximos aos do trabalho de Bologna et al. (2014), que apresenta um valor de resistividade de aproximadamente $1000 \Omega \mathrm{m}$ para a zona externa e de aproximadamente $10000 \Omega \mathrm{m}$ para a zona interna da Faixa Paraguai. 
Figura 37: Modelo geoelétrico resultante da inversão 2D simultâneo (TM + TE) para 8 km de profundidade.

\begin{tabular}{|l|l|l|}
\hline \multicolumn{2}{|c|}{ LEGENDA } \\
Cobertura de Plataforma Cratônica & Zona Externa & Zona Interna \\
\hline
\end{tabular}
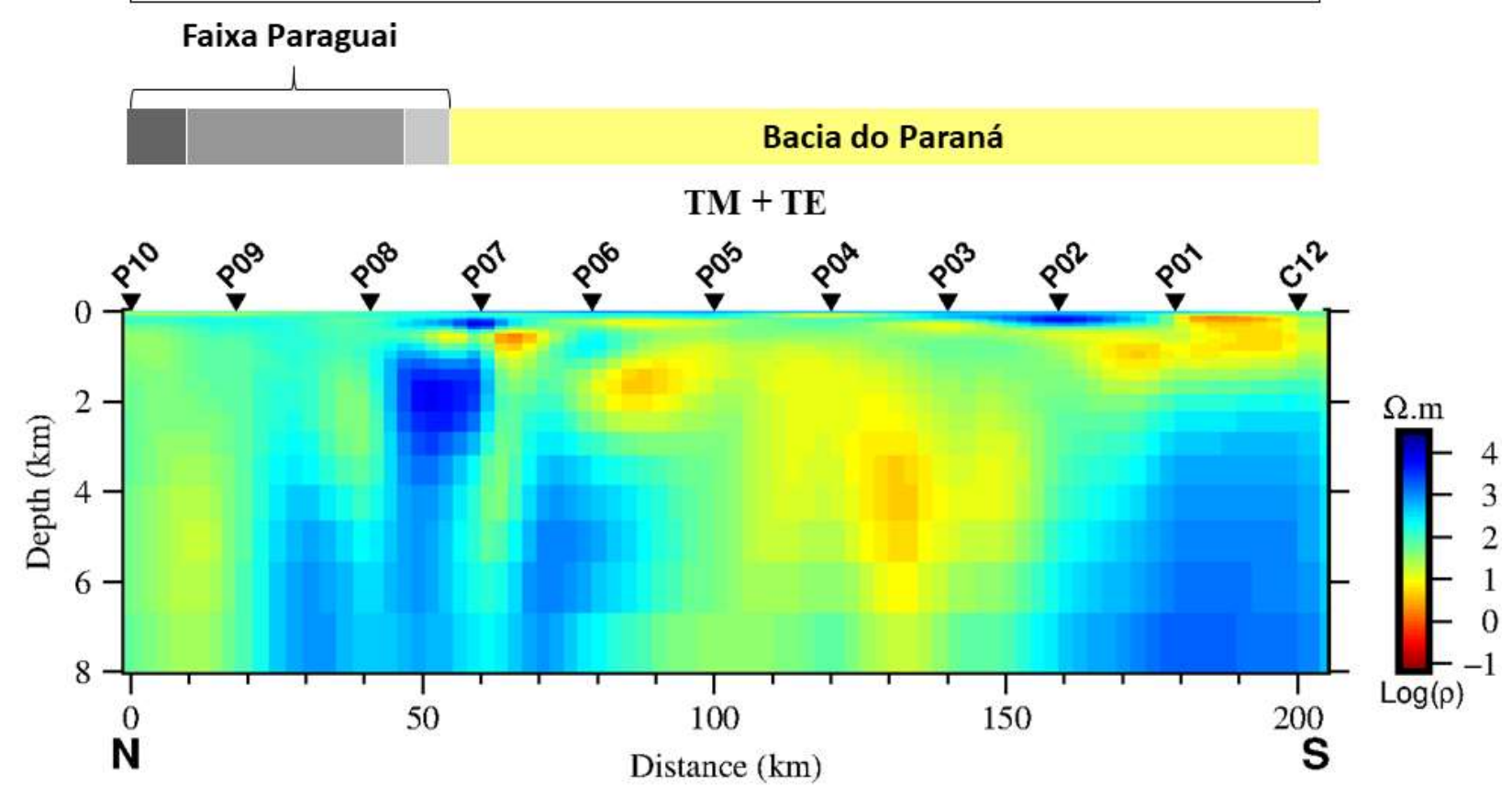

A principal feição geoelétrica modelada em grandes profundidades é um par de anomalias condutivas na parte central do perfil MT. A localização destas anomalias coincide com o traçado regional da PACA mapeado no trabalho de Bologna et al. (2014). O par de anomalias aparecem sempre nos resultados das inversões, sendo independente dos parâmetros de inversão. Entretanto, no resultado da inversão do tipper, este par de anomalias aparece como uma estrutura única. Apesar disto, em todos os modelos gerados, estas estruturas estão compreendidas entre as estações MT P07 e P02 sendo coincidentes com a posição indicada pelos vetores de indução (estação P06).

É possível indicar semelhanças e diferenças entre os modelos de resistividade prediletos deste trabalho e o modelo de resistividade do modo TM (Figura 38) apresentado por Bologna et al. (2014). Para estes autores, a PACA é uma única estrutura com $100 \mathrm{~km}$ de largura, resistividade em torno de $1 \Omega \mathrm{m}$, profundidade do topo variando entre 2 e $5 \mathrm{~km}$ e que se estende até ao menos 10-15 km de profundidade. Já para o presente trabalho, a PACA consiste de duas estruturas condutoras com mesmos valores de largura e resistividade que o descrito por Bologna et al. (2014); com profundidade do topo variando entre 10 e $15 \mathrm{~km}$; podendo se estender por ao menos $30 \mathrm{~km}$ de profundidade. As diferenças entre o modelo de Bologna e o deste trabalho está relacionado com a localização de cada perfil magnetotelúrico ao longo da PACA. 
Apesar das diferenças entre as anomalias modeladas na região de Cuiabá e as deste trabalho, observamos que em ambas as localidades as estruturas elétricas associadas à PACA o limite norte das anomalias coincide com a transição entre as zonas interna e externa. Isto confirma que a PACA, pelo menos ao norte da Faixa Paraguai, é uma feição elétrica contida na Zona Interna da Faixa Paraguai, que é a zona mais deformada (maior grau metamórfico). Isto provavelmente implica numa relação genética entre a PACA e o evento deformacional que formou a Faixa no final do Neoproterozoíco.

Estudos magnetotelúricos ao redor do mundo relatam que as principais anomalias de condutividade elétrica representam feições de processos tectônicos antigos (ERNST et al., 2008; LOGVINOV; TARASOV, 2018). As anomalias condutivas localizadas em provincias tectônicas estáveis, são geralmente relacionadas à zonas de sutura fóssil (SELWAY et al., 2009; NAGANJANEYULU; SANTOSH, 2011). Na prática, limites de placas colisionais são associados a uma assinatura elétrica, em forma de um condutor linear.

Como exemplo mundial há anomalia condutiva das Planícies Centrais da América do Norte (North American Central Plains - NACP), conhecida como a mais longa anomalia condutiva do mundo. Segundo Jones et al. (1993), a NACP é associada à rochas metassedimentares do orógeno Trans-Hudson e interpretada como tendo sido empurrada abaixo da margem continental durante uma colisão arco-continente através de processos de subducção. Os altos valores de condutividade destas anomalias são atribuidas à deformação e ao metamorfismo de rochas sedimentares grafiticas ou sulfidicas formadas em um restrito e redutor ambiente oceânico, como em Boerner et al. (1996).

As anomalias NACP e PACA apresentam assinaturas elétricas similares e contexto tectônicos próximos, podendo assim, ser relacionadas. A NACP é uma estrutura condutiva arqueada composta por dois corpos de aproximadamente $10 \Omega \mathrm{m}$ de resistividade, com o topo da anomalia localizada entre 5 e $10 \mathrm{~km}$ de profundidade; com a anomalia se estendendo por aproximadamente $20 \mathrm{~km}$ de profundidade. Essas características são similares às observadas para a PACA. Isto favorece a ideia de que a PACA seja construída de pelo menos dois condutores.

A correlação espacial entre a zona condutiva na base da Bacia do Paraná e o condutor na crosta inferior e manto litosférico centrado sob as estações P04 e P05 pode indicar uma relação genética entre ambas anomalias. Uma possibilidade é que elas tenham sido formadas no Cretáceo Inferior, durante o evento que deu origem à Província Poxoréu ( $\sim 85 \mathrm{Ma}$; GIBSON et al., 1997). A anomalia profunda (C2) poderia ter relação com os processos de estiramento da litosfera que deram origem ao rifte Rios das Mortes. 
Outra possibilidade é que a anomalia condutiva seja associada à intrusões carbonáticas não aflorantes. Uma interpretação similar foi dada por Padilha et al. (2015) para explicar um condutor isolado próximo à borda oeste da Bacia do Paraná. Os autores argumentam que a ocorrência de vários complexos alcalinos-carbonatíticos ao redor da bacia torna plausível supor a presença de complexos ocultos sob a bacia.

Figura 38: Comparação entre os modelos geoelétricos desse trabalho e o modelo geoelétrico de Bologna et al. (2014). Em a) modelo geoelétrico resultante da inversão 2D para o modo TE; em b) para o modo TM, ambos resultados deste trabalho. E em c) o modelo de resistividade resultante da inversão 2D para o modo TM realizado por Bologna e colaboradores.

\begin{tabular}{|l|l|l|}
\hline \multicolumn{3}{|c|}{ LEGENDA } \\
\hline Cobertura de Plataforma Cratônica & Zona Externa & Zona Interna \\
\hline
\end{tabular}
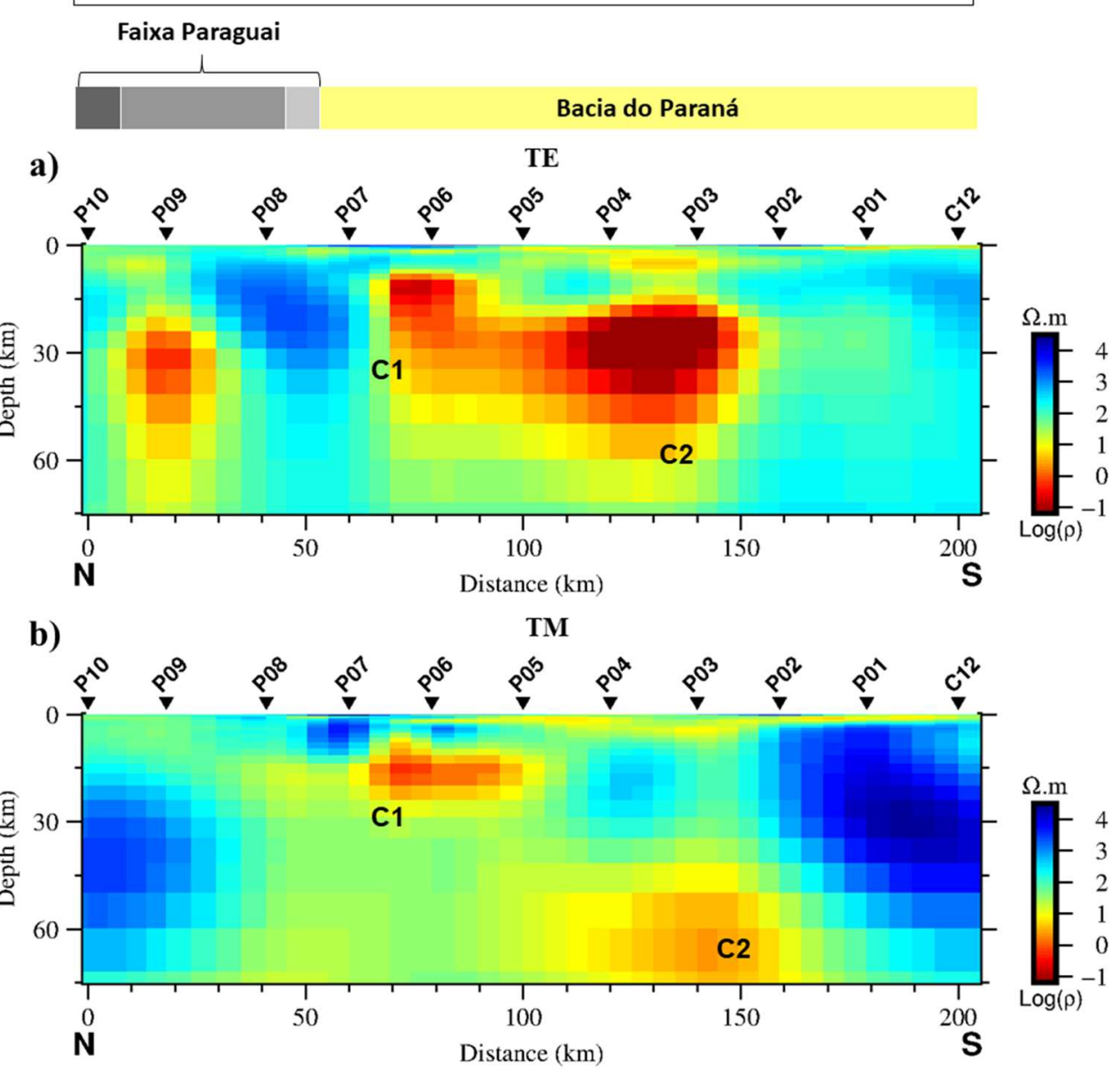

c)

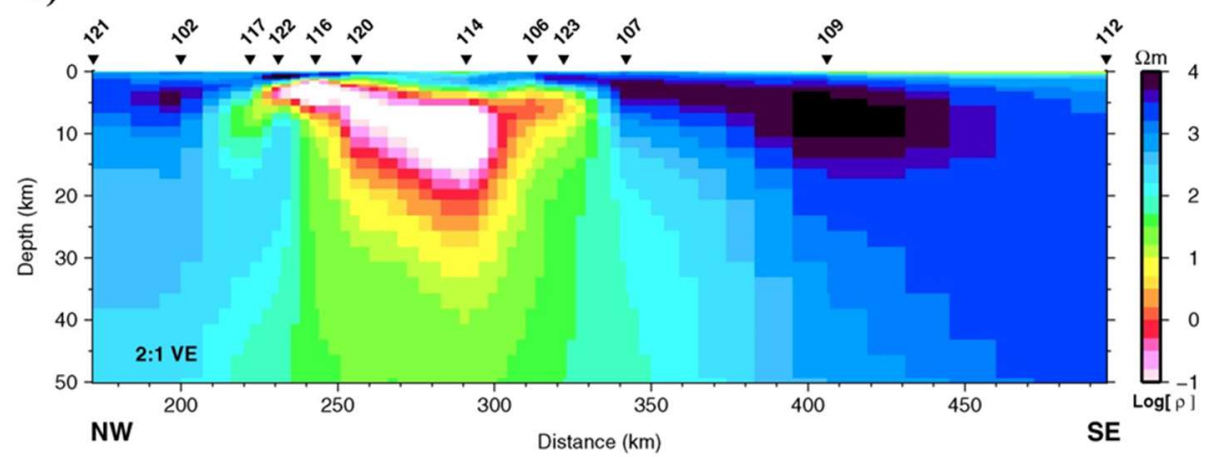


Figura 39: Comparação entre o modelo da inversão 2D simultâneo dos modos TE e TM desse trabalho e o modelo geoelétrico de Jones et al. (1993). Em a) modelo geoelétrico resultante da inversão 2D simultâneo dos modos TE e TM; em b) modelo de resistividade realizado por Jones e colaboradores.

\begin{tabular}{|l|l|l|}
\hline \multicolumn{2}{|c|}{ LEGENDA } \\
Cobertura de Plataforma Cratônica & Zona Externa & Zona Interna \\
\hline
\end{tabular}

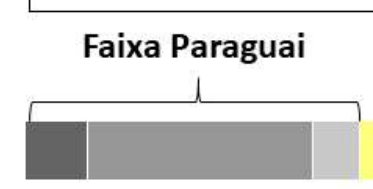

a)

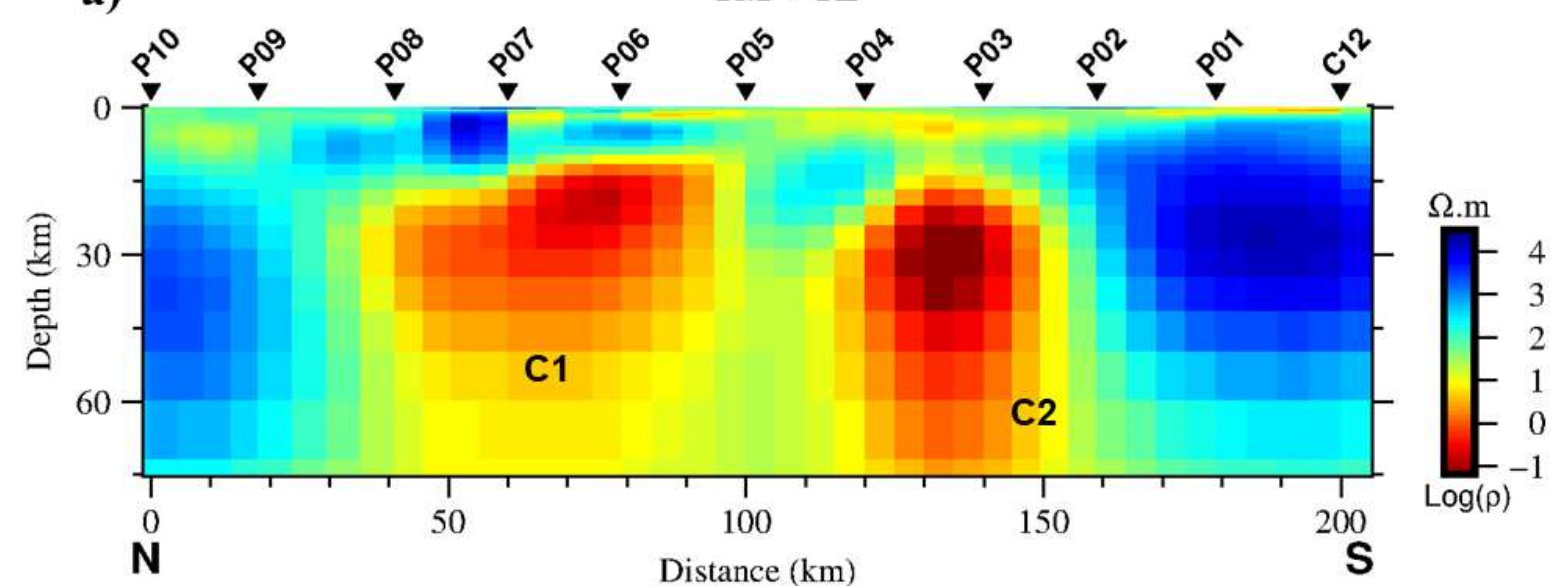

b)

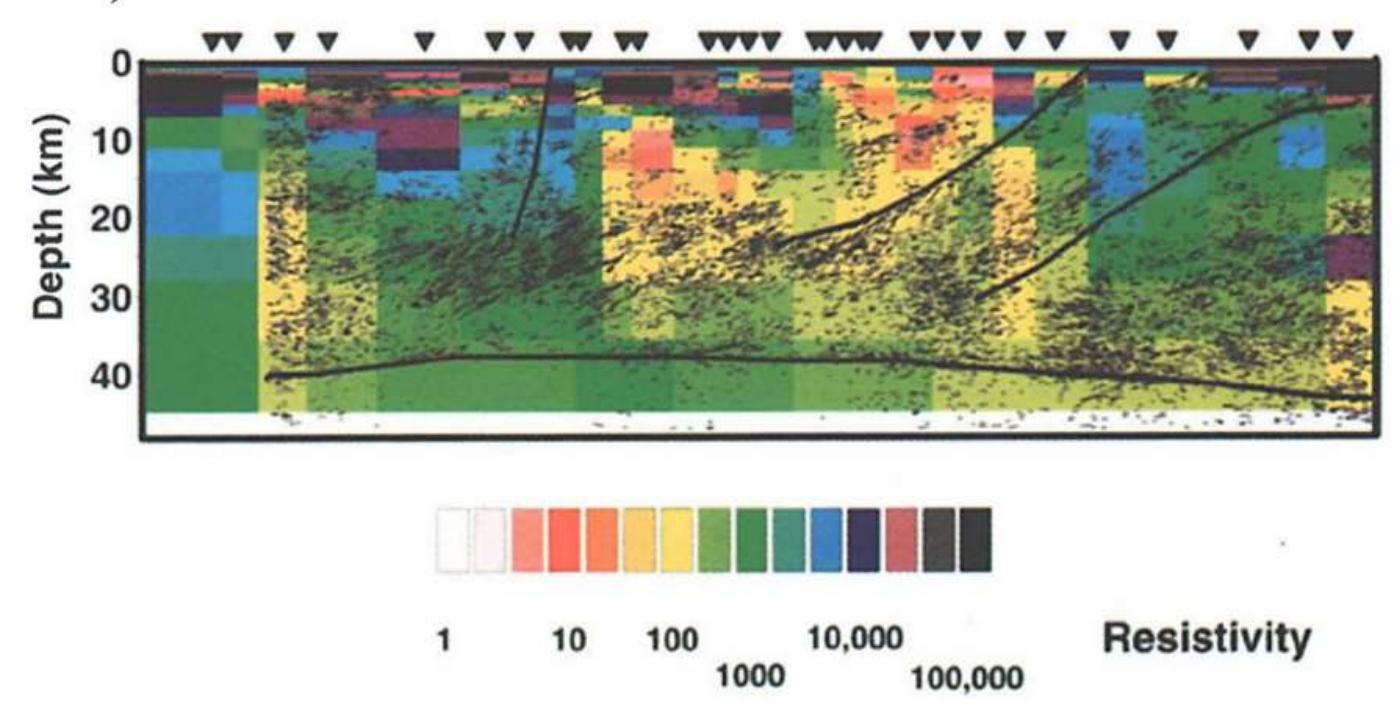

\section{CONCLUSÕES}

Este trabalho descreve os resultados de um perfil MT de $200 \mathrm{~km}$ de extensão indo do extremo norte da Bacia do Paraná até o limite em superfície do Cráton Amazônico para estudar a distribuição de condutividade elétrica sob a Faixa Paraguai Norte. O modelo geoelétrico aqui obtido através de inversão 2D dos dados MT fornece um aumento da resolução em relação aos modelos de resistividade previamente publicados. 
Para obter uma resposta robusta sobre a PACA, foram realizados inúmeros testes (como variação do tamanho da malha e correção do efeito static shift) durante as etapas da inversão 2D. Os modelos preferidos adotados por este trabalho fornecerem detalhes sobre a anomalia e regiões adjacentes. Além das análises dimensionais realizadas, optou-se por utilizar a inversão $2 \mathrm{D}$, e não a $3 \mathrm{D}$, devido a rapidez computacional em se obter os modelos podendo assim, realizar mais testes nos parâmetros de inversão.

Dos modelos prediletos foi possivel estabelecer relações destes modelos com estudos geológicos e geofísicos anteriores. Sobre a parte mais rasa do perfil, notou-se uma possível variação da profundidade do embasamento da Bacia do Paraná na área de estudo. O espessamento do pacote sedimentar pode está relacionado com a existência de um gráben soterrado. Uma interpretação alternativa sobre a anomalia condutivana base da bacia, é que esta anomalia esteja relacionada coma presença de fluidos salinos interconectados, indicando um embasamento localmente mais fraturado.

Sobre o par de anomalias condutivas em torno de $10 \mathrm{~km}$ de profundidade, na parte central do perfil, há duas hipóteses. A primeira hipótese sugere que, assim como a NACP do Orógeno Trans-Hudson, a PACA é uma anomalia constituída por múltiplos corpos condutivos. No caso dessa segunda hipótese, o condutor mais sul possuiria uma origem independente da PACA, possivelmente relacionada com a formação do rift Rio das Mortes. Mais estudos geofísicos e geológicos são necessários para discernir entre as duas hipóteses. 


\section{REFERÊNCIAS}

ALMEIDA, F. F. M. 1965. Geologia da Serra da Bodoquena: Mato Grosso. Rio de Janeiro: DNPM-DG

ALMEIDA, F. F. M. 1974. Sistema Tectônico Marginal do Cráton do Guaporé. In.: Congresso Brasileiro de Geologia, 28.,1974, Porto Alegre. Anais ... Porto Alegre: SBG, v.4. p.11-12.

ALMEIDA, F. F. M. 1985. Alguns problemas das relações geológicas entre o cráton amazônico e as faixas de dobramentos marginais a leste. In: Simposio de Geologia do Centro-Oeste, 2., 28-31 maio, Goiânia. Ata. Goiânia: SBG Núcleo Centro-Oeste, 1986. p. 314. il. Geologia do pré-cambriano.

ALMEIDA, F.F.M., 1986. Distribuição Regional e Relações Tectônicas do Magmatismo Pós-Paleozoico no Brasil. Rev. Bras. Geociencias 16 (4), 325-349.

ALMEIDA, F. F. M.; HASUI, Y., BRITO NEVES, B. B. 1977. The upper Precambrian of South America. Boletim IG/Universidade de São Paulo, v. 7, p. 45-80.

ALMEIDA, F. F. M.; HASUI, Y.; BRITO NEVES, B. B.; FUCK, R. 1981. Brazilian Structural Provinces: An Introduction. Earth Sciences Reviews, v. 17, p.1-29.

ALVARENGA, C. J. S. 1984. Dobramentos da Faixa Paraguai na borda sudeste do Cráton Amazônico. In: Congresso Brasileiro de Geologia, 33., 28 out. - 04 nov. 1984, Rio de Janeiro. Anais... Rio de Janeiro: SBG-Núcleo Rio de Janeiro, 1984. v.7, p.3258-3271.

ALVARENGA, C. J. S. 1990. Phenomenes sedimentaires, structuraux et circulation de fluides developpes a la transition chaine-craton: exemple de la chaine Paraguai d'age proterozoique superieur, Mato Grosso, Brèsil. Soutenue. 177f. Tese (Doutorado em Ciências)-Universite de Droit, d'Économie et des Sciences d'aix-Marselle, Faculte des Sciences et Techniques de St-Jerome, Soutenue, 1990.

ALVARENGA, C. J. S.; TROMPETTE, R. 1992. Glacial influenced turbidite sedimentation in the uppermost Proterozoic and Lower Cambrian of the Paraguay Belt (Mato Grosso, Brazil). Palaeogeography, Palaeoclimatology, Palaeoecology, v.92, p.85-105, DOI: 10.1016/0031 - 0182(92)90136-S.

ALVARENGA, C. J. S; TROMPETTE, R. 1993. Evolução tectônica Brasiliana da Faixa Paraguai: a estruturação da região de Cuiabá. Revista Brasileira de Geociências, São Paulo, v.23, n.1, p. 18-30, il.

ALVARENGA, C. J. S.; MOURA, C. A. V.; GORAYEB, P. S. S.; ABREU, F. A. M. 2000. Paraguay and Araguaia Belts, in Tectonic Evolution of South America. Edited by U. G. Cordani et al., pp. 183-193, 31st Int. Geol. Congress, Rio de Janeiro, Brazil.

ASSUMPÇÃO, M.; FENG, M.; TASSARA, A.; JULIÀ J. 2013. Models of crustal thickness for a South America from seismic refraction, receiver functions and surface wave tomography. Tectonophysics. v. 609. p. 82-96. 2013. 
ASSUMPÇÃO, M.; SACEK, V. 2013. Intra-plate seismicity and flexural stresses in central Brazil. Geophysical Research Letters, [s.1.], v. 40, n. 3, p.487-491, 11 fev. 2013. American Geophysical Union (AGU). http://dx.doi.org/10.1002/grl.50142

BAHR, K. 1988. Interpretation of the magnetotelluric impedance tensor: regional induction and local telluric distortion. Journal of Geophysics, 62(2): 119-127.

BARROS, A.M., SILVA, R.M., CARDOSO, O.R.F.A., FREIRE, F.A., DE SOUZA JR., J.J., RIVETTI, M., LUZ, D.S. DA PALMEIRA, R.C.B., TASSINARI, C.C.G. 1982. In: BRASIL. Departamento Nacional da Produção Mineral. Projeto RADAMBRASIL. Folha SD. 21 Cuiabá: geologia, geomorfologia, pedologia, vegetação e uso potencial da terra. Rio de Janeiro, p.25-192. il. color. (Levantamento de Recursos Naturais, 26)

BERDICHEVSKY, M. N.; ZHDANOV, M. S. 1984. Advanced theory of deep geomagnetic sounding. n. 19. Elsevier Science LTD. 1984.

BOERNER, D. E.; KURTZ, R. D.; CRAVEN, J. A. 1996. Electrical conductivity and PaleoProterozoic foredeeps. J. Geophys. Res., 101, 13,775- 13,791, doi:10.1029/96JB00171.

BOLOGNA, M. S.; NUNES, H. O.; PADILHA, A. L.; VITORELLO, I.; PÁDUA, M. B. 2013. Anomalous electrical structure in the northwestern Paraná Basin, Brazil, observed with broadband magnetotellurics. Journal Of South American Earth Sciences, [S.L.], v. 42, p. 7482, mar. 2013. Elsevier BV. http://dx.doi.org/10.1016/j.jsames.2012.07.006.

BOLOGNA, M. S.; PADILHA, A. L.; PÁDUA, M. B.; VITORELLO, I.; CHAMALAUN, F. H. 2014. Paraguay-Araguaia Belt Conductivity Anomaly: A fundamental tectonic boundary in South American Platform imaged by electromagnetic induction surveys. Geochemistry, Geophysics, Geosystems, [s.1.], v. 15, n. 3, p.509-515, mar. 2014. American Geophysical Union (AGU). http://dx.doi.org/10.1002/2013gc004970.

BOSTICK, F. 1977. A simple almost exact method of MT analysis. Salt Lake City, USA. 1977. In: Workshop on Electrical Methods in Geothermal Exploration, U.S. Geol. Survey contract no. 14080001-8-359. 26

BRITO NEVES, B. B.; CORDANI, U. G. 1991. Tectonic evolution of South America during the late Proterozoic. Precambrian Research., v.53, p.23 - 40.

BRITO NEVES, B.B. DE; FUCK, R.A.; CORDANI, U.G. AND THOMAZ FILHO, A. 1984. Influence of basement structures on the evolution of major sedimentry basins of Brazil: a case of tectonic heritage. J. Geod., v.1, n.3/5, p.495-510.

BRITO NEVES, B.B.; CAMPOS NETO, M.C.; FUCK, R.A. 1999. From Rodinia to Western Gondwana: an approach to the Brasiliano-Pan African Cycle and orogenic collage. Episodes, v.22, n.3, p.155-166.

CAGNIARD, L. 1953. Basic theory of the magneto-telluric method of geophysical prospecting. 1953. Geophysics, v. 18, p.605-635.

CALDWELL, T. G.; BIBBT, H. M.; BROWN, C. 2004. The magnetotelluric phase tensor. Geophys. J. Int., 158, 457-469. 2004. Doi: 10.111/j.1365-246X.2004.02281.x 
CAMPANHA G.A.C., BOGGIANI P.C., FILHO W.S., SÁ F.R., ZUQUIM M.P.S., PLACENTINI T. 2011. A Faixa de Dobramentos Paraguai na Serra da Bodoquena e Depressão do Rio Miranda, Mato Grosso do Sul. São Paulo, Geologia USP, Série Científica, 11(3):79-96.

CONSTABLE, S. C.; PARKER, R. L.; CONSTABLE, C. G. 1987. Occam's inversion: A practical algorithm for generating smooth models from electromagnetic sounding data. Geophysics, v. 52, n 3, p. 289-300, mar. 1987. http://dx.doi.org/10.1190/1.1442303.

CORDANI, U.G., BRITO NEVES, B.B., FILHO, A.T., 2009. Estudo preliminar de integração do Pré-cambriano com os eventos tectonicos das bacias sedimentares brasileiras (atualização). Bol. Geociências Petrobras 17 (1), 205-219.

CORDANI, U. G.; RAMOS, V. A.; FRAGA, L. M.; CEGARRA, M.; DELGADO, I.; DE SOUZA, K. G.; GOMES, F. E. M.; SCHOBBENHAUS, C. 2016. Tectonic Map of South America at 1:5.9 M, CGMW-CPRM-SEGEMAR. 2016. Printed by Gilbert Clarey Imprimeurs, Chambray-lès-Tours, France.

CURTO, J. B.; VIDOTTI, R. M.; FUCK, R. A.; BLAKELY, R. J.; ALVARENGA, C. J. S.; DANTAS, E. L. 2014. The tectonic evolution of the Transbrasiliano Lineament in northern Paraná Basin, Brazil, as inferred from aeromagnetic data. Journal of Geophysical Research: Solid Earth, v. 119, p. 1544-1562, 2014.

EGBERT, G. D. 1997. Robust multiple-station magnetotelluric data processing. Geophysical Journal International, v.130, p.475-496.

EGBERT, G. D.; BOOKER, J. R. 1986. Robust estimation of geomagnetic transfer functions. Geophysical Journal of the Royal Astronomical Society. v. 87. n. 1. p. 173-194.

ERNST, T.; BRASSE, H.; CERV, V.; HOFFMANN, N.; JANKOWSKI, J.; JOZWIAK, W.; KREUTZMANN, A.; NESKA, A.; PALSHIN, N.; PEDERSEN, L. B.; SMIRNOV, M.; SOKOLOVA, E.; SMIRNOV, M. 2008; Electromagnetic images of the deep structure of the Trans-European Suture Zone beneath Polish Pomerania. Geophys Res Lett 35(15):L15307.

EVANS, R. L.; BENOIT, M. H.; LONG, M. D.; ELSENBECK, J.; FORD, H. A.; ZHU, J.; GARCIA, X. 2019. Thin lithosphere beneath the central Appalachian Mountains: a combined seismic and magnetotelluric study. Earth And Planetary Science Letters, [S.L.], v. 519, p. 308-316, ago. 2019. Elsevier BV. http://dx.doi.org/10.1016/j.epsl.2019.04.046.

FONTES, S. L. 2010. O Método Magnetotelúrico: Fundamentos, resultados e simulações na bacia do Paraná. Rio de Janeiro: Observatório Nacional, 2010. 43 slides, color.

GIBSON, S.A.; THOMPSON, R.N.; WESKA, R.K.; DICKIN, A.P.; LEONARDOS, O.H. 1997. Late Cretaceous rift-related upwelling and melting of the Trindade starting mantle plume head beneath western Brazil. Contrib. Mineral. Petrol. 126 (3), 303-314. https://doi.org/10.1007/s004100050252. 
GROOM, R. W.; BAILEY, R. C. 1989. Decomposition of the magnetotelluric impedance tensor in the presence of local tree-dimensional galvanic distortion. J. Geophys. Res. Vol 94:B2:p 1913-1925.

GROOM, R. W.; KURTZ, R. D.; JONES, A. G.; BOERNER, D. E. 1993. A quantitative methodology to extract regional magnetotelluric impedances and determine the dimension of the conductivity structure. Geophysical Journal International, 115: 1095-1118. doi: 10.1111/j.1365-246X.1993.tb01512.x

JAMES, F. L. 2013. (United States). Smithsonian (Ed.).; EARTH: The Definitive Visual Guide. 2. ed. New York: Dk Publishing, 2013. 525 p.

JIRACEK, G., HAAK, V., OLSEN, K., 2006. Practical magnetotellurics in a continental rift environment. In: Developments in Geotectonics, v. 25, Elsevier, pp. 103-129.

JONES, A. G. 1983. On the equivalence of the Niblett and Bostick transformations in the magnetotelluric method. Journal of Geophysics, 53: 72-73.

JONES, A. G. 1988. Static Shift of magnetotelluric data and its removal in a sedimentar basin environment. 1988. Geophysics, v. 53 (7), p.967-978.

JONES, A. G. 1992. Electrical conductivity of the continental lower crust. In: Fountain DM, ARCULUS, R. J.; KAY, R. W.; ed. Continental lower crust. Amsterdam: Elsevier, 1992. 23(3): p.81-143

JONES, A. G. 2012 Distortion of magnetotelluric data: its identification and removal. In: CHAVE, A. D.; JONES, A. G. The Magnetotelluric Method: Theory and practice. 1. Ed. Nova York: Cambridge University Press, 2012. Cap. 6. p. 219-302.

JONES, A. G.; CRAVEN, J. A.; MCNEICE, G. W.; FERGUNSON, I. J.; BOYCE, T.; FARQUARSON, C.; ELIS, R. G. 1993. North American Central Plains conductivity anomaly within the Trans-Hudson orogen in northern Saskatchewan. Canada, Geology, 21, 1027-1030.

KAUFMAN, A. A.; KELLER, G. V. 1981. The magnetotelluric sounding method. In Methods in Geochemistry and Geophysics. Elsevier Scientific Publ., Amsterdam, 1981.

LITHERLAND, M. et al. 1986. The geology and mineral resources of the Bolivian precambrian shield. London, Bristhish Geological Survey, Overseas Memoir 9, 1986. 153p. (Natural Environment Research Council).

LOGVINOV, I. M.; TARASOV, V. N. 2018. Electric resistivity distribution in the Earth's crust and upper mantle for the southern East European Platform and Crimea from areawide 2D models. Acta Geophysica, 10.1007/s11600-018-0125-2, 66, 2, 131-139, 2018.

MARTÍ, A.; QUERALTI, P.; LEDO, J. 2009. WALDIM: A code for the dimensionality analysis of magnetotelluric data using the rotational invariants of the magnetotelluric tensor. 2009. Computers and Geosciences, v. 35, p.2295-2303. 
MCNEICE, G. W.; JONES, A. G. 2001. Multisite, multifrequency tensor decomposition of magnetotelluric data. Geophysics. 66, 158-173, doi:10.1190/1.1444891.

MENEZES, P. T. L. 2013. Fundamentos do Método Magnetotelúrico na exploração de Hidrocarbonetos. Rio de Janeiro. SBGF. 2013.

MEYER, B.; SALTUS, R.; CHULLIAT, A. 2017. EMAG2v3: Earth Magnetic Anomaly Grid (2-arc-minute resolution). Version 3. NOAA National Centers for Environmental Information. https://doi.org/10.7289/V5H70CVX.

MILANI, E. J. 1997. Evolução tectono-estratigráfica da Bacia do Paraná e seu relacionamento com a geodinâmica fanerozóica do Gondwana Sul-ocidental. Tese de Doutorado - Universidade Federal do Rio Grande do Sul, Porto Alegre, 2v, 1997.

MILANI, E. J. 2004. Comentários sobre a origem e a evolução tectônica da Bacia do Paraná. In: Mantesso-Neto, V.; Bartorelli, A.; Carneiro, C.D.R.; Brito Neves, B.B. (Eds.), Geologia do Continente Sul-Americano. Beca, Brazil, pp. 265-280.

MILANI, E. J.; RAMOS, V. 1998. Orogenias paleozoicas no domínio sul-ocidental do Gondwana e os ciclos de subsidência da Bacia do Paraná. Revista Brasileira de Geociências, v. 28, n. 4 , p. $473-484,1998$.

MILANI, E. J.; MELO, J. H. G.; SOUZA, P. A.; FERNANDES, L. A.; FRANÇA, A. B. 2007. Bacia do Paraná. Boletim de Geociências da Petrobrás. v.15(2). p. 265-287.

NAGANJANEYULU, K.; SANTOSH, M. 2011. Crustal architecture beneath Madurai Block, southern India deduced from magnetotelluric studies: Implications for subductionaccretion tectonics associated with Gondwana assembly. J. Asian Earth Sci., 40, 132-143, doi:10.1016/j.jseaes.2010.08.014.

NIBLETT, E. R.; SAYAN-WITTGENSTEIN, C. 1960. Variation of electrical conductivity with depth by the magneto-telluric method. Geophysics, 25: 998-1008

OLIVA, L.A. et al. 1979. In BRASIL. DNPM. Carta Geológica do Brasil ao Milionésimo; folha SD.21- Cuiabá. Brasília, 1979.

OSBORNE, G. C. 2001. Geotectonics and Mineralization in the Ophiolite Assemblages of the Arl Basin, Paraguaia Marginal Basin, Pará and Tocantins States, Central Brasil. In: Simpósio de Geologia da Amazônia, 7. Resumos Expandidos. Belém: SBG. Núcleo Norte, 2001. CD Rom.

PADILHA, A. L.; VITORELLO, I.; PÁDUA, M. B. 2015. Imaging three-dimensional crustal conductivity structures reflecting continental flood basalt effects hidden beneath thick intracratonic sedimentary basin. Journal of Geophysical Research: Solid Earth, v. 120, n. 1, p. $4702-4719$.

PALACKY, G. 1988. Resistivity characteristics of geologic targets. Electromagnetic methods in applied geophysics. v. 1. p. 53-130. 
PARKER, R. L.; BOOKER, J. R. 1996. Optimal One-Dimensional inversion and bounding of magnetotelluric apparent resistivity and phase measurement. Physics of earth and planetary interior, 1996. p.269-282

PARKINSON, W. D. 1959. Directions of Rapid Geomagnetic Fluctuations. Geophysical Journal International, [s.1.], v. 2, n. 1, p.1-14, mar. 1959. Oxford University Press (OUP). http://dx.doi.org/10.1111/j.1365-246x.1959.tb05776.x.

QUINTAS, M.C.L.; MANTOVANI, M.S.M.; ZALÁN, P.V. 1999. Contribuição ao estudo da evolução mecânica da Bacia do Paraná. Revista Brasileira de Geociências. v.29, n.2, p.217-226.

SCHOBBENHAUS FILHO, C.; OLIVA, L. A. 1979. Carta geológica do Brasil ao milionésimo Corumbá SE.21. [s.1.]: DNPM, Escala 1:1.000.000, Impresso.

SCHOBBENHAUS FILHO, C.; CAMPOS, D. A.; DERZE, G. R.; ASMUS, H. E. 1981. Mapa Geológico do Brasil e da Área Oceânica Adjacente Incluindo Depósitos Minerais - Escala 1/2.500.000. Brasília, DNPM.

SCHOBBENHAUS FILHO, C.; CAMPOS, D. A.; DERZE, G. R.; ASMUS, H. E. 1984. Geologia do Brasil. Texto Explicativo do Mapa Geológico do Brasil e da Área Oceânica Adjacente Incluindo Depósitos Minerais. Brasília, DNPM. 501 p.

SCHOBBENHAUS FILHO, C.; GONCALVES, J. H.; SANTOS, J.O.S.; ABRAM, M. B.; LEAO NETO, R.; MATOS, G. M. M.; VIDOTTI, R. M. 2003. Carta geologica do Brasil ao milionesimo, Programa levantamentos geologicos Basicos do Brasil. In: In: Bizzi, L.A., Schobbenhaus, C., Vidotti, R.M., Goncalves, J.H. (Eds.), Geologia, Tectonica e Recursos Minerais do Brasil. vol. 35 Servico Geologico do Brasil (CPRM), Brazil CD-ROMs).

SELWAY, K.; HAND, M.; HEINSON, G. S.; PAYNE, J. L. 2009. Magnetotelluric constraints on subduction polarity: Reversing reconstruction models for Proterozoic Australia, Geology, 37, 799- 802, doi:10.1130/G30175A.1.

SIMPSON, F.; BAHR, K. 2005. Practical Magnetotellurics. Cambridge: Cambridge University Press, 2005. 270 p.

SIRIPUNVARAPORN, W.; EGBERT, G. 2000. An efficient data-subspace inversion method for 2-d magnetotelluric data. Geophysics, v. 65, n. 1, p. 791-803, 2000.

SIRIPUNVARAPORN, W.; EGBERT, G. 2009. WSINV3DMT: Vertical magnetic field transfer function inversion and parallel implementation. Physics of the Earth and Planetary Interiors, v. 173, n. 2, p. 317-329, 2009.

STRIEDER, A. J.; NILSON, A. A. 1993. Análise preliminar de lineamentos na Província Estrutural do Tocantins. In: SIMP. NAC. EST. TECT., 4, Belo Horizonte, 1993. Anais...Belo Horizonte, SBG, p.272-275.

STROPPER, J. L. 2014. Petrologia do complexo alcalino Planalto da Serra - MT. xii, 74 f., il. Dissertação (Mestrado em Geologia) - Universidade de Brasília, Brasília, 2014. 
SWIFT, C. M. 1967. Magnetotelluric investigation of electrical conductivity anomaly in the southwestern. United States: PhD thesis, MIT, Cambridge, MA.

TIKHONOV, A. 1950. On determining electrical characteristics of the deep layers of the earth's crust. Doklady Akademii Nauk SSSR, v. 73, p.295-297.

TROMPETTE, R. 1994. Geology of Western Gondwana (2000-500 Ma)_Pan-African Brasiliano Aggregation of South America and Africa. 350 pp., A. A. Brakeman, Rotterdam, Netherlands

UNSWORTH, M. J.; MALIN, P. E.; EGBERT, G. D.; BOOKER, J. R. 1997. Internal structure of the San Andreas fault at Parkfield, California. Geology, v. 25, p. 359-362.

VAN DER MEIJDE, M.; JULIÀ, J.; ASSUMPÇÃO, M. 2013. Gravity derived Moho for South America. Tectonophysics, 609, 456-467, doi:10.1016/j.tecto.2013.03.023.

VIDOTTI, R. M; EBINGER, C. J; FAIRHEAD, J. D. 1998. Gravity signature of the western Paraná basin, Brazil. Earth and Planetary Science Letters, [S.L.], v. 159, n. 3-4, p. 117-132, jun. 1998. Elsevier BV. http://dx.doi.org/10.1016/s0012-821x(98)00070-3.

VOZOFF, D. 1991. The magnetotelluric method, in M. N. Nabighian (ed.), Electromagnetic Methods in Applied Geophysics. v. 2, 1991. p. 641-711.

WEAVER, J. T.; AGARWAL, A. K.; LILLEY F. E. M. 2000. Characterization of the magnetotelluric tensor in terms of its invariants. Geophysical Journal Internacional. 2000. v. 141. p. 321-336. 
APÊNDICE A - Curvas de Resistividade Aparente e Fase
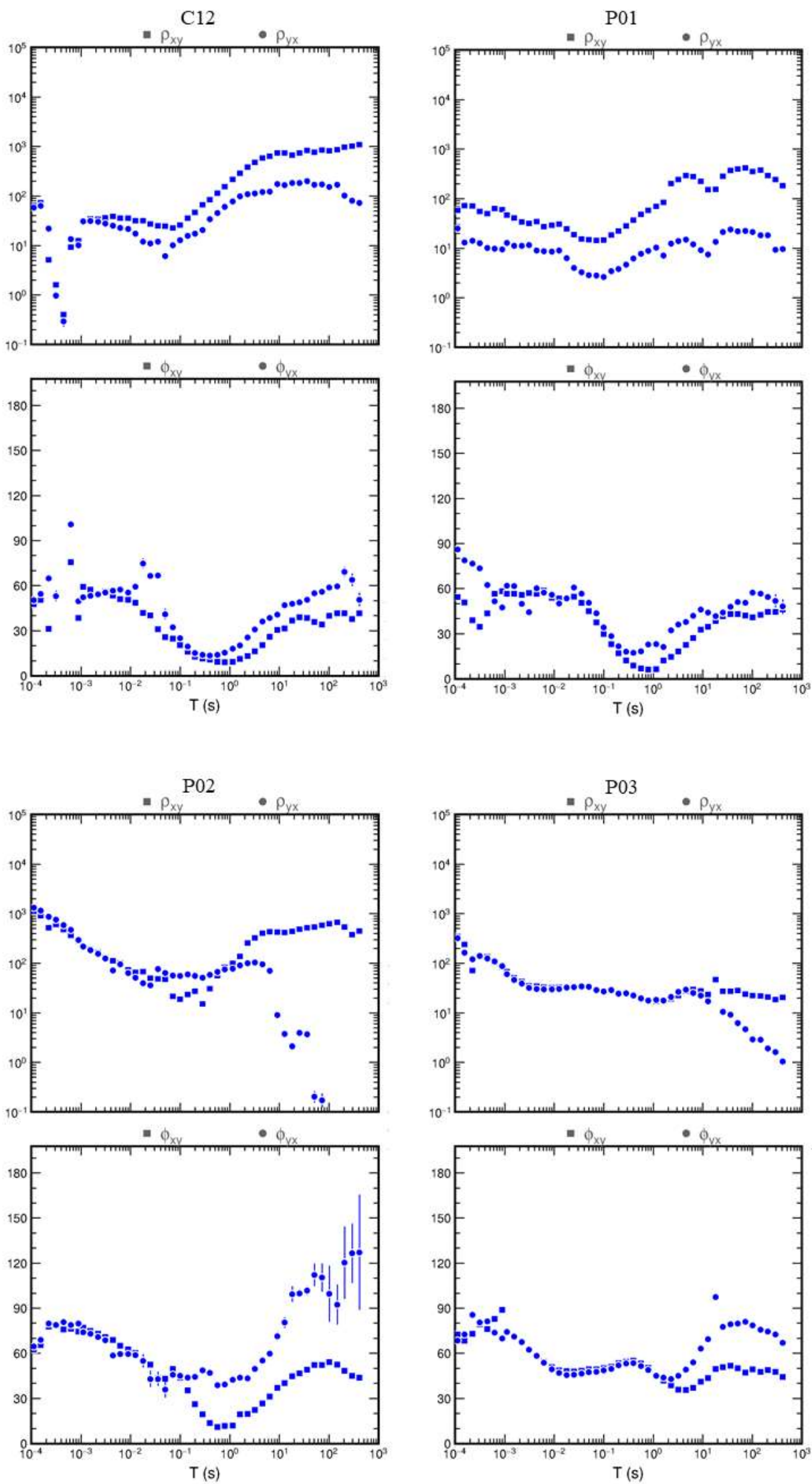

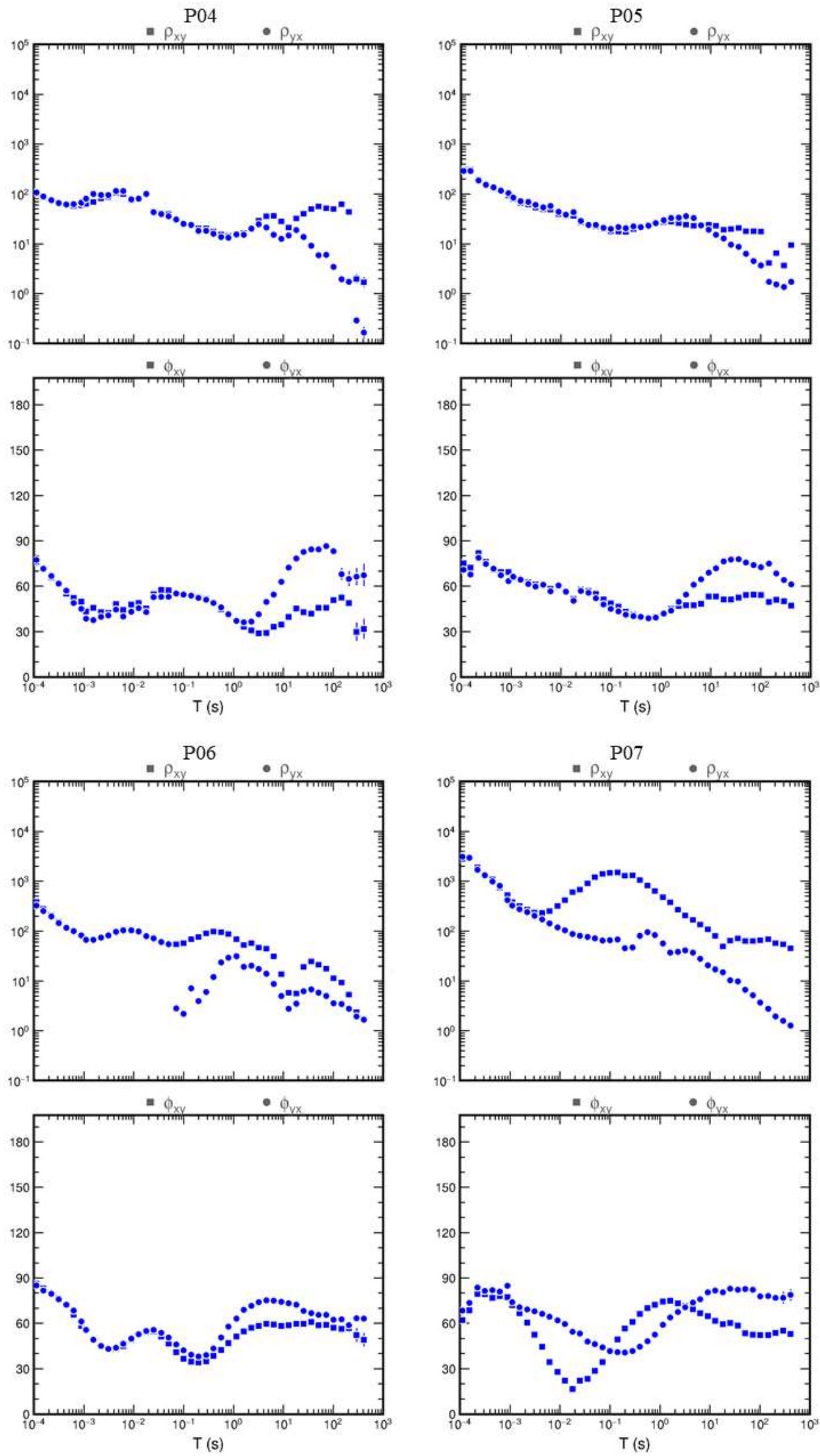

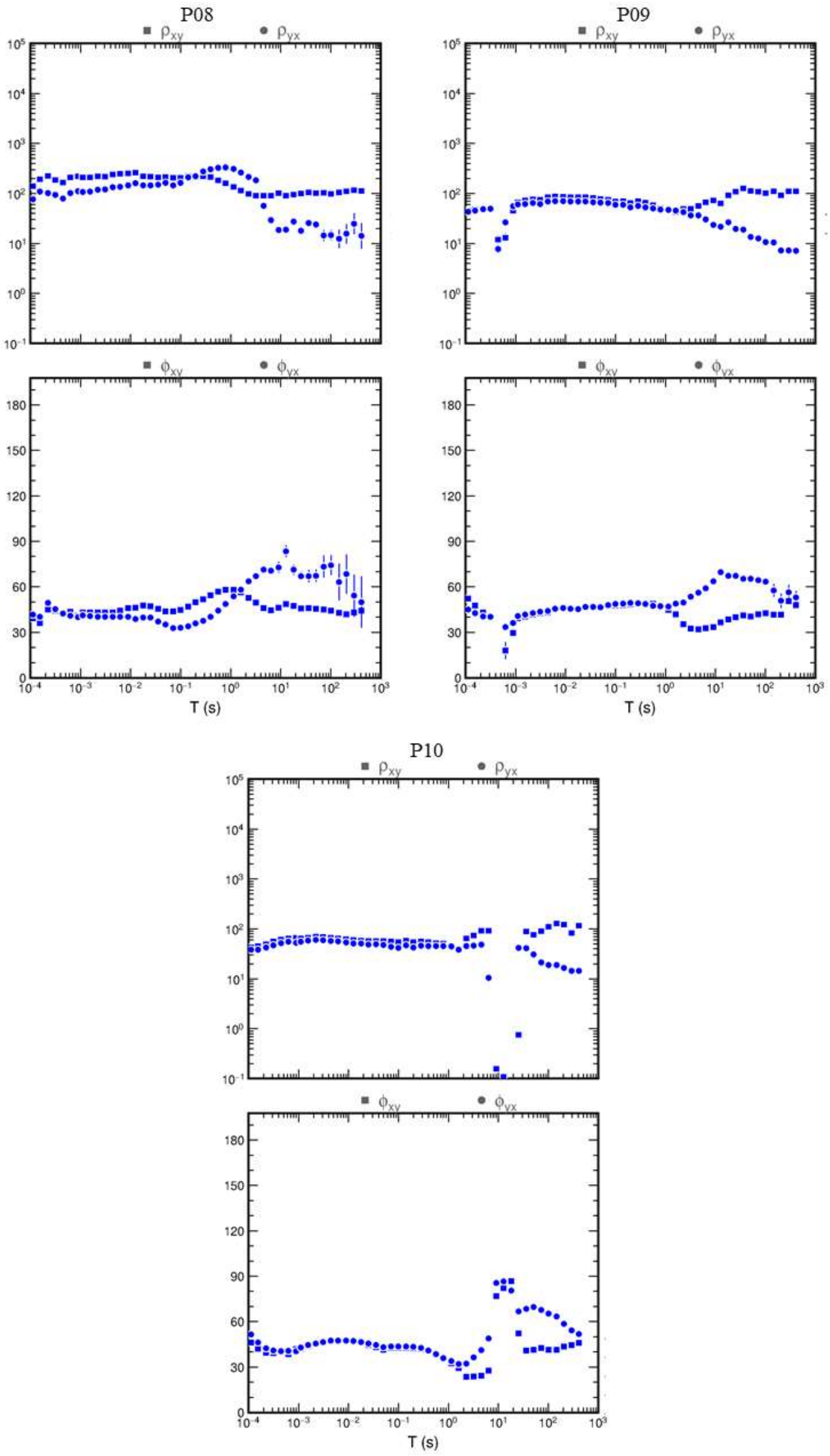


\section{APÊNDICE B - Teste dos Parâmetros: Inversão TE+TM}

Aqui, é disponibilizado os resultados intermediários para a inversão dos modos TE e TM simultaneamente. Correção automática do static shift, realizado pelo programa REBOCC, habilitando todas as estações em ambos os modos. Em $\mathbf{X}$ estão os resultados para o error floor igual a $12 \%$ (resistividade aparente) e $4 \%$ (fase) e em $\mathbf{Y}$, os resultados para o error floor de $25 \%$ para a resistividade aparente e $5 \%$ para a fase.

Além da correção automática, optou-se também, por testar uma correção manual do static shift na estação P08. Primeiro, realizou-se uma média geométrica que resultou na soma de um fator de 0,1476 na resistividade aparente do modo TE e na subtração de 0,1583 na resistividade aparente do modo TM (resultados disponíveis em A). Em B , testou-se somar os valores de resistividade aparente do modo TE com um fator de 0,25 para "subir" a curva de resistividade aparente do modo TE para um nível próximo da curva do modo TM na escala de valores de resistividade aparente. A última tentativa foi "descer" a curva de resistividade aparente do modo TM para um nível próximo da curva do modo TE. Assim, foi subtraído um fator de 0,3 dos valores de resistividade aparente do modo TM, esses resultados estão em $\mathbf{C}$. Foram utilizados dados com error floor de 25\% (resistividade aparente) e 5\% (fase).

Tabela 2: Valores de RMS para os resultados intermediários para a inversão simultânea dos modos TE e TM.

\begin{tabular}{|c|c|c|c|c|c|c|}
\cline { 3 - 7 } \multicolumn{2}{c}{} & \multicolumn{5}{c|}{ RMS } \\
\hline Item & Modelo & $\mathbf{X}$ & $\mathbf{Y}$ & $\mathbf{A}$ & $\mathbf{B}$ & $\mathbf{C}$ \\
\hline $\mathbf{a}$ & 1 & 1,9984 & 1,5091 & 2,2908 & 2,2562 & 3,0810 \\
\hline $\mathbf{b}$ & 2 & 2,0687 & 1,8030 & 1,7421 & 1,8178 & 1,6934 \\
\hline $\mathbf{c}$ & 3 & 3,0280 & 1,8254 & 1,9522 & 2,0134 & 1,8879 \\
\hline $\mathbf{d}$ & 4 & 1,9810 & 1,6136 & 2,6118 & 2,4868 & 2,6183 \\
\hline $\mathbf{e}$ & 5 & 1,9975 & 1,8125 & 1,7389 & 1,8352 & 2,0133 \\
\hline $\mathbf{f}$ & 6 & 2,9378 & 1,8126 & 1,9254 & 1,9884 & 1,8603 \\
\hline $\mathbf{g}$ & 7 & 2,0554 & 1,5117 & 2,4326 & 2,3813 & 3,1258 \\
\hline $\mathbf{h}$ & 8 & 2,0871 & 1,7980 & 1,7572 & 1,8325 & 1,7111 \\
\hline $\mathbf{i}$ & 9 & 3,0826 & 1,8511 & 1,9632 & 2,0247 & 1,8986 \\
\hline $\mathbf{j}$ & 10 & 2,7344 & 1,8948 & 3,2823 & 3,7910 & 3,2797 \\
\hline $\mathbf{k}$ & 11 & 2,1239 & 1,9137 & 2,4560 & 2,5055 & 2,4031 \\
\hline $\mathbf{I}$ & 12 & 3,6466 & 2,3368 & 2,7632 & 2,8167 & 2,7291 \\
\hline $\mathbf{m}$ & 13 & 2,6097 & 1,8943 & 3,1744 & 3,1947 & 3,1678 \\
\hline $\mathbf{n}$ & 14 & 2,0477 & 1,9168 & 2,4167 & 2,4870 & 2,3493 \\
\hline $\mathbf{o}$ & 15 & 2,8329 & 2,3136 & 2,6902 & 2,7482 & 2,6521 \\
\hline $\mathbf{p}$ & 16 & 2,8443 & 1,5181 & 3,3409 & 3,2528 & 3,3414 \\
\hline $\mathbf{q}$ & 17 & 2,1460 & 1,5221 & 2,4643 & 2,7964 & 2,4187 \\
\hline $\mathbf{r}$ & 18 & 3,6695 & 2,3414 & 2,8089 & 2,8406 & 2,7772 \\
\hline
\end{tabular}


Modelos geoelétricos e ajustes de curvas resultantes de $\mathbf{X}$.
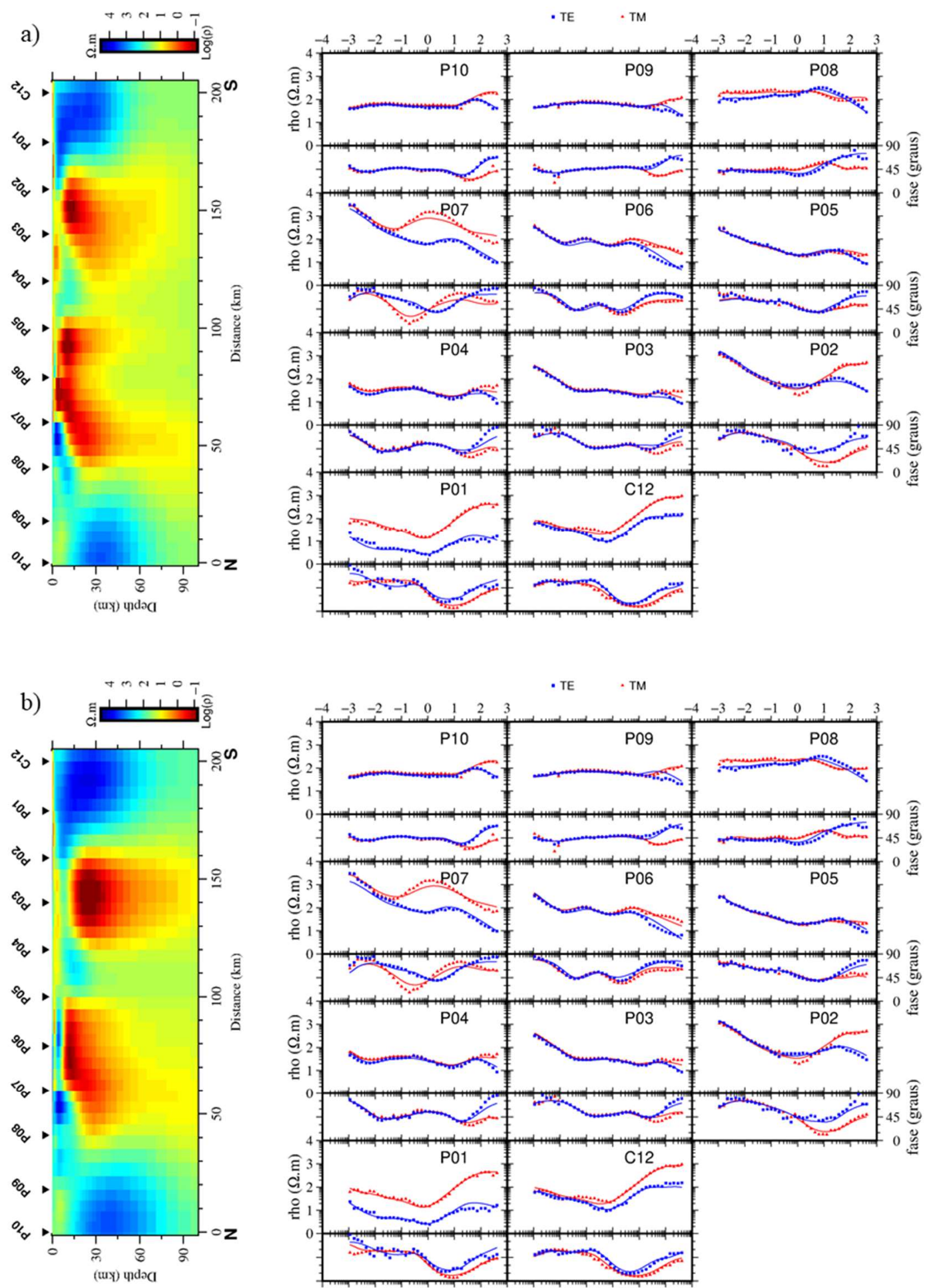

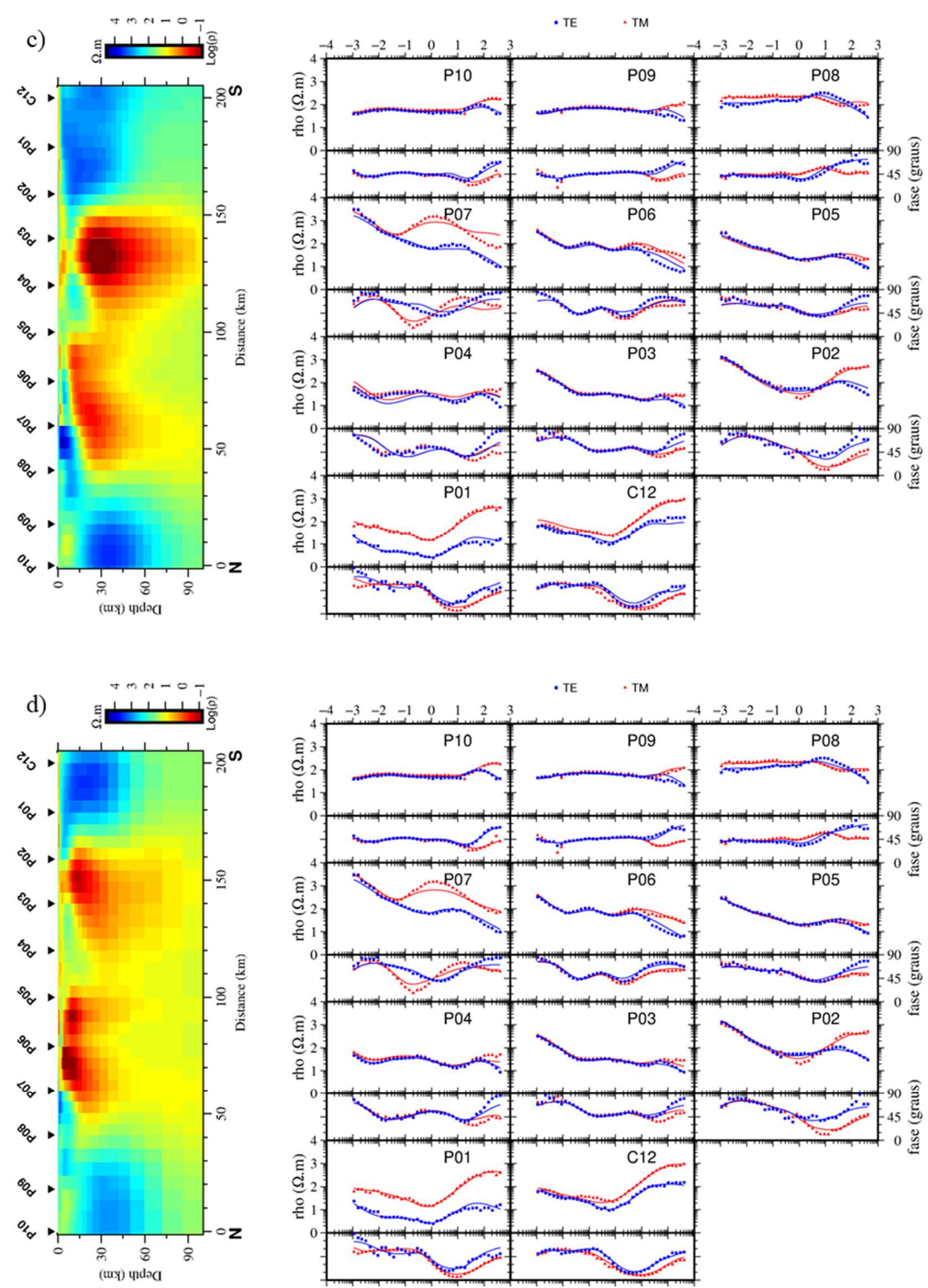

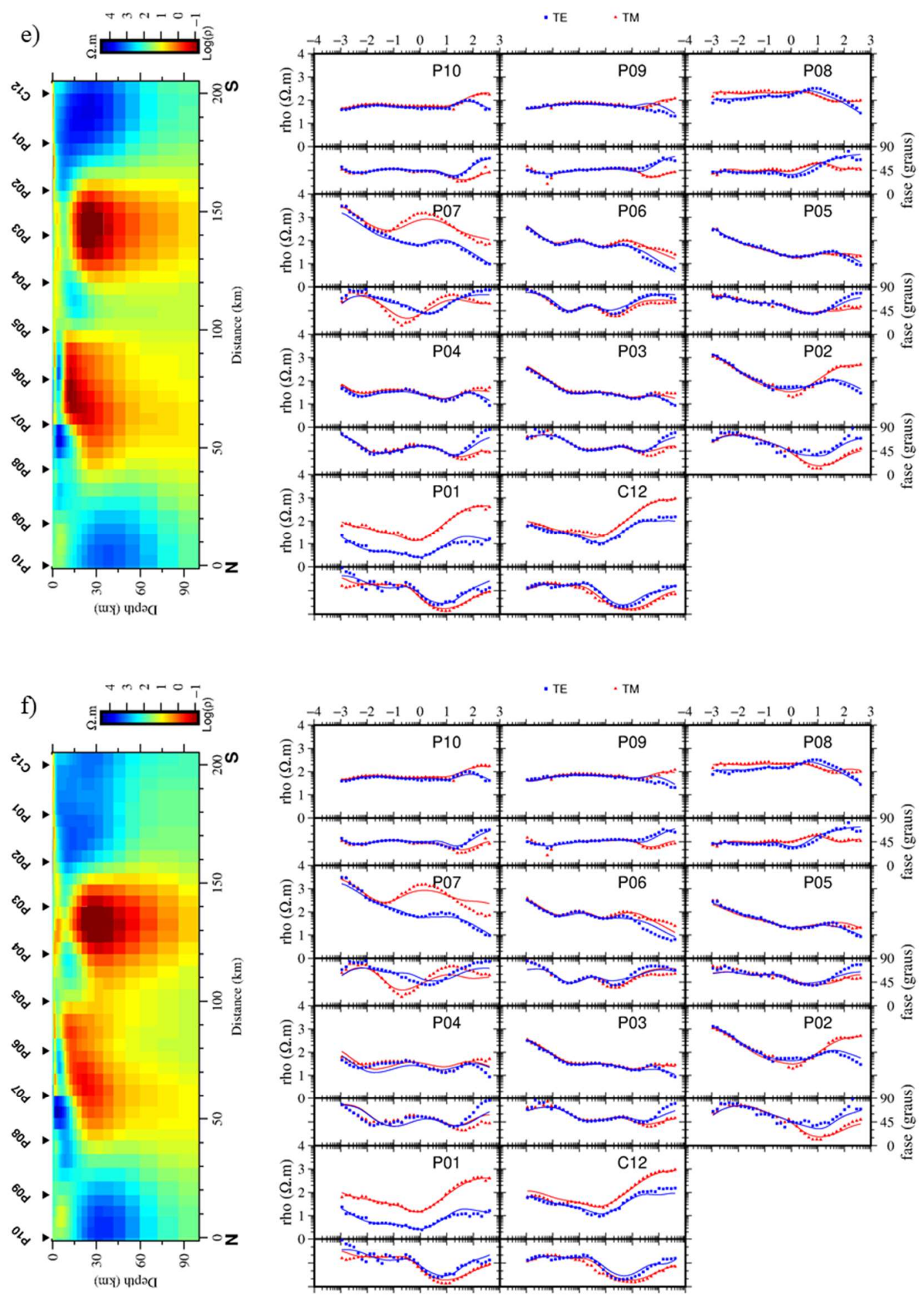

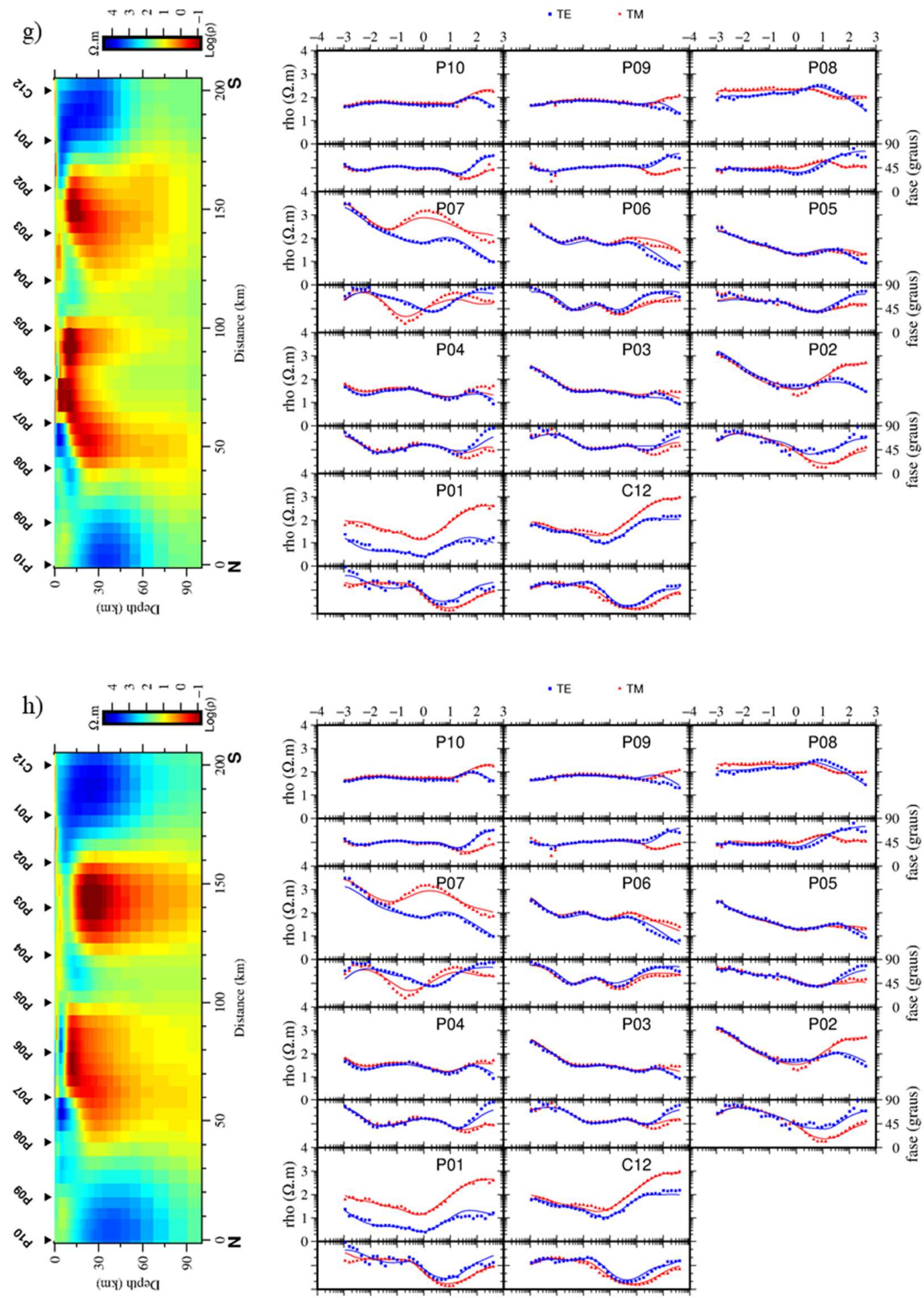

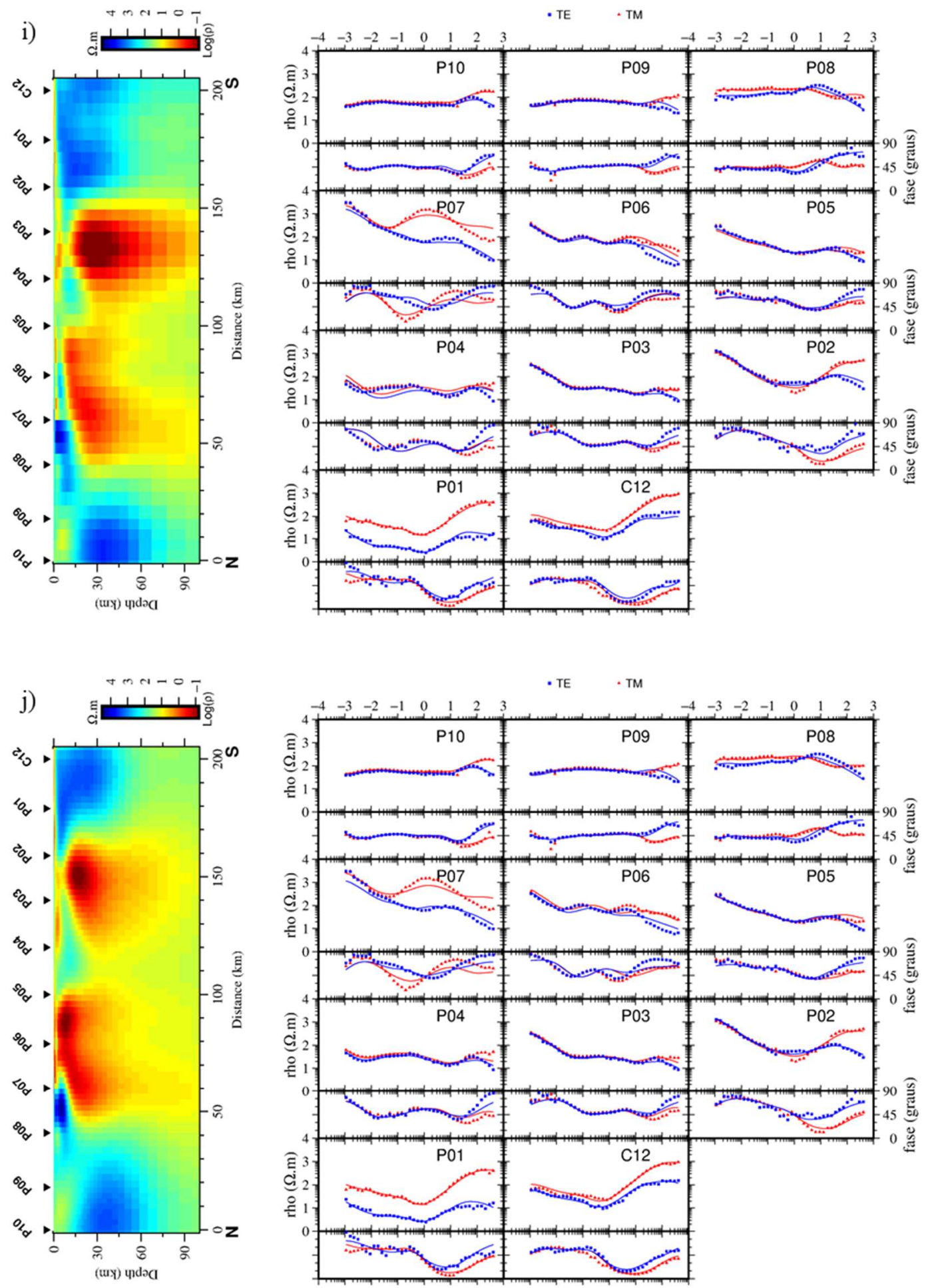

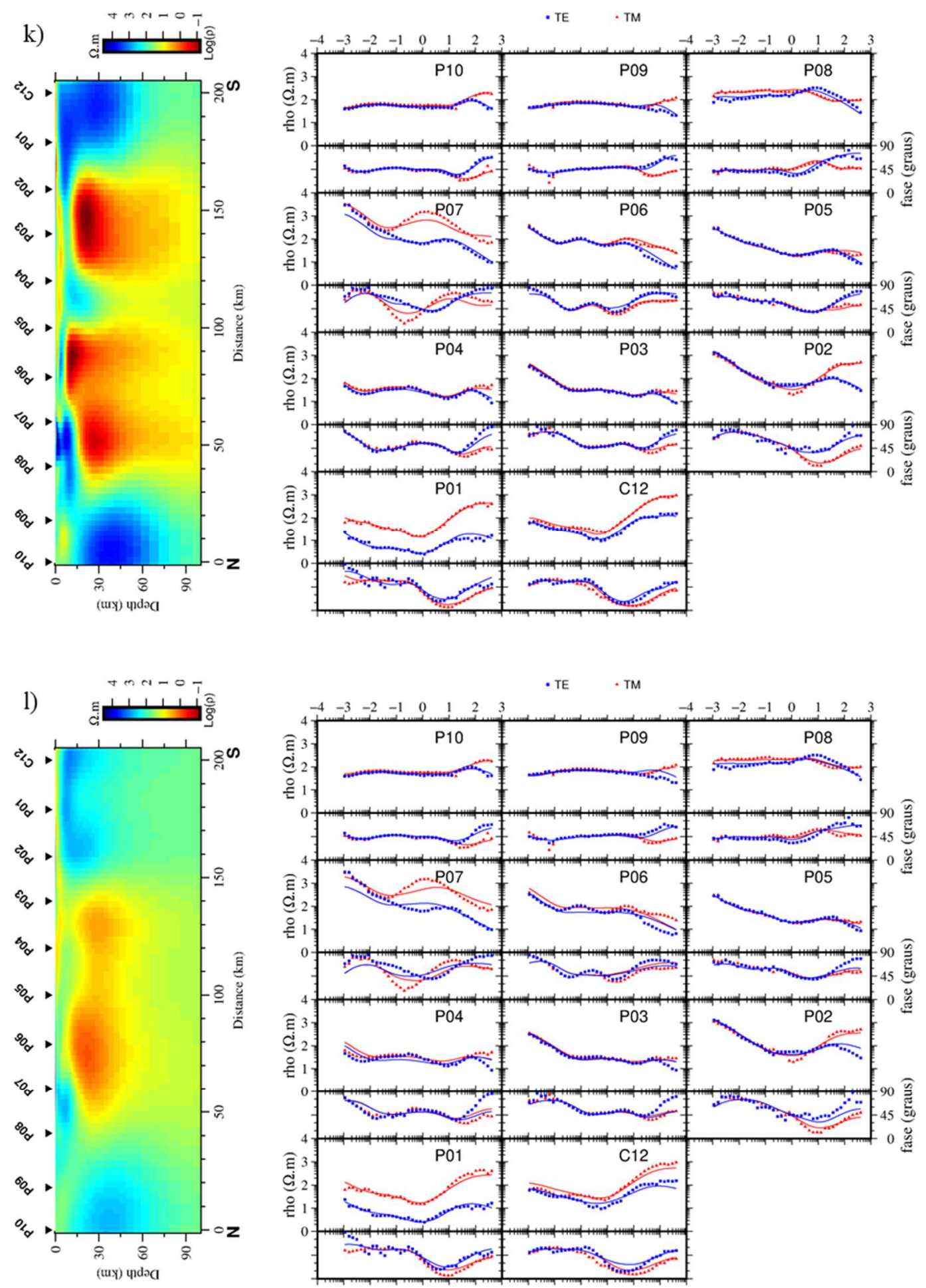

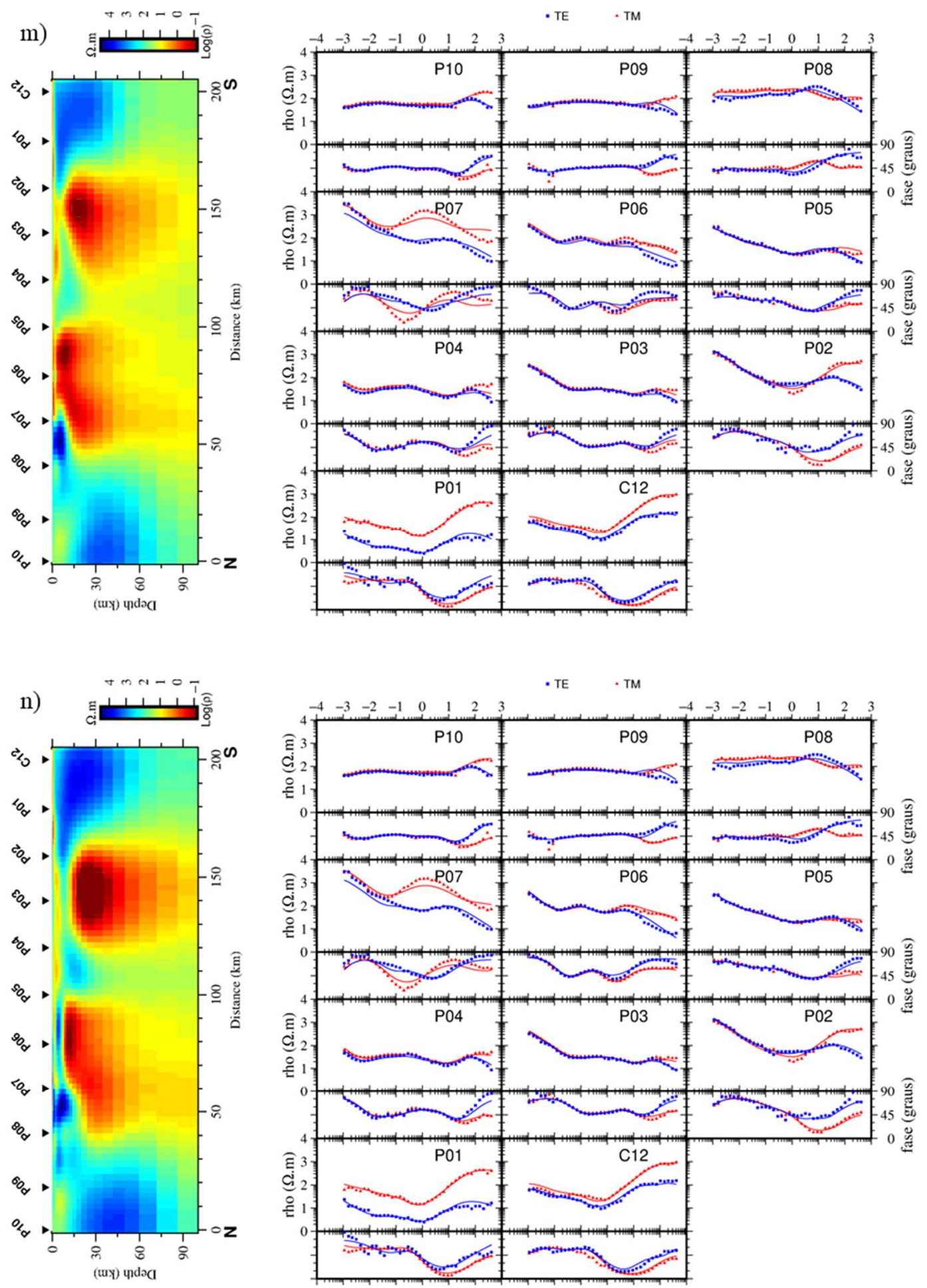

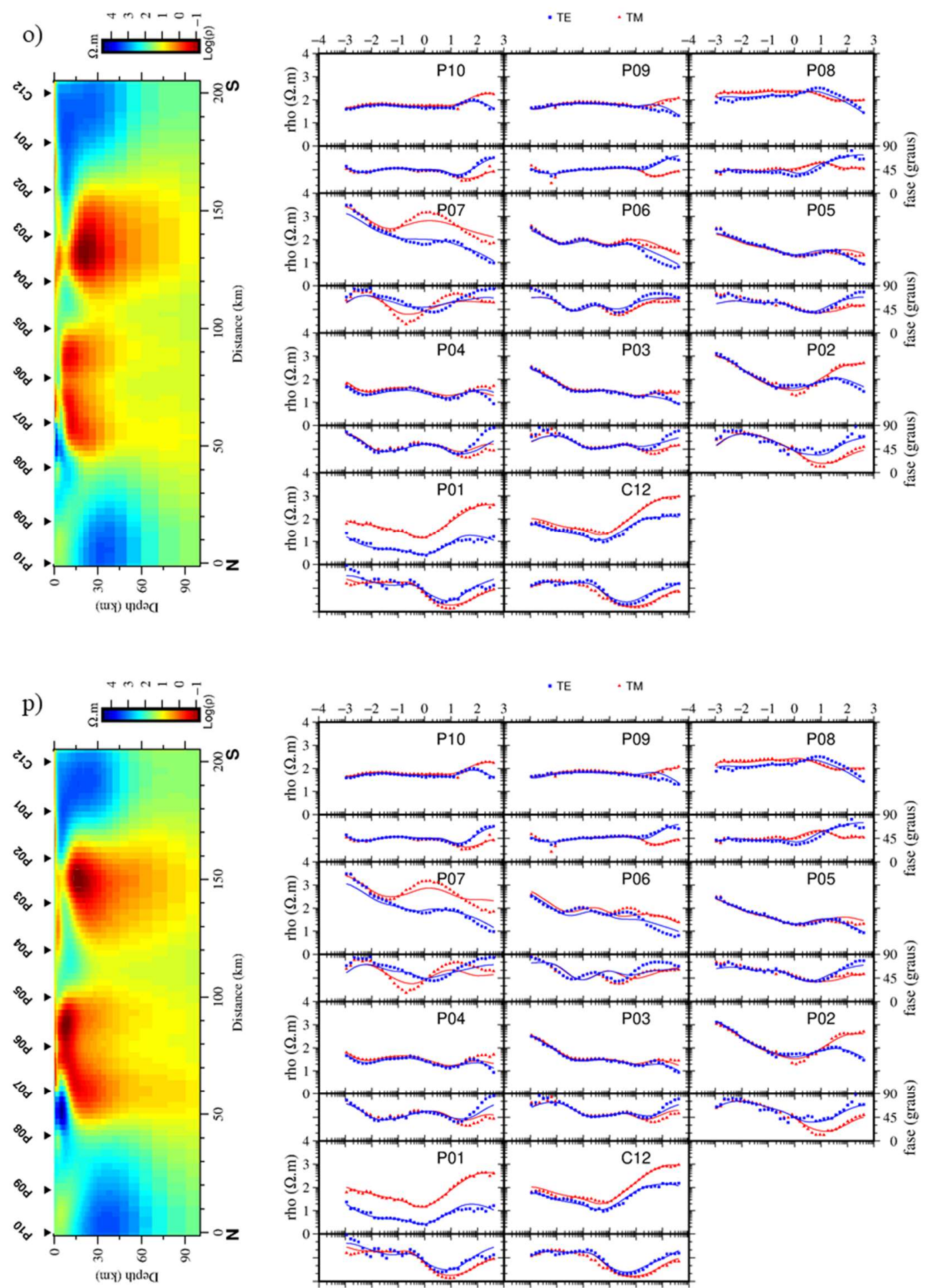

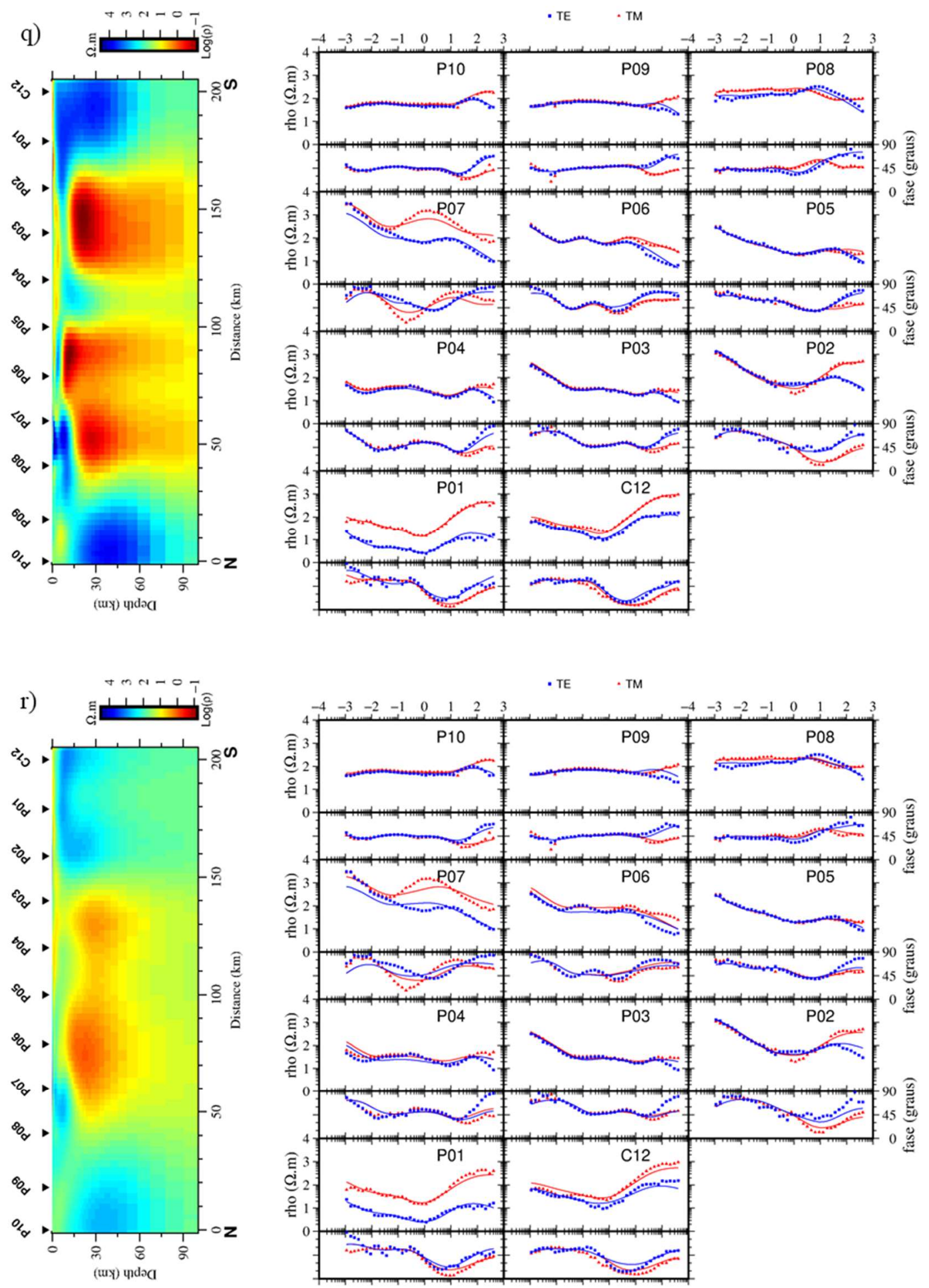
Modelos geoelétricos e ajustes de curvas resultantes de $\mathbf{Y}$.
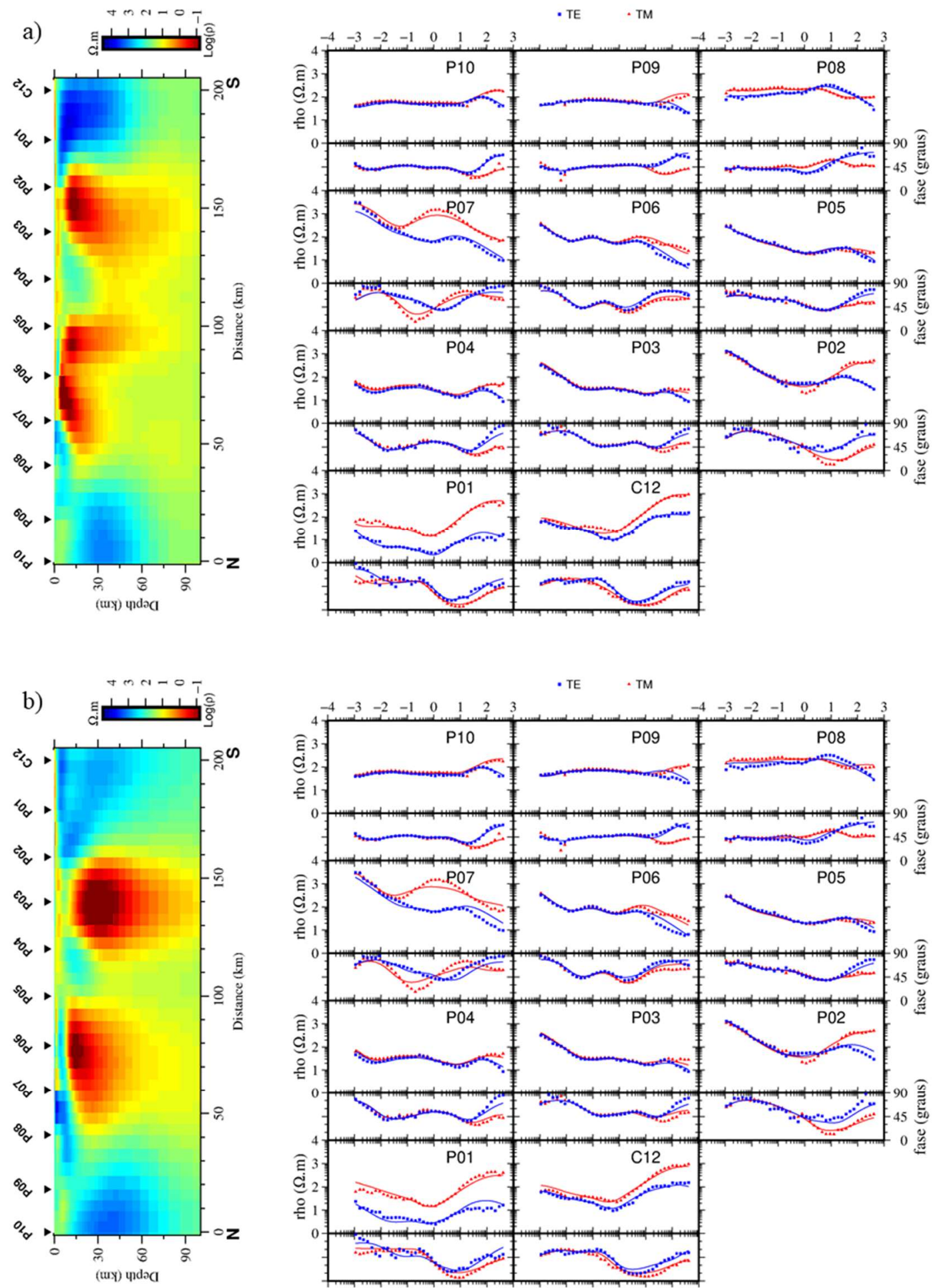

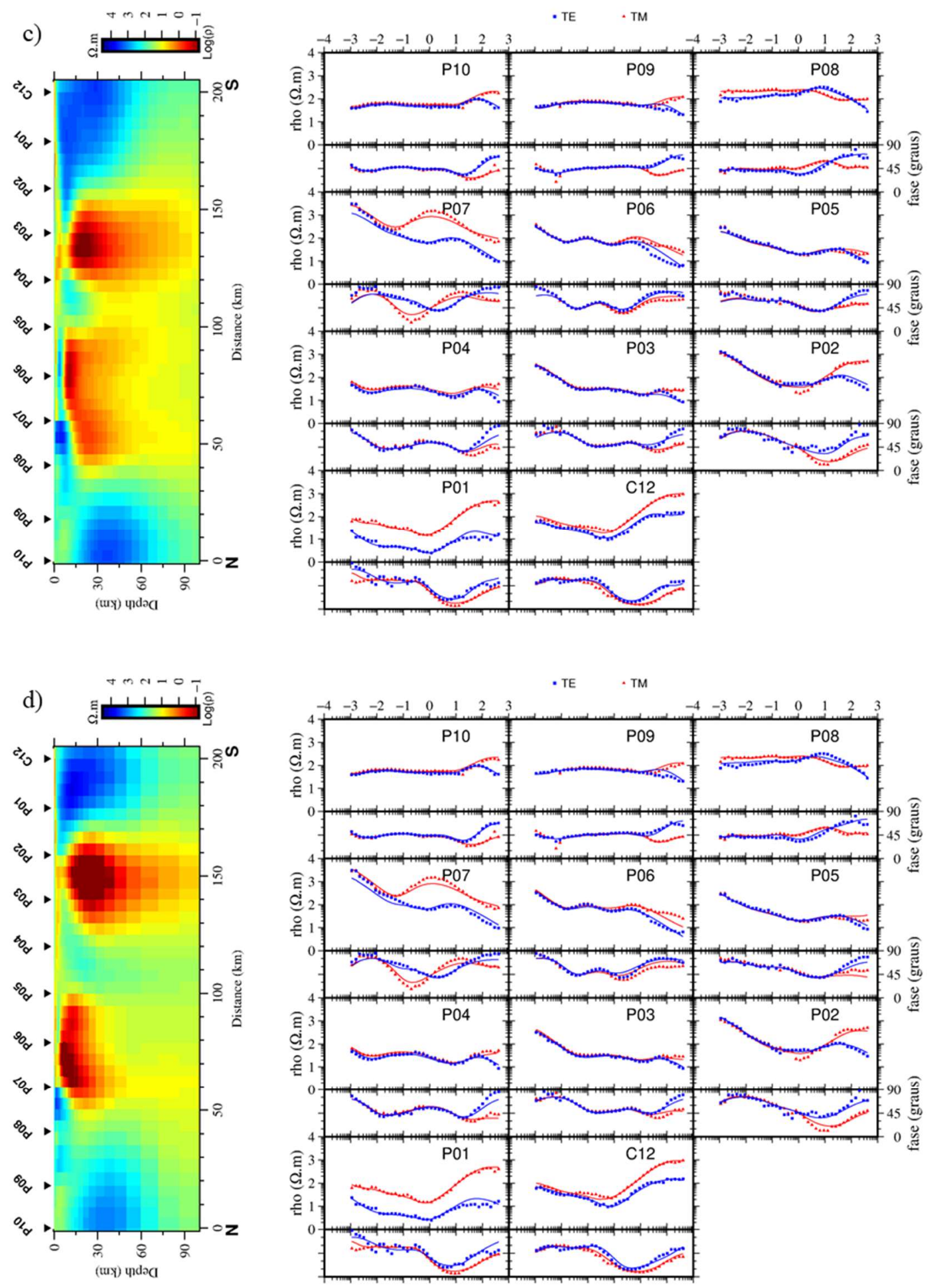

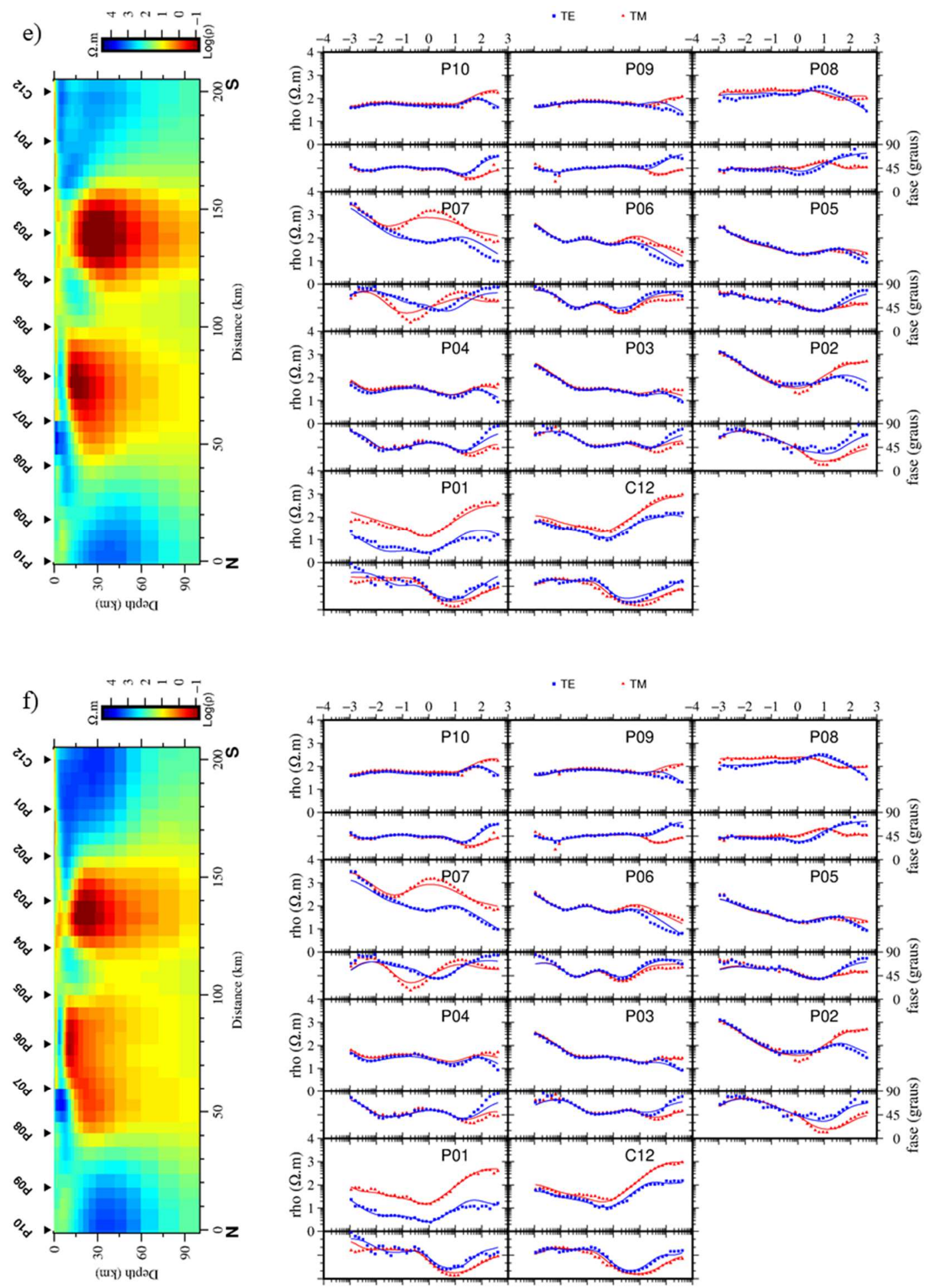

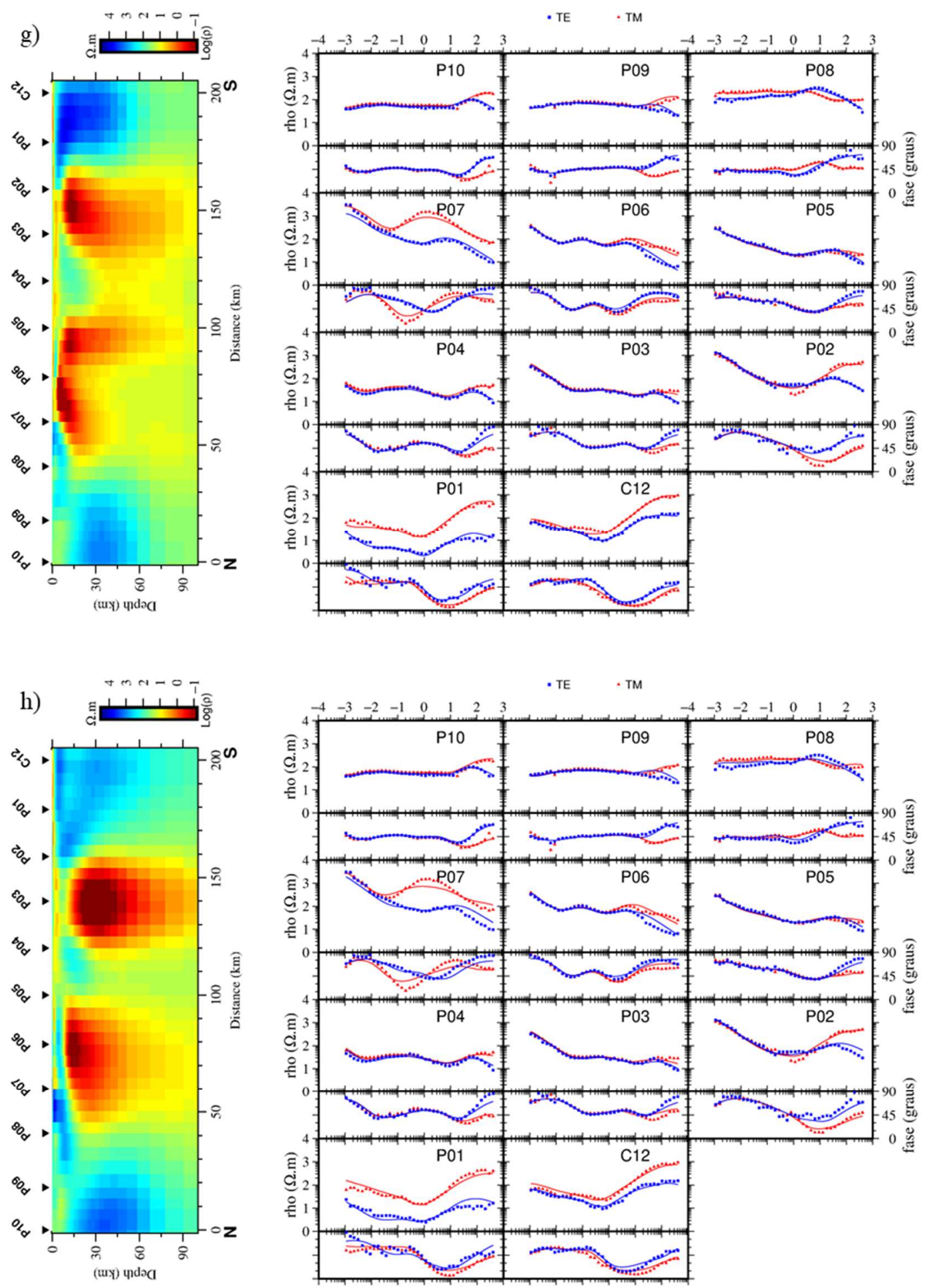

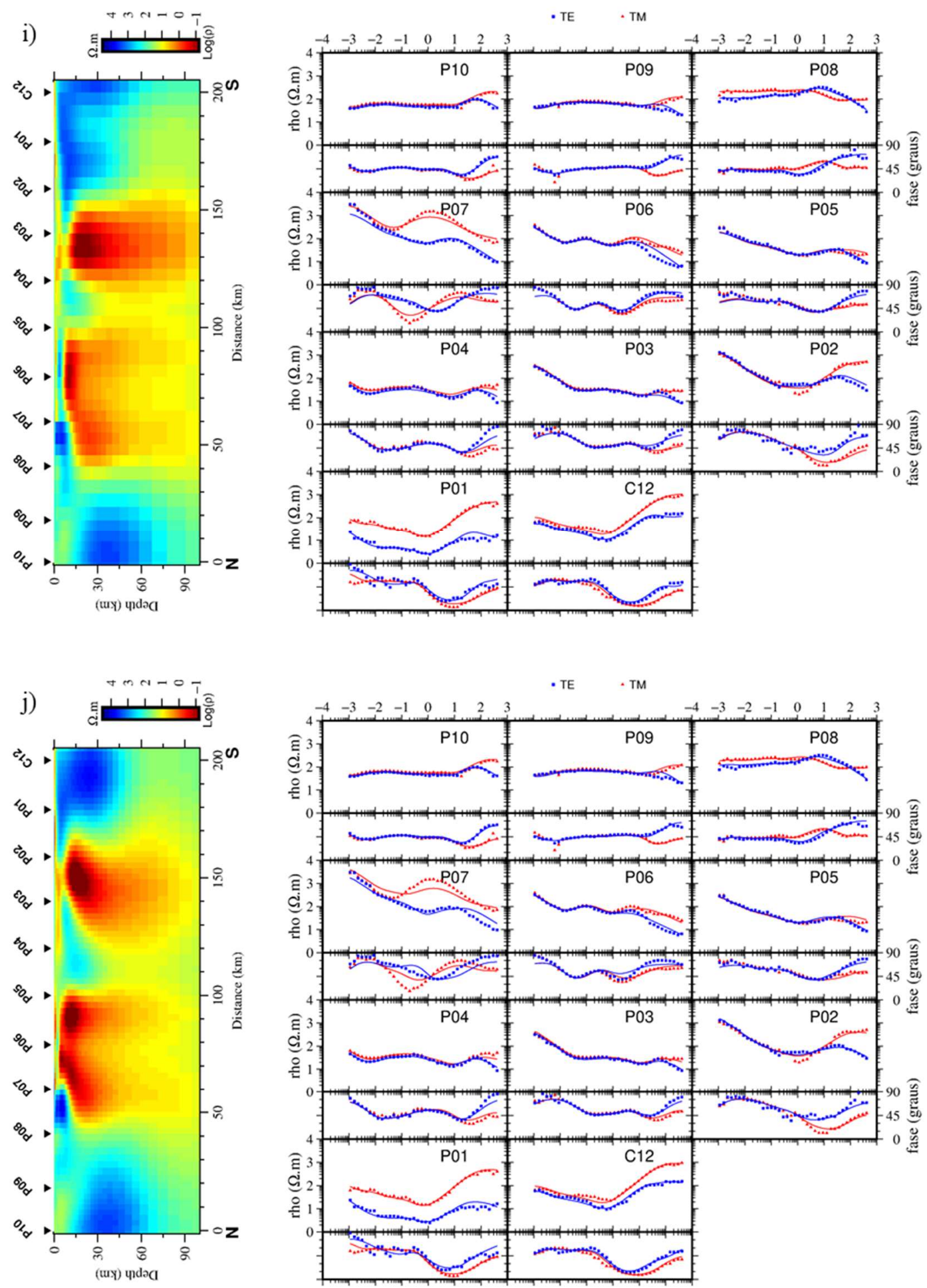

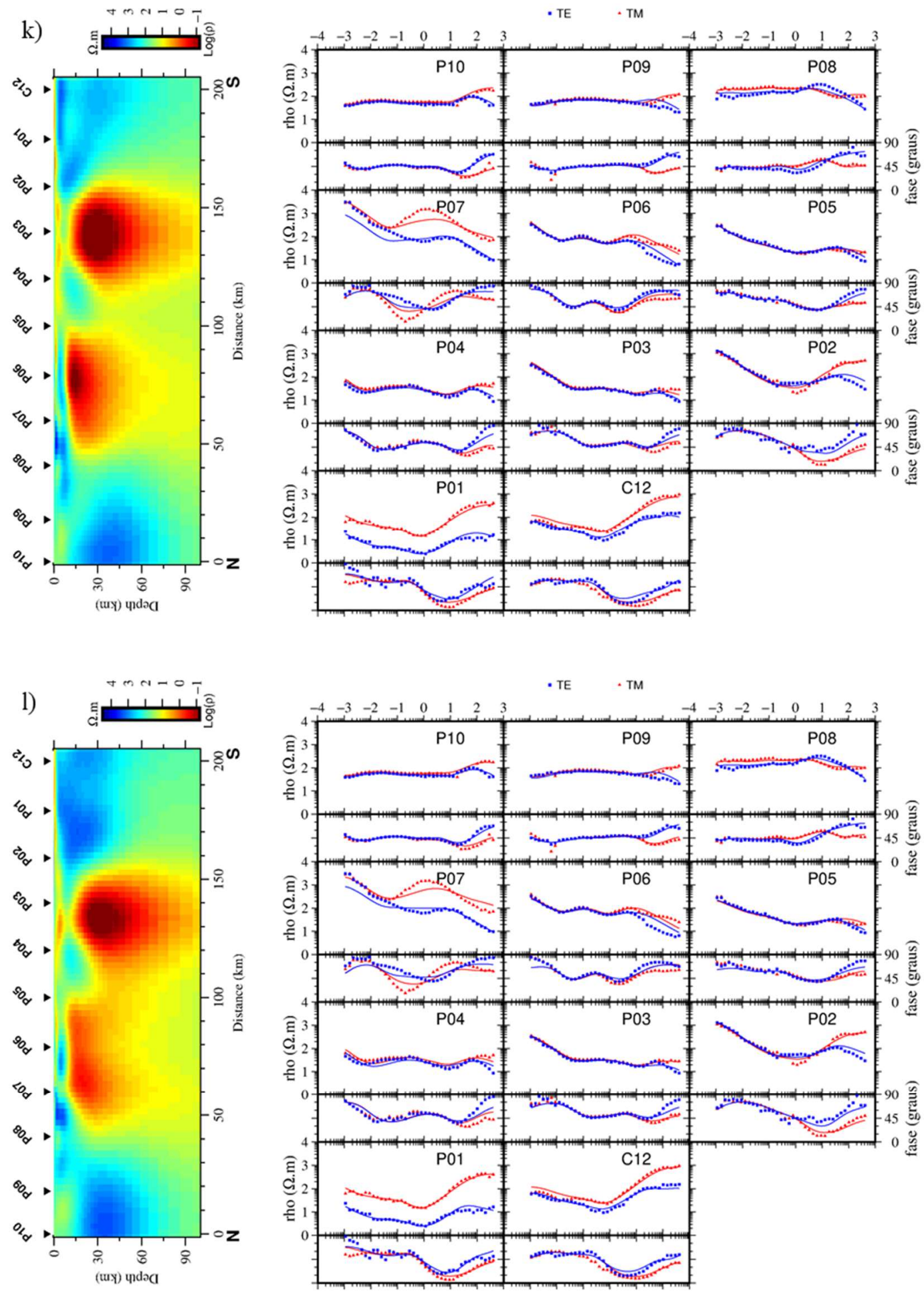

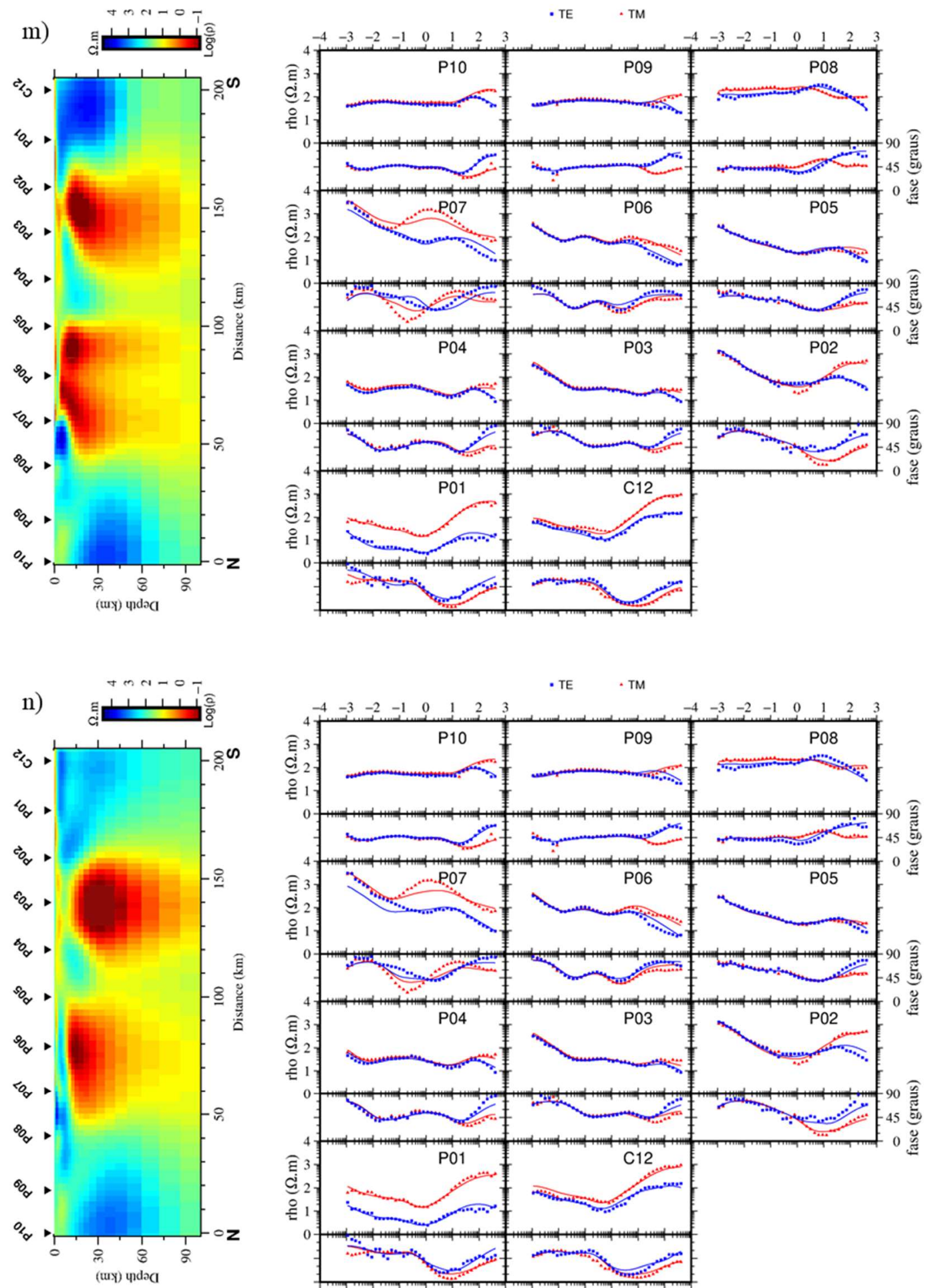

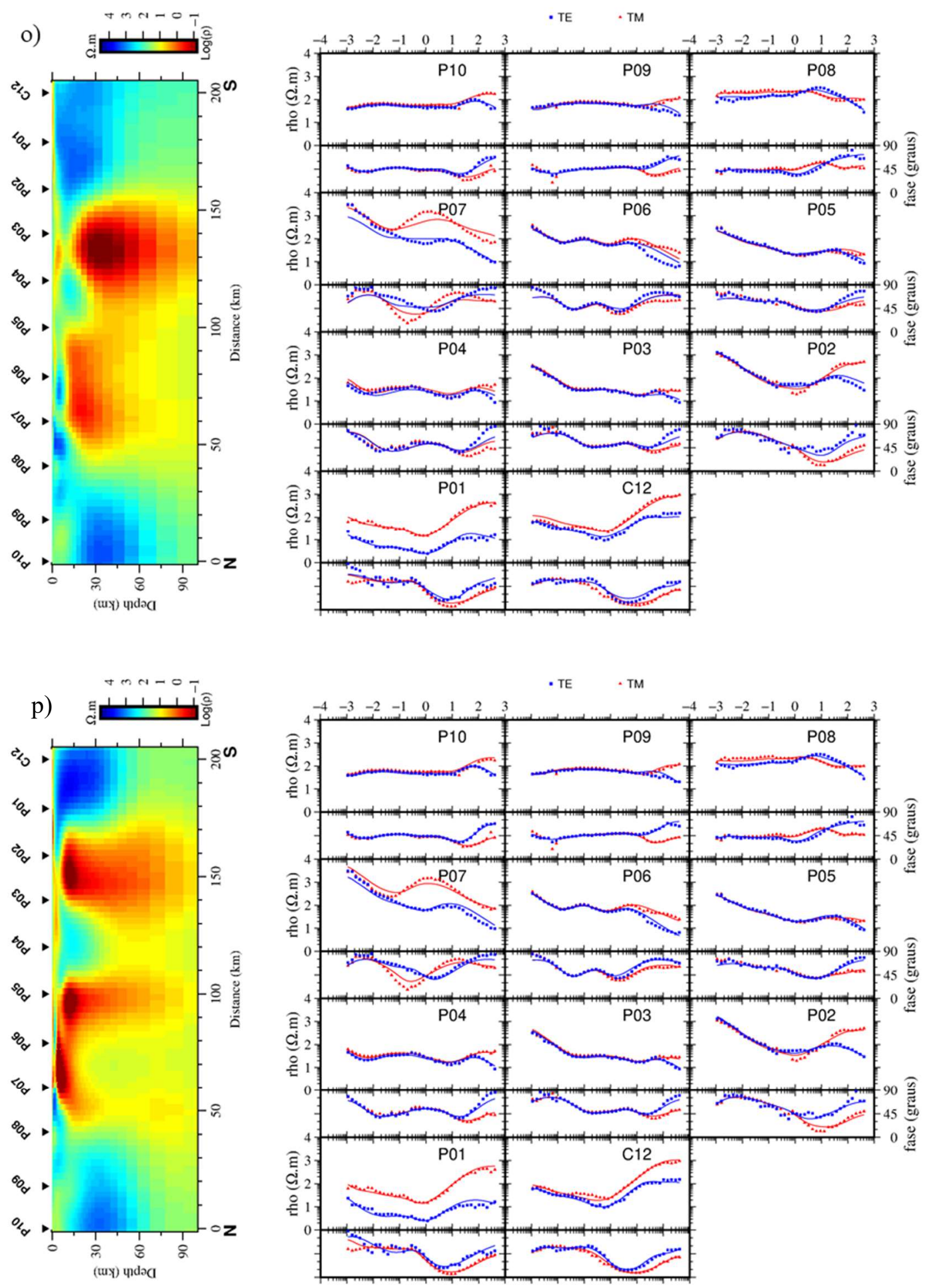

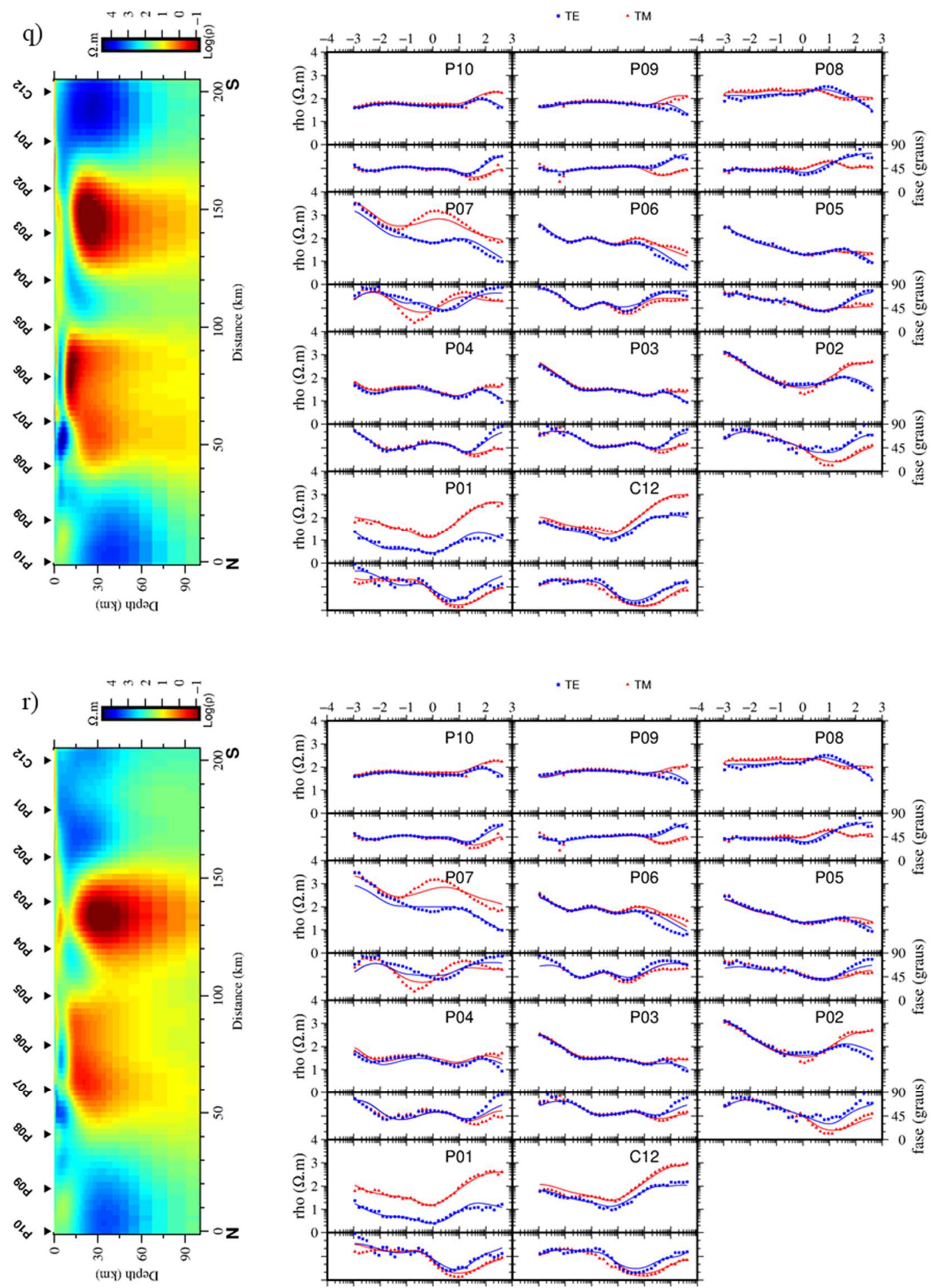
Modelos geoelétricos e ajustes de curvas resultantes de $\mathbf{A}$.
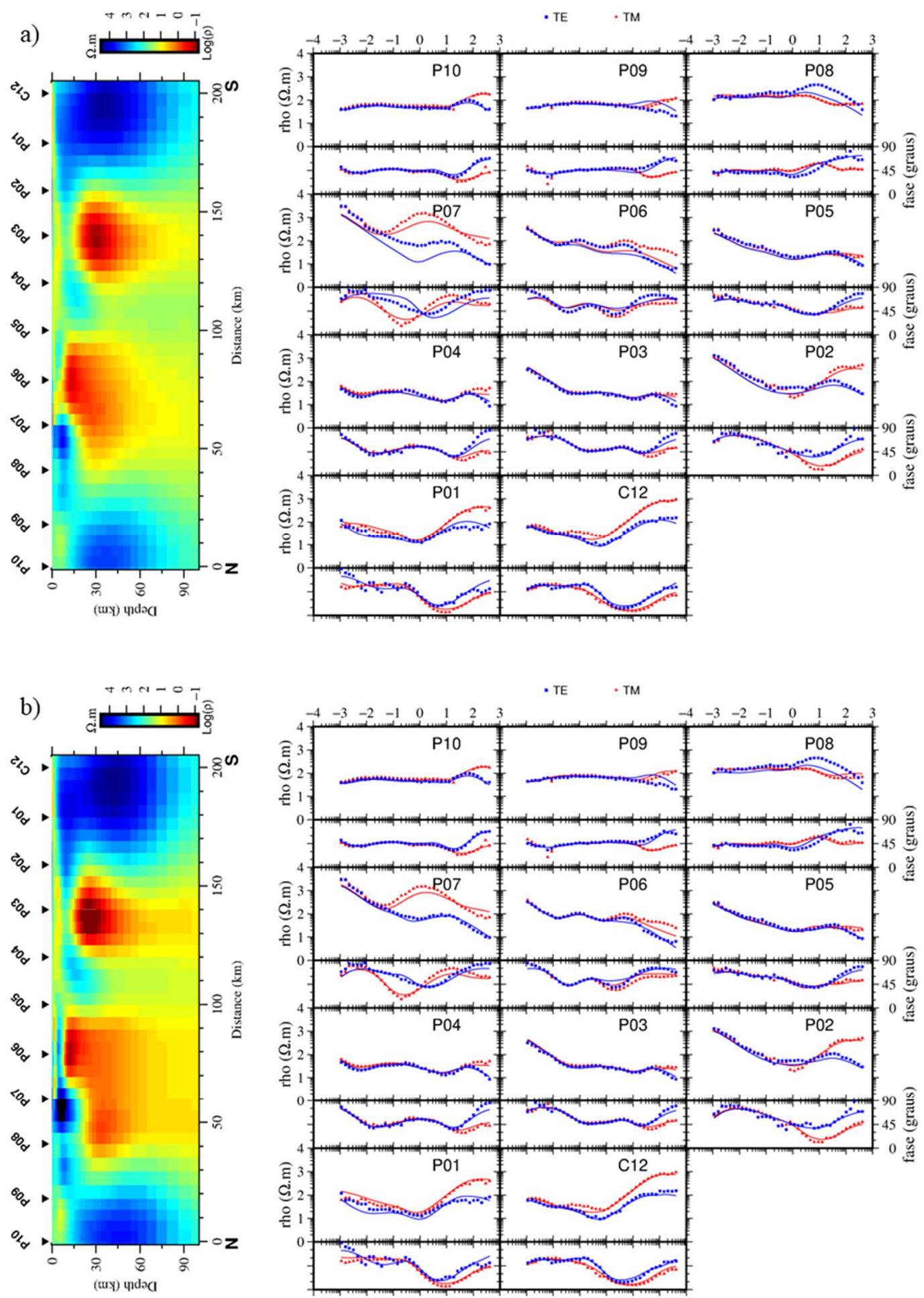

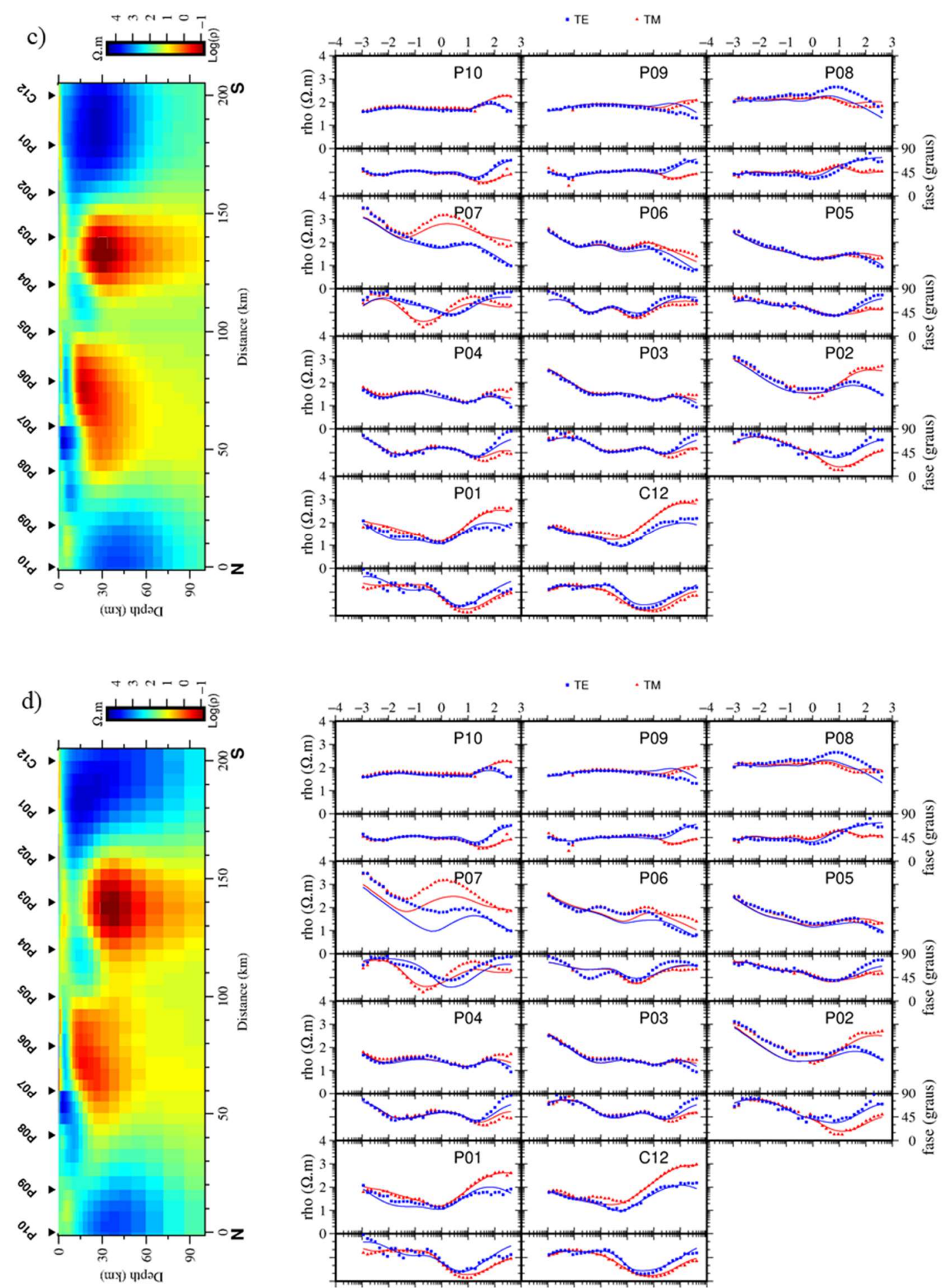

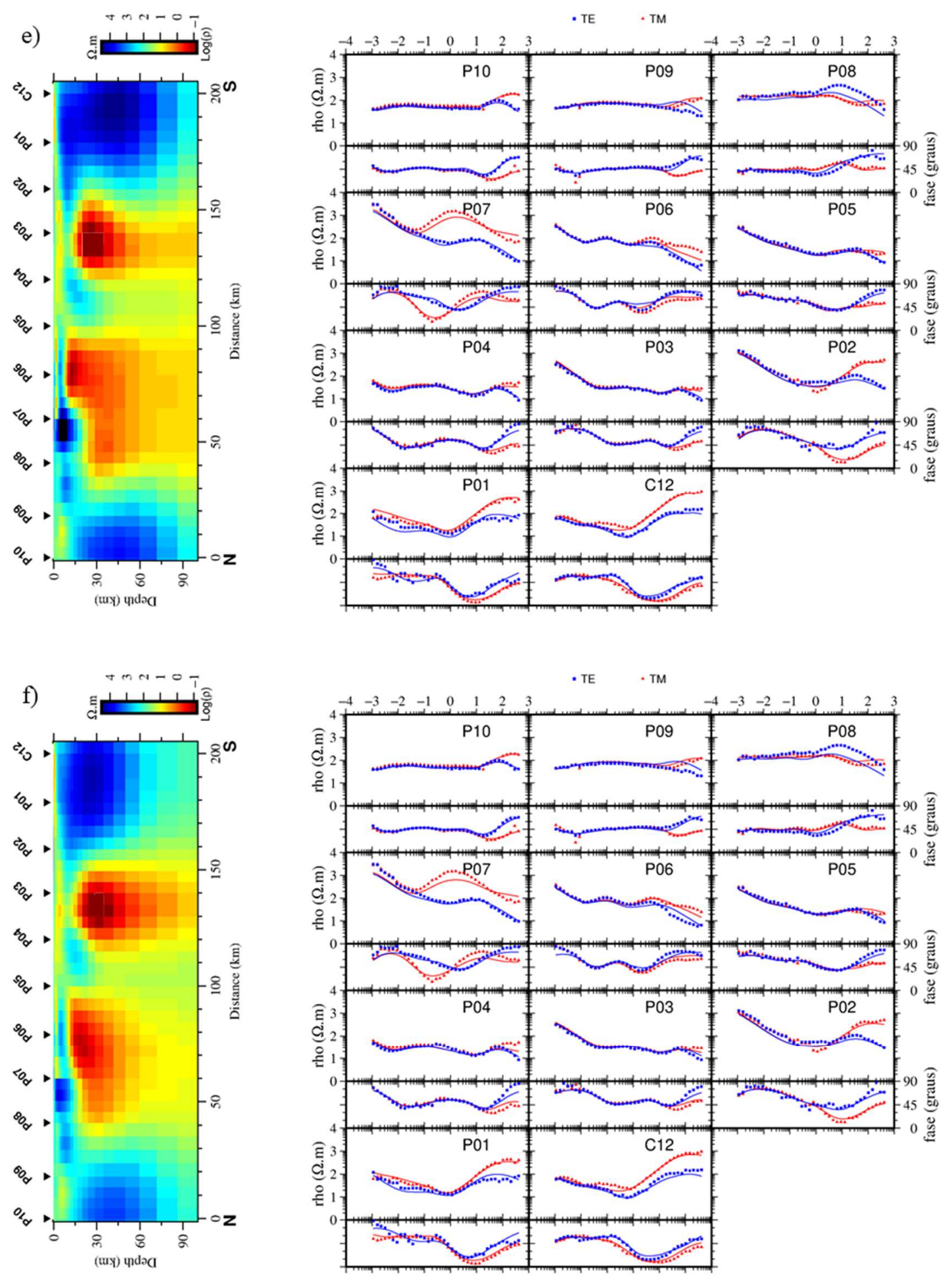

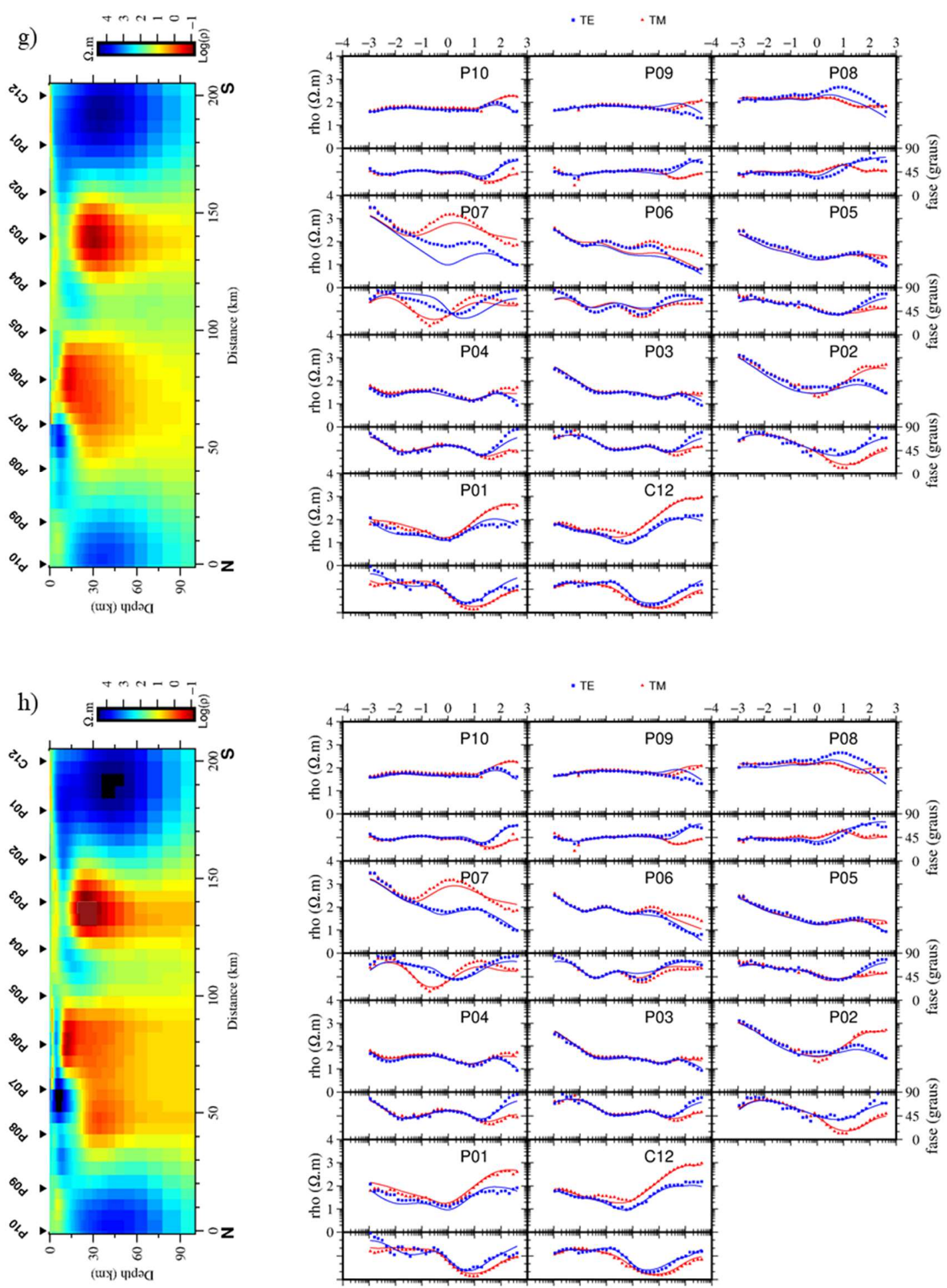

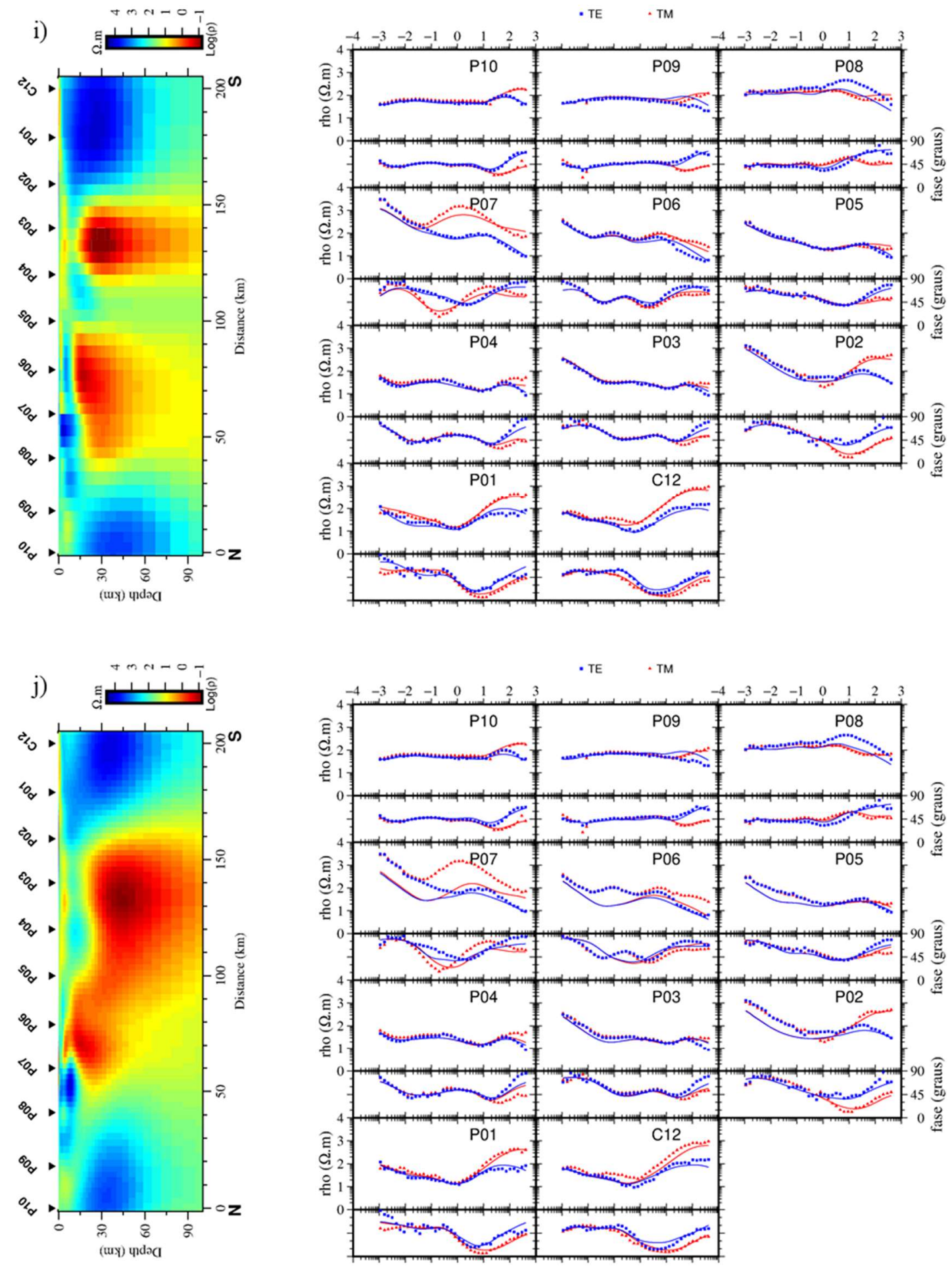

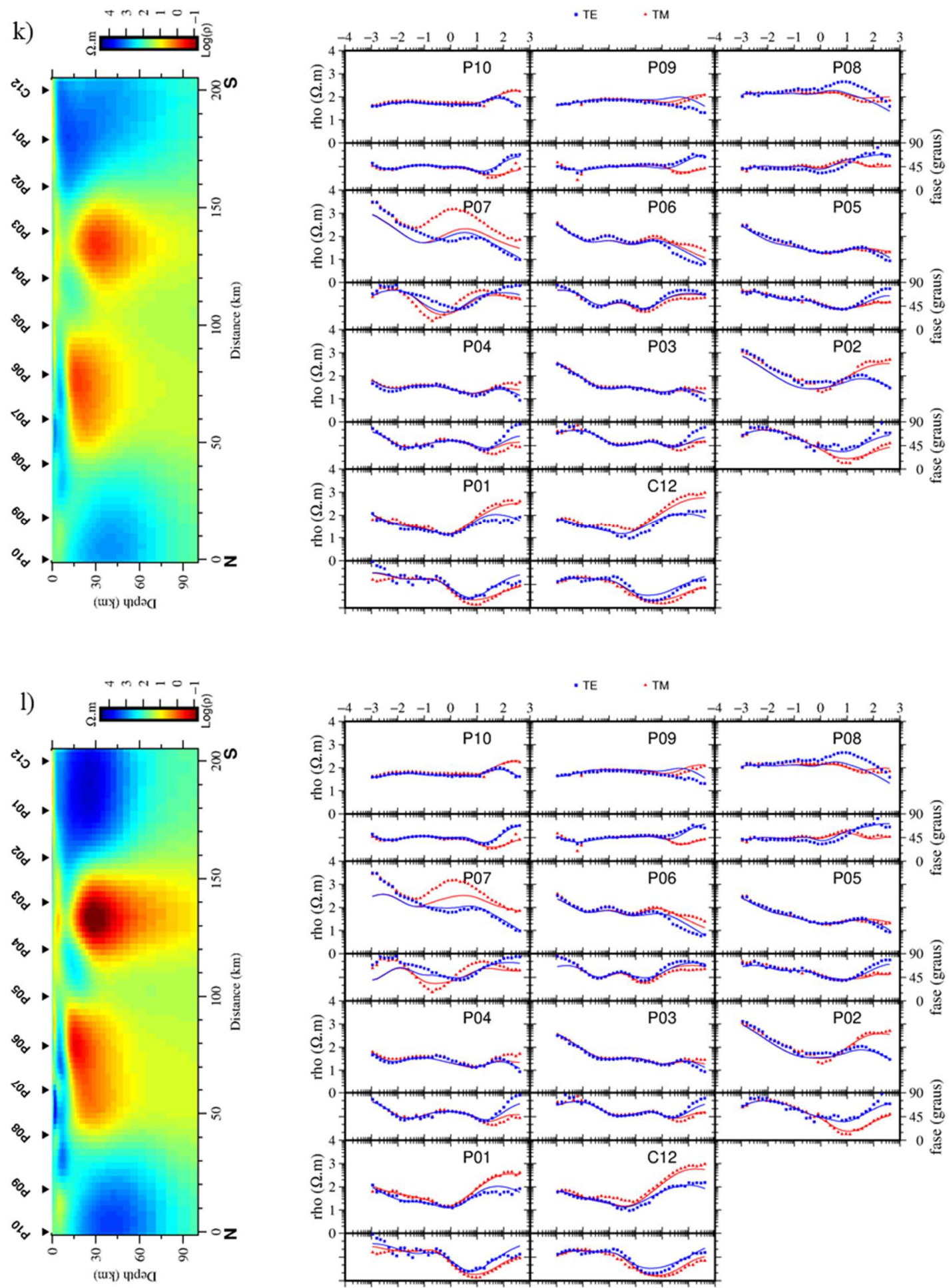

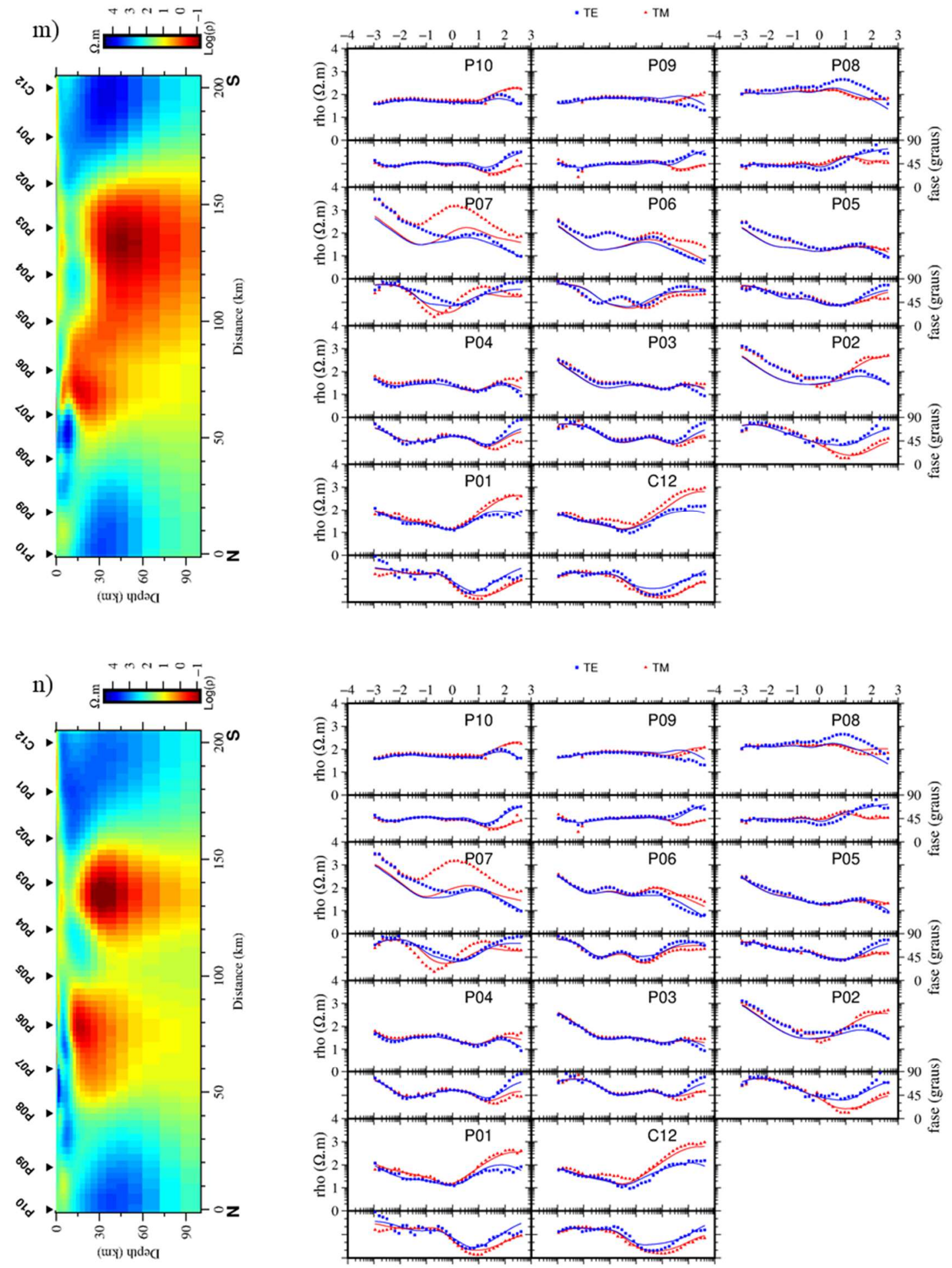

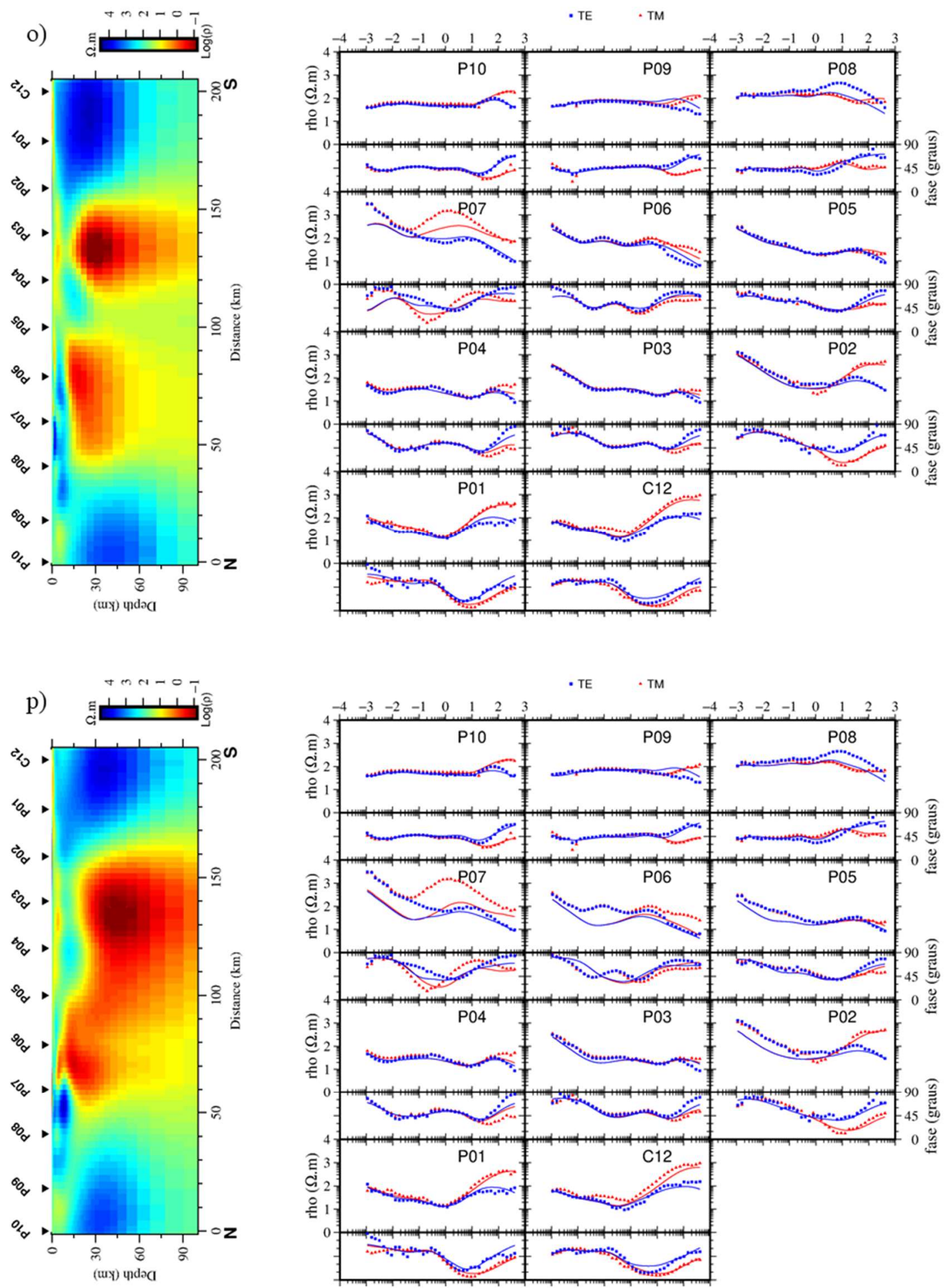

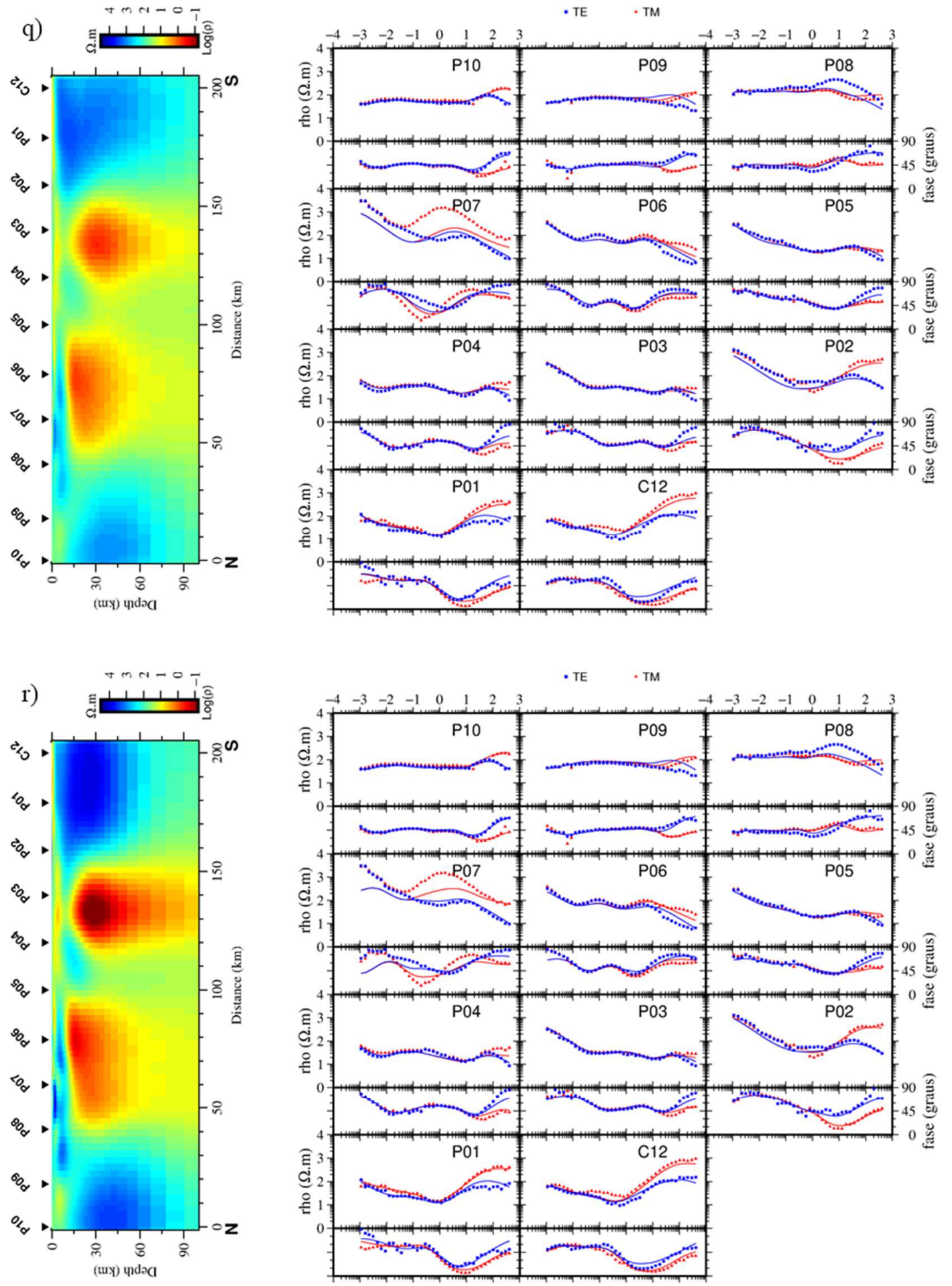
Modelos geoelétricos e ajustes de curvas resultantes de $\mathbf{B}$.
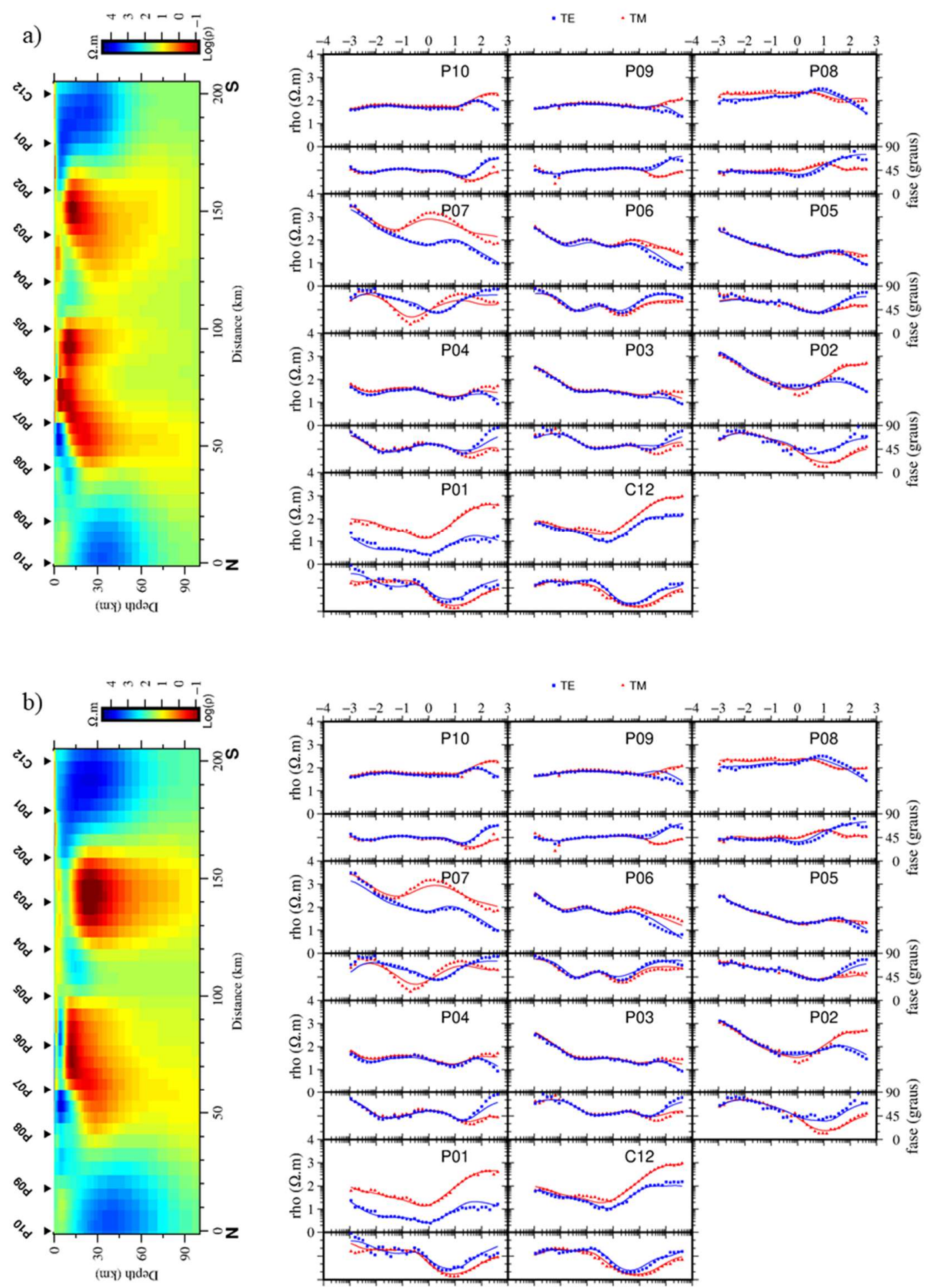

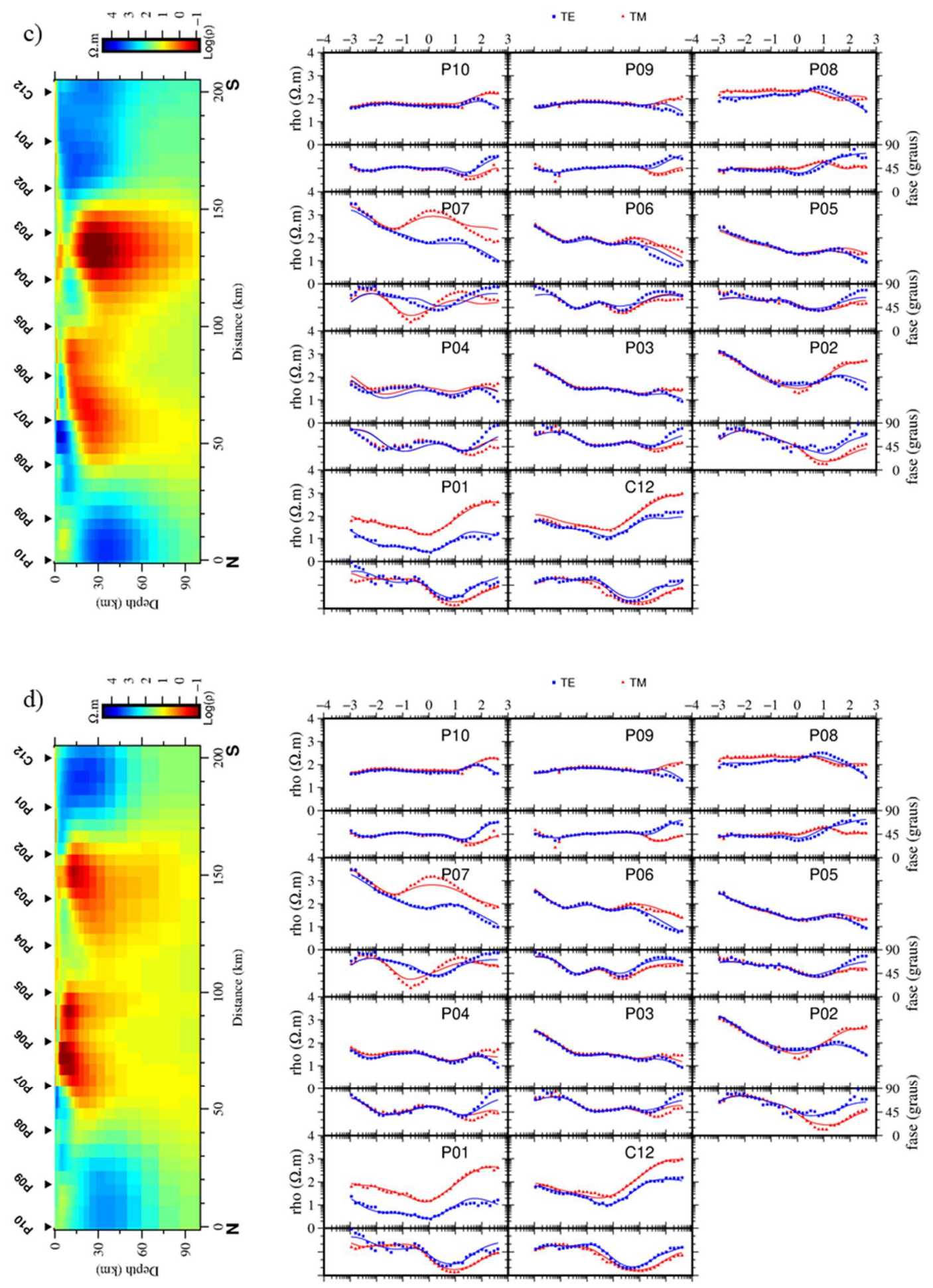

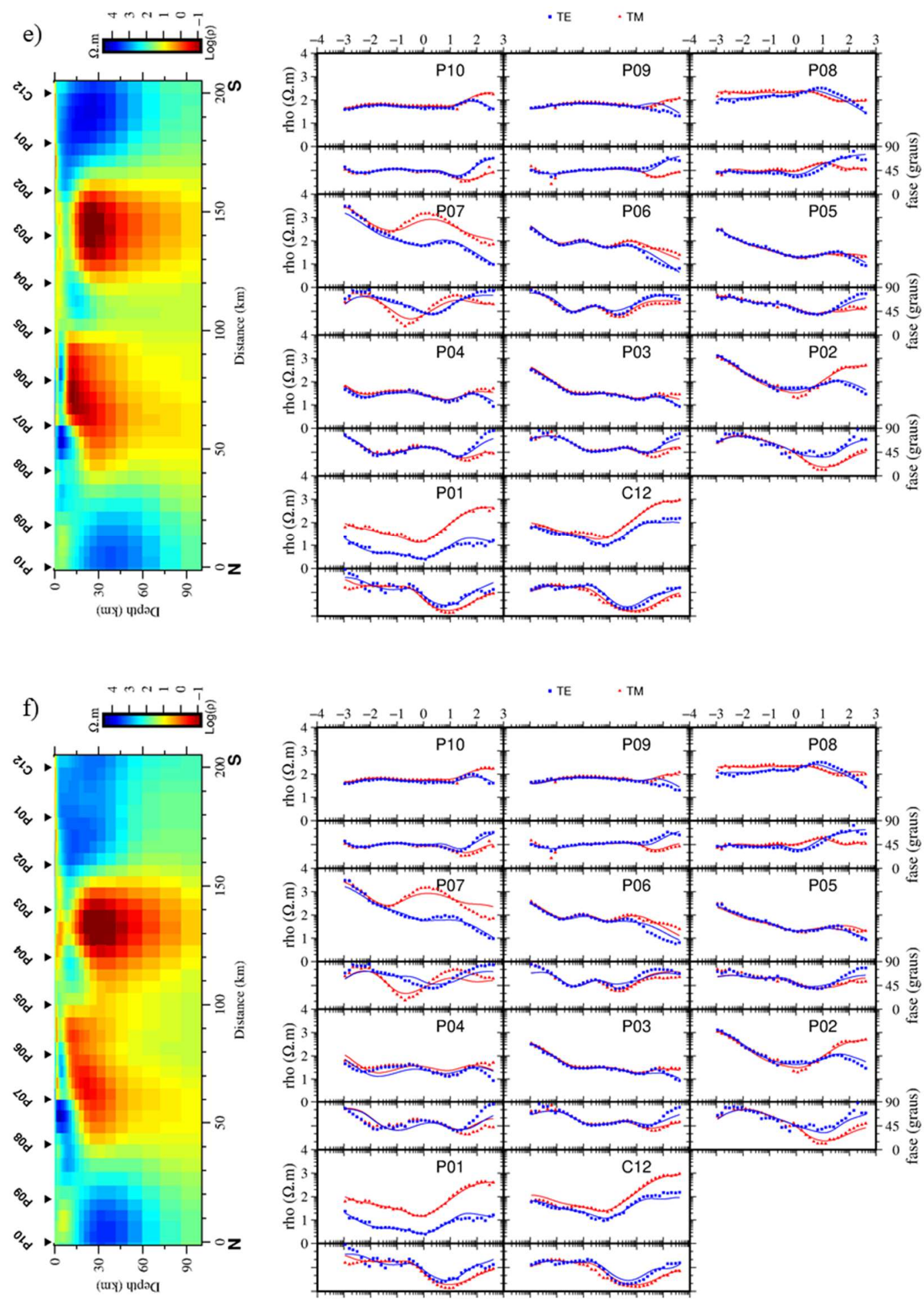

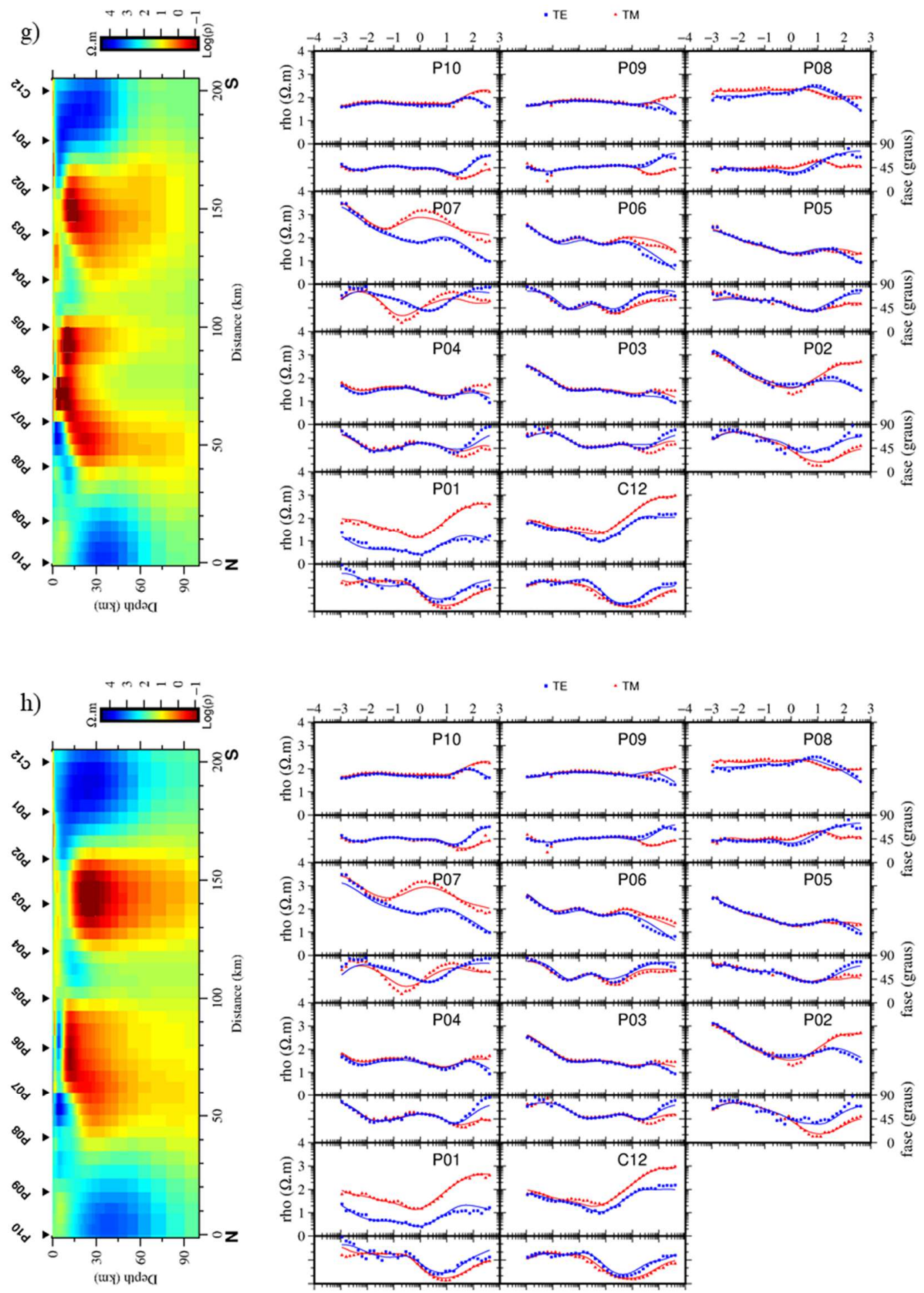

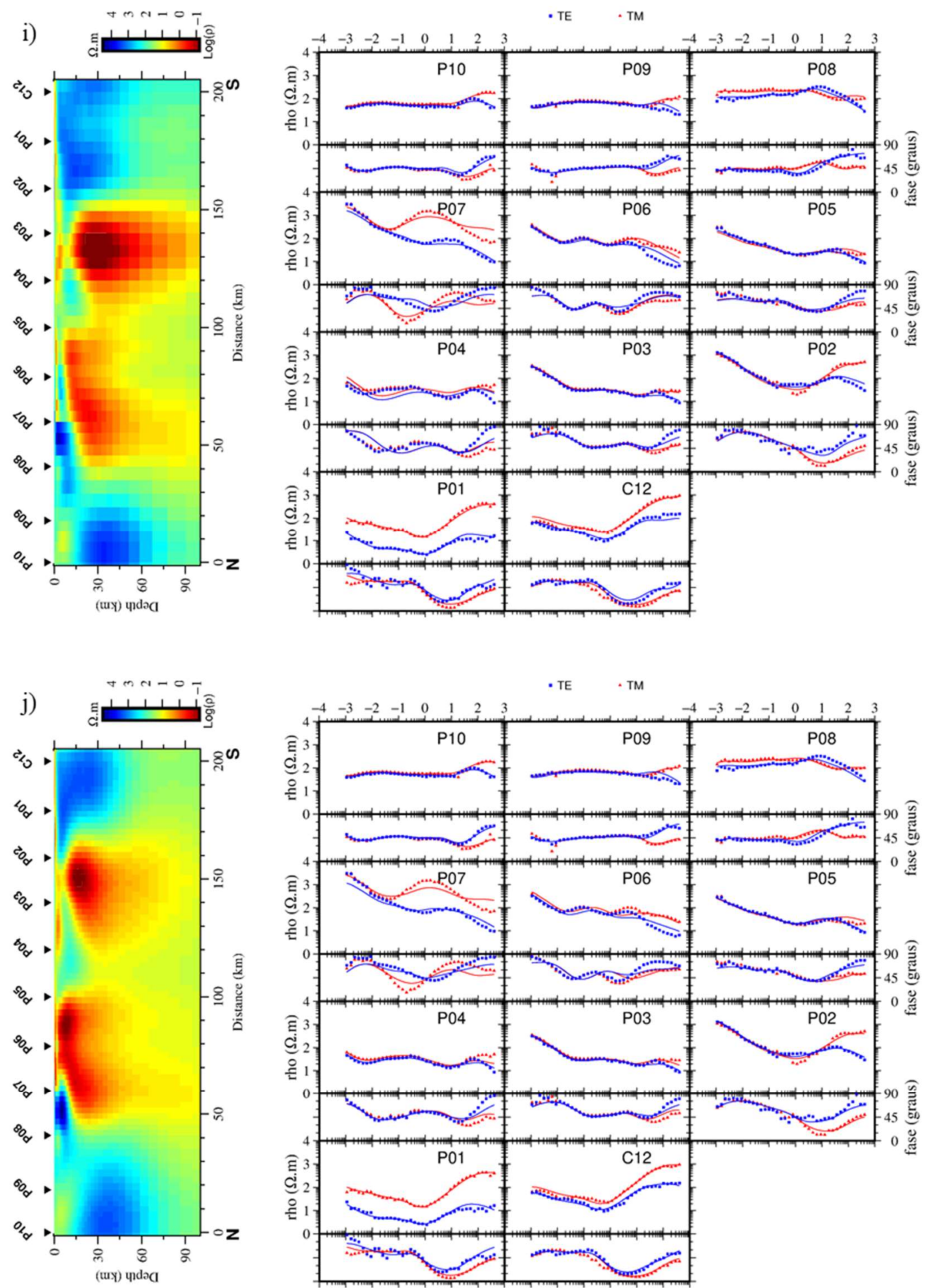

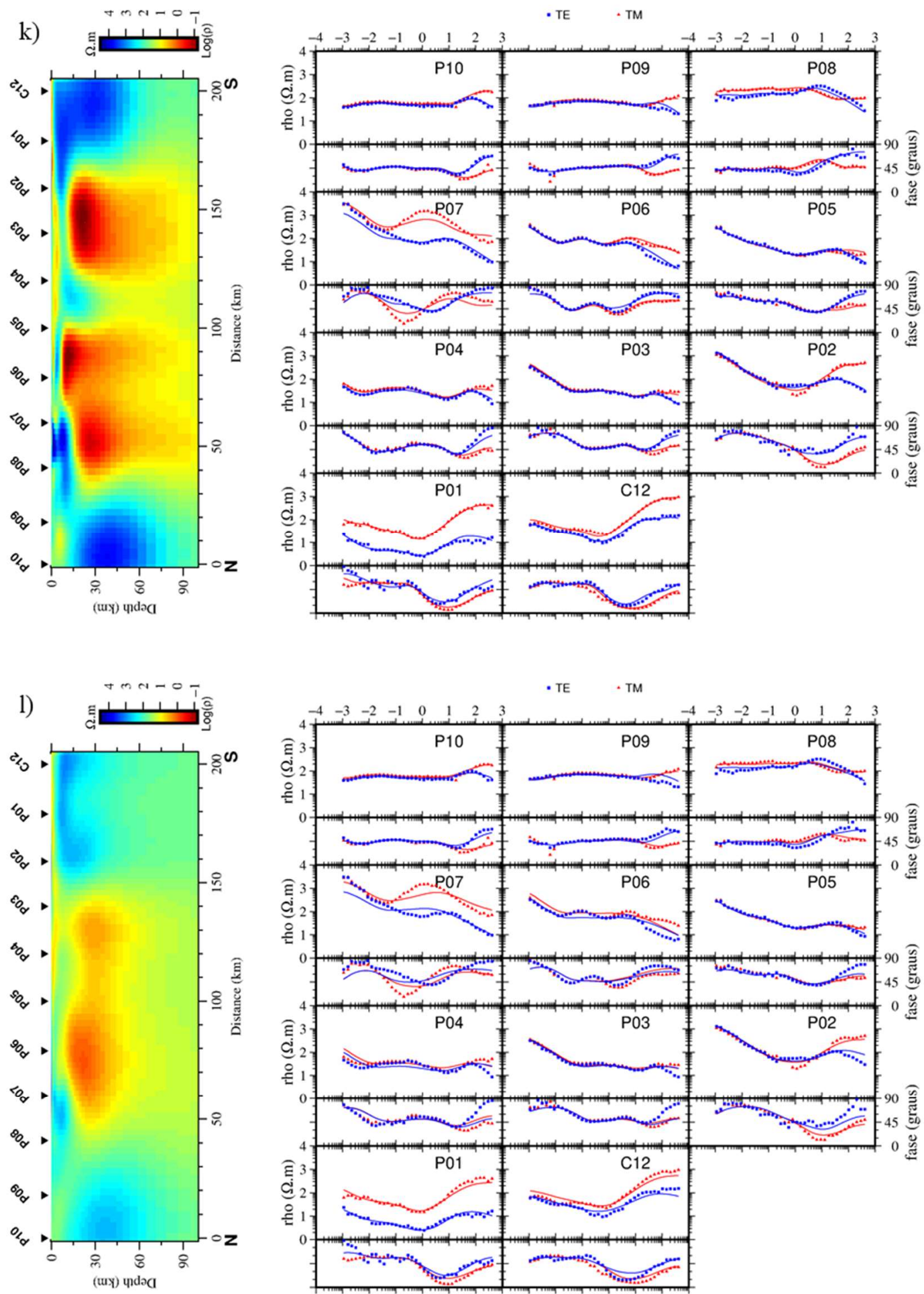

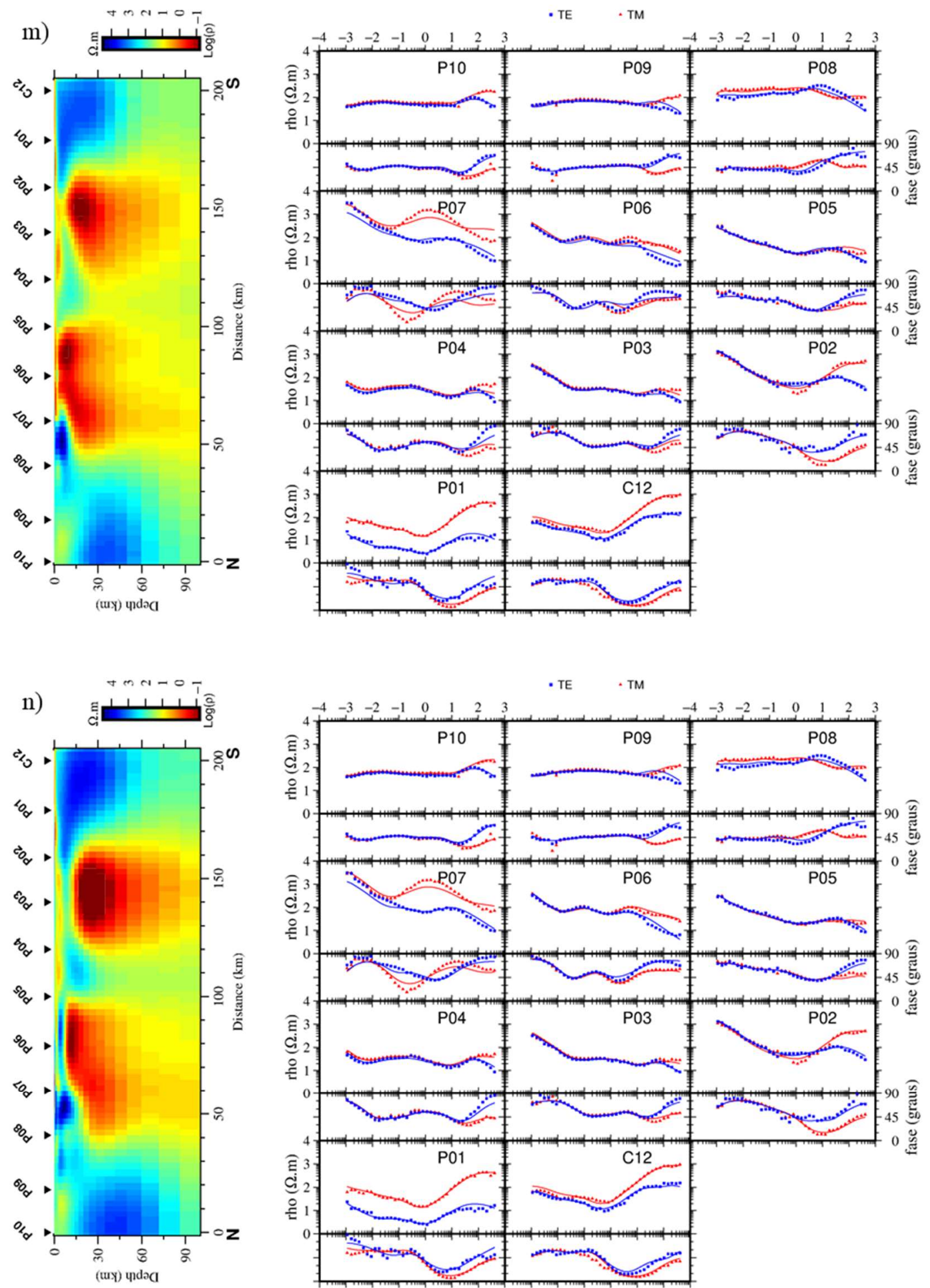

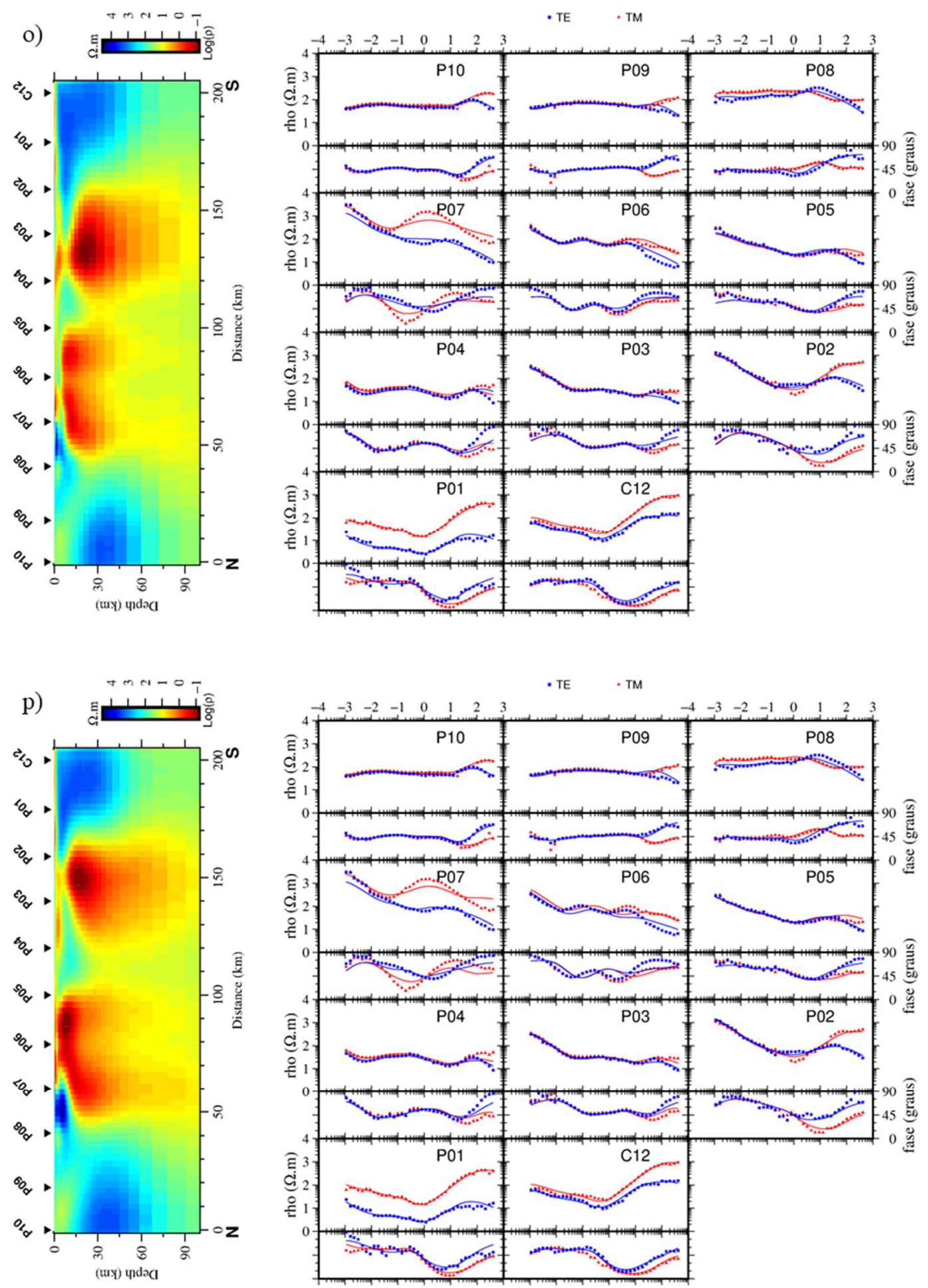

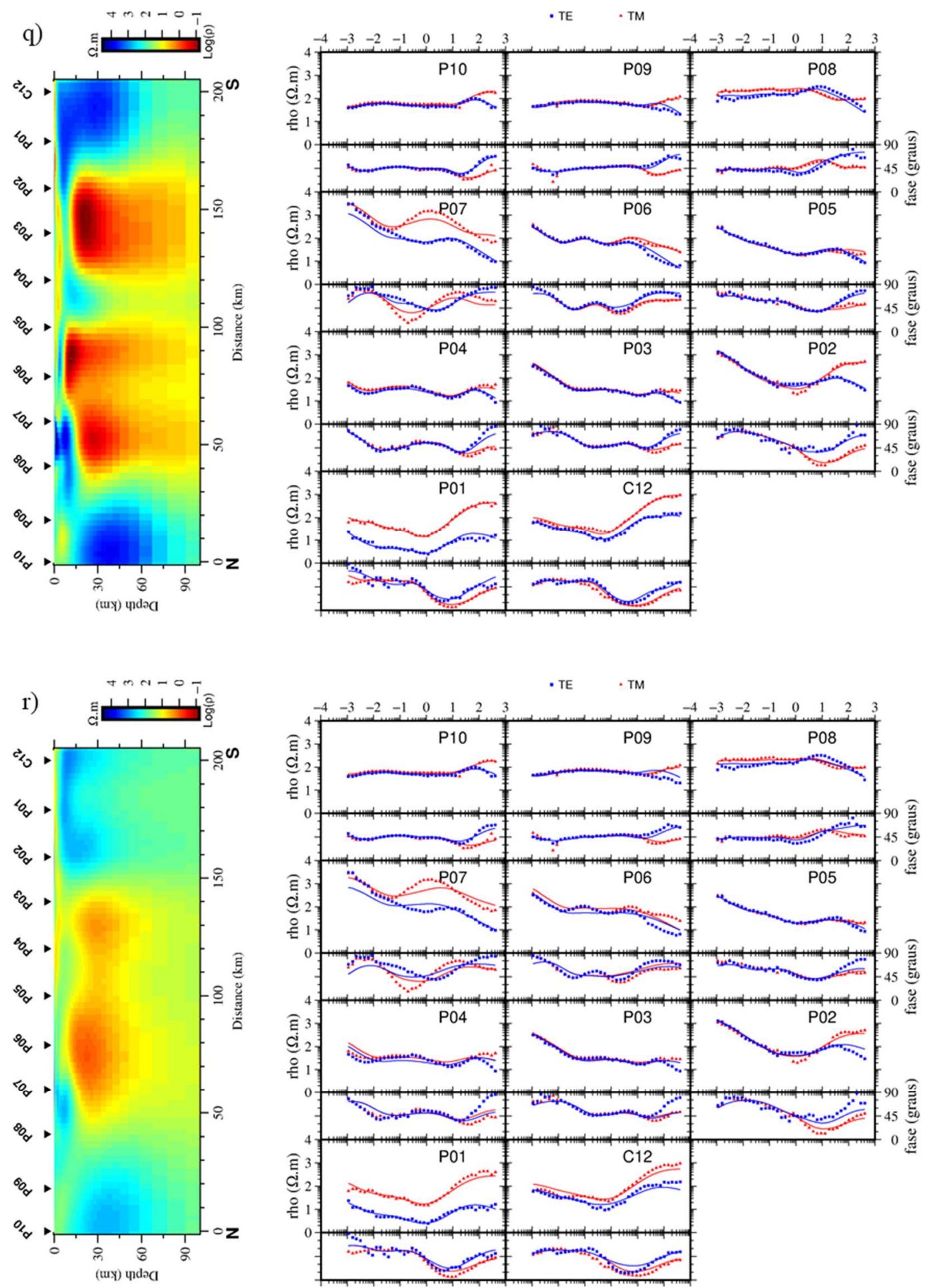
Modelos geoelétricos e ajustes de curvas resultantes de $\mathbf{C}$.
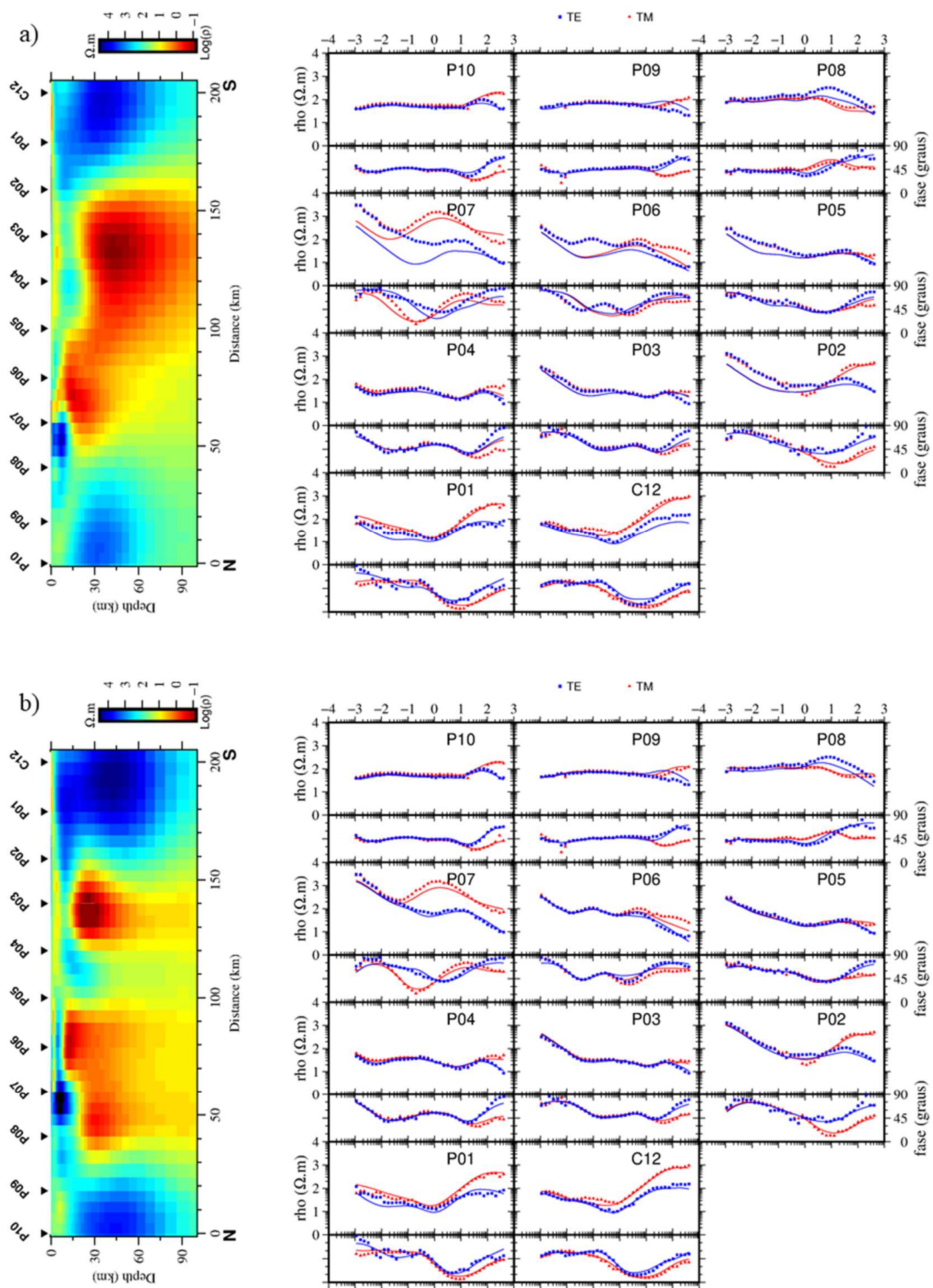

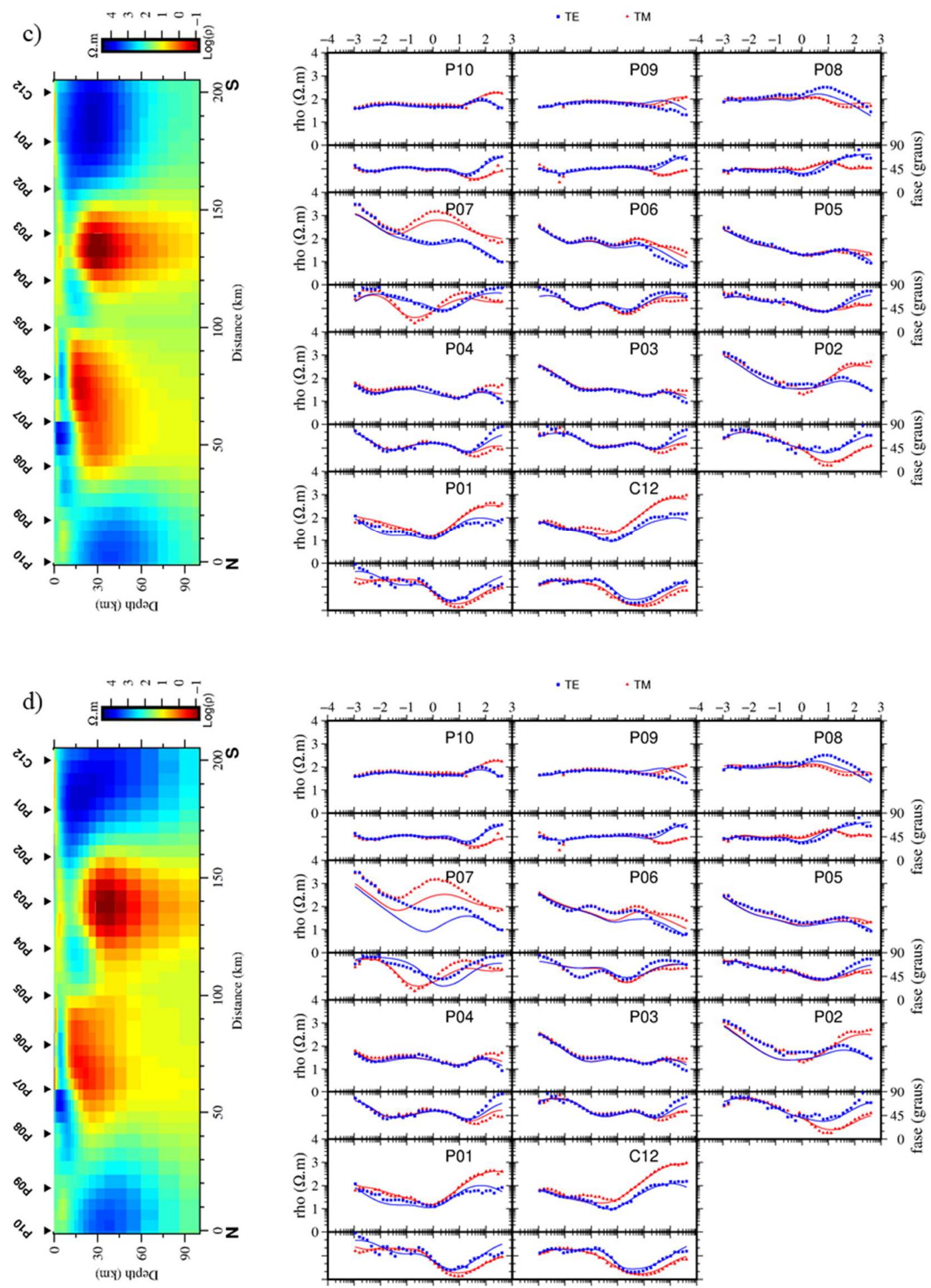

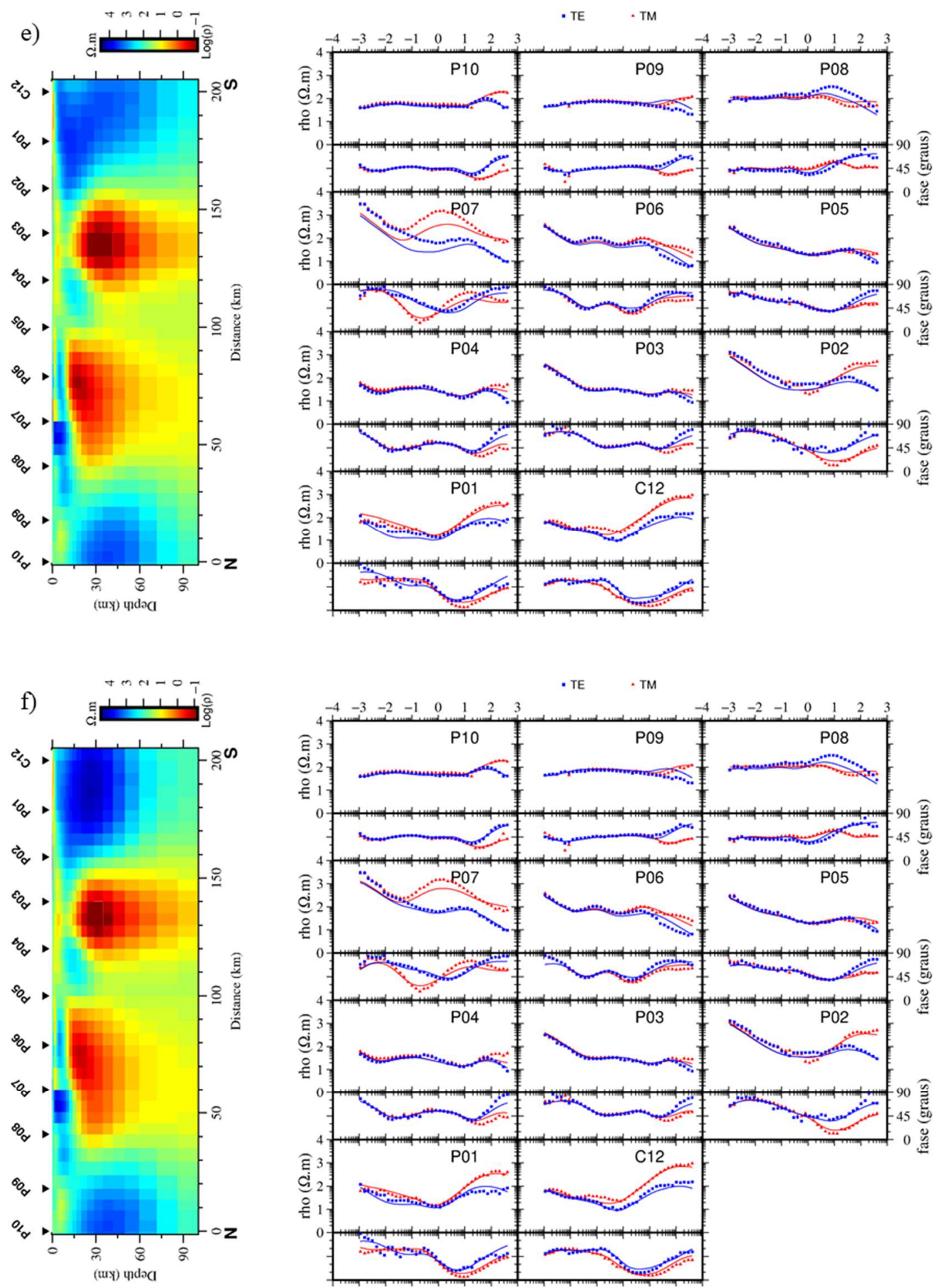

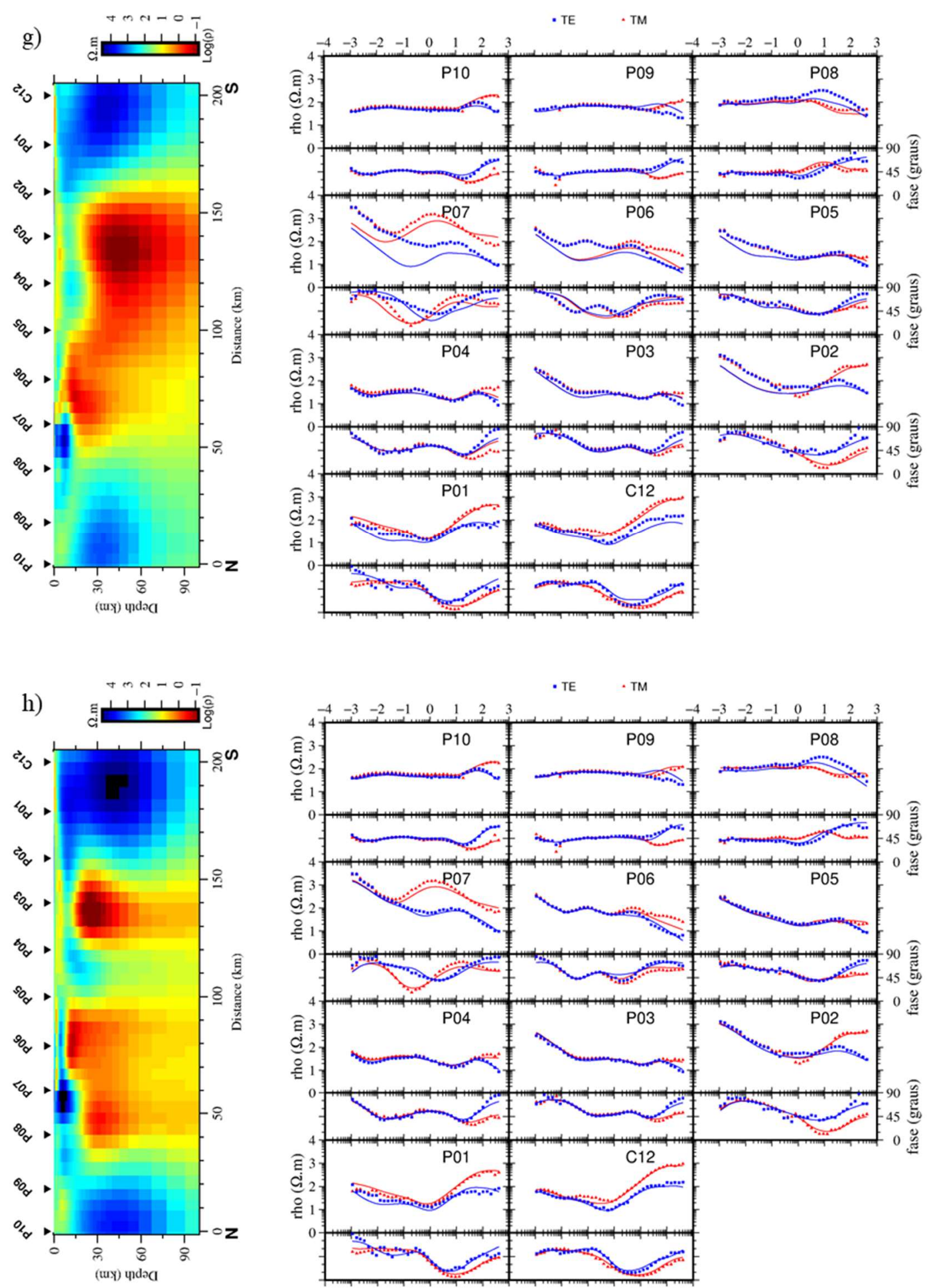

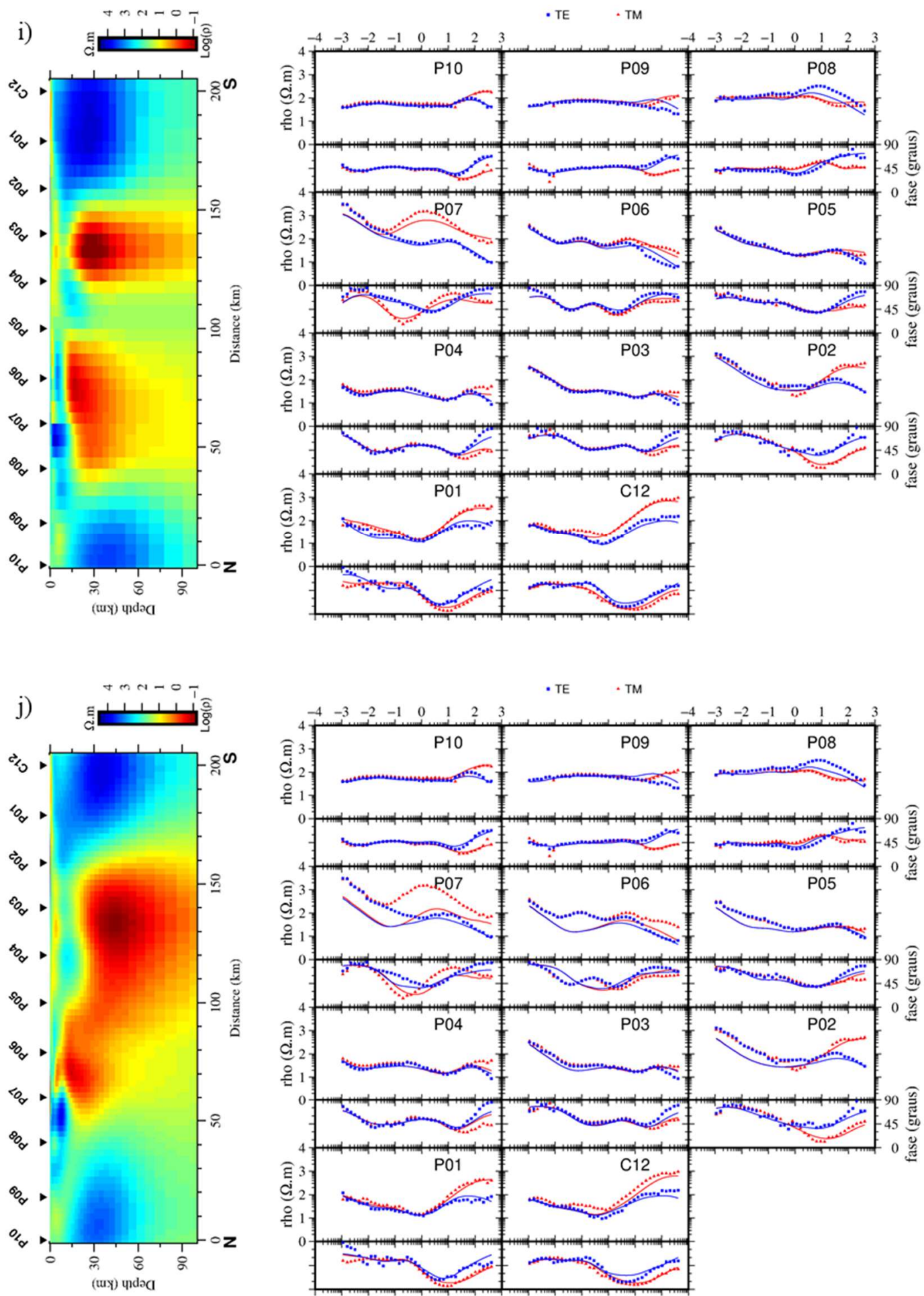

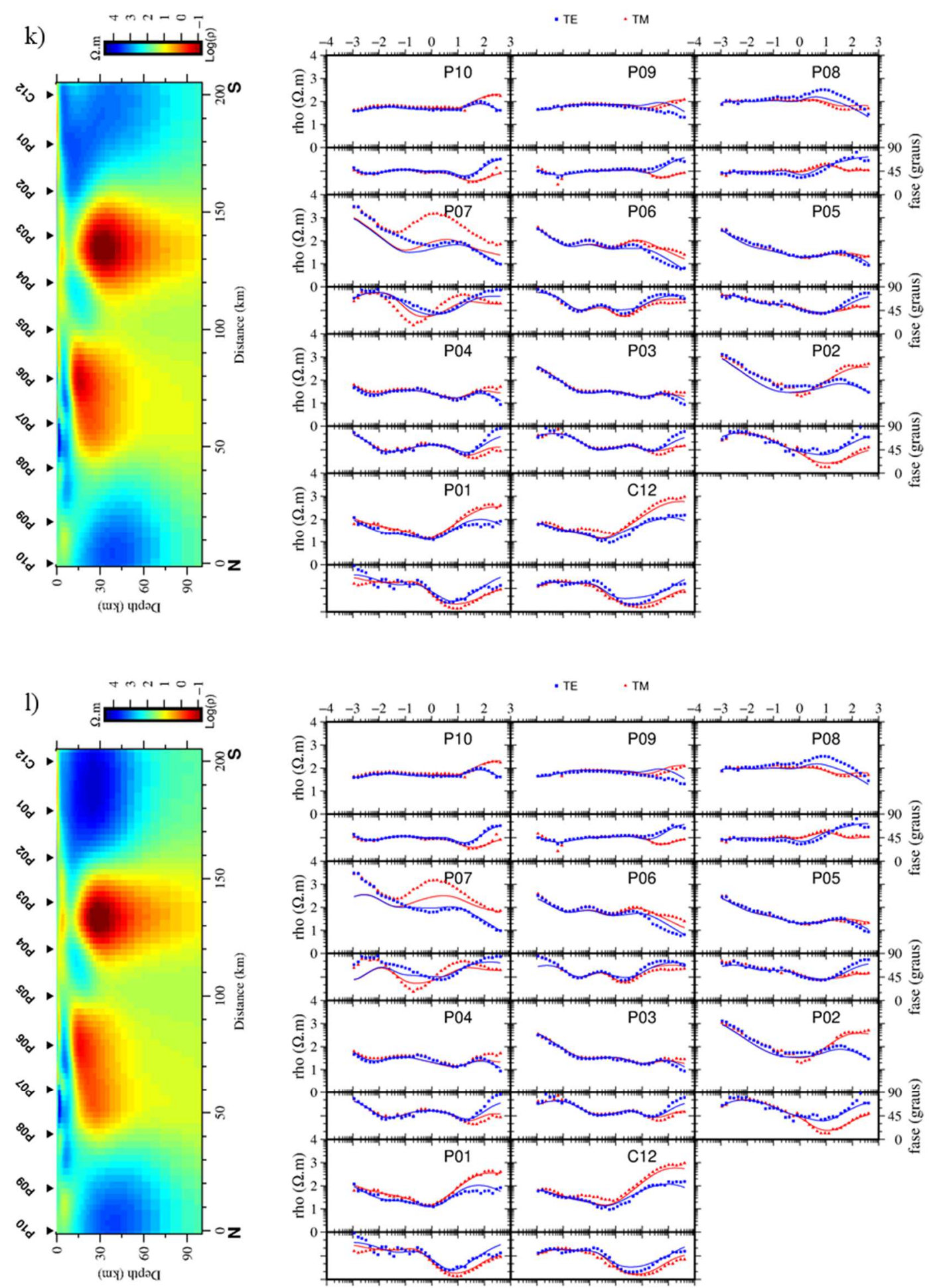

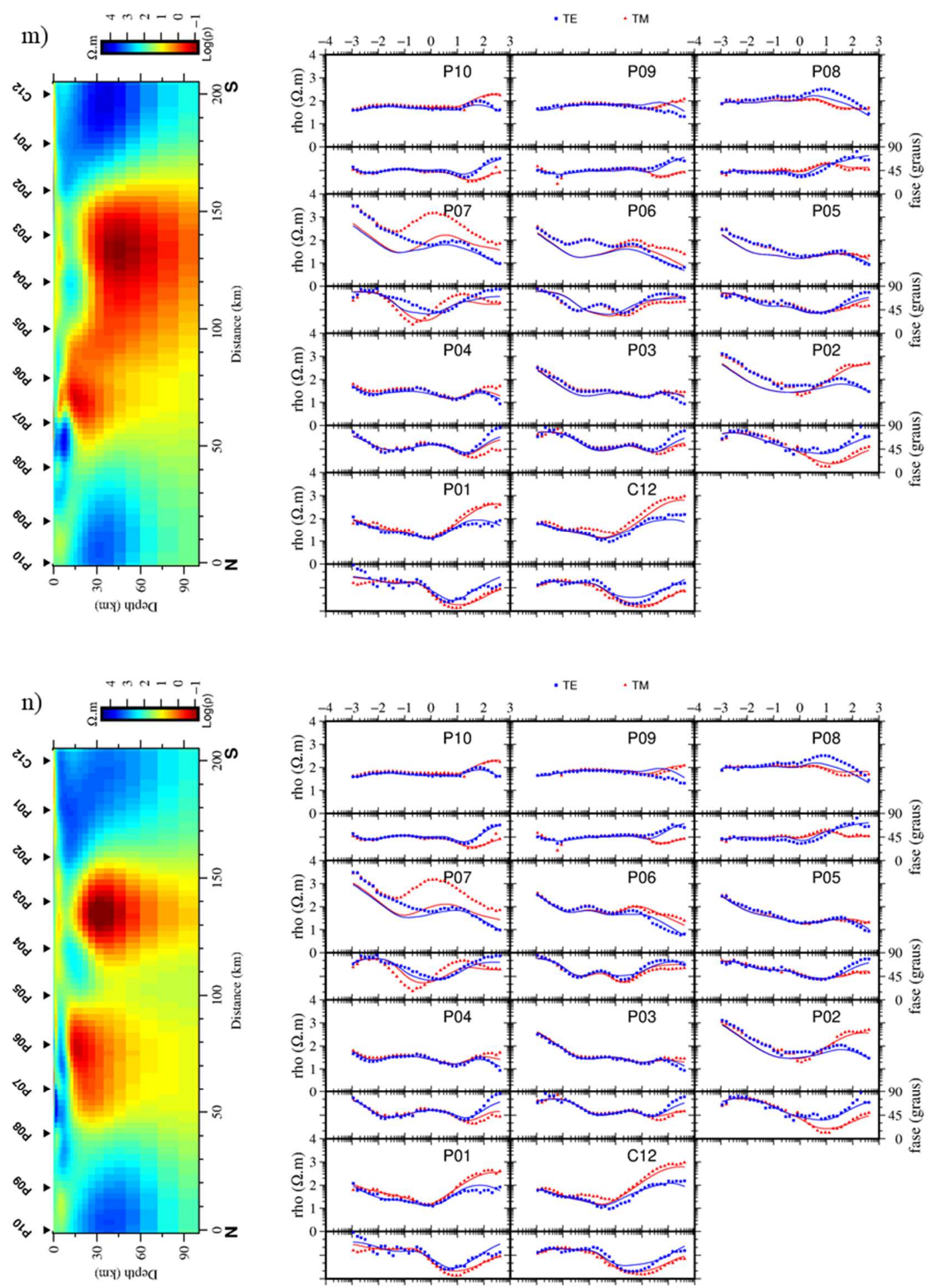

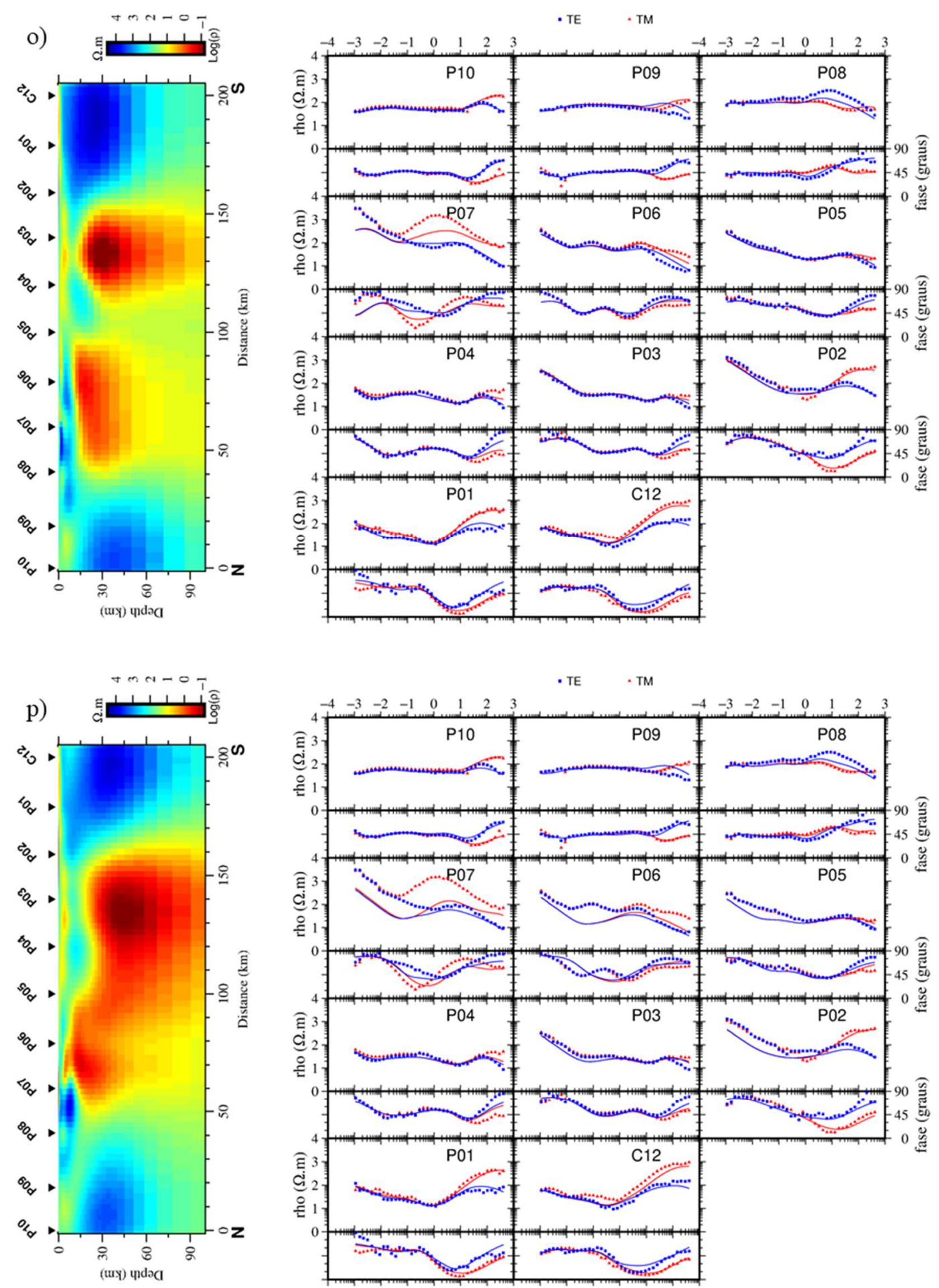

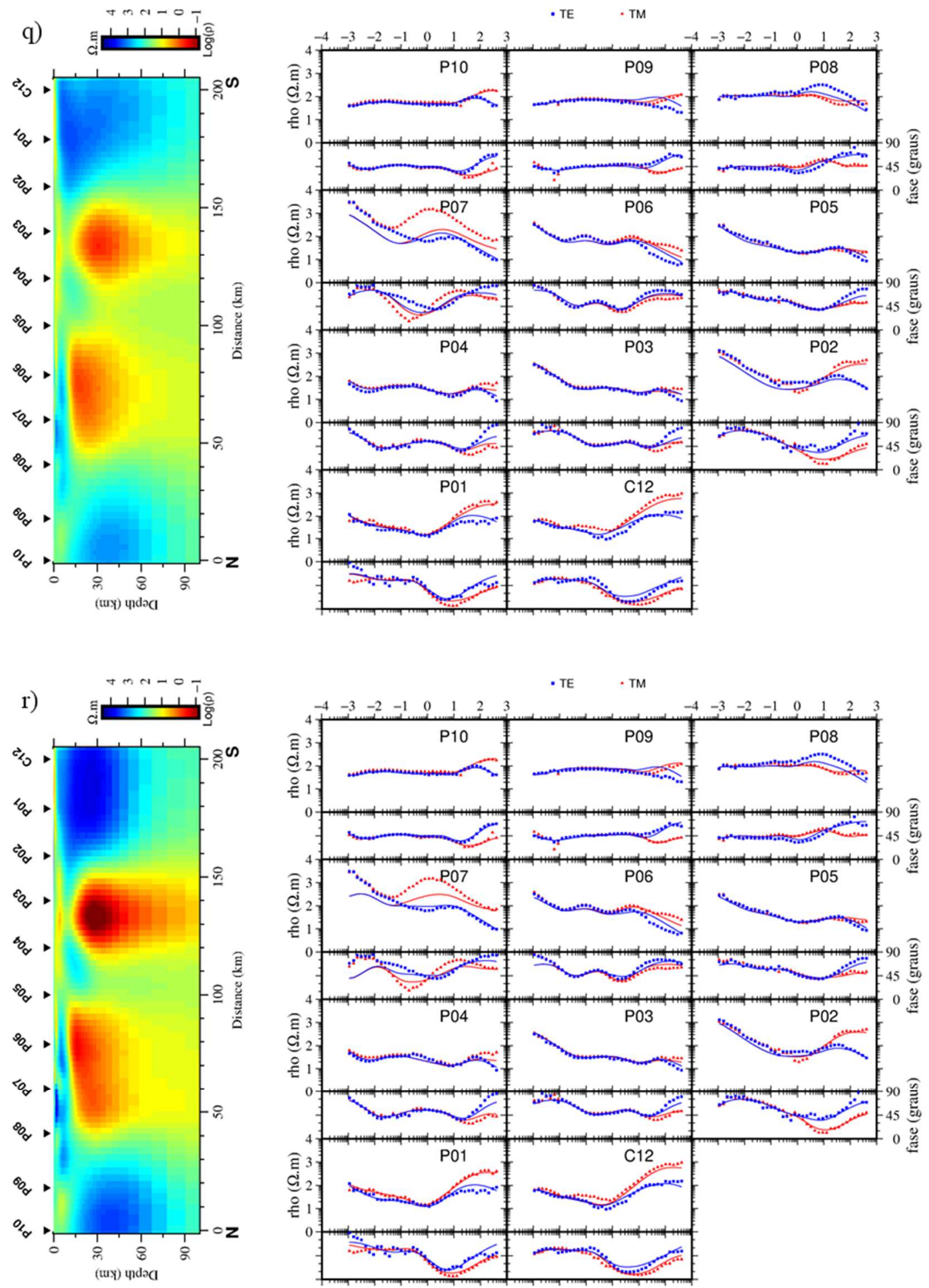